\title{
Weekly Headache in Children and Adolescents: \\ Biopsychosocial Correlates and Their Specificity
}

\author{
Dissertation \\ zur Erlangung des Doktorgrades \\ der Mathematisch-Naturwissenschaftlichen Fakultäten \\ der Georg-August-Universität zu Göttingen
}

\author{
vorgelegt von \\ Lisette Morris \\ aus Oklahoma City, Oklahoma, USA
}

Göttingen, 2006 
D7

Referent: Prof. Dr. Birgit Kröner-Herwig

Korreferent: Prof. Dr. Marcus Hasselhorn

Tag der mündlichen Prüfung: 03. Mai 2006 
Every head has its own headache.

Arab Proverb 


\section{CONTENTS}

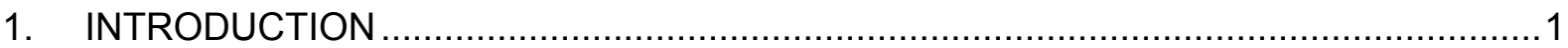

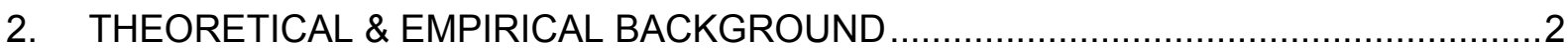

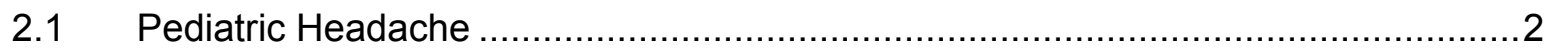

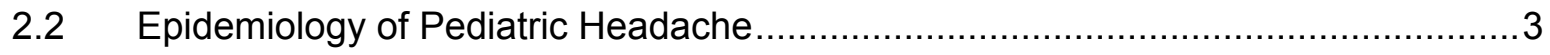

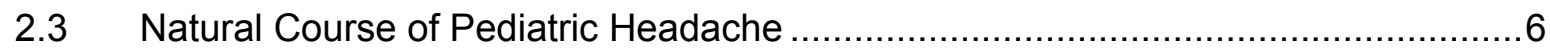

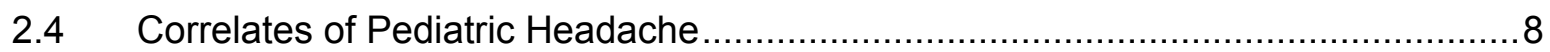

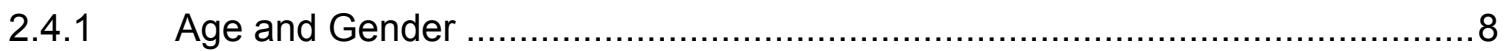

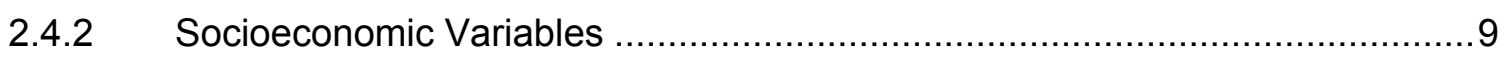

2.4.3 Child Psychological Variables.................................................................... 10

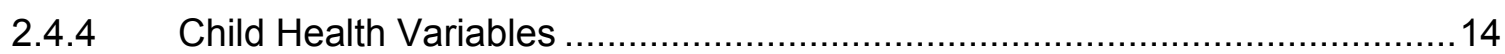

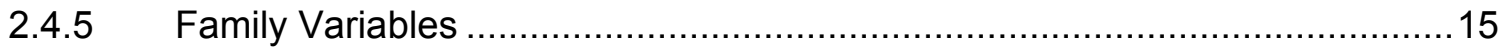

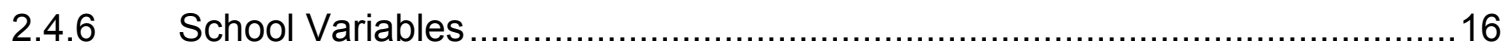

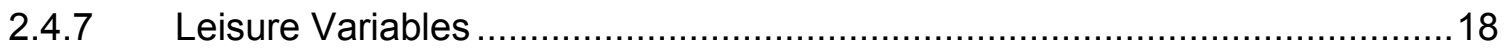

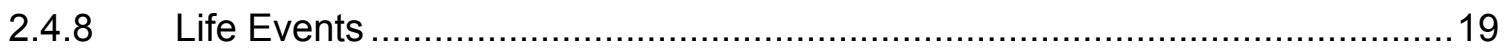

2.4.9 Parental Psychological Variables ........................................................... 20

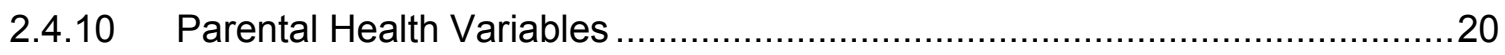

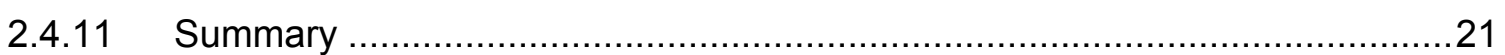

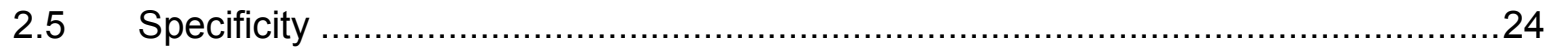

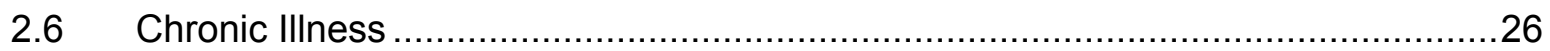

2.7 Specificity Research Regarding Pediatric Headache ......................................28

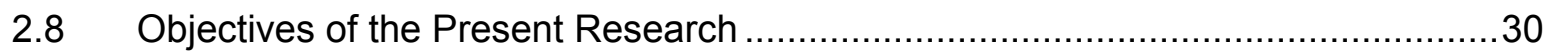

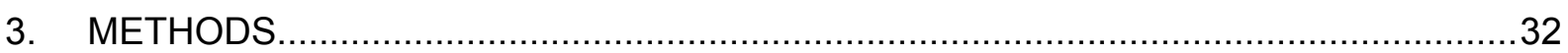

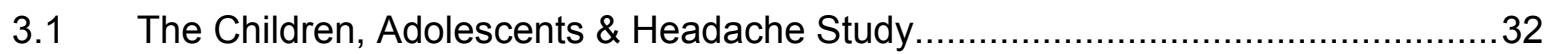

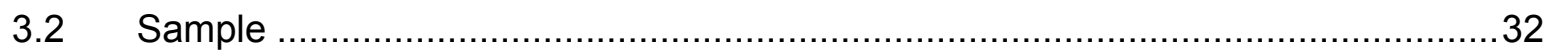

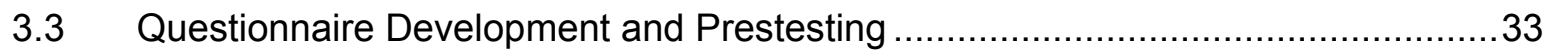

3.4 Operationalization of the Outcome Variables Weekly Headache, Chronic Illness, and Good Health ...................................................................................... 34

3.5 Operationalization of the Potentially Relevant Biopsychosocial Variables .............35

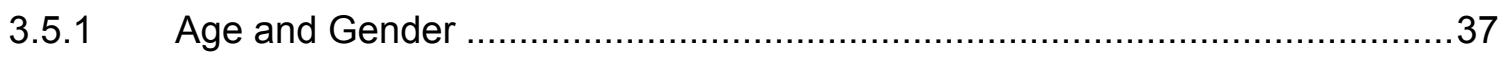

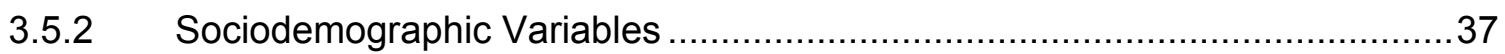

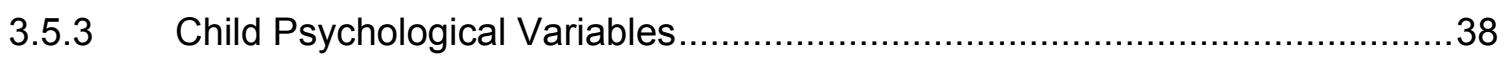

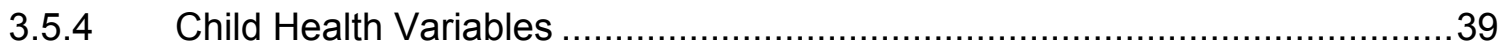

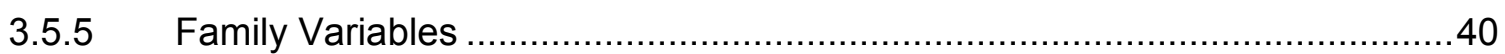

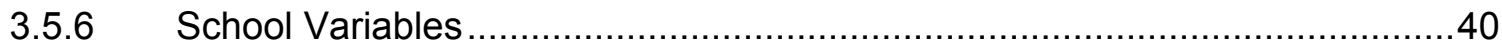

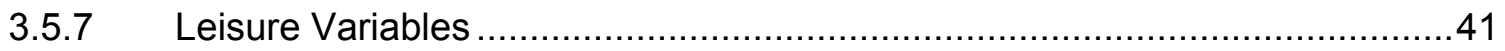

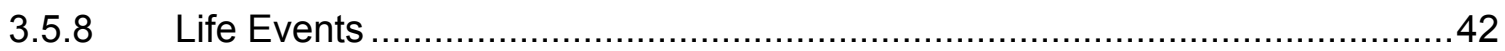

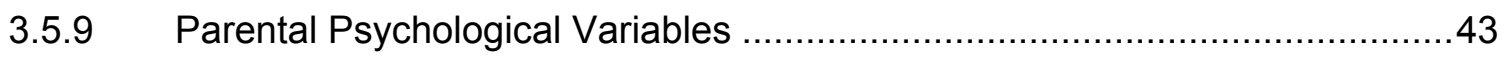

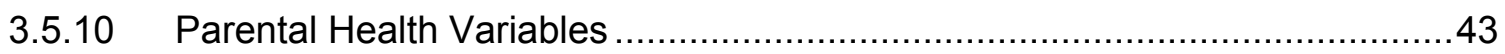

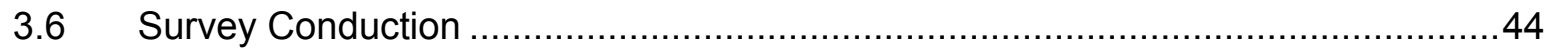

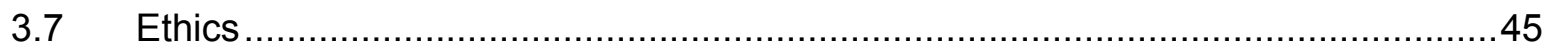

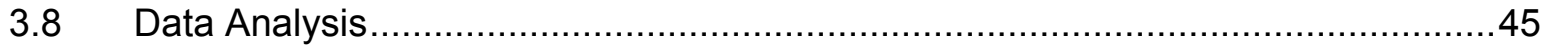




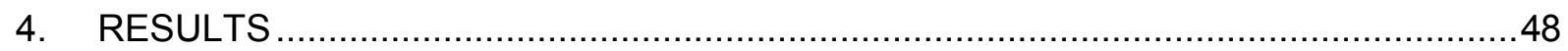

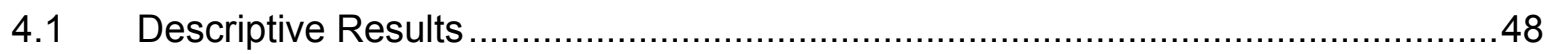

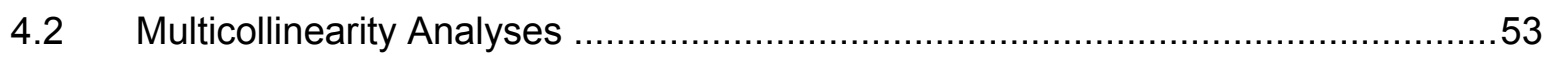

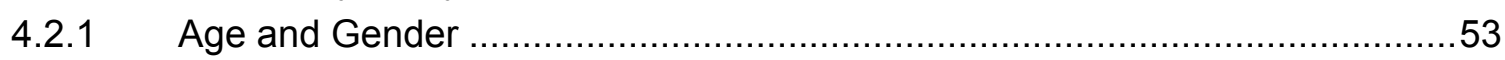

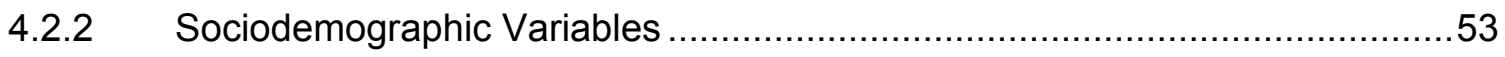

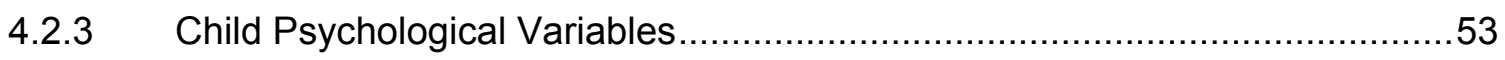

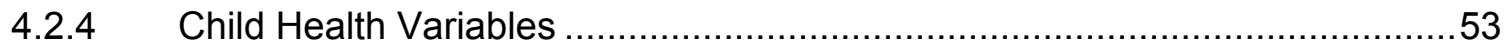

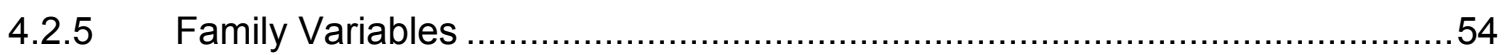

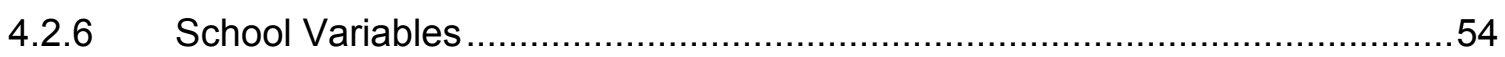

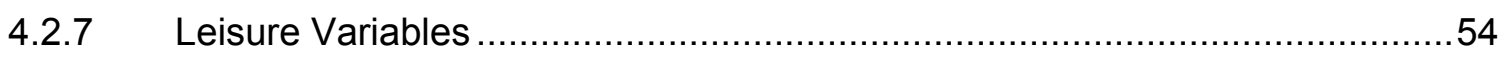

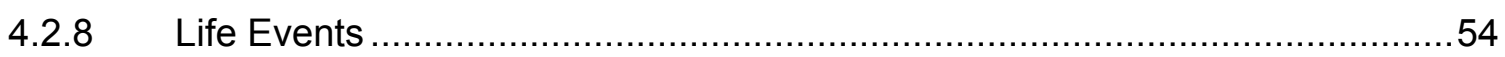

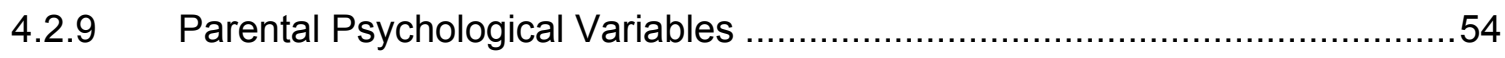

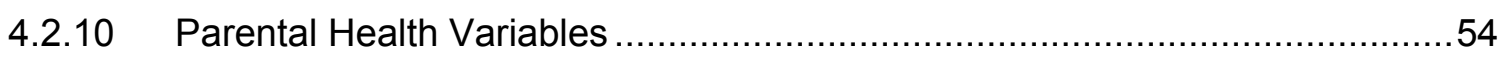

4.3 Analyses Regarding Weekly Headache vs. Good Health.....................................54

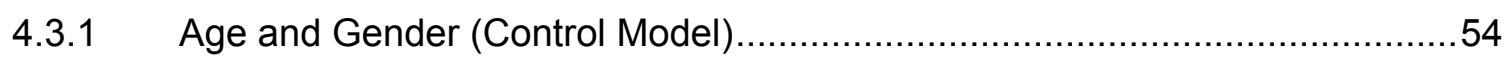

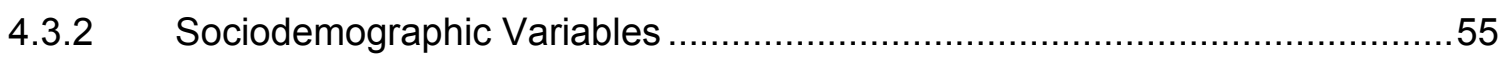

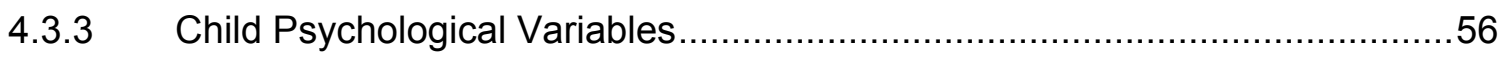

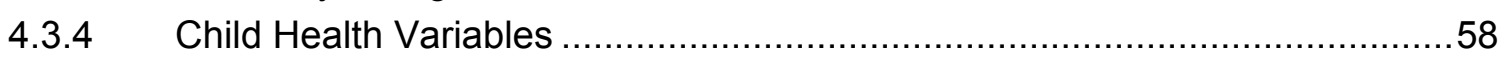

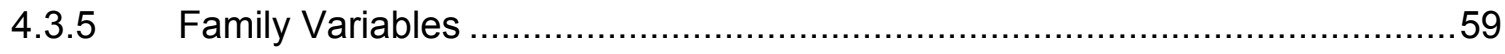

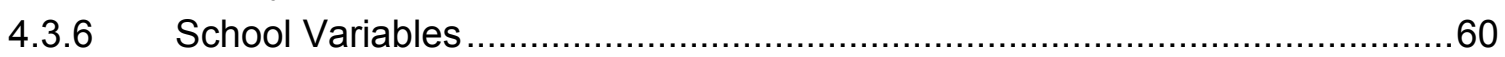

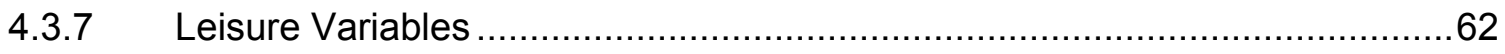

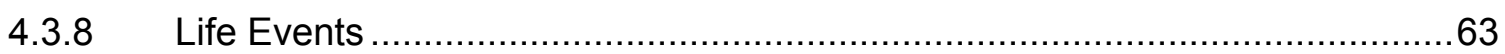

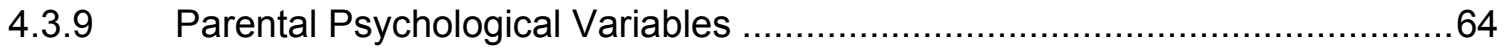

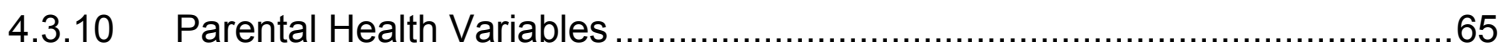

4.3.11 Summary of Full Domain Model Analyses .................................................66

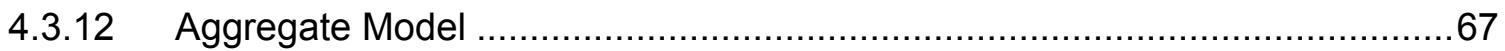

4.4 Analyses Regarding Chronic Illness vs. Good Health .......................................69

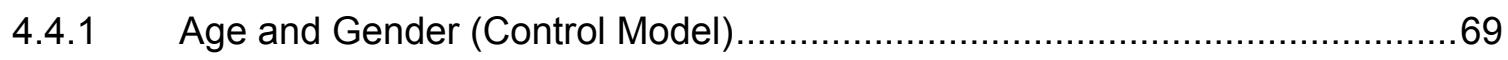

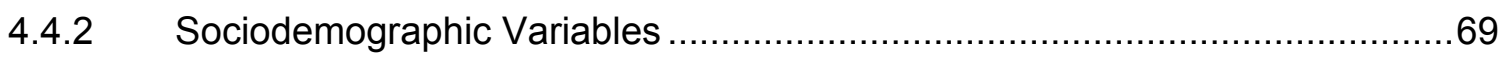

4.4.3 Child Psychological Variables............................................................. 70

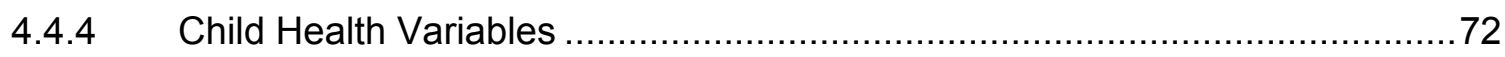

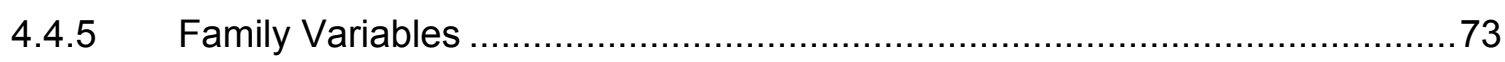

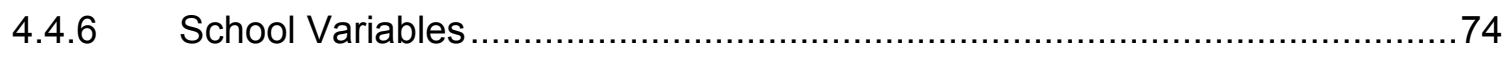

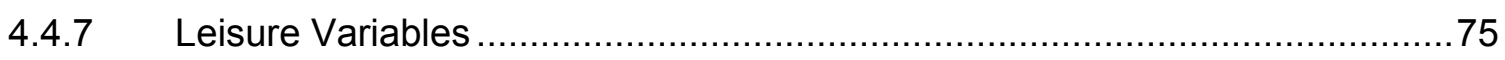

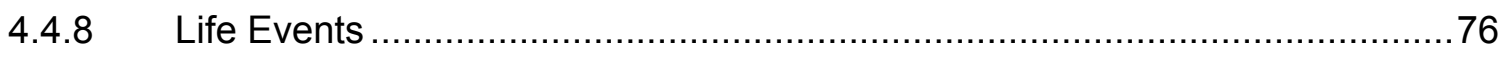

4.4.9 Parental Psychological Variables ........................................................... 77

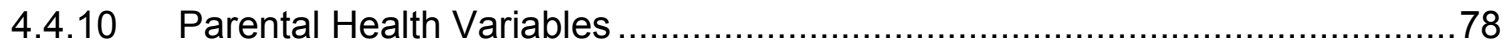

4.4.11 Summary of Full Domain Model Analyses ..................................................... 79

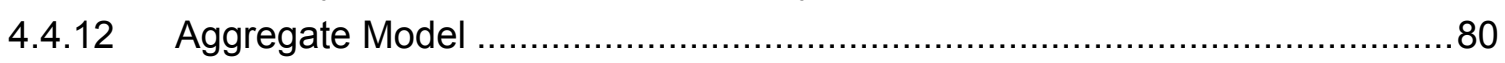

4. 5 Specificity Model (Analyses Regarding Weekly Headache vs. Chronic Illness).....81

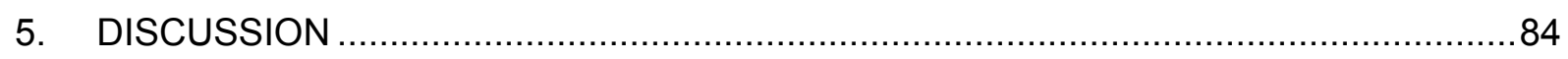

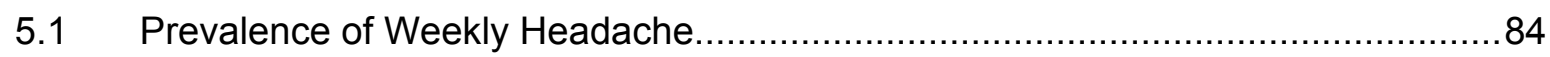

5.2 Correlates of Weekly Headache ...................................................................... 85

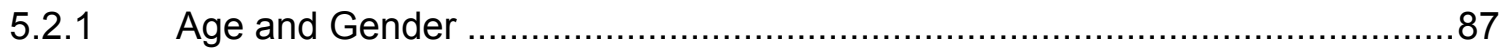




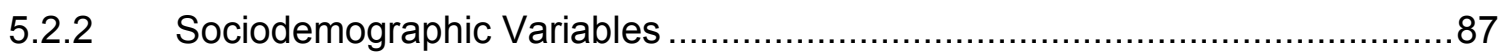

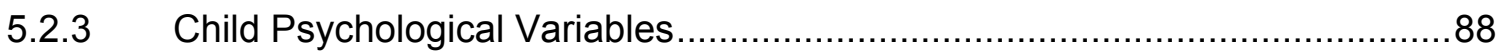

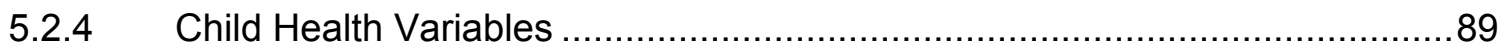

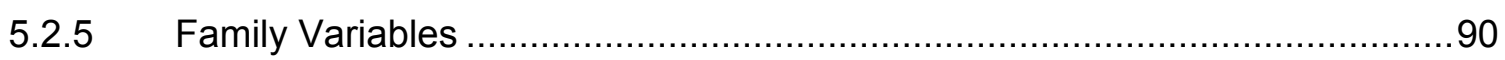

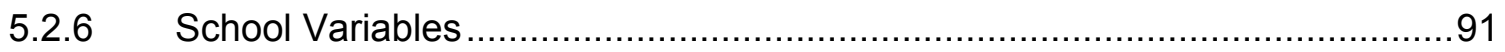

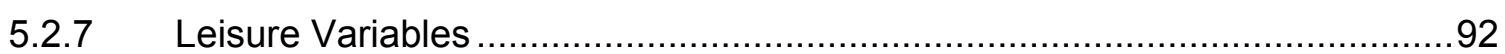

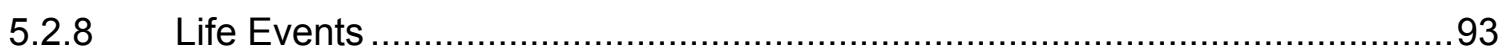

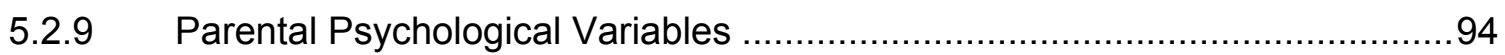

5.2.10 Parental Health Variables ..................................................................... 94

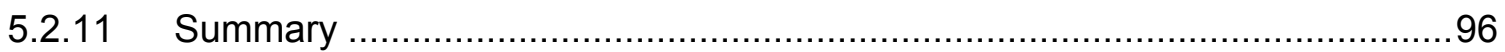

5.3 Aggregate Model for Weekly Headache vs. Good Health ....................................96

5.4 Specificity Model (Weekly Headache vs. Chronic Illness) ....................................102

5.5 Summary and Future Directions ........................................................................ 109

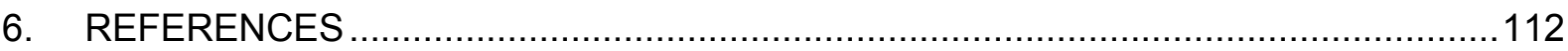

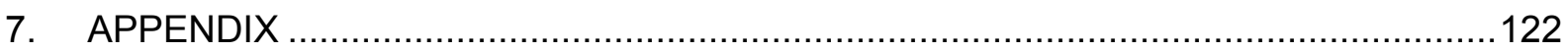

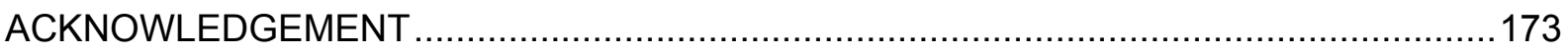

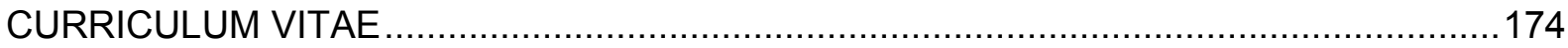




\section{INTRODUCTION}

The health of children and adolescents gives cause for concern, according to German experts in the field (Hurrelmann, Klocke, Melzer, \& Ravens-Sieberer, 2003). While advances in medical care and improved control of infectious diseases have reduced infant and child mortality and led to better overall pediatric health, certain somatic complaints and chronic illnesses seem to be alarmingly on the rise (Neuhauser, Dippelhofer, \& Holling, 2002; Newacheck, Budetti, \& McManus, 1984). Headache appears to belong to this group of increasingly prevalent pediatric health issues: A number of studies have reported waxing rates of headache and weekly headache among children and adolescents (Bandell-Hoekstra et al., 2001; Scheidt, Overpeck, Wyatt, \& Aszmann, 2000; Sillanpää \& Anttila, 1996).

Headache often begins in puberty or adolescence, though onset can also occur in childhood. The majority of children and adolescents experience headache (e.g., King \& Sharpley, 1990; Rhee, 2000; Zwart, Dyb, Holmen, Stovner, \& Sand, 2004), and more severe and impairing headache is also common: One in ten children and adolescents report having headache on a weekly basis (Laurell, Larsson, \& Eeg-Olofsson, 2004; Passchier \& Orlebeke, 1985). In addition, headache has a tendency to recur. Longitudinal studies have shown it to be a relatively stable health condition (Brattberg, 1994; Schmidt, Blanz, \& Esser, 1992; Virtanen et al., 2002). Given this situation, it is unsurprising that pediatric headache is receiving increased attention (McGrath \& Hillier, 2001). Implementing effective interventions at an early age has been given priority, especially as a means to prevent headache from becoming a life-long health condition (World Health Organization, 2000).

Children and adolescents with weekly headache are at elevated risk not only for the development of adult headache, but also for multiple physical symptoms and psychiatric morbidity in adulthood (Fearon \& Hotopf, 2001). These children and adolescents are therefore in particular need of effective intervention. The best manner with which this can be provided is through the development of prevention programs tailored to the specific needs of this group. However, this requires detailed knowledge of the biological, psychological, and social aspects of weekly headache. The goal of the present research is to provide such knowledge by first identifying biopsychosocial correlates of weekly headache in comparison to good health and then determining the specificity of these correlates for weekly headache in comparison to other chronic illnesses. 


\section{THEORETICAL \& EMPIRICAL BACKGROUND}

\subsection{Pediatric Headache}

Headache is thought to have first been described about 25 centuries ago by Hippocrates, and given the name "hemicrania" 600 years thereafter by Galen (Rothner, 2001). More recently (as early as the 16th century), pediatric headache was distinguished from headache in adulthood (e.g., Tissot, 1780; cited according to Connelly, 2003) and it was included in Day's (1873) "Essays on Diseases in Children" (cited according to Rothner, 2001). Nevertheless, it was not until the last two decades that headache in childhood and adolescence began to receive real scientific and clinical attention (McGrath \& Hillier, 2001).

Pediatric headache, like headache in general, can be differentiated according to causation into primary and secondary headache. Headache that can be directly attributed to a specific underlying cause or condition (e.g., infection, disease, injury) is referred to as secondary or symptomatic headache. Headache that occurs on its own (i.e., not as a 'side effect' of some other underlying cause or condition) is referred to as primary or idiopathic headache. Primary headache is the predominant type of headache, being present in $90 \%$ to $95 \%$ of all occurrences of head pain (Denecke \& Kröner-Herwig, 2000; Göbel, 1997). While the exact pathophysiology of primary headache is yet unknown (Connelly, 2003), etiologies of the central nervous system (Hershey, 2005) and contributing genetic, biochemical, psychological, and environmental factors (Connelly, 2003) have been postulated.

Frequency, duration, and intensity of pediatric headache can be characterized as being quite heterogeneous (McGrath, 2001). Headache frequency can vary from less than once a month to several times a week (McGrath et al., 2000). Headache may even occur on a daily basis (Scalas \& Calistri, 2005; Wiendels, van der Geest, Neven, Ferrari, \& Laan, 2005). Duration of headache can range from episodes of less than 15 minutes to almost constant pain, while intensity can vary from slight to severe (McGrath \& Koster, 2001). Additionally, headache can occur as a solitary complaint or be accompanied by further somatic and/or neurological symptoms.

In line with the variability of headache features and accompanying symptoms, pediatric headache, and headache in general, can take on different forms. Historically, two main types of headache, migraine and tension-type headache, have been distinguished on the basis of accompanying symptoms (e.g., nausea, photophobia) and pain quality (e.g., pulsing, tightening; Connelly, 2003). The International Headache Society (IHS) published operationalized criteria for these and other headache disorders in 1988 and a revised version thereof in 2004 (Headache Classification Committee of the International Headache Society, 1988, 2004). The criteria are known as the International Classification of Headache Disorders, versions I and II (ICHD-I and -II). The current criteria for migraine and tension-type headache (from the ICHD-II) can be found in Appendix A.

In general, children tend to describe headache pain as either throbbing or aching. These descriptions of headache quality typically correspond to diagnoses of migraine and tension-type headache, respectively (McGrath, 2001). In addition to the throbbing or pulsating quality of headache, children with migraine tend to rate their pain as moderate to 
severe and report accompanying symptoms of nausea, vomiting, and photophobia (Labbé, 1998). Generally, migraine pain is unilateral and located in the frontal or temporal area (Labbé, 1998); however, bilateral pain is also common in children and adolescents (Headache Classification Committee of the International Headache Society, 2004; McGrath, 2001). Children with tension-type headache describe pain of an aching or tightening quality that is less severe and localized at the back of the head and shoulders or in the frontal area (Labbé, 1998).

Despite these differences and the presence of operational classification criteria, it is not always easy to distinguish between migraine and tension-type headache (Connelly, 2003). Children often have difficulties describing the quality of their headache pain (Rossi et al., 2001). In addition, characteristics of both migraine and tension-type headache may be present in a single headache episode (Rossi et al., 2001). Accordingly, some skepticism has been voiced regarding the applicability of the ICHD to children and adolescents (deGrauw, Hershey, Powers, \& Bentti, 1999; Rossi et al., 2001; Seshia, 1996). A final consensus has not yet been reached. Nevertheless a large portion of pediatric headache research has focused and continues to focus on headache diagnoses and associated characteristics and variables.

Research has, however, also concentrated on the frequency with which pediatric headache occurs. Headache occurrence has been examined in comparison to nonoccurrence (Aromaa, Rautava, Helenius, \& Sillanpää, 1998), frequent headache has been compared to infrequent or no headache (Gordon, Dooley, \& Wood, 2004; Larsson, 1988; Luka-Krausgrill \& Reinhold, 1996), and predictors of headache frequency have been investigated (Passchier \& Orlebeke, 1985). In line with this second area of headache research, the focus of the present study is on headache that occurs frequently (i.e., at least once a week) without further differentiation according to headache diagnosis.

\subsection{Epidemiology of Pediatric Headache}

Over forty years ago, Bille (1962) conducted the first large-scale epidemiological study on headache in children and adolescents. In this seminal study, headache was reported for $58.6 \%$ of the sample, which comprised approximately 9,000 Swedish school children, aged 7 to 15 .

International research in the past decades has confirmed that headache is a common experience in childhood and adolescence. However, the reported prevalence rates vary substantially. Lifetime prevalence rates for having ever experienced headache have been reported to range from 21.7\% (Aromaa et al., 1998) to 37.7\% (Sillanpää, 1976) for preschool children, and from 58.6\% (Bille, 1962) to 97\% (Bandell-Hoekstra et al., 2001) for older children and adolescents. Reported 12-month prevalence rates for headache among school children are somewhat lower, varying from 44.8\% (Laurell et al., 2004) to 92\%, (BandellHoekstra et al., 2001).

The prevalence of frequent headache has also been investigated: Headache occurring at least once a week in the past 12 months has been reported to range from $10.8 \%$ for 7 - to 15 -year-olds (Laurell et al., 2004) to $29.7 \%$ for adolescents and young adults aged 
11 to 21 (Rhee, 2000). Lower prevalence rates have also been reported: Linna, Moilanen and Keistinen (1991) found $2.8 \%$ of 8 -year-olds to have experienced weekly headache, while a 6-month prevalence of $8.1 \%$ was reported for adolescents aged 13 to 18 (Zwart et al., 2004). A comprehensive overview of epidemiological findings regarding weekly headache is given in Table 1. The studies are listed in ascending order according to prevalence.

Table 1. Prevalence of weekly headache in the extant epidemiological literature

\begin{tabular}{|c|c|c|c|c|c|}
\hline Research group & Country & $\begin{array}{l}\text { Size of } \\
\text { sample }\end{array}$ & Age of sample & $\begin{array}{c}\text { Type of } \\
\text { prevalence }\end{array}$ & $\begin{array}{l}\text { Prevalence } \\
\text { rate }\end{array}$ \\
\hline Sillanpää (1976) & Finland & 4,235 & 7 & not specified & $2.5 \%$ \\
\hline Sillanpää \& Antilla (1996) & Finland & 1,433 & 7 & 6-month & $2.6 \%$ \\
\hline Linna et al. (1991) & Finland & 1,101 & 8 & not specified & $2.8 \%^{\mathrm{a}}$ \\
\hline Carlsson (1996) & Sweden & 1,144 & $7-16$ & not specified & $6 \%^{b}$ \\
\hline Kristjánsdóttir (1997) & Iceland & 2,098 & $11-12,15-16$ & 6-month & $6.2 \%$ \\
\hline $\begin{array}{l}\text { Linet, Stewart, Celentano, Ziegler, \& } \\
\text { Sprecher (1989) }\end{array}$ & USA & 3,158 & $12-17$ & 4-week & $7 \%$ \\
\hline Zwart et al. (2004) & Norway & 5,847 & $13-18$ & 6-month & $8.1 \%$ \\
\hline Sillanpää (1983b) & Finland & 3,784 & 13 & 12-month & $8.3 \%$ \\
\hline Sillanpää (1983a) & Finland & 2,915 & 14 & not specified & $8.7 \%$ \\
\hline Egermark-Eriksson (1982) & Sweden & 402 & $7,11,15$ & not specified & $9 \%$ \\
\hline Laurell et al. (2004) & Sweden & 1,371 & $7-15$ & 12-month & $10.8 \%$ \\
\hline Engström (1992) & Sweden & 3,878 & $8-19$ & 12-month & $11 \%$ \\
\hline Larsson (1988), survey II & Sweden & 1,564 & $16-18$ & not specified & $14 \%$ \\
\hline Larsson (1988), survey I & Sweden & 1,287 & $16-18$ & not specified & $15 \%$ \\
\hline Passchier \& Orlebeke (1985) & Netherlands & 2,181 & $10-17$ & 12-month & $16.9 \%$ \\
\hline Brattberg \& Wickman (1992) & Sweden & 1,245 & $8,11,13,17$ & not specified & $17.6 \%^{\mathrm{c}}$ \\
\hline Frankenberg \& Pothmann (1995) & Germany & 4,835 & $8-9,12-13,15-16$ & lifetime & $21.2 \%$ \\
\hline Kristjánsdóttir \& Wahlberg (1993) & Iceland & 2,140 & $11-12,15-16$ & not specified & $21.9 \%$ \\
\hline Petersen, Bergström, \& Brulin (2003) & Sweden & 1,155 & $6-13$ & 6-month & $22.6 \%$ \\
\hline Bandell-Hoekstra et al. (2001) & Netherlands & 2,358 & $10-17$ & 12-month & $23 \%$ \\
\hline $\begin{array}{l}\text { Ravens-Sieberer, Thomas, \& Erhart } \\
(2003)\end{array}$ & Germany & 5,650 & $11-15$ & 6-month & $24.5 \%^{\mathrm{d}}$ \\
\hline $\begin{array}{l}\text { Scheidt, Overpeck, Wyatt, \& Aszmann } \\
(2000)\end{array}$ & Germany & 4,792 & $11-15$ & 6-month & $25 \%$ d,e \\
\hline Gordon et al. (2004) & Canada & 2,900 & $12-13$ & 6-month & $26.6 \%$ \\
\hline King \& Sharpley (1990) & Australian & 900 & $10-18$ & not specified & $29.4 \%$ \\
\hline Rhee (2000) & USA & 6,072 & $11-21$ & 12-month & $29.7 \%$ \\
\hline Fichtel \& Larsson (2002) & Sweden & 793 & $13-19$ & 6-month & $32.5 \%$ \\
\hline
\end{tabular}

a Possible underestimation as percentage pertains to headache "more than once a week"

'Possible underestimation as percentage pertains to headache "several times a week", "once a week" was not included

${ }^{c}$ Possible overestimation as head and neck pain were assessed together

${ }^{d}$ Possible overestimation as percentage pertains to headache "almost every week" or more often

${ }^{\mathrm{e}}$ Mean prevalence rate calculated on the basis of the reported gender and age-specific rates

Epidemiological research on pediatric headache in Germany has just recently begun. Pothmann, von Frankenberg and colleagues conducted the first such study a decade ago with a school-based sample of 4,835 students, aged 8 to 16 (Frankenberg \& Pothmann, 
1995; Pothmann, Frankenberg, Müller, Sartory, \& Hellmeier, 1994). The vast majority of the students, namely $88.8 \%$, reported having experienced headache at some point in their lives. Approximately every fifth child reported having frequent headache, with $5.7 \%$ reporting daily and further $15.5 \%$ weekly headache $(21.2 \%$ in total).

To date, research on children and adolescents in Germany has shown headache to be common, though probably less widespread than first thought. While no data are currently available regarding preschool children, reported lifetime prevalence rates for older children and adolescents range from $15.5 \%$ (Essau, Conradt, \& Petermann, 1999) to $88.8 \%$ (Frankenberg \& Pothmann, 1995). A 12-month prevalence rate of $39.4 \%$ for 12 - to 16 -yearolds (Kolip, Nordlohne, \& Hurrelmann, 1995) and a 3-month rate of $65.6 \%$ for children and adolescents aged 10 to 18 (Roth-Isigkeit, Thyen, Raspe, Stoven, \& Schmucker, 2004) have also been reported. Rates of headache occurring at least once a week in the past 6 months has been reported to range for adolescents from 15.5\% (Luka-Krausgrill \& Reinhold, 1996) to $25 \%$ (Scheidt et al., 2000). However, limitations regarding two of the German studies should be noted: First, the focus of the study from Essau et al. (1999) was on somatoform and other psychiatric disorders. It is possible that headache was less likely to be affirmed within this context, resulting in an underestimation of its prevalence. Second, due to the small sample size $(n=226)$ in the study from Luka-Krausgrill and Reinhold (1996), the reported proportion of children with headache should be considered a rough estimate rather than a reliable prevalence rate.

In general, the prevalence of pediatric headache has been found to increase with age (e.g., Carlsson, 1996; Egermark-Eriksson, 1982; Egger, Angold, \& Costello, 1998; Laurell et al., 2004; Mortimer, Kay, \& Jaron, 1992; Ravens-Sieberer et al., 2003; Sillanpää, 1983). There is evidence of an age-related increase in the prevalence of weekly headache (Egermark-Eriksson, 1982; Scheidt et al., 2000) as well. In addition, headache prevalence has been found to be higher among female children and adolescents than among their male counterparts (e.g., Essau et al., 1999; Grøholt, Stigum, Nordhagen, \& Kohler, 2003; RavensSieberer et al., 2003; Zwart et al., 2004). The relevance of age and gender for headache will be covered in more detail in the section on Correlates of Pediatric Headache.

Altogether, there is a considerable variability in the prevalence rates that have been published in the literature, German and otherwise. This variability has been attributed to differences in sampling method, age and sex distribution of study population, diagnostic criteria, and country of origin (McGrath, 2001). An additional and more alarming attribution has also been proposed, namely that headache prevalence has increased substantially in the past decades.

On the basis of the literature since 1960, Sillanpää and Anttila (1996) came to the conclusion that, although the results of the studies were not necessarily comparable (e.g., due to differing methodology and headache criteria), they seemed to indicate that prevalence of pediatric headache had increased over time from $35 \%$ to $38 \%$ in the 1960 s to 1970 s to $42 \%$ to $50 \%$ in the 1980 s and 1990 s.

To investigate this assumption, Sillanpää and Anttila (1996) replicated an earlier epidemiological study (Sillanpää, 1976), while utilizing the same design, age group, and child 
population in order to facilitate comparison. The resulting data confirmed a significant increase in headache prevalence among Finnish 7-year-olds. While $14.4 \%$ experienced headache in 1974, the proportion of 7 -year-olds with headache more than tripled to $51.5 \%$ in 1992. Corresponding developments were also reported for recurrent headache: Monthly headache increased from $3.4 \%$ to $9.1 \%$, and weekly headache from $1.3 \%$ to $2.6 \%$ in the same time span.

More recently, a similar development was reported in the Health Behavior in SchoolAged Children (HBSC) study, a cross-national research project that is conducted in collaboration with the World Health Organization (WHO) at four-year intervals in numerous countries: According to Scheidt et al. (2000), the prevalence of headache increased approximately $5 \%$ between the surveys that took place in 1993/1994 and 1997/1998.

There is also evidence that the prevalence of weekly headache has increased over time: Rhee (2000) reported a prevalence rate of $29.8 \%$ for U.S. students, aged 11 to 21 , which in comparison to a previously reported prevalence rate of $7 \%$ (Linet et al., 1989), suggested "a rapid increase in the number of adolescents with recurrent headaches in the United States" (Rhee, 2000, p. 534). Furthermore, Bandell-Hoekstra et al. (2001) assessed headache in Dutch school children aged 10 to 17 using the prevalence questions previously employed by Passchier and Orlebeke (1985) and found the prevalence of weekly headache to have increased from $17 \%$ to $23 \%$.

In sum, research has shown that pediatric headache is widespread. The majority of children and adolescents have experienced headache in the past year, and at least one in ten has experienced weekly headache. There is also evidence that pediatric headache has increased in the past decades. The question is, what natural course does pediatric headache follow (i.e., is it of a transient or enduring nature)?

\subsection{Natural Course of Pediatric Headache}

Studies on migraine have reported a moderate to high stability of headache, depending on the length of the investigated time span: In a 4-year follow-up study, Metsähonkala et al. (1997) found migraine to remain stable in $83.3 \%$ of a Finnish adolescent migraineur sample. A further $11.9 \%$ of the sample reported non-migrainous headache, while only $4.8 \%$ of the children were headache-free. In a sample of Italian adolescents with migraine, $70.3 \%$ continued to have headache at 5-year follow-up, though the type of headache had changed in $37.5 \%$. Less than one third $(29.7 \%)$ of the sample had become headache-free (Camarda et al., 2002). In a 7-year follow-up Sillanpää (1983) found that migraine occurring at age 7 had disappeared by age 14 in $22 \%$, was improved in $37 \%$, but remained unchanged or grew more severe in $41 \%$ of a Finnish sample. Finally, in an unparalleled follow-up study of Swedish children with migraine, Bille documented headache evolution of 73 children over a time span of 40 years (Bille, 1962, 1989, 1997). At the 40-year follow-up, $46 \%$ were migraine-free, half of which had been migraine-free since age 25 (23\% of total sample). On the other hand, $51 \%$ of the study participants continued to experience migraine. 
Moderate to high rates of headache stability have also been found in studies on children and adolescents presenting at headache clinics. Some of these studies have additionally investigated diagnosis-specific differences in stability. In a 2- to 5-year follow-up study, Zebenholzer et al. (2000) reported headache stability of $71 \%$ in a pediatric patient sample, though type of headache had changed in $20 \%$. Less than one third $(29 \%)$ of the patients had become headache-free. In an 8-year follow-up of Italian patients Guidetti and Galli (1998) found stability of headache to be $71.9 \%$ for migraine and $55.6 \%$ for tension-type headache. Similarly, in a 10-year follow-up of consecutive pediatric patients, Dooley and Bagnell (1995) found headache stability of $50 \%$ for tension-type headache, $79.6 \%$ for migraine without aura, and $100 \%$ for migraine with aura (i.e., migraine with antecedent neurological symptoms affecting vision, sensation or speech, see Appendix A). Less than a third of the patient sample (27.3\%) had become headache-free.

Unselected community- and school-based studies have reported somewhat lesser rates of headache stability. On the basis of data reported by Brattberg (1994), frequent headache remained stable in $62.5 \%$ of Swedish students over a 2 -year period $(48 \%$ of the sample reported frequent headache at first assessment and $30 \%$ of the total sample had headache at both assessments). Headache that disturbed daily activities was found to remain stable in $40.8 \%$ of Finnish children over a period of 6 years (Virtanen et al., 2002). Moderate to high rates of headache stability were also found in a longitudinal cohort study of 399 German children (Schmidt et al., 1992): Regarding a time span of five years, stability rates of $73 \%$ (age 8 to age 13) and $56 \%$ (age 13 to age 18) were reported. For a time span of ten years headache stability was $47 \%$ (age 8 to age 18). Data from the National Birth Cohort Study in Great Britain also corroborates the association between headache in childhood and adult headache (Fearon \& Hotopf, 2001). Furthermore, the results indicate that the risk of having headache in adulthood is particularly increased in children with recurrent headache.

Altogether, research indicates that pediatric headache is not a transient complaint. Indeed, the stability of the pain over time points to a high risk of headache becoming an enduring health condition, in some cases intractable over the lifespan. Children and adolescents with frequent headache appear to be at particular risk.

In addition, there is mounting evidence that children and adolescents with headache are faced with long-term consequences beyond an elevated risk for adult headache. Data from the National Birth Cohort Study has indicated childhood headache to be associated with both multiple physical symptoms (i.e., presence of 3 or more physical symptoms) and psychiatric morbidity (i.e., presence of 4 or more symptoms of the Malaise Inventory) in adulthood (Fearon \& Hotopf, 2001). In line with the latter, Waldie and Poulton (2002) have reported childhood headache to confer a particular risk for anxiety disorder in young adulthood (age 18 and 21). On the basis of their data, (Fearon \& Hotopf, 2001, p. 3) appropriately concluded that "children with headache do not simply 'grow out' of their somatic complaint and may also 'grow into' others". 


\subsection{Correlates of Pediatric Headache}

Weekly headache in children and adolescents clearly needs to be addressed. In order to do so properly, knowledge about the biological, psychological, and social aspects of weekly headache is needed (Schwarzer, 2004). Numerous studies examining such correlates of and risk factors for headache have been conducted. However, the bulk of pediatric headache research has focused on headache in general or different types of headache. In addition, research that has focused on frequent headache has been hampered by the lack of a concrete definition of what is meant with "frequent" in some studies, and by the use inconsistent operationalizations of the terms "recurrent" and "frequent" in others. Nevertheless, a number of the studies on "frequent" or "recurrent" headache examined headache that occurred at least once a week and thus offer information regarding pediatric weekly headache. However, due to the small number of such studies, the following review of the empirical literature will cover pediatric headache as a whole, while emphasizing results regarding weekly headache.

\subsubsection{Age and Gender}

Numerous studies have documented that headache prevalence increases substantially with age (Barea, Tannhauser, \& Rotta, 1996; Carlsson, 1996; EgermarkEriksson, 1982; Egger et al., 1998; Laurell et al., 2004; Mortimer et al., 1992; RavensSieberer et al., 2003; Sillanpää, 1983). There is also evidence of an age-related increase in prevalence of weekly headache (Egermark-Eriksson, 1982; Scheidt et al., 2000). However, some contradictory results have also been reported. For example, Kristjánsdóttir (1993) found a significant inverse relationship, with both headache and weekly headache being more prevalent among younger than older children. In addition, a number studies found age to be unrelated to headache (King \& Sharpley, 1990, age 10 to18; Rhee, 2000, age 11 to 21; Zwart et al., 2004, age 13 to 18) and unrelated to weekly headache (Carlsson, 1996; King \& Sharpley, 1990; Passchier \& Orlebeke, 1985).

A gender difference has been reported in the majority of epidemiological studies, with more females than males experiencing headache (Brattberg \& Wickman, 1992; Essau et al., 1999; Fichtel \& Larsson, 2002; Grøholt et al., 2003; Kristjánsdóttir \& Wahlberg, 1993; Laurell et al., 2004; Pine, Cohen, \& Brook, 1996; Ravens-Sieberer et al., 2003; Zwart et al., 2004). Studies also indicate a female preponderance in weekly headache (Bandell-Hoekstra et al., 2001; Brattberg \& Wickman, 1992; Carlsson, 1996; Fichtel \& Larsson, 2002; King \& Sharpley, 1990; Larsson, 1988; Passchier \& Orlebeke, 1985; Rhee, 2000; Scheidt et al., 2000; Sillanpää, 1983; Zwart et al., 2004). The female predominance, however, first seems to appear around 10 to 12 years of age (Bille, 1981; Carlsson, 1996; Guidetti \& Galli, 1998; Laurell et al., 2004), or perhaps even later (Kristjánsdóttir \& Wahlberg, 1993; Sillanpää, 1983). Therefore, the gender differences may well reflect an interaction between age and

\footnotetext{
${ }^{1}$ For example, 'recurrent' headache has been defined as headache in the past 4 weeks plus headache prior thereto (Zuckerman, Stevenson, \& Bailey, 1987), headache more than twice in the past year (Cooper, Bawden, Camfield, \& Camfield, 1987), and headache once a week or more (Linna et al., 1991). Similarly, 'frequent' headache has been defined as headache more than once a month (Virtanen et al., 2002) or more than once a week (Gordon et al., 2004).
} 
gender. Indeed, some of studies that found no gender difference employed prepubertal samples (Anttila, Metsähonkala, Helenius, \& Sillanpää, 2000; Aromaa et al., 1998; Waldie, 2001). However, a lack of gender difference has also been reported for older samples (Egger et al., 1998, age 9 to 13; Virtanen et al., 2002, age 12).

Though some contradictory results have been reported, the majority of studies have indicated an age-related increase in headache prevalence and a female preponderance. The latter has also been reported for weekly headache. However, due to contradictory results further research is necessary before any definitive conclusions regarding the relationship between weekly headache and age can be drawn.

\subsubsection{Socioeconomic Variables}

The extent to which socioeconomic variables influence headache in children and adolescents has been investigated in a number of studies. Depending on the study, individual components of social class (e.g., household income, educational level of parents, occupational prestige of parents), an aggregate measure thereof, or other related socioeconomic variables have been examined. The relevant findings of the studies will be presented in the following paragraphs, grouped according to socioeconomic variable. Subsequently, the empirical status of the reported variables will be determined.

Studies investigating household income, an individual component of social class, have yielded conflicting results. While Grøholt et al. (2003) reported recurrent pediatric headache to be associated with lower disposable household income, Carlson (1996) found no association between weekly headache and average net income of households in the district of residence. Parental unemployment, a closely related variable, has also been investigated: While Metsähonkala, Sillanpää and Tuominen (1998) found no influence of maternal employment status on pediatric headache, fathers' employment status was associated with migraine. Additionally, Carlsson (1996) found weekly headache to be more common in high unemployment districts, though unrelated to need for social security benefits.

Parental educational level has been found to be related to headache, with lower parental education associated with non-migrainous headache (Metsähonkala et al., 1998) and recurrent headache (Grøholt et al., 2003). However, other studies have yielded contradictory results, finding parental educational level to be unrelated to headache (Zuckerman et al., 1987) and weekly headache (Carlsson, 1996).

While in some studies occupational prestige of the parents was not significantly associated with headache (Grøholt et al., 2003; Pothmann et al., 1994; Virtanen et al., 2002) or weekly headache (Carlsson, 1996), in at least one study a significant association was reported (Fearon \& Hotopf, 2001), with headache being related to lower occupational prestige.

On the aggregate level, results regarding the influence of social class on headache are equally contradictory. Some studies have found a significant association, indicating a higher prevalence of pediatric headache in the lower social class (Ravens-Sieberer et al., 2003; Sillanpää, Piekkala, \& Kero, 1991). Other studies found no relationship between 
headache and social class of family (Kristjánsdóttir \& Wahlberg, 1993; Zuckerman et al., 1987 ) or district (Passchier \& Orlebeke, 1985), or between weekly headache and social class (Larsson, 1988)

Housing conditions are related to socioeconomic status and have been investigated in headache studies. Sillanpää et al. (1991) found pediatric headache to be significantly associated with a lower housing standard and poorer living conditions. They also found a significant association between household crowding (i.e., higher number of inhabitants per room) and headache. On the other hand, Karwautz et al. (1999) found neither objectively measured nor subjectively perceived household crowding to be associated with headache. Nor did Zuckerman et al. (1987) find an association between household crowding and recurrent headache in preschool children.

Altogether, the number of studies indicating a significant association between socioeconomic variables and headache was equal or similar to the number of opposing studies. This was the case for both components of social class and aggregate measures thereof, with one exception: The number of studies which found headache to be unrelated to occupational prestige outweighs the single study reporting such an association. This is understood as an indication that occupational prestige is unrelated to headache. One study per variable, at most, examined weekly headache, thus it is not possible to draw any conclusions in this area. In sum, the results regarding socioeconomic variables can best be described as being inconclusive.

\subsubsection{Child Psychological Variables}

Psychological variables have also been investigated in pediatric headache studies. The examined variables have ranged from psychiatric disorders over psychological symptoms to aggregate measures of such symptoms. The results will be depicted followed by the evaluation of the variables' empirical status.

Evidence of an association between pediatric headache and psychiatric disorder has been provided by several studies. According to Maratos and Wilkinson (1982), patients with childhood migraine were significantly more likely to have a psychiatric disorder than nonheadache controls. Similarly, Schmidt et al. (1992) found the likelihood of having a psychiatric disturbance to be twice as high among children with headache as compared to their headache-free counterparts in a German birth cohort study.

Psychiatric disorders were also found to be associated with weekly headache in a population-based study of U.S. school children (Egger et al., 1998). Of children who met the criteria of the Diagnostic and Statistical Manual for Mental Disorders (third edition, revised [DSM-III-R]) for at least one psychiatric diagnosis, 20.5\% reported weekly headaches, compared to $9.2 \%$ of children without psychiatric disorder. The relationships between individual disorders and headache were also examined. Neither oppositional defiant disorder nor attention deficit disorder was associated with weekly headache. However, conduct disorder was associated with the presence of weekly headaches in boys: The likelihood of having such headache was twice as high among boys with the disorder. Furthermore, anxiety disorders and mood disorders were associated with weekly headache in girls: In comparison to girls without a disorder, girls with any anxiety disorder were twice, and girls 
with mood disorder fourfold more likely to have weekly headache. In contrast, Engström (1992) found DSM-III-R psychiatric diagnoses to be no more common among children and adolescents with weekly tension-type headache than among healthy controls.

Anxiety, nervousness, and related psychological symptoms have been investigated in association with pediatric headache in a number of studies. Children and adolescents with headache have been found to report significantly more anxiety-related symptoms such as anxiety/nervousness, worry/fright, restlessness (Carlsson, Larsson, \& Mark, 1996). In addition, pediatric patients with headache (Mazzone, Vitiello, Incorpora, \& Mazzone, 2006) and migraine (Smith, Martin-Herz, Marsigan, \& Womack, 2003) have been found to report more anxiety than headache-free controls. Children with weekly headache have also been found to have higher levels of anxiety than those with infrequent or no headache (Fichtel \& Larsson, 2002), or than healthy children (Engström, 1992). Similarly, Larsson (1988) found nervous problems and anxiety to be more common among students with weekly headache (aged 16 to 18) than those without.

Two further studies partially corroborated the relationship. Andrasik et al. (1988) found anxiety to be associated with weekly ${ }^{2}$ migraine among adolescents, but not among younger children, and Martin-Herz, Smith, and McMahon (1999) found trait anxiety to be related to weekly ${ }^{3}$ headache in boys, but not in girls.

On the other hand, neither Cunningham et al. (1987) nor Cooper et al. (1987) found anxiety to be related to occurrence of migraine, though it was positively correlated with migraine frequency and severity (Cooper et al., 1987). Similarly, Kowal and Pritchard (1990) reported a significant association between anxiety and severity of pediatric headache (defined as headache frequency plus headache intensity), though not between anxiety and headache occurrence, frequency, or intensity, when examined individually.

Turning to a different psychological variable, a number of studies investigated depressive symptoms in relation to pediatric headache. Higher depression scores in comparison to headache-free counterparts have been found for pediatric patients with headache (Mazzone et al., 2006), migraine (Cooper et al., 1987), and weekly migraine (Andrasik et al., 1988). There is also evidence that the magnitude of the association increases with age: While younger patients with weekly migraine scored twice as high as controls, adolescent migraineurs scored almost three times higher (Andrasik et al., 1988).

Large-scale population-based studies have corroborated the presence of an association between depression scores and headache (Fearon \& Hotopf, 2001; Rhee, 2000). This association has been found to extend to frequent headache (Luka-Krausgrill \& Reinhold, 1996) and weekly headache as well: For example Gordon et al. (2004) found weekly headache to be negatively associated with personal happiness and future optimism, and positively associated with depression. Similarly, Engström (1992) found children with weekly

\footnotetext{
${ }^{2}$ Andrasik et al. (1988) did not explicitly study weekly migraine. However, the migraine subjects reported an average of 9.5 headaches during a 4-week monitoring period and on the basis of this data, it can be assumed that they experienced weekly headache.

${ }^{3}$ Martin-Herz et al. (1999) did not explicitly study weekly headache. However, the subjects in their "frequent headache" group reported a median rating of more than one headache a week. Therefore, it can be assumed that they experienced weekly headache.
} 
tension-type headache to score significantly higher on a measure of depression than healthy children. The relationship between depression and weekly headache has been confirmed in two further studies (Fichtel \& Larsson, 2002; Martin-Herz et al., 1999).

In addition, suicidal ideation has also been found to be more common in children with headache than the headache-free counterparts (Aromaa, Sillanpää, Rautava, \& Helenius, 2000), with Gordon et al. (2004) reporting that $13 \%$ of young adolescents with weekly headache endorse having given committing suicide "serious consideration" in comparison to $4 \%$ of those with infrequent or no headache.

On the other hand, Kowal and Pritchard (1990) and Anttila et al. (2004) found headache and depression to be unrelated. In addition, no difference with regard to depression was found between children with migraine, other pain, and no pain (Cunningham et al., 1987), or between pediatric migraine patients and healthy controls (Smith et al., 2003).

In a further study, children and adolescents with weekly tension-type headache were found to have reported significantly lower self-esteem than healthy controls (Engström, 1992).

Insomnia and sleeping disorders, which can be considered to be psychophysiological disturbances (Riemann, Backhaus, Schramm, \& Hohagen, 1996), have also been investigated in association with pediatric headache. While Kowal and Pritchard (1990) found no significant association between sleeping difficulties and headache occurrence in 9- to 12year-old Australian children, insomnia has been found to be related to pediatric headache in population-based studies in the United States (Rhee, 2000) and the Nordic countries of Sweden, Norway, Finland, and Denmark (Grøholt et al., 2003; Laurell, Larsson, \& Eeg Olofsson, 2005). Furthermore, in a study by Aromaa et al. (1998), sleeping difficulties at age 3 were found to be predictive of later headache.

Along with measures tapping individual psychological variables, aggregate measures of emotional problems and internalizing disorders (i.e., depression, anxiety, withdrawal, and somatization) have also been employed in headache studies. For example, Anttila et al. (2004) found scores on an aggregate measure of anxiety and depression to be unrelated to headache in Finnish 13-year-olds. However, using the same measure, children and adolescents with migraine (but not tension-type headache; Just et al., 2003) and adolescents with weekly headache (Larsson, 1988) were found to be more anxious and depressed than their headache-free counterparts. Using a different measure, pediatric migraine patients were found to exhibit significantly lower emotional functioning in comparison to normative data on healthy controls (Powers, Patton, Hommel, \& Hershey, 2003). Adolescent weekly headache was also found to be significantly associated with elevated scores on measures of emotional disorders (Gordon et al., 2004), and mental health difficulties (Martin-Herz et al., 1999). However, Engström (1992) found emotional maladjustment to be no more common among children and adolescents with weekly tension-type headache than among healthy controls.

In addition, significantly higher scores on an aggregate measure of internalizing disorders have been reported for children and adolescents with headache (Just et al., 2003), pediatric headache patients (Mazzone et al., 2006), and patients with weekly migraine (Andrasik et al., 1988) in comparison to their headache-free counterparts. Using the same 
measure Cunningham et al. (1987) found children with migraine to exhibit more internalizing behavior than no-pain counterparts, but not than other pain controls. Similarly, Anttila et al. (2004) found elevated internalizing in adolescents with migraine, but not in those with tension-type headache. Finally, children with weekly tension headache scored higher on the measure than healthy children (Engström, 1992).

While some evidence linking anger and pain has been reported (Bandell-Hoekstra, Abu-Saad, Passchier, \& Knipschild, 2000; Fernandez \& Turk, 1995), anger and related variables have received only marginal attention in research on headache in children and adolescents. Carlsson et al. (1996) found getting easily angry or annoyed to be more common among children with headache than headache-free controls. Temper tantrums were also found to be more common among children with headache as among those without (Sillanpää et al., 1991).

A significant association between aggressive behavior and migraine with aura (though not with other headache) was reported by Just et al. (2003). Associations approaching significance between weekly headache and aggressive behavior or conduct disorder were reported by Gordon et al. (2004). In contrast, a number of studies found headache to be unrelated to aggressive behavior (Anttila et al., 2004; Cunningham et al., 1987) and delinquent behavior (Anttila et al., 2004; Cunningham et al., 1987; Just et al., 2003).

Inattentiveness and hyperactivity have been examined in a number of headache studies with inconclusive results. Just et al. (2003) found attention problems and hyperactivity to be more common among children and adolescents with migraine (but not tension-type headache) than among headache-free controls, while others found them to be unrelated to headache (Anttila et al., 2004), or migraine (Cunningham et al., 1987). Gordon et al. (2004) reported an association between attention problems or hyperactivity and weekly headache that approached significance. On the other hand, Aromaa et al. (1998) found concentration problems at age 5 to be predictive of headache one year later in Finnish children.

Aggregate measures tapping behavioral problems and externalizing disorders (e.g., aggressive behavior, delinquent behavior) have also been investigated in several headache studies. For example, Mazzone et al. (2006) reported externalizing to be more common among pediatric headache patients than healthy controls. Similarly, Just et al. (2003) found children and adolescents with migraine (but not tension-type headache) to score significantly higher on a measure of externalizing than their headache-free counterparts. Partial corroboration was also provided by Andrasik et al. (1988), who reported male children and adolescents with weekly migraine (but not female ones) to score significantly higher on the externalizing measure than headache-free controls. In contrast, no significant difference in comparison to healthy controls was reported for adolescents with headache (Anttila et al., 2004), or children and adolescents with weekly tension-type headache (Engström, 1992).

Stress has been repeatedly reported as a headache trigger in children and adolescents (Bandell-Hoekstra et al., 2001). In a German study, 29\% of adolescents with weekly headache and $10 \%$ of adolescents with seldom headache reported believing their 
headaches were stress-related (Luka-Krausgrill \& Reinhold, 1996). Similarly, Cooper et al. (1987) reported that $41 \%$ of migraine children and $46 \%$ of their parents cited stress as a trigger for headache. Additionally, children with headache have been found to report more everyday stress (Carlsson et al., 1996; Luka-Krausgrill \& Reinhold, 1996) and greater difficulties to relax (Carlsson et al., 1996) than headache-free controls. More everyday stress has also been reported for adolescents with weekly headache (Larsson, 1988).

While coping with stress has been incorporated in treatment programs for pediatric headache (Denecke \& Kröner-Herwig, 2000; Kerbeck \& Luka-Krausgrill, 1999), it has received scant attention in research on headache. In the only study that has investigated it to date, Luka-Krausgrill and Reinhold (1996) found adolescents with frequent headache to use avoidance strategies significantly more often than children with seldom or no headache, no differences were found with regard to the use of active or internal coping strategies.

In sum, the results indicate that pediatric headache is related to stress and tentatively related to psychiatric disorders, depressive symptoms, sleeping disorders, internalizing disorders, and anger. It can also be tentatively concluded that pediatric headache is unrelated to aggressive and delinquent behavior. The results regarding anxiety, hyperactivity/inattentiveness, externalizing disorders, and coping strategies are inconclusive. The pattern of results for weekly headache is somewhat different. They indicate that weekly headache is related to anxiety and depression and tentatively associated with internalizing disorders. No conclusions can be drawn regarding psychiatric disorders, emotional problems, aggressive behavior, hyperactivity/inattentiveness, and externalizing disorders. Substantial further research is necessary in order to confirm the tentative associations and to elucidate the inconclusive ones.

\subsubsection{Child Health Variables}

It has been suggested that pediatric headache may be a manifestation of a child's general tendency to experience somatic symptoms when under stress (Aromaa et al., 2000; Martin \& Smith, 1995) and numerous studies have investigated the association between headache and somatic symptoms. The examined variables have ranged from non-headache pains (e.g., back pain, stomach ache) over other somatic complaints (e.g., dizziness, tiredness), to aggregate somatic symptom scales.

Children and adolescents with headache seem to experience non-headache pain more often than their headache-free counterparts. For example, several studies have shown pediatric headache to be significantly associated with stomach aches or pains (Aromaa et al., 2000; Carlsson et al., 1996; Grøholt et al., 2003). Indeed, Sillanpää et al. (1991) found stomach ache to be about fourfold as frequent in 5-year-old Finnish children with headache than in children without headache. Similarly, back pain has been found to be more frequent in children and adolescents with headache (Carlsson et al., 1996; Grøholt et al., 2003), though one study found no such relationship (Aromaa et al., 2000). Significant associations have been also found between headache and growing pains in 7-year-olds (Aromaa et al., 2000), and neck pain in Swedish students, aged 8 to 15 (Carlsson et al., 1996). Two thirds of adolescents with weekly headache have reported experiencing at least one non-headache pain (Fichtel \& Larsson, 2002). Furthermore, according to Aromaa et al. (2000) the parents of 
children with headache were more likely to describe their child as extremely sensitive to pain than parents of headache-free children.

Other somatic complaints also appear to be more common among children and adolescents with headache. Significant associations have been found between pediatric headache and tiredness (Aromaa et al., 2000; Carlsson et al., 1996), dizziness (Grøholt et al., 2003), motion sickness (Aromaa et al., 1998), loss of appetite (Carlsson et al., 1996; Grøholt et al., 2003), breathing problems (Carlsson et al., 1996), and nocturnal or diurnal enuresis (Aromaa et al., 1998; Sillanpää et al., 1991).

Furthermore, numerous studies have documented that children and adolescents with headache score significantly higher than their headache-free counterparts on somatic symptom scales that encompass both various pains and somatic symptoms (Anttila et al., 2004; Carlsson et al., 1996; Just et al., 2003; Kowal \& Pritchard, 1990; Luka-Krausgrill \& Reinhold, 1996). The same relationship has been found for children and adolescents with weekly headache (Engström, 1992; Larsson, 1988; Martin-Herz et al., 1999) and pediatric migraine patients (Smith et al., 2003). Indeed, in a study that employed three different aggregate measures of somatic complaints, children and adolescents with weekly migraine were found to have scored significantly higher than headache-free controls on each of the three measures (Andrasik et al., 1988). Children with migraine were also found to score higher on a somatic symptom scale than children with other pain (e.g., chronic musculoskeletal pain), or pain-free controls (Cunningham et al., 1987).

Finally, Powers et al. (2003) reported that in comparison to normative data on healthy controls, pediatric migraine patients exhibited significantly lower physical functioning, a compound variable encompassing low energy level, aches and pains, and ability to perform basic physical activities.

Altogether, research indicates non-headache pain and other somatic complaints are factors relevant to both pediatric headache and pediatric weekly headache. Though almost no studies have reported on associations between individual pains or somatic symptoms and weekly headache, the results regarding the aggregate measure of somatic complaints are convincing.

\subsubsection{Family Variables}

Family characteristics, such as marital relationship, number of siblings, and family conflict, have been the focus of interest in a number of headache studies. However, the results have been largely inconclusive.

A few studies have indicated that divorce or separation is associated with tensiontype headache (Karwautz et al., 1999), headache in general (Carlsson et al., 1996), and weekly headache (Larsson, 1988) in children and adolescents. The majority of studies, however, have found no such relationship between headache and parental status (Aromaa et al., 1998; Fearon \& Hotopf, 2001; Metsähonkala et al., 1998; Pothmann et al., 1994; Virtanen et al., 2002; Zuckerman et al., 1987). Nor has an association between quality of marital relationship and headache (Zuckerman et al., 1987) or weekly headache (Larsson, 1988) been found, though one study indicated that a poor marital relationship was more common 
among adolescents with migraine and comorbid psychiatric problems (Maratos \& Wilkinson, 1982).

Number of siblings was not found to be significantly associated with headache in children and adolescents (Aromaa et al., 1998; Carlsson et al., 1996; Metsähonkala et al., 1998). One study indicated that children with non-migrainous headache are often the eldest child in the family (Metsähonkala et al., 1998). However, in view of age-specific increases in headache prevalence, it seems unclear whether this result should be attributed to birth order or child's age.

Turning to family environment, difficulties talking with mother (but not with father) have been found to be significantly associated with headache in children and adolescents (Brattberg, 1994). Additionally, it has been found that familial conflicts leading to open quarreling and sulking are significantly more often present in families of children with headache than in those with headache-free children (Aromaa et al., 2000). In a study by Kowal and Pritchard (1990), parents of children with headache reported significantly less achievement orientation than control parents.

Altogether, the results indicate that pediatric headache is unrelated to separation / divorce of parents and tentatively unrelated to number of siblings. On the other hand, there is tentative evidence that headache is related to a negative family environment. However, the aspects of negative family environment that have been investigated are so diverse that caution is warranted regarding generalizations. In addition, with the exception of parental separation or divorce, the number of studies conducted per variable is small. Further studies are needed before definitive conclusions can be drawn. This is particularly true for weekly headache, as almost no research focusing on family variables and weekly headache has been conducted. Noteworthy is, however, that $11 \%$ of German adolescents with weekly headache have cited their family as a headache trigger (Luka-Krausgrill \& Reinhold, 1996).

\subsubsection{School Variables}

Many different variables related to school have been investigated in association with headache in children and adolescents. The focus of the examined variables has ranged from school performance (e.g., difficulties with specific courses of study, repeating a grade) to school climate (e.g., fear of classmates, being bullied).

Metsähonkala et al. (1998) found difficulties with writing and mathematics to be more common among girls with non-migrainous headache, and difficulties in sports to be more common among boys with non-migrainous headache than among their respective headachefree counterparts. Similarly, Gordon et al. (2004) reported poor academic achievement to be associated with weekly headache. In contrast, Karwautz et al. (1999) found repeating a grade to be no more common among headache patients than among headache-free controls and Metsähonkala et al. (1997) found no significant differences between boys with frequent migraine and boys with infrequent or no migraine in coping with school subjects. Along the same lines, Egermark-Eriksson (1982) reported average grades in all classes except physical education to be unrelated to headache in Swedish school children. Further studies indicated that headache was not associated with school problems (Passchier \& Orlebeke, 1985), or with needing extra supervision by a teacher (Metsähonkala et al., 1998). Indeed, 
Engström (1992) found no significant differences on an aggregate measure of academic performance, need of special education, and having to repeat a school grade between children with weekly tension headache and healthy children.

With regard to homework, Larsson (1988) reported spending more time on homework to be significantly associated with both weekly headache and headache severity. Similarly, Luka-Krausgrill and Reinhold (1996) found that in comparison to adolescents with no or seldom headache, more adolescents with recurrent headache tended to report investing two or more hours on homework a day $(14.3 \%$ and $18.5 \%$ vs. $34.4 \%$, respectively). On the other hand, less frequent homework completion was also reported to be significantly associated with weekly headache (Gordon et al., 2004). It is, however, unclear what this exactly implies.

Metsähonkala et al. (1998) found "stressing about school" to be more common in children with headache than in their headache-free counterparts. Similarly, Passchier and Orlebeke (1985) found headache and headache parameters to be significantly associated with fear of failure, though unrelated to achievement motivation. However, suffering under stress of performance in school has been found to be no more common among headache patients than among headache-free controls (Karwautz et al., 1999). Along the same line, Larsson (1988) reported satisfaction with school to be unrelated to weekly headache.

With regard to school climate, Gordon et al. (2004) found negative feelings about school, being unfairly treated by teachers, and feeling "left out" to be significantly associated with weekly headache in Canadian adolescents. Feelings of loneliness and being an outsider have also been found to be associated with headache (Brattberg, 1994). In addition, Brattberg (1994) reported that fear of one or more classmates was present in $12 \%$ of a Swedish student sample (aged 10 to 16), and that headache was significantly more prevalent within this group than among students without such fear. Similarly, Gordon et al. (2004) found feeling unsafe at school or while traveling to and from school to be associated with weekly headache. Being bullied at school has also been found to be more common in children and adolescents with headache than in their headache-free counterparts (Brattberg, 1994; Metsähonkala et al., 1998; Williams, Chambers, Logan, \& Robinson, 1996).

Finally, Powers et al. (2003) reported that in comparison to normative data on healthy controls, pediatric migraine patients exhibited significantly lower school functioning, a compound variable encompassing attentiveness in class, keeping up with homework, and school absence.

Altogether, the results indicate that pediatric headache is related to a negative school climate, but unrelated to poor academic achievement. Further studies are needed before conclusions can be drawn with regard to time spent on homework and fear of failure. The former as too few studies have been conducted to date, the latter because the results are inconclusive. Further research is also necessary with regard to weekly headache, as almost no studies have investigated school variables. The only conclusion that can be drawn is that a negative school climate is relevant to weekly headache. Noteworthy is that school has also been reported as a headache trigger: Twenty-nine percent of adolescents with weekly headache and $19 \%$ of adolescents with seldom headache reported believing their headaches were school-related (Luka-Krausgrill \& Reinhold, 1996). 


\subsubsection{Leisure Variables}

A number of variables related to recreation and use of leisure time have been investigated in headache studies. Oksanen et al. (2005) found that children with migraine engaged in physical activity more often than headache-free children. Similarly, Carlsson et al. (1996) reported that children with headache played sports more often during their spare time than headache-free controls. Other studies, however, found no association between physical activity and occurrence of headache (Brattberg, 1994), or weekly headache (Gordon et al., 2004).

While Sillanpää et al. (1991) reported headache to be associated with recreational activities, Aromaa et al. (2000) found an inverse relationship, with headache children participating in significantly fewer social hobbies such as scout or club meetings than their headache-free counterparts. In line with the latter, Engström (1992) found children with weekly tension-type headache to score significantly lower on an aggregate measure of physical activity, hobbies, and household tasks than healthy children. No significant association was found between recreational activities and weekly headache (Gordon et al., 2004), or time spent on hobbies and migraine (Metsähonkala et al., 1997).

Watching television has been documented as a headache trigger (Luka-Krausgrill \& Reinhold, 1996) and children with headache have been found to watch significantly more television daily than their headache-free counterparts (Aromaa et al., 2000). The amount of television watched at age 3 and 5, however, was not predictive of headache occurring at age 6 (Aromaa et al., 1998). A further sedentary activity, spending time on a computer, has also been investigated: Oksanen et al. (2005) found that children with headache used computers significantly more often than children without headache.

Moderate to poor peer relationships have been reported to be more common in children with headache than in their headache-free counterparts (Metsähonkala et al., 1998). In contrast, no significant difference was found between headache and non-headache children with regard to friends (Aromaa et al., 2000), or between those with weekly headache and no headache with regard to satisfaction with peers (Larsson, 1988). Similarly, Engström (1992) reported finding no significant differences between children with weekly tension-type headache and healthy children on an aggregate measure tapping amount of friends, quality of peer relationships, and hobbies. In contrast, Cunningham et al. (1987) found children with migraine to score significantly lower on this aggregate measure than pain-free and other pain controls. Pediatric migraine patients have also been found to exhibit lower social functioning (a compound variable encompassing peer relationships, teasing, and ability to participate in leisure activities) in comparison to normative data on healthy controls (Powers et al., 2003).

The results regarding leisure activities can be characterized as being inconclusive at best, for both headache and weekly headache. The only tentative conclusion that can be drawn is that poor peer relations are related to headache. Altogether, too few studies have examined leisure activities in relation to pediatric headache. In addition, the results regarding physical activities, recreational activities, TV, and peer relations are contradictory. Further research is necessary before conclusions can be drawn in this area. 


\subsubsection{Life Events}

Stressful experiences have been shown to be significantly associated with somatization (Poikolainen, Aalto-Setala, Marttunen, Tuulio-Henriksson, \& Lonnqvist, 2000) and the development of many acute and chronic illnesses (Cooper et al., 1987; Haggerty, 1983). Unsurprisingly, both individual negative life events and aggregate indices thereof have been examined in association with pediatric headache.

On the level of individual life events, Sillanpää et al. (1991) found children with headache to have relocated more often than headache-free children. In addition, Fearon and Hotopf (2001) found a significant association between maternal (but not paternal) chronic physical illness and pediatric headache, while Larsson (1988) reported parental illness to be unrelated to pediatric weekly headache. Conflicting results have also been reported regarding parental rating of a subjective poor family financial situation: While Sillanpää et al. (1991) found a significant association between pediatric headache and poor financial situation, Aromaa et al. (2000) found no such relationship.

Research that has examined the loss of a family member or significant other (through relocation, separation, death) in relation to pediatric headache has focused almost exclusively on parental divorce or separation. In the present research, loss of a family member or significant other is understood as a life event and parental status as a family variable. The latter has, therefore, been previously covered in detail in the section on Family Variables. The results can be summarized as follows: A few studies have indicated divorce or separation to be related to pediatric headache (Carlsson et al., 1996; Karwautz et al., 1999; Larsson, 1988), but the majority reported no such relationship (Aromaa et al., 1998; Fearon \& Hotopf, 2001; Metsähonkala et al., 1998; Pothmann et al., 1994; Virtanen et al., 2002; Zuckerman et al., 1987).

On the more general or aggregate level, Liakopoulou-Kairis et al. (2002) found children with headache to have experienced significantly more negative life events than their headache-free counterparts, though no difference was found between children with headache and children with recurrent abdominal pain. In a study by Cooper et al. (1987), children with migraine did not differ from migraine-free best friends on a life event scale, or with regard to maternal life events. Similarly, Karwautz et al. (1999) found no significant association between pediatric headache and maternal or paternal life events. On the other hand, Kowal and Pritchard (1990) reported a significant association between units of life change (i.e., total need for readjustment associated with the experienced life events) and severity of pediatric headache (defined as headache frequency plus headache intensity). Units of life change, however, were not associated with headache presence, frequency, or intensity, when examined individually. Along the same line, Andrasik et al. (1988) reported weekly migraine to be unrelated to units of life change.

The results regarding life events, on both the individual and aggregate level, can be characterized as being inconclusive. Exceptions are parental separation or divorce and parental life events, both of which appear to be unrelated to pediatric headache. Further research is needed to increase the number of studies conducted per variable and to 
elucidate contradictory results. In addition, almost no research has focused on weekly headache making this an area wanting attention.

\subsubsection{Parental Psychological Variables}

The psychological characteristics of parents have only received marginal attention in pediatric headache research and this marginal attention has been focused primarily on maternal psychological variables, such as maternal depression.

Study results indicate that headache in children and adolescents is associated with elevated maternal depression scores (Zuckerman et al., 1987) and a history of maternal depression (Mortimer, Kay, Jaron, \& Good, 1992). A tendency for headache to be associated with elevated maternal depression scores has also been reported (Liakopoulou-Kairis et al., 2002). Similarly, Larsson (1988) found an association between pediatric weekly headache and parental nervous problems that approached significance.

In a recent study, a number of parental psychophysiological complaints, including insomnia, were investigated in association with headache in children and adolescents: Grøholt et al. (2003) found parental insomnia to be significantly associated with child's recurrent headache.

Liakopoulou-Kairis et al. (2002) examined the relevance of maternal psychological variables for pediatric headache in a clinical sample: No significant associations were found between pediatric headache and maternal scores for obsessive-compulsiveness, anxiety, phobic anxiety, interpersonal sensitivity, anger/hostility, paranoid ideation or psychoticism. Paternal psychological variables were not investigated. A further study indicated that parental anxiety (state and trait) was unrelated to child's headache (Cunningham et al., 1987).

Finally, Aromaa et al. (1998) found parents of children with headache to be so concerned about their child's headache that they reported having symptoms of fear, anxiety, tension, nervousness, excessive worry, or insomnia. Though the reported symptoms were viewed as reactions to child's headache, they may be an indication of parental vulnerability for psychological symptoms.

The results of these studies tentatively indicate that maternal depression is a factor relevant to pediatric headache, while further research is necessary in order to determine the relevance of the other parental psychological variables to headache. Only one study investigated parental psychological variables and weekly headache. This lack of research needs to be remedied before any conclusions regarding weekly headache can be drawn.

\subsubsection{Parental Health Variables}

Parental health variables have received substantially more attention than parental psychological variables in research on pediatric headache. In particular, parents' general health, headache, and non-headache pain have been examined.

Pediatric headache has not been found to be significantly associated with parental general health status (Karwautz et al., 1999; Zuckerman et al., 1987), or number of maternal doctor appointments (Zuckerman et al., 1987). 
In contrast, a family history of headache, maternal headache in particular, has long been considered a risk factor for pediatric headache (McGrath, 2001). Studies of both crosssectional and longitudinal nature have provided evidence for this relationship (Aromaa et al., 1998; Larsson, 1988). For example, Virtanen et al. (2002) found Finnish adolescents to be significantly more likely to have headache if frequent headache was present in a family member (mother, father, or sibling). A history of maternal migraine was also found to increase the likelihood of child's migraine or other headache (Mortimer et al., 1992). Similarly, parental headache was found to be significantly associated with both recurrent (Grøholt et al., 2003) and weekly pediatric headache (Larsson, 1988). Longitudinally, both mother's frequent headache prior to pregnancy and earlier history of headache in other family members have been found to be predictive of child's later headache (Aromaa et al., 1998). Indeed, a history of maternal headache has been found not only to increase the risk of frequent headaches in childhood, but also to increase the likelihood of the child experiencing migraine and combined headache in adulthood (Waldie \& Poulton, 2002).

With regard to parental non-headache pain, Grøholt et al. (2003) found parental back pain and abdominal pain to be significantly associated with recurrent pediatric headache. An association between parental abdominal pain and adolescent weekly headache that approached significance was also reported by Larsson (1988). Similarly, maternal weekly pain was found to be significantly associated with child's headache (Brattberg, 1994). However, significant associations were not found between paternal weekly pain and child's headache (Brattberg, 1994) or between a history of chronic pain in a family member (mother, father, or sibling) and child's migraine (Cunningham et al., 1987).

With regard to parental other somatic complaints, Liakopoulou-Kairis et al. (2002) found maternal somatization to be unrelated to pediatric headache. Though Grøholt et al. (2003) reported dizziness and loss of appetite to be significantly associated with recurrent pediatric headache, when controlling for these and all other somatic and pain complaints in a multivariate model only parental headache remained significantly associated with pediatric headache.

Altogether the studies indicate that parental headache is related to pediatric headache, while parental general health is not. The results regarding parental non-headache pain and somatic complaints are contradictory and the number of studies limited. In addition, almost no research has investigated the relevance of the factors for weekly headache. Further research is necessary before any conclusions can be drawn in these areas.

\subsubsection{Summary}

The studies investigating pediatric headache and potentially related variables have yielded mixed results. For some of the variables only one study has been conducted to date. Drawing conclusions on the basis of a single study can be seen as being premature. Therefore, these variables are classified as being inconclusive pending further research. The status of a second group of variables is also inconclusive, as contradictory results have been reported that are relatively balanced between affirmation and refutation of the given variable's association with headache. In these cases further research is necessary in order to clarify the relevance of the variables. For a third group of variables, tentatively conclusive 
results have been reported, as the status of the variable has been corroborated in several studies and the number of studies affirming its status (as related or unrelated) exceeds the number of opposing studies by at least two. For a final group of variables, the status of the variable has been conclusively corroborated, as the number of studies affirming its status (as related or unrelated) exceeds the number of opposing studies by at least four. The empirical status of the reviewed variables as inconclusive, tentative, or conclusive is shown for headache in Table 2 and for weekly headache in Table 3.

Table 2. Current empirical status of variables potentially relevant to pediatric headache

\begin{tabular}{|c|c|c|c|c|c|}
\hline Related $^{\mathrm{a}}$ & Unrelated $^{\mathrm{a}}$ & $\begin{array}{l}\text { Tentatively } \\
\text { related }^{\mathrm{b}}\end{array}$ & $\begin{array}{l}\text { Tentatively } \\
\text { unrelated }^{\text {b }}\end{array}$ & $\begin{array}{l}\text { Inconclusive due } \\
\text { to contradictory } \\
\text { results }\end{array}$ & $\begin{array}{l}\text { Inconclusive due } \\
\text { to examination in } \\
\text { a single study }\end{array}$ \\
\hline $\begin{array}{l}\text { - Age } \\
\text { - Gender } \\
\text { - Stress } \\
\text { - Non-headache } \\
\text { pain } \\
\text { - Other somatic } \\
\text { complaints } \\
\text { - Somatic } \\
\text { symptom scales } \\
\text { - Negative school } \\
\text { climate } \\
\text { - Parental } \\
\text { headache }\end{array}$ & $\begin{array}{l}\text { - Delinquent } \\
\text { behavior } \\
\text { - Divorce / } \\
\text { Separation } \\
\text { - Poor academic } \\
\text { achievement }\end{array}$ & $\begin{array}{l}\text { - Psychiatric } \\
\text { disorder } \\
\text { - Depression } \\
\text { - Sleeping } \\
\text { disorders } \\
\text { - Internalizing } \\
\text { - Anger } \\
\text { - Negative family } \\
\text { environment } \\
\text { - Poor peer } \\
\text { relations } \\
\text { - Maternal } \\
\text { depression }\end{array}$ & $\begin{array}{l}\text { - Occupational } \\
\text { prestige } \\
\text { - Aggressive } \\
\text { behavior } \\
\text { - Number of } \\
\text { siblings } \\
\text { - Parental life } \\
\text { events } \\
\text { - Parental anxiety } \\
\text { - Parental } \\
\text { general health }\end{array}$ & $\begin{array}{l}\text { - Parental } \\
\text { unemployment } \\
\text { - Parental } \\
\text { educational } \\
\text { level } \\
\text { - Social class } \\
\text { - Household } \\
\text { crowding } \\
\text { - Anxiety } \\
\text { - Anxiety / } \\
\text { Depression } \\
\text { - Hyperactivity } \\
\text { - Externalizing } \\
\text { - Fear of failure } \\
\text { - Physical } \\
\text { activities } \\
\text { - Recreational } \\
\text { activities } \\
\text { - Time spent on } \\
\text { TV / video } \\
\text { - Financial } \\
\text { situation } \\
\text { - Index of life } \\
\text { events } \\
\text { - Parental other } \\
\text { pain } \\
\text { - Parental other } \\
\text { somatic } \\
\text { complaints }\end{array}$ & $\begin{array}{l}\text { - Household } \\
\text { income } \\
\text { - Housing } \\
\text { conditions } \\
\text { - Birth order } \\
\text { - Lower } \\
\text { emotional } \\
\text { functioning } \\
\text { - Avoidance } \\
\text { coping } \\
\text { - Active coping } \\
\text { - Internal coping } \\
\text { - Lower physical } \\
\text { functioning } \\
\text { - Time spent on } \\
\text { homework } \\
\text { - Lower school } \\
\text { functioning } \\
\text { - Time spent on } \\
\text { computer / } \\
\text { game console } \\
\text { - Relocation } \\
\text { - Parental } \\
\text { Insomnia } \\
\text { - Parental chronic } \\
\text { illness }\end{array}$ \\
\hline
\end{tabular}

\footnotetext{
a The number of studies affirming the variable's status exceeds the number of opposing studies by at least four
}

${ }^{b}$ The number of studies affirming the variable's status exceeds the number of opposing studies by at least two

The disparity in the amount of research that has been conducted on headache as opposed to weekly headache is easily recognizable by comparing Table 2 to Table 3 . While data regarding the empirical status of 55 variables is shown for headache in Table 2, only 34 variables are presented with regard to weekly headache in Table 3. In addition, the majority of the potentially relevant variables for weekly headache have only been investigated in a single study, while this is the case for only one fourth of the variables examined with regard to headache. This inequality is unsurprising as weekly headache and potentially relevant variables have only been investigated in eight studies to date (Andrasik et al., 1988; 
Carlsson, 1996; Egger et al., 1998; Engström, 1992; Fichtel \& Larsson, 2002; Gordon et al., 2004; Larsson, 1988; Martin-Herz et al., 1999).

Table 2 and Table 3 also reveal that the majority of the examined variables are of either tentative or inconclusive status. This is true for both headache and weekly headache. Indeed, only eight variables can be seen as being conclusively related to headache, namely age, gender, stress, non-headache pain, other somatic complaints, somatic symptoms (as measured with a somatic symptoms scale), negative school climate, and parental headache. An additional three variables with conclusive status have been found to be unrelated to headache (delinquent behavior, divorce / separation, poor academic achievement). In contrast, only four variables can be seen as being conclusively related to weekly headache, namely gender, anxiety, depression, and somatic symptoms (as measured with a somatic symptoms scale). To date, no variables have been found to be conclusively unrelated to weekly headache.

Table 3. Current empirical status of variables potentially relevant to pediatric weekly headache

\begin{tabular}{|c|c|c|c|c|c|}
\hline Related $^{\mathrm{a}}$ & Unrelated $^{a}$ & $\begin{array}{l}\text { Tentatively } \\
\text { related }^{\mathrm{b}}\end{array}$ & $\begin{array}{l}\text { Tentatively } \\
\text { unrelated }^{\mathrm{b}}\end{array}$ & $\begin{array}{l}\text { Inconclusive due } \\
\text { to contradictory } \\
\text { results }\end{array}$ & $\begin{array}{l}\text { Inconclusive due } \\
\text { to examination in } \\
\text { a single study }\end{array}$ \\
\hline $\begin{array}{l}\text { - Gender } \\
\text { - Anxiety } \\
\text { - Depression } \\
\text { - Somatic } \\
\text { symptom scales }\end{array}$ & & $\begin{array}{l}\text { - Emotional } \\
\text { problems } \\
\text { - Internalizing } \\
\text { - Stress } \\
\text { - Negative school } \\
\text { climate }\end{array}$ & $\begin{array}{l}\text { - Poor peer } \\
\text { relations }\end{array}$ & $\begin{array}{l}\text { - Age } \\
\text { - Divorce / } \\
\text { Separation } \\
\text { - Psychiatric } \\
\text { disorder } \\
\text { - Externalizing } \\
\text { - Poor academic } \\
\text { achievement } \\
\text { - Recreational } \\
\text { activities }\end{array}$ & 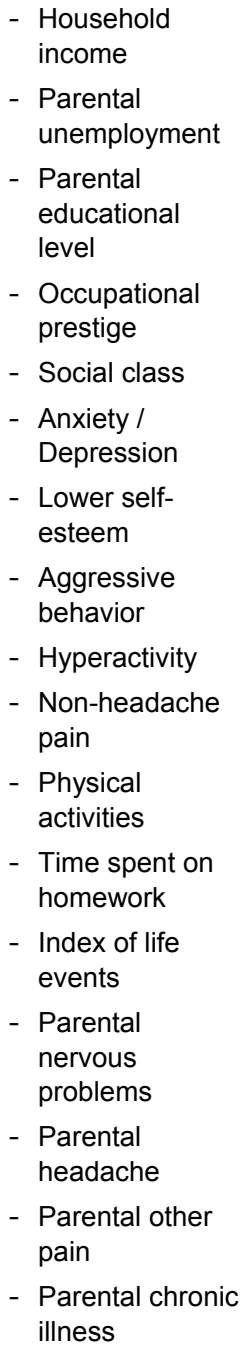 \\
\hline
\end{tabular}

\footnotetext{
a The number of studies affirming the variable's status exceeds the number of opposing studies by at least four
}

${ }^{b}$ The number of studies affirming the variable's status exceeds the number of opposing studies by at least two 
Clearly, further studies focusing on weekly headache are needed in order to ameliorate the existing research disparity and to extend current knowledge of related variables by confirming variables of tentative status, elucidating those of inconclusive status, and investigating potentially relevant variables that as yet have not been examined with regard to weekly headache.

Limitations pertaining to a number of the reviewed studies warrant comment. Some of the studies focused on a single headache type, migraine or tension-type headache, instead of investigating headache in general (Andrasik et al., 1988; Cunningham et al., 1987; Engström, 1992; Powers et al., 2003). In addition, a number of the studies investigated pediatric headache patients as opposed to non-clinical or population-based samples (Andrasik et al., 1988; Cooper et al., 1987; Maratos \& Wilkinson, 1982; Mazzone et al., 2006; Powers et al., 2003; Smith et al., 2003). In the present review of headache research, utmost care was taken to indicate those studies that examined a subgroup of pediatric headache or employed a clinical sample. Nevertheless, the final conclusions were drawn on the basis of all of the reviewed studies in order integrate results from a maximal number of studies.

A final limitation concerns the comparison groups that were employed in the reviewed studies. In the majority of the studies, children with headache or weekly headache were compared only to a group of headache-free controls. Further controls groups (e.g., of children with a comparable disorder) were not employed. While comparisons of children with and without weekly headache allow for the identification of the variables that are relevant to weekly headache, they do not allow for determining whether the identified correlates are unique to weekly headache or common to a larger category that comprises pediatric headache as well as other comparable disorders (e.g., pediatric chronic illness or pediatric frequent non-headache pain). In other words, a further issue that needs to be addressed is the uniqueness, or specificity, of the potentially related variables.

\subsection{Specificity}

Specificity denotes the presence of a unique relationship between a given factor and a given outcome. Research that focuses on the question of uniqueness versus commonality can accordingly be termed specificity research. In an article on stress and psychopathology McMahon, Grant, Compas, Thurm, and Ey (2003) reviewed specificity from a theoretical perspective and described three different investigative approaches that have been utilized in specificity research. These approaches are illustrated in Figure 1.

In the first of the three approaches, the factor-specific approach ${ }^{4}$, several potentially relevant factors and one outcome are examined. Using this approach, it is possible to determine the specificity of the potentially relevant factors in relation to the one outcome. However, since only one outcome is examined, it cannot be ruled out that the factors are related to other outcomes as well. In other words, it is not possible to determine the specificity of the outcome.

\footnotetext{
${ }^{4}$ McMahon et al. (2003) use the term stressor specific in accordance with their focus was on stress and associated psychopathology. To enhance generalizability the term factor is used in this presentation in lieu of stressor.
} 
In the outcome-specific approach, on the other hand, one potentially relevant factor and several different outcomes are examined. Using this approach, it is possible to determine the specificity of the outcomes in relation to the one factor. However, as only one factor is examined, it cannot be ruled out that the outcomes are related to other factors as well (i.e., it is not possible to determine the specificity of the factor).

Finally, in the factor-outcome-specific approach, a heterogeneous selection of potentially relevant factors and a number of different outcomes are examined. Using this approach, it is possible to determine the specificity of the relationships between potentially relevant factors and the different outcomes. It is also possible to determine relations between factors and outcomes that are common.
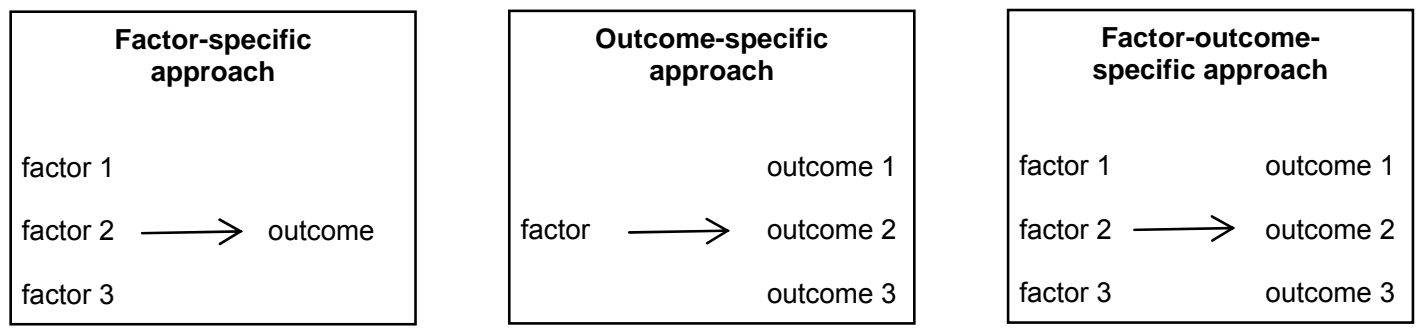

Figure 1. Approaches used in specificity research (McMahon et al., 2003)

McMahon et al. (2003) conclude that the factor-outcome-specific approach is the most comprehensive of the three approaches and can therefore be considered the optimal approach in specificity research. Garber and Hollon (1991) concur that specificity is typically investigated by comparing an outcome of interest with one or more other clinical outcomes in order to determine whether unique associations exist between the outcome of interest and the potentially relevant factors. The authors go on to describe two different types of specificity, broad and narrow specificity, and the corresponding requirements for the comparison outcome(s).

In broad specificity the question is whether a potentially relevant factor (e.g., a certain biological abnormality) is unique to the outcome of interest (e.g., unipolar depression) or whether it is common to all outcomes of a higher-order category which encompasses the outcome of interest (e.g., psychopathology). In narrow specificity the question is whether a potentially relevant factor is unique to the outcome of interest or common to other instantiations of a higher-order category (e.g., bipolar affective disorder, general anxiety disorder).

Garber and Hollon (1991) suggest that it is appropriate to begin specificity research in a given domain by first addressing the question of broad specificity while using a heterogeneous sample of other outcomes belonging to the same higher-order category. If a factor is found to be specific to the outcome of interest, it can be concluded that the factor is not simply a function of membership in the corresponding higher-order category. Once broad specificity has been determined, the question of narrow specificity then becomes relevant. In order to determine whether the feature is unique to the outcome of interest relative to other instantiations of the higher-order category, homogeneous control groups are necessary. 
Transferred to the domain of weekly headache, broad specificity would be the question whether potentially relevant factors (e.g., anxiety, depression) are unique to weekly headache or are common to a higher-order category that encompasses weekly headache. Narrow specificity would pertain to the question whether potentially relevant factors are unique to weekly headache or common to other instantiations of the higher-order category.

The question is what higher-order category is appropriate for specificity research regarding pediatric weekly headache. To date, comparison groups from two higher-order categories have been employed in research on pediatric headache. A number of studies have compared children and adolescents with headache to those with pain at other locations (Cunningham et al., 1987; Egger, Costello, Erkanli, \& Angold, 1999; Grøholt et al., 2003; Liakopoulou-Kairis et al., 2002), while several other studies have compared children with headache to children with chronic illness (Engström, 1992; Powers et al., 2003; Smith et al., 2003). Of these two possibilities, pediatric chronic illness appears the more appropriate higher-order category for the present research, as weekly headache and other chronic illnesses are health issues that affect the afflicted children and adolescents regularly. In order to verify pediatric chronic illness as a suitable higher-order category for weekly headache it seems fitting to look at chronic illness in more depth.

\subsection{Chronic IIIness}

There is no one universally accepted definition for chronic illness (Perrin et al., 1993; Warschburger, 2000) and the breadth of health conditions that have been subsumed under this term has ranged from physical disease, over physical impairment, to mental disorders (Hoepner-Stamos, 1995; Newacheck \& Taylor, 1992). Inherent in the term chronic illness, however, is chronicity and its implication of a lengthy duration. Accordingly, there is a consensus that chronic illnesses are health conditions that persist for an extended period of time.

Mattsson (1972, p. 801) defined chronic illness as "a disorder with a protracted course which can be progressive and fatal, or associated with a relatively normal life span despite impaired physical or mental functioning" and offered the following examples: asthma, epilepsy, cardiac conditions, cerebral palsy, and diabetes. Though emphasizing lengthiness of the condition, Mattsson (1972) proposed no specific duration threshold in his definition.

A concrete duration criterion was, however, proposed by Pless and Douglas (1971) in their characterization of chronic illness as "a physical, usually non-fatal condition which lasted longer than three months in a given year". This proposed 3-month criterion has become the standard in the field of pediatric chronic illness research (Stein, Bauman, Westbrook, Coupey, \& Ireys, 1993). In empirical studies, it has been implemented by ascertaining which, if any, of a prepared list of conditions was present in a child and whether the actual or expected duration of the condition exceeded 3 months (e.g., Gortmaker, Walker, Weitzman, \& Sobol, 1990). Employing the 3-month definition, "frequent or severe headache" has been classified as a chronic illness together with 13 other chronic diseases (e.g., asthma, diabetes, arthritis, eczema) and 5 impairments (e.g., deafness and hearing loss, speech defects; Newacheck \& Stoddard, 1994; Newacheck \& Taylor, 1992). 
Criticism has been voiced, however, that the 3-month duration criterion may allow for the misclassification of acute illness or injury as a chronic condition (Perrin et al., 1993; Stein et al., 1993). Several solutions for this problem have been suggested, e.g., the addition of an impairment criterion (Perrin et al., 1993), or the extension of the duration criterion to 12 months (Stein et al., 1993). Thus, one recent definition of chronic illness requires the presence of a condition with actual or expected duration of at least 12 months and associated consequences such as functional limitation, dependence on compensatory mechanisms, or elevated use of health care services (see Figure 2; Stein et al., 1993; Stein \& Silver, 1999).

Chronic pediatric health conditions are defined as disorders that:

1. Have a biological, psychological, or cognitive basis, and

2. Have lasted or are relatively certain to last at least 12 months, and

3. Produce one or more of the following sequelae:

a. Limitation of function, activities, or social role in comparison with healthy age peers in the general areas of physical, cognitive, emotional, and social growth and development

b. Dependency on one of the following to compensate for or minimize limitations of function, activities, or social roles:
(1) Medication
(2) Special diet
(3) Medical technology
(4) Assistive device
(5) Personal assistance

c. Need for medical care, psychological or educational services in excess of the usual for the child's age, or for special ongoing treatments, interventions, or accommodations at home or in school

Figure 2. Noncategorical definition of pediatric chronic health conditions (Stein et al., 1993)

It can be argued that pediatric headache that occurs at least once a week over a time span of 6 months qualifies as a chronic illness on the basis of duration, as the time span of 6 months lies in the middle ground between the proposed duration criteria of 3 months (Perrin et al., 1993; Pless \& Douglas, 1971) and 12 months (Stein et al., 1993). Furthermore, as recurrent pediatric headache has been found to be associated with functional disability (Connelly, 2003; Holden, Deichmann, \& Levy, 1999; Luka-Krausgrill \& Reinhold, 1996; McGrath, 2001) and increased usage of health care services (Connelly, 2003; LukaKrausgrill \& Reinhold, 1996; McGrath, 2001), it also fulfills the impairment criterion and thus clearly warrants classification as a chronic illness. Therefore, in the present research, pediatric headache occurring at least once a week over a time span of 6 months is considered to be a chronic illness.

Consequently, pediatric chronic illness (comprising such illnesses as asthma, atopic dermatitis, and diabetes) is considered to be the appropriate higher-order category with which pediatric weekly headache can be compared in order to determine the broad specificity of its correlates. As previously mentioned, several pediatric headache studies 
have employed a chronic illness comparison group. These studies will be the focus of the next section.

\subsection{Specificity Research Regarding Pediatric Headache}

Three studies have been conducted, to date, that have examined pediatric headache in comparison to other chronic illnesses. These studies offer information regarding the specificity of variables related to headache, though they were not explicitly designated as "specificity" studies.

Powers et al. (2003) compared the functioning of consecutive migraine patients at a headache clinic (aged 2 to 18) to preexisting normative data on children and adolescents with cancer, rheumatoid conditions, and healthy controls in the first study. Parent and child report $^{5}$ on four domains of functioning (i.e., physical, emotional, social, school) were examined. The authors also looked at psychosocial functioning (aggregate measure of emotional, social, and school functioning) and functioning in general (aggregate measure over all four domains).

In comparison to healthy controls, migraineurs were found to exhibit significantly lower general and psychosocial functioning, and lower functioning in each of the four domains, in both parent and child report. The comparison with children and adolescents with chronic illnesses yielded more complex results: On the basis of child report, migraineurs did not differ from children and adolescents with cancer or rheumatoid conditions with regard to general or psychosocial functioning, but they reported significantly higher physical and social functioning, and significantly lower school and emotional functioning than the other two chronic illness groups. Parent report yielded equivalent results regarding general and psychosocial functioning, as well as physical and social functioning. In the other two domains (school and emotional) migraineurs functioning was rated as lower than that of children with cancer, but similar to that of children with rheumatoid conditions.

In the second study, clinic-referred adolescents with migraine or chronic fatigue syndrome (aged 11 to 18) were compared to healthy controls (Smith et al., 2003). For the analyses, the authors differentiated between chronic fatigue syndrome as defined by the Centers for Disease Control and Prevention (CDC-CFS) and idiopathic chronic fatigue syndrome not fulfilling all CDC criteria (I-CFS).

The results indicated that adolescents with migraine and CDC-CFS had significantly higher anxiety scores than those with I-CFS or healthy controls. Depression scores were elevated in CDC-CFS in comparison to all other groups, which did not differ from one another. With regard to somatization, adolescents CDC-CFS reported significantly more symptoms than all others, but adolescents with migraine and I-CFS reported more symptoms than healthy controls.

In the final of the three studies, Engström (1992) compared children and adolescents with chronic illnesses (weekly tension-type headache, inflammatory bowel disease [IBD], and

\footnotetext{
${ }^{5}$ For children age 2 to 4 only parent report was assessed.
} 
diabetes) with one another and with healthy controls. Parent and child report on a number of questionnaires were examined.

Psychiatric interviews were conducted with the children and adolescents in order to determine whether the DSM-III-R criteria for a mental disorder were fulfilled. While children with IBD had a mental disorder significantly more often than healthy controls, those with weekly headache and diabetes did not differ significantly from IBD, each other, or healthy children. Accordingly, children with IBD scored significantly higher on a scale of emotional maladjustment than healthy controls. Children with weekly headache and diabetes did not differ significantly from IBD, each other, or healthy children.

Symptoms of depression assessed via questionnaire were significantly higher in children with weekly headache and IBD than in healthy controls, but did not differ from children with diabetes. Children with weekly headache also reported more symptoms of anxiety than healthy controls, though there was no difference in comparison to the other chronic illness groups. On the level of constituent anxiety subscales, children with weekly headache reported significantly more physiological anxiety than children with IBD or healthy controls, but did not differ from those with diabetes. No differences between groups were found on the scales Worry and Oversensitivity, and Concentration Anxiety.

Children with weekly headache did not differ from those with other chronic illnesses or healthy controls with regard to externalizing. However, they and children with IBD had elevated internalizing scores in comparison to healthy controls, though they did not differ from one another or from children with diabetes ${ }^{6}$. Children with IBD scored significantly lower on the composite Social Competence scale than healthy controls, but did not differ from children with weekly headache or diabetes. No other comparisons yielded significant results. On the level of the constituent subscales of Social Competence, children with weekly headache and IBD scored significantly lower on the Activities subscale than healthy controls, but did not differ from children with diabetes or from one another. There were no significant differences with regard to the subscales Social or School.

Children with weekly headache and IBD also reported significantly lower self-esteem than healthy controls, but did not differ from children with diabetes. Subscales of the instrument focused on different areas of self esteem. On this level, children with weekly headache and IBD reported significantly lower self-esteem regarding Mental Characteristics and Relations with Others in comparison to healthy controls. No differences were found on the subscales Physical Characteristics, Skills and Talents, and Relations with Parents.

Altogether, the results of the two comparative studies that focused on migraine can be summarized as follows: Impairment in school functioning and in emotional functioning were found to be specific to children and adolescents with headache (Powers et al., 2003), while anxiety (Smith et al., 2003), and impairment in psychosocial and general functioning (Powers et al., 2003) were found to be common to both headache and other chronic illness. Finally, somatization (Smith et al., 2003), depression (Smith et al., 2003), and impairment in

\footnotetext{
${ }^{6}$ Engström (1992) also compared the groups with regard to the gender-specific, empirically derived subscales of the Child Behavior Checklist (CBCL). This data, however, will not be presented here, as the empirically derived subscales do not lend themselves to integration with the previously covered studies which opted for the evaluation of symptom subscales.
} 
social functioning (Powers et al., 2003) were determined to be more specific to other chronic illness than to headache. However, none of the results are conclusive, as only one study per variable addressed the question of specificity. Therefore, confirmation of the results is needed before tentative conclusions can be drawn. Furthermore, both studies are employed clinical samples and focused on migraine alone, thus limiting the generalizability of the result to the whole of pediatric headache.

With regard to weekly headache Engström (1992) identified five variables as being common to weekly headache and to at least one of the examined chronic illnesses. The common variables were anxiety, depression, internalizing, fewer recreational activities, and lower self-esteem. No variables were identified as being specific to weekly headache or to one of the other chronic illnesses. Once again, these results are not to be considered as being conclusive, as only one study investigated the specificity of the variables for weekly headache. Before tentative conclusions can be drawn, the results must be confirmed in further research. In addition, the study focused on weekly tension-type headache as opposed to weekly headache in general. Furthermore, the study is limited by the small size of the comparison groups $(n=20)$.

Though three studies, to date, have employed a comparison group of children and adolescents with chronic illness, two focused on migraine without regard to headache frequency and the third investigated only weekly tension-type headache. None of the studies addressed the specificity of variables related to weekly headache. In addition, all three studies investigated narrow rather than broad specificity, though the latter has been suggested as the appropriate type of specificity to initially study (Garber \& Hollon, 1991). The present research aims at filling the gap by addressing the question of broad specificity with regard to weekly headache.

\subsection{Objectives of the Present Research}

The health of children and adolescents as a whole has been found to give cause for concern (Hurrelmann et al., 2003) and there are substantial grounds for considering children and adolescents with weekly headache to be a subgroup warranting particular concern: Weekly headache is common (Laurell et al., 2004; Passchier \& Orlebeke, 1985) and on the rise (Rhee, 2000), has been found to persist over time (Brattberg, 1994; Schmidt et al., 1992; Virtanen et al., 2002), and appears to be a stepping stone on the path to physical and psychiatric symptoms in adulthood (Fearon \& Hotopf, 2001).

Clearly, there is a demand for interventions targeting weekly headache. Sufficient knowledge of the biological, psychological, and social factors associated with weekly headache is required as the basis upon which such interventions can be developed. However, the current status of knowledge regarding weekly headache does not suffice: The vast majority of studies that have examined potentially relevant variables have focused on headache in general or different types of headache. Only a limited amount of research has focused on weekly headache. In addition, the majority of the variables that have been investigated with regard to weekly headache are of either tentative or inconclusive status (see Table 3). 
Furthermore, almost all studies that have examined variables potentially relevant to headache have compared children with headache to those without. The few exceptions to this rule have implemented comparison groups of children and adolescents with pain at other locations (Cunningham et al., 1987; Egger et al., 1999; Grøholt et al., 2003; LiakopoulouKairis et al., 2002) or with chronic illness (Engström, 1992; Powers et al., 2003; Smith et al., 2003). The latter three studies were described in some detail, as chronic illness was deemed the appropriate comparison group for weekly headache. However, none of these studies examined weekly headache in general, nor did they employ comparison groups of children with heterogeneous chronic illnesses. Instead comparison groups that were homogeneous to a particular chronic illness were implemented (see section Specificity Research Regarding Pediatric Headache). Thus, all three studies investigated narrow rather than broad specificity.

The present research aims at extending the currently limited knowledge of variables related to weekly headache by investigating variables of tentative and inconclusive status, as well as potentially relevant variables that, as yet, have not been examined in studies on weekly headache. Variables of conclusive status will also be examined in order to determine the relative importance of the individual variables for weekly headache. In total, a broad range of variables coming from all of the depicted variable domains will be investigated (see section Correlates of Pediatric Headache).

In addition the present research aims at investigating the broad specificity of the variables related to weekly headache by comparing children and adolescents with weekly headache to a group of children and adolescents with diverse chronic illnesses (e.g., asthma, atopic dermatitis, diabetes). However, in order to allow for identification of variables (1) specific to weekly headache, (2) common to chronic illnesses including weekly headache, and (3) specific to chronic illness other than weekly headache, it is necessary to identify the variables related to chronic illness (vs. good health) prior to the direct comparison of children and adolescents with weekly headache to those with other chronic illnesses.

In sum, the objectives of the present research are

- to identify variables related to weekly headache by comparing children and adolescents with weekly headache to those in good health,

- to identify variables related to chronic illness (excluding weekly headache) by comparing a heterogeneous group of children and adolescents with diverse chronic illnesses (e.g., asthma, atopic dermatitis, diabetes) to those in good health,

- and finally to determine the specificity of the variables related to weekly headache by comparing children and adolescents with weekly headache to those with chronic illness (excluding weekly headache). 


\section{METHODS}

\subsection{The Children, Adolescents \& Headache Study}

The present research was conducted within the framework of the Children, Adolescents \& Headache Study (Kinder, Jugendliche \& Kopfschmerz), an ongoing longitudinal study funded by the German Ministry of Research and Education (Bundesministerium für Bildung und Forschung, BMBF; Förderkennzeichen 01EM0521). The Children, Adolescents \& Headache Study is one of a number of BMBF-funded research projects that are collaboratively united within the German Headache Consortium (Deutsches Kopfschmerz-Konsortium).

The objectives of the Children, Adolescents \& Headache Study include the assessment of headache prevalence in German children and adolescents, the identification of biopsychosocial risk factors for recurrent and chronic headache, and the analysis of change in headache status (e.g., spontaneous recovery, development of chronic headache) over a period of four years. Results will be analyzed for their utility in the development of preventive programs targeting recurrent and chronic pediatric headache.

The Children, Adolescents \& Headache Study is conceptualized as a longitudinal postal survey with four annual waves. The first wave of the study took place from October 2003 to January 2004. Questionnaires were mailed out to a random sample of households with a child between 7 and 14 years of age. Parent questionnaires were sent to all households in the sample. Child questionnaires were sent to households with a child age 9 or older.

\subsection{Sample}

The sample size necessary for the stated objectives of the Children, Adolescents \& Headache Study was ascertained with the help of the Institute for Medical Informatics, Biometry and Epidemiology at the University of Duisburg-Essen. Conservative estimates for the prevalence of headache per age group of children and adolescents and an estimated nonresponse rate of $40 \%$ and were taken into account in the calculation. This procedure was implemented to ensure adequate sample size for the calculation of reliable age-specific prevalence rates and for the identification of risk factors for chronic pediatric headache.

According to the calculation, the total sample size needed for the Children, Adolescents \& Headache Study comprised 8,800 households. For the youngest subjects (7to 10-year-olds) 1,200 households per age group were determined necessary, and for the older subjects (11- to 14-year-olds) 1,000 households per age group. This difference reflects expected increases in headache prevalence with age, as the higher the expected headache rate (based on the literature), the smaller the required sample size in order to reliably determine prevalence within the study.

The sample of 8,800 households was randomly selected from community registries in four districts of southern Lower Saxony and the city of Hannover. German citizenship was required for inclusion in the sample. This criterion was selected as the best estimate of German language capability available in the data of the community registries. The Southern 
Lower Saxony Center for Municipal Data Administration (Kommunale Datenverwaltungszentrale Südniedersachsen) performed the random selection and subsequent compilation of data sets for the districts of Göttingen, Holzminden, Osterode and Northeim after receiving approval from the constituent community registries. The community registry of the city of Hannover performed the random selection and compilation of data sets for Hannover. The complete data set (southern Lower Saxony and Hannover) was manually checked for multiply drawn households. If a specific household was drawn for more than one age group, a substitute household was obtained from the applicable registry.

\subsection{Questionnaire Development and Prestesting}

A detailed search of the literature on headache in children and adolescents, and related biopsychosocial correlates and risk factors served as the foundation for the selection of variables for assessment in the Children, Adolescents \& Headache Study. The following nine variable domains were determined relevant for the study:

- sociodemographic variables,

- child psychological variables,

- child health variables,

- family variables,

- school variables,

- leisure variables,

- life events,

- parental psychological variables,

- parental health variables.

Assessment measures utilized in headache studies were reviewed with regard to psychometric properties, and German translations or alternative German-language measures were identified. Standard instruments tapping relevant variables were also examined. When possible, items or scales from psychometrically validated and/or frequently employed measures were selected for questionnaire inclusion. Some items and scales were translated into German for the questionnaire, and several further items were developed specifically for the study. The result was a first draft of the parent questionnaire and the child questionnaire.

Rigorous pretesting of the questionnaires and the planned study method was conducted following the testing phases delineated by Dillman (2000). A first draft of the questionnaires was reviewed by project coordinators, knowledgeable colleagues, and analysts with regard to aspects of comprehension, question-response-fit, ageappropriateness and statistical analysis. On this basis of the illicited feedback, a second draft of the questionnaires was completed.

In the second phase of pretesting, 10 children of the appropriate age range and one parent of each child completed the respective questionnaire under observation of the researchers, who noted any subject behavior indicative of possible comprehension problems (e.g., hesitation, confused expression, making corrections). Questions requiring long deliberation were also noted. Following questionnaire completion, retrospective interviews concerning these issues were conducted with the subjects. The noted possible comprehension problems were queried, as were item comprehension in general, 
comprehension of instruction sheet, and attractiveness of questionnaire and auxiliary survey material (e.g., cover letter, instruction sheet, logo, envelope, return envelope). The child questionnaire proved to be too time consuming and difficult for the youngest subjects. As a result it was decided (1) to forgo administration to 7- and 8-year-olds and (2) to administer a shortened version to 9- and 10-year-old children. A third draft of the assessment measures (parent questionnaire, child questionnaire for 9- and 10-year-olds, child questionnaire for 11to 14-year-olds) was then developed.

In the third phase of pretesting, a pilot study was conducted in order to evaluate the planned procedure for the survey in every methodological respect. A random sample of 100 households with children aged 7 to 14 , selected from the community registry of the city of Göttingen, was contacted (postal survey). The response rate was high (82\%). Questionnaire items were analyzed with regard to missing values and to response consistency. A number of questionnaire items were modified as a result. It was possible to shorten the adult questionnaire. Subsequently, the fourth draft of the questionnaires was completed.

In the fourth and final phase of pretesting, six colleagues, who had not been involved in the questionnaire development, double checked the questionnaires. The final draft of the parent questionnaire consisted of 111 items and a total of 28 pages. The child questionnaire for 9- and 10-year-old comprised 35 items, the child questionnaire for 11- to 14-year-olds 43 items. Both child questionnaires were 12 pages long. The parent questionnaire and other relevant study materials can be found in Appendix B.

\subsection{Operationalization of the Outcome Variables Weekly Headache, Chronic IIIness, and Good Health}

The objectives of the present research are

- to identify the correlates of weekly headache by comparing children and adolescents with weekly headache to those in good health,

- to identify the correlates of other chronic illness by comparing children and adolescents with other chronic illnesses to those in good health, and finally

- to determine the specificity of the variables related to weekly headache by comparing children and adolescents with weekly headache to those with other chronic illnesses.

In order to focus on these three groups, children and adolescents with other health conditions (e.g., impairments or disabilities) had to be excluded, as did children and adolescents with comorbid weekly headache and other chronic illness. Therefore, the three health status groups of interest were defined as follows: Weekly headache was defined as (1) the presence of headache episodes occurring at least once a week in the past six months, (2) the absence of impairment or disability, and (3) the absence of any other chronic illness. Chronic illness was defined as (1) the presence of a chronic illness, (2) the absence of impairment or disability, and (3) headache occurring less than once a month. Good health was defined as (1) the absence of impairment or disability, (2) headache occurring less than once a month, and (3) the absence of chronic illness.

Several questionnaire items asked about child's headache. A gate question asked whether the child had experienced headache in the past six months. If this initial question 
was answered with "no" or "don't know", the parent was instructed to skip the section on child's headache and continue with the next section of the questionnaire. If the gate question was answered with "yes", a number of questions regarding the child's headache were to be completed. A mixed format question, combining multiple choice and fill in the blank, queried the frequency of child's headache. The parent was asked to check the appropriate frequency category ("at least once a week", "at least once a month, but less than once a week", or "less than once a month") and then to specify the absolute number of headache episodes in the appropriate time span (per week, per month, or per six months). This information allowed the calculation of the absolute number of child's headache episodes in the past six months. If the specific number of headache episodes was not reported, a conservative estimate of one headache episode per given time span was made (e.g., if the frequency category of "at least once a week" was checked but the absolute number of episodes per week not reported, a value of 1 headache episode per week was assumed, equaling 26 headache episodes in the past six months). In some cases, the frequency category was left missing but the absolute number of headache episodes was reported. Therefore, the absolute number of headache episodes in the past six months was used to re-categorize for headache frequency into the following four groups ("weekly headache", "monthly headache", "seldom headache", "no headache"). Additionally, the frequency was recoded into a new variable indicating whether the child had experienced chronic headache, defined as headache at least once a week in the past six months. Values for this variable were scored "no" (0) and "yes" (1).

Impairments and disabilities were assessed with items asking whether the following conditions were present: (a) delayed development or mental retardation, (b) hearing impairment or deafness, (c) communication disorder/s, (d) vision impairment or blindness. Values were scored "no" (0) and "yes" (1).

Chronic illness was assessed with items asking whether the child had the following chronic illnesses: (a) asthma, (b) atopic dermatitis, (c) epilepsy, (d) congenital heart disease, (e) inflammatory bowel disease, (f) chronic kidney disease, (g) muscle diseases, (h) juvenile rheumatoid arthritis, (i) diabetes, (j) other. Values were scored "no" (0) and "yes" (1).

\subsection{Operationalization of the Potentially Relevant Biopsychosocial Variables}

The biopsychosocial variables investigated in the present research are shown in Table 4 together with the domain to which they belong. Some operationalizations were taken from psychometrically validated instruments. The sources are listed in the right-hand column of Table 4. Other operationalizations were generated during questionnaire development. Detailed information regarding the operationalization of the variables will be provided in the subsequent sections. 
Table 4. Overview of variable domains, potentially relevant variables, and their source

\begin{tabular}{|c|c|c|}
\hline Domain & Variable & Source \\
\hline \multirow{2}{*}{$\begin{array}{c}\text { Control } \\
\text { variables }\end{array}$} & Age & Community registry \\
\hline & Gender & \\
\hline \multirow{2}{*}{$\begin{array}{l}\text { Sociodemographic } \\
\text { variables }\end{array}$} & Socioeconomic status & Winkler Index \\
\hline & Household crowding & Number of household members / Number of rooms \\
\hline \multirow{6}{*}{$\begin{array}{c}\text { Child } \\
\text { psychological } \\
\text { variables }\end{array}$} & Habitual coping strategies & $\begin{array}{l}\text { German Coping Questionnaire for Children and Adolescents } \\
\text { (SVF-KJ) }\end{array}$ \\
\hline & Anger expression & State-Trait Anger Expression Inventory (STAXI) \\
\hline & Anxiety / depression & Child Behavior Checklist (CBCL) \\
\hline & Aggressive behavior & Child Behavior Checklist (CBCL) \\
\hline & Hyperactivity & Child Behavior Checklist (CBCL) \\
\hline & Sleep disturbance & \\
\hline \multirow{2}{*}{$\begin{array}{l}\text { Child health } \\
\text { variables }\end{array}$} & Pain other than headache & \\
\hline & Other somatic complaints & \\
\hline \multirow{5}{*}{$\begin{array}{c}\text { Family } \\
\text { variables }\end{array}$} & Number of parents in household & \\
\hline & Number of children in household & \\
\hline & Negative family environment & Mannheim Parent Interview (MEI) \\
\hline & Negative conflict solving strategies & \\
\hline & Weekly family conflict & Mannheim Parent Interview (MEI) \\
\hline \multirow{4}{*}{$\begin{array}{l}\text { School } \\
\text { variables }\end{array}$} & School difficulties & \\
\hline & Time spent on homework & \\
\hline & School stress & \\
\hline & Reaction to failure & Hamburger Personality Questionnaire for Children (HAPEF-K) \\
\hline \multirow{6}{*}{$\begin{array}{l}\text { Leisure } \\
\text { variables }\end{array}$} & Physical activities & \\
\hline & Recreational activities & \\
\hline & Amount of ree time & \\
\hline & Time spent on TV / videos & \\
\hline & Time spent on computer / game console & \\
\hline & Amount of good friends & \\
\hline Life events & Life events & \\
\hline \multirow{5}{*}{$\begin{array}{c}\text { Parental } \\
\text { psychological } \\
\text { variables }\end{array}$} & Anxiety / depression & Child Health Questionnaire - Parent Report (CHQ-PF50) \\
\hline & Anxiety & \\
\hline & Depression & \\
\hline & Habitual worry & Penn Sate Worry Questionnaire (PSWQ) \\
\hline & Sleep disturbance & \\
\hline \multirow{6}{*}{$\begin{array}{l}\text { Parental health } \\
\text { variables }\end{array}$} & General health & \\
\hline & Doctor appointments & \\
\hline & Regular medication & \\
\hline & Headache & \\
\hline & Pain other than headache & \\
\hline & Other somatic complaints & \\
\hline
\end{tabular}


The psychometrically validated scales were abridged for the present research. Length constraints associated with a large-scale epidemiological survey such as the Children, Adolescents \& Headache Study made this necessary. Research has shown that response rates have a tendency to decline the more extensive and time consuming the questionnaire (Dillman, 2000). Therefore, in order to cover a broad range of potentially relevant variables the number of items per variable had to be limited.

In addition, original response categories were modified to a five point Likert scale, when possible. This adaptation was performed in order to simplify completion of the questionnaire and reduce potential errors.

\subsubsection{Age and Gender}

The data sets compiled by the Southern Lower Saxony Center for Municipal Data Administration and Hannover's community registry included child's age at time of sample selection and child's gender. Additionally, child's date of birth and gender were inquired in the parental questionnaire. This "redundant" information made it possible to determine through cross-checking, whether the data in the questionnaire referred to the intended child. Since date of questionnaire completion was not documented, age at time of sample selection was selected as the relevant operationalization of child's age for the statistical analyses.

As substantial research has indicated age and gender to be relevant to both pediatric headache and pediatric weekly headache, and as age and gender effects are not uncommon in the further potentially relevant biopsychosocial variables, age and gender will be treated as control variables in the present research.

\subsubsection{Sociodemographic Variables}

The first item of the parent questionnaire assessed the constellation of the child's primary caregivers and allowed for the differentiation between (a) two biological parents, (b) biological parent plus significant other, (c) single biological parent, (d) adoptive or foster parents, (e) grandparents or other relatives, or (f) home or institution. A further item assessed which caregiver completed the questionnaire: (a) mother, (b) father, (c) both, (d) grandparents or other relatives, (e) other caregiver. On the basis of these items, it was possible to determine whether the family, parental psychological and parental health variables should be included in the analyses. These variables were only included if the person completing the questionnaire was the child's (biological or other) parent.

Household socioeconomic position was selected as the measure of social class to be used in the analyses. Socioeconomic position in two-parent households was determined according to the "dominance approach", i.e., by equating household class "with the most dominant and powerful individual class position in the household, regardless of gender" (Krieger, Williams, \& Moss, 1997, p. 352). In order to compute socioeconomic status using the Winkler index (Winkler, 1998) questions regarding the parents' level of educational, occupational prestige and the household net income were included in the questionnaire. Missing values on one of the constituent variables (education, occupational status, net 
income) were substituted by the mean of the other two constituent variables. If two variables were missing, the Winkler index was not computed. ${ }^{7}$

Household crowding was assessed via an item asking about the number of rooms in the household (excluding the bathroom/s) and an item asking about the number of people living in the household. The household crowding index was calculated by dividing the number of household residents by the number of rooms in the household.

\subsubsection{Child Psychological Variables}

Child's maladaptive stress coping strategies were assessed using items from the German Coping Questionnaire for Children and Adolescents (Stressverarbeitungsfragebogen für Kinder und Jugendliche, SVF-KJ) from Hampel, Petermann, and Dickow (2001). The subscales Passive Avoidance, Rumination, Resignation, and Aggression were selected for inclusion in the parental questionnaire. Internal consistencies for the subscales have been described as ranging from .74 for Aggression to .86 for Rumination (Hampel et al., 2001). The maladaptive coping strategies have been shown to correlate positively with psychological distress and negatively with psychological well-being. A moderate intercorrelation of the subscales ( $r=.38$ to $r=.58$ ) has also been reported (Hampel et al., 2001). The original instructions, which differentiated between interpersonal stress situations and academic stress situations, were combined to enable direct assessment of cross-situational coping. Item formulations were reworded for parent rating and while the five-point Likert scale was retained, the response labels were modified from 1 ("not at all") to 5 ("in any case") to range from 1 ("never") to 5 ("always"). For each of the scales, 2 of the original 4 items were selected for inclusion on the basis of item content and factor loading. To minimize the effect of a skipped item, the sum was calculated as the product of the mean item value and the total number of corresponding items included in the parent questionnaire. Total sum scores ranges from 2 to 10; the higher the score, the more prevalent the particular maladaptive coping strategy.

Child's mode of anger expression (e.g., the tendency to generally hold anger in, to express anger outwardly, or to remain calm and control anger) was assessed using items from the State-Trait Anger Expression Inventory (STAXI) from Spielberger (1988) and in German translation from Schwenkmezger, Hodapp and Spielberger (1992). The following three subscales were employed: Anger-Out, Anger-In, Anger Control. For these anger expression scales internal consistencies ranging from .73 to .89 have been reported (Schwenkmezger et al., 1992). For each of the subscales, 2 of the original 8 items were selected for inclusion on the basis of item content and factor loading. Item formulations were reworded for parent rating and the response categories of the items were modified from a 4point Likert scale from 1 ("almost never") to 4 ("almost always") to the standard five-point scale of the questionnaire from 1 ("never") to 5 ("always"). Though "don't know" was also offered as a response category $(=6)$ in the parent questionnaire, it was treated as a missing value in the analyses. To minimize the effect of a skipped item, the sum was calculated as the product of the mean item value and the total number of corresponding items included in

\footnotetext{
${ }^{7}$ The Robert Koch Institute courteously provided the necessary questions and analysis syntax.
} 
the parent questionnaire. Total sum scores for each subscale ranged from 2 to 10; the higher the score, the greater tendency to engage in that particular mode of anger expression.

Items from the Anxious/Depressed subscale of the Child Behavior Checklist (CBCL) from Achenbach (1991) in German translation (Arbeitsgruppe Deutsche Child Behavior Checklist, 1998) were employed to assess child's anxiousness and depressivity. For the German version of this subscale Cronbach's alphas of .83 to .89 have been reported (Döpfner, Schmeck, Berner, Lehmkuhl, \& Poustka, 1994). Eight of the original 16 items were selected for inclusion on the basis of item content and factor loading. Items assessing suicidal ideation and behavior were excluded. The response categories were modified to a five-point Likert scale from 1 ("never") to 5 ("always"). To minimize the effect of skipped items, the sum was calculated as the product of the mean item value and the total number of corresponding items included in the parent questionnaire. Total sum scores ranges from 8 to 40; the higher the score, the more anxious and depressed the child.

Items from the Aggressive Behavior subscale of the CBCL (Achenbach, 1991) in German translation (Arbeitsgruppe Deutsche Child Behavior Checklist, 1998) were employed to assess child's aggressive behavior. For the German version of this subscale Cronbach's alphas of .89 to .83 have been reported (Döpfner et al., 1994). Three of the original 19 items were selected for inclusion on the basis of item content and factor loading. Again, the response categories were modified to a five-point Likert scale from 1 ("never") to 5 ("always"). To minimize the effect of a skipped item, the sum was calculated as the product of the mean item value and the total number of corresponding items included in the parent questionnaire. Total sum scores ranges from 3 to 15; the higher the score, the more aggressive the child's behavior.

Items from the Attention Problems subscale of the CBCL (Achenbach, 1991) in German translation (Arbeitsgruppe Deutsche Child Behavior Checklist, 1998) were employed to assess child's hyperactivity. The Cronbach's alphas reported for this subscale ranged from .81 to .84 (Döpfner et al., 1994). Three of the original 9 items were selected for inclusion on the basis of item content and factor loading. Items that focused on symptoms of hyperactivity were selected in particular. Once again, response categories were modified to a five-point Likert scale from 1 ("never") to 5 ("always"). To minimize the effect of a skipped item, the sum was calculated as the product of the mean item value and the total number of corresponding items included in the parent questionnaire. Total sum scores ranges from 3 to 15; the higher the score, the stronger the child's hyperactivity.

In a single question the frequency of child sleep disturbance was assessed. Values were scored from 1 ("never") to 5 ("always").

\subsubsection{Child Health Variables}

Child's pain other than headache was assessed via two questions that asked about the frequency of stomach pain and back pain in the past three months. Values were scored from 1 ("never") to 5 ("always"). Total sum scores ranges from 2 to 10; the higher the score, the more frequent the other pain. 
Other somatic complaints were assessed via six questionnaire items that asked about the frequency of (a) lack of appetite, (b) dizziness, (c) constipation, (d) nausea or vomiting (in the absence of headache), (e) travel sickness, (f) tiredness/fatigue. Values were scored from 1 ("never") to 5 ("always"). Total sum scores ranges from 6 to 30; the higher the score, the larger the number and/or the more frequent the occurrence of other somatic complaints. The sum was calculated only for cases without missing data on any of the six items.

\subsubsection{Family Variables}

One item of the questionnaire asked about the number of other children residing in the household. These could be biological siblings, adoptive, half- or step-siblings. The original question required the parent to report whether the child was an only child, and if not to indicate how many older, younger, and same aged children lived in the household. The answers to these questions were summed in order to calculate the total number of other children residing in the household.

Negative family environment was assessed with three items, which were based on the Mannheim Parent Interview (Mannheimer Elterninterview, MEI) from Esser, Blanz, Geisel and Laucht (1989). In the original version these questions focused on the parental relationship. The wording was modified to tap family relationships in general. The frequency with which the family had enough time for one another, engaged in satisfying familial activities, and spoke about problems and worries was assessed. Values were scored from 1 ("never") to 5 ("always"). Prior to calculation of the total sum, all questions were coded inversely to facilitate interpretation of negative family environment. To minimize the effect of a skipped item, the sum was calculated as the product of the mean item value and the total number of corresponding items included in the parent questionnaire. Total sum scores ranges from 3 to 15; the higher the score, the more negative the family environment.

Negative conflict solving strategies were assessed using three items. The questions asked (a) whether the family tries to solve problems by talking about them, (b) whether they fight loudly with one another, or (c) whether when the family fights "plates sometimes fly". The first question was coded inversely for consistency. Values were scored from 1 ("never") to 5 ("always"). To minimize the effect of a skipped item, the sum was calculated as the product of the mean item value and the total number of corresponding items included in the parent questionnaire. Total sum scores ranges from 3 to 15; the higher the score, the more negative the familial problem solving strategies.

The presence of weekly fights in the family was assessed using an item which was based on the Mannheim Parent Interview (Esser et al., 1989). The item asked how often fights had occurred in the past three months in the family, with "daily", "several times a week", "once a week", "more seldom", and "never" as response categories. The frequency was recoded into a new variable for analyses which indicated whether fights had occurred on a weekly basis. Values were scored from 0 ("no") to 1 ("yes").

\subsubsection{School Variables}

School difficulties were assessed via questions that asked whether the child had the following four school-related problems: (a) being held back / repeating a grade, (b) having 
learning difficulties or other school problems, (c) deteriorating school performance, (d) potentially jeopardized passing of required courses. Values for each item were scored from 0 ("no") to 1 ("yes"). An index was created by summing the presence of the four school difficulties. Index scores ranged from 0 to 4 ; the higher the score was, the larger the extent of school difficulties.

Time spent on homework was assessed via a single question asking how much time the child spent on homework per day. The response categories were "up to 1 hour", " 1 to 2 hours", "2 to 3 hours", and "more than three hours".

School stress was assessed via six questionnaire items that asked about the frequency of the following potentially stressful school experiences: (a) negative school climate, (b) being academically over-challenged, (c) being teased or bullied by other students, (d) being alone or isolated in school, (e) being afraid of school or of certain teachers, (f) being bored or academically under-challenged. Values were scored from 1 ("never") to 5 ("always"). Though the response category "don't know" was offered as a response category, it was treated as a missing value in the analyses. To minimize the effect of skipped items, the sum was calculated as the product of the mean item value and the total number of corresponding items included in the parent questionnaire. Total sum scores ranges from 6 to 30; the higher the score, the more frequent the child's school stress.

Items from the Reaction to Failure scale of the Hamburg Personality Questionnaire for Children (Hamburger Persönlichkeitsfragebogen für Kinder, HAPEF-K) from Wagner and Baumgärtel (1978) were employed to assess child's neurotic reaction to failure. The Reaction to Failure scale has an internal consistency reported to range from .82 to .84 , and has been shown to correlate positively with measures of test anxiety, effort avoidance and manifest anxiety (Wagner \& Baumgärtel, 1978). Three of the original 11 items were selected for inclusion on the basis of item content and factor loading. The item formulations were reworded for parent response. The original six-point Likert scale for item response from 1 ("always or almost always") to 6 ("never or almost never") was modified to a five-point Likert scale from 1 ("never") to 5 ("always"). To minimize the effect of a skipped item, the sum was calculated as the product of the mean item value and the total number of corresponding items included in the parent questionnaire. Total sum scores ranges from 3 to 15; the higher the score, the stronger the child's neurotic reaction to failure.

\subsubsection{Leisure Variables}

Physical activities were assessed via items that inquired how often the index child engaged in the following physical activities per week outside of school physical education: (a) cycling, (b) ball games (e.g., volleyball, soccer), (c) swimming, (d) racquet sports (e.g., tennis, badminton), (e) gymnastics, (f) track and field athletics, (g) outdoor physical activities (e.g., running, climbing), (h) dancing, (i) horseback riding, (j) skating (e.g., inline skates, skateboard). The response categories were "less than once a week", "1 to 2 times a week", "3 to 5 times a week", "more than 5 times a week", and "my child does not engage in this physical activity". The response categories were given the values 1 thru 4 and 0 , respectively. An index for the amount and frequency of physical activity was calculated by summing the values for each of the physical activities. 
Other recreational activities were assessed via items that asked how often the index child engaged in the following other activities per week outside of school: (a) reading, (b) painting/drawing/handicrafts, (c) listening to music, (d) playing an instrument. The response categories were "less than once a week", " 1 to 2 times a week", " 3 to 5 times a week", "more than 5 times a week", and "my child does not engage in this activity". The response categories were given the values 1 thru 4 and 0 , respectively. An index for the amount and frequency of these other activities was calculated by summing the values for each of the other activities.

A single question asked how often the child had free time with the response categories "never", "seldom", "sometimes", "often", "always" and "don't know". The category "don't know" was treated as a missing value in the analyses. The remaining response categories were considered to be continuous with values from 1 ("never") to 5 ("always").

The amount of time spent on electronic media daily was assessed (a) for television and videos and (b) for computer, internet, and game consoles. The response categories were "not at all", "less than 30 minutes", "about 30 to 60 minutes", "about 1 to 2 hours", "about 3 to 4 hours", "more than 4 hours". The response categories are considered to be continuous for the analyses with values ranging from 1 ("not at all") to 6 ("more than 4 hours").

A single mixed format question, combining multiple choice and fill in the blank, queried the number of good friends the child has. The parent was asked to check the appropriate amount category ("no good friends", "one good friend", "more than one good friend", "don't know") and then to specify the absolute number of good friends, if the category "more than 1" was checked. This information allowed the calculation of the absolute number of child's good friends. The response category 'don't know' was considered a missing value. For the analyses the absolute number of friends was grouped into the following categories: "no or one good friend", "2 to 5 good friends", and "6 or more good friends" with corresponding values ranging from 1 to 3 .

\subsubsection{Life Events}

Life events were assessed via questions that asked whether, in the past five years, the index child had (a) been in a home or at boarding school, (b) changed schools (other than normal change from primary school to secondary school), (c) experienced the loss of a family member or other significant person (through death, divorce, relocation), (d) experienced gaining a new family member (birth of a sibling, new significant other of parent). Further items inquired whether there had been (e) a severe accident in the family in the past five years, (f) chronic somatic illness with severe impairment in the family, (g) a high financial burden, or (h) home caregiving. Values were scored from 0 ("no") to 1 ("yes"). An additional fill-in-the-blank item regarding in-patient treatment queried the absolute number of nights the child had spent in in-patient treatment in the past 12 months. For the purpose of the life event index the response was categorized into presence of in-patient treatment in the past 12 months 0 ("no") to 1 ("yes"). Finally, a life event index was calculated by summing the presence of the individual life events. Index scores ranged from 0 to 9 ; the higher the score, the more life events experienced. 


\subsubsection{Parental Psychological Variables}

Parental anxiety and depression was assessed with the Parental Mental Health scale of the Child Health Questionnaire - Parent Report (CHQ-PF50) from Landgraf et al. (1998). Values were scored from 1 ("never") to 5 ("always"). To minimize the effect of skipped items, the sum was calculated as the product of the mean item value and the corresponding number of items answered. Total sum scores ranges from 5 to 25; the higher the score, the more symptoms of anxiety and depression were present.

The frequency of parental anxiety and depressed mood were also assessed directly with two corresponding items. Values were scored from 1 ("never") to 5 ("always").

Parental habitual worry was assessed with items of the Penn State Worry Questionnaire (PSWQ) from Meyer, Miller, Metzger and Borkovec (1990) in German translation (Stöber, 1995). The questionnaire taps generalized worry. A Cronbach's alpha of .85 has been reported for the German version (Stöber, 1995). Three of the original 16 items were selected for inclusion on the basis of item content and factor loading (of the German version). Values were scored from 1 ("not at all typical of me") to 5 ("very typical of me"). To minimize the effect of a skipped item, the sum was calculated as the product of the mean item value and the total number of corresponding items included in the parent questionnaire. Total sum scores ranges from 3 to 15 ; the higher the score, the stronger the parental tendency to worry habitually.

In a single question the frequency of parental sleep disturbance was assessed. Values were scored from 1 ("never") to 5 ("always").

\subsubsection{Parental Health Variables}

Parental general health was assessed with two items. The items inquired whether the parent considered herself/himself to be generally healthy and whether the parent believed that she/he is more prone to illness than others. The second question was coded inversely for consistency. Values were scored from 1 ("not at all typical of me") to 5 ("very typical of me"). To minimize the effect of a skipped item, the sum was calculated as the product of the mean item value and the total number of corresponding items included in the parent questionnaire. Total sum scores ranges from 2 to 10; the higher the score, the better the parental general health.

The number of parental doctor appointments was assessed via a single questionnaire item. The fill in the blank item queried the absolute number of doctor appointments in the past six months.

A single item asked the parent whether she/he took medication regularly. Values were scored from 0 ("no") to 1 ("yes").

Several questionnaire items asked about parental headache in the past 6 months. These items were formulated analogous to the child's headache prevalence questions. The absolute number of parental headache episodes in the past six months was calculated. For the purpose of the present research the frequency was recoded into a new variable 
indicating whether the parent had experienced headache in the past six months. Values were scored from 0 ("no") to 1 ("yes").

The presence of parental pain other than headache was assessed via a single question that queried the frequency of pain at other locations (e.g., back, joint). Values were scored from 1 ("never") to 5 ("always").

Other parental somatic complaints were assessed via four questionnaire items that asked about the frequency of (a) gastrointestinal complaints / disorders, (b) asthma / allergies, (c) thyroid disease, (d) high blood pressure / heart problems / circulatory problems. Values were scored from 1 ("never") to 5 ("always"). Total sum scores ranges from 4 to 20; the higher the score, the larger the number and/or the more frequent the occurrence of parental other somatic complaints. The sum was calculated only for cases without missing data on any of the four items.

\subsection{Survey Conduction}

The first wave of the postal survey took place between October 2003 and January 2004 and was conducted in accordance with Dillman's (2000) recommendations for survey implementation and response optimization (see Figure 3).

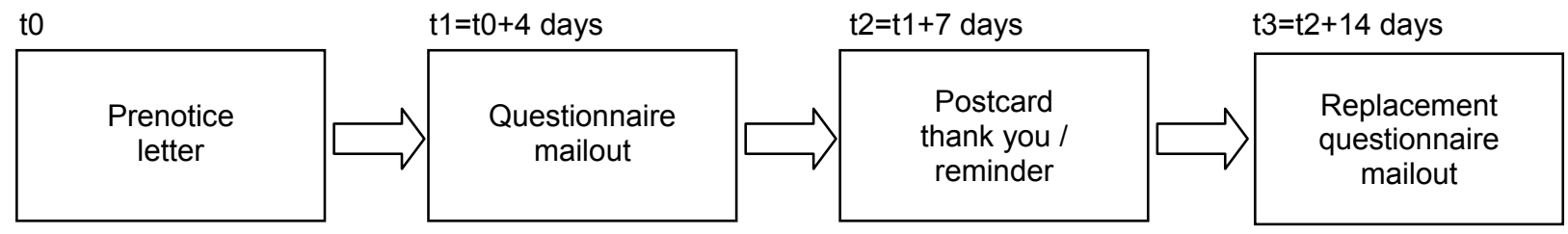

Figure 3. Survey implementation timeline

Several days before the questionnaires were mailed, a prenotice letter was sent to all sample households to inform them about the survey and the material they would soon receive. Four days later the questionnaire(s) and auxiliary survey material (cover letter, additional instruction sheet, return envelope) were mailed. A postcard thanking those subjects who had returned the questionnaires for their participation, and requesting the remaining subjects to complete the questionnaires was mailed a week later. Two weeks following the postcard all nonresponders were sent replacement questionnaire packets (all survey materials can be found in Appendix B).

A lottery with a chance to win one of a total of 21 prizes ranging from a mini hi-fi system to various gift certificates (for books, music CDs, movie tickets etc.) was implemented as an incentive for participation. The lottery drawing took place approximately 3 months after completion of the first survey wave. Prize winners were randomly drawn from the survey responders.

Contact information (address, email-address, telephone number of the project coordinators) was provided in all the letters and inside the questionnaires in case questions should arise. Postcards with an Easter greeting were sent to all participating households in April to maintain contact with the study sample. 
Returned questionnaires were sent to a contractor for computerization of the data. The quality of data entry was verified at the project center by manually comparing $5 \%$ of total data (randomly selected) with the original questionnaires. The error rate for data entry was substantially lower than the maximum allowable rate of $1.5 \%(0.11 \%$ error rate for parent questionnaires).

\subsection{Ethics}

Ethical issues were considered in every phase of the study. Recommendations regarding confidentiality and data protection issues were obtained from the data protection officer of the University of Göttingen and rigorously followed throughout study implementation. Approval for the study was also gained from the Ethics Committee of the German Psychological Association. The surveyed households were informed of data protection regulations and procedure, the aims of the study, and the voluntary nature of study participation.

\subsection{Data Analysis}

Statistical computations were performed with the Statistical software Package for Social Sciences, version 12.0 (SPSS Inc., Chicago, Illinois).

Prior to data analysis the metric variables were z-transformed. The Z-scores were used in the crude and multivariate logistic regression analyses. Before the multivariate full model analyses were performed (see Table 5), correlation matrices were inspected and multicollinearity diagnostics conducted. Data transformations were necessary prior to calculation of some of the correlation matrices, e.g. values of continuous variables were rounded to obtain discrete variables and thus enable the calculation of Spearman correlations.

Table 5 depicts the data analyses performed. As shown, analyses were computed for three outcome comparisons: (a) weekly headache vs. good health, (b) chronic illness vs. good health, (c) weekly headache vs. chronic illness. The following four consecutive analysis steps were performed for the first two comparisons:

- First, a control model was analyzed via direct logistic regression with health status as outcome and age and gender as predictor variables. This was done in order to determine the predictivity of the control variables, on their own.

- Second, single-predictor models were analyzed via direct logistic regression on health status as outcome, age and gender as control variables, and each of the potentially relevant variables, individually. This was done in order to determine the predicitivity of each individual variable while controlling for age and gender.

- Third, full domain models were analyzed. A multivariate sequential logistic regression was performed on health status as outcome, age and gender as control variables (block 1 ), and all variables of a given variable domain (block 2), in order to determine the predictivity of the domain variables, as a set, and to determine whether the domain variables significantly added to health status prediction above that afforded by the control variables alone. 
- Fourth, full aggregate models were analyzed via sequential logistic regression with health status as outcome, age and gender as control variables (block 1), and all variables, which reached significance $(p<.01)$ in the domain analyses (block 2$)$. This was done in order to determine the predictivity of the variables, individually and as a set, and to determine whether the variables significantly added to health status prediction above that afforded by the control variables alone.

Table 5. Overview of data analyses

\begin{tabular}{|c|c|c|}
\hline Weekly headache vs. Good health & Chronic illness vs. Good health & $\begin{array}{c}\text { Specificity } \\
\text { Weekly headache vs. Chronic illness }\end{array}$ \\
\hline Control model & Control model & Control model \\
\hline Direct logistic regression & Direct logistic regression & Method: Direct logistic regression \\
\hline Predictors: Age, gender & Predictors: Age, gender & Predictors: Age, gender \\
\hline Outcome: Health status & Outcome: Health status & Outcome: Health status \\
\hline Single-predictor model & Single-predictor model & Single-predictor model \\
\hline Method: Direct logistic regression & Method: Direct logistic regression & Direct logistic regression \\
\hline $\begin{array}{l}\text { Predictors: Each potentially relevant } \\
\text { variables }\end{array}$ & $\begin{array}{l}\text { Predictors: Each potentially relevant } \\
\text { variables }\end{array}$ & $\begin{array}{l}\text { Predictors: Each variables that reached } \\
\text { significance }(p \leq .01) \text { in one }\end{array}$ \\
\hline Controls: Age, gender & Controls: Age, gender & of the full aggregate models \\
\hline Outcome: Health status & Outcome: Health status & $\begin{array}{ll}\text { Controls: } & \text { Age, gender } \\
\text { Outcome: } & \text { Health status }\end{array}$ \\
\hline Full domain model & Full domain model & \\
\hline $\begin{array}{ll}\text { Method: } & \begin{array}{l}\text { Sequential logistic } \\
\text { regression }\end{array}\end{array}$ & $\begin{array}{l}\text { Sequential logistic } \\
\text { regression }\end{array}$ & \\
\hline $\begin{array}{l}\text { Predictors: All potentially relevant } \\
\text { domain variables }\end{array}$ & $\begin{array}{c}\text { Predictors: All potentially relevant } \\
\text { domain variables }\end{array}$ & \\
\hline Controls: Age, gender & Controls: Age, gender & \\
\hline Outcome: Health status & Outcome: Health status & \\
\hline Full aggregate model & Full aggregate model & Full specificity model \\
\hline $\begin{array}{l}\text { Sequential logistic } \\
\text { regression }\end{array}$ & $\begin{array}{l}\text { Sequential logistic } \\
\text { regression }\end{array}$ & $\begin{array}{l}\text { Sequential logistic } \\
\text { regression }\end{array}$ \\
\hline $\begin{array}{l}\text { Predictors: } \text { All variables that reached } \\
\text { significance }(p \leq .01) \text { in the } \\
\text { full domain models }\end{array}$ & $\begin{array}{l}\text { Predictors: } \text { All variables that reached } \\
\text { significance }(p \leq .01) \text { in the } \\
\text { full domain models }\end{array}$ & $\begin{aligned} \text { Predictors: All variables that reached } \\
\text { significance }(p \leq .01) \text { in one } \\
\text { of the full aggregate models }\end{aligned}$ \\
\hline Controls: Age, gender & Controls: Age, gender & Controls: Age, gender \\
\hline Outcome: Health status & Outcome: Health status & Outcome: Health status \\
\hline
\end{tabular}

In the specificity analyses, comparing weekly headache to chronic illness, all variables that maintained their significance in one of the full aggregate models $(p<.01)$ were examined. Three consecutive analysis steps were performed:

- First, a control model was analyzed via direct logistic regression with health status as outcome and age and gender as predictor variables.

- Second, single-predictor models were analyzed via direct logistic regression on health status as outcome, age and gender as control variables, and each of the variables that reached significance $(p<.01)$ in one of the full aggregate models.

- Third, the full specificity model was analyzed via sequential logistic regression with health status as outcome, age and gender as control variables (block 1 ), and all of the variables that reached significance $(p<.01)$ in one of the full aggregate models (block 2$)$. 
In the single-predictor analyses only those cases with non-missing data on age, gender, and the variable of interest were included. In the multivariate analyses of the full domain model, full aggregate model, and full specificity model only those cases with nonmissing data on all variables were included. Hence the results in the tables for the singlepredictor model and the various full models are based on samples of slightly varying size.

Note that for dichotomous or categorical variables simple contrasts to a reference group were performed. 


\section{RESULTS}

\subsection{Descriptive Results}

Questionnaires were mailed out to the entire sample of 8,800 households in the first wave of the study. As 132 of the questionnaires were returned to sender (e.g., address unknown), it can be assumed that 8,668 questionnaires were successfully delivered. Over half of the sample, 4,784 households, returned the parent questionnaires within three weeks. Further 802 households responded after receiving a replacement questionnaire packet. Parent questionnaires were completed and returned by 5,586 households, yielding a crude response rate of $63.5 \%$. However, among these were a number of questionnaires deemed invalid for analysis. Data from 112 questionnaires had to be excluded from statistical analysis for one of the following reasons:

- data in the questionnaire did not refer to the intended child,

- missing data made confirmation that the questionnaire referred to the intended child impossible, or

- missing data in questionnaire exceeded $50 \%$.

The progression from the initial random sample of 8,800 households to the 5,474 parental questionnaires (62.2\%) deemed valid for analysis is illustrated in Figure 4.

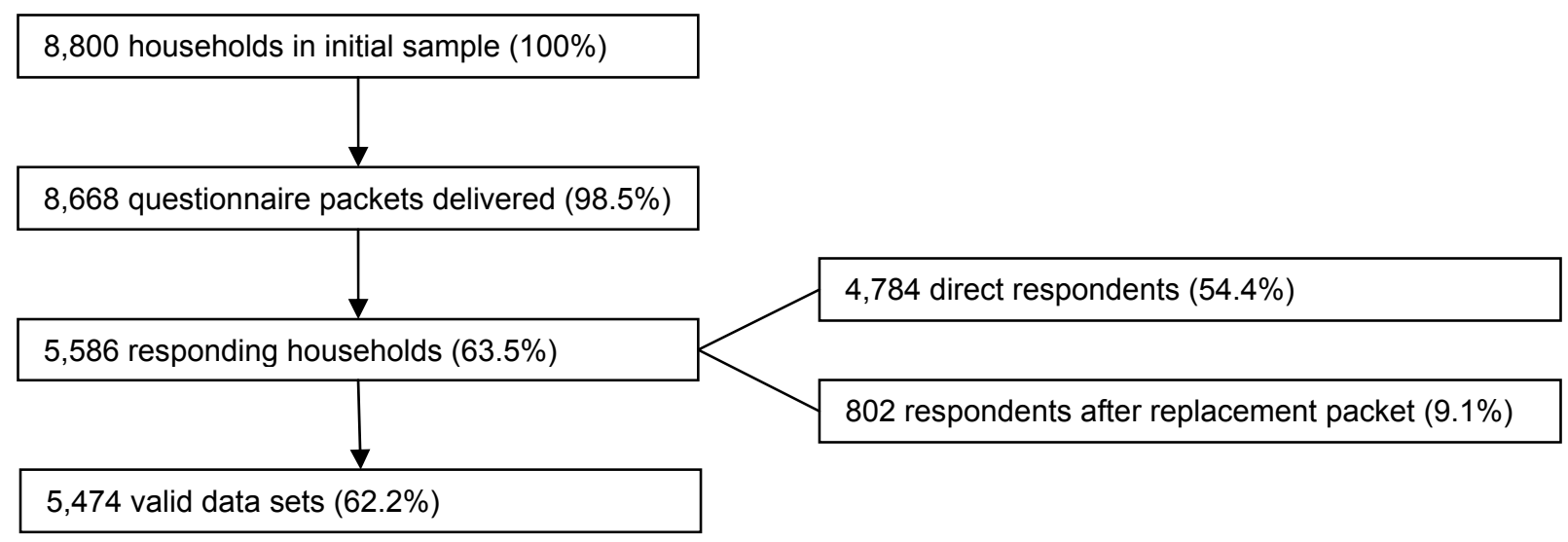

Figure 4. Response to the first wave of the Children, Adolescents \& Headache Study

Valid parent questionnaire data was reported for a total of 5,474 children and adolescents. The gender distribution of the children was approximately equal with 2,706 females $(49.4 \%)$ and 2,768 males (50.6\%). The children and adolescents ranged in age from 7 to 14 and had a mean age of 10.3 years.

Prevalence rates for weekly headache and chronic illnesses were calculated on the basis of the 5,474 valid parental questionnaires prior to creation of the outcome groups of interest. This was done to maintain comparability of the results to prior epidemiological research. Weekly headache was reported for $6.5 \%$ and chronic illness (excluding weekly headache) for $17.9 \%$ of the children and adolescents. The prevalence of chronic illness is $22.6 \%$ if weekly headache is included. 
Of the children and adolescents with valid data sets, 3,753 fulfilled the criteria for the outcome groups of interest (i.e., weekly headache, chronic illness, good health). The remaining 1,901 children did not fulfill the criteria and were filtered out prior to statistical analysis for one of the following reasons:

- presence of impairment or disability,

- missing data regarding impairment or disability,

- presence of monthly headaches,

- missing data regarding headache frequency,

- presence of chronic headache and chronic illness (i.e., comorbidity), or

- missing data regarding chronic illness.

Figure 5 depicts the progression from the total 5,474 children and adolescents to the three outcome groups of interest.

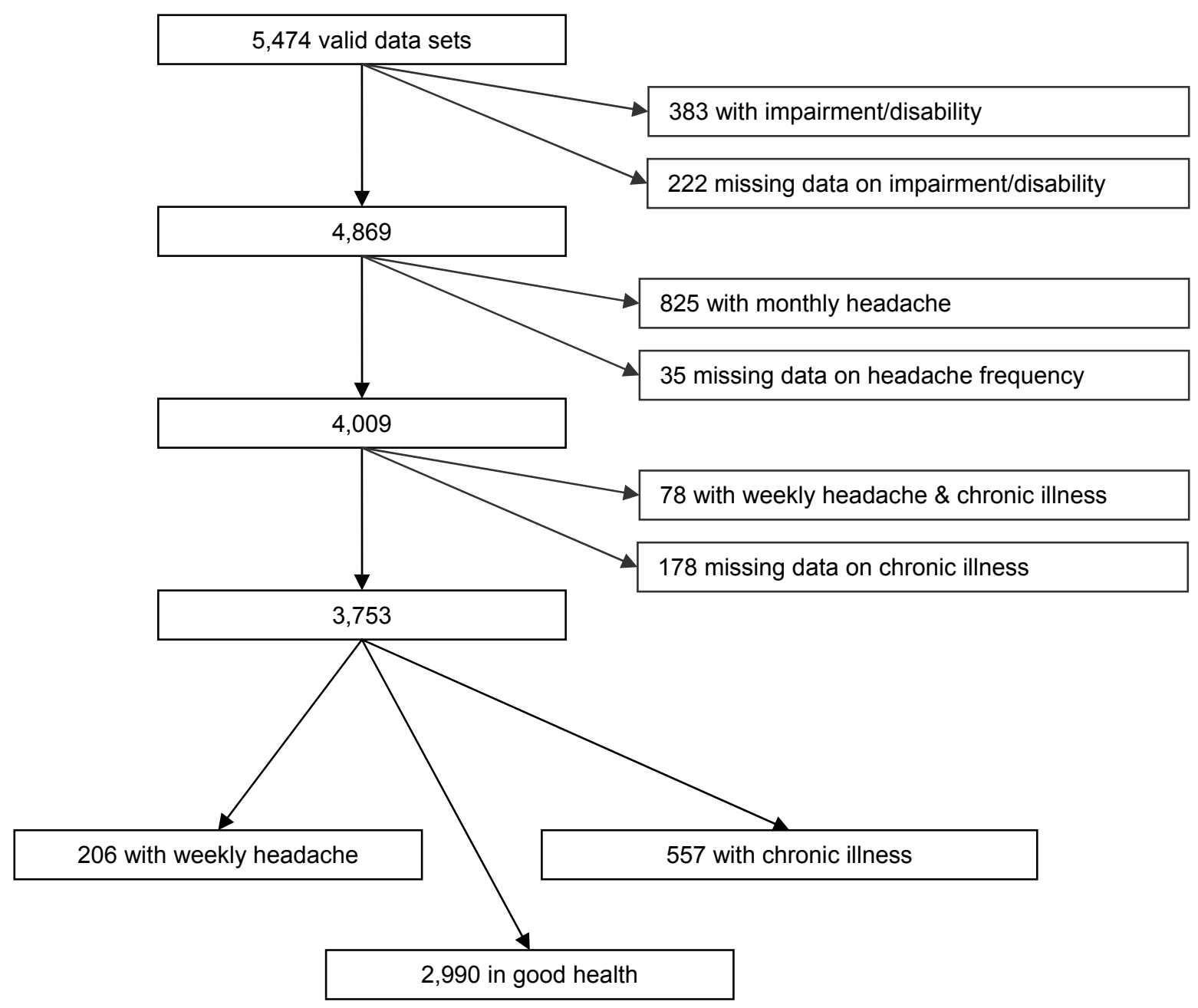

Figure 5. Progression of the Children, Adolescents \& Headache Study sample from 5,474 valid data sets to the three comparison groups for statistical analysis

In the first step of sample progression, 605 children were filtered out. The presence of impairment or disability was reported for $383(7 \%)$ of the children and adolescents (see Appendix C). For 222 (4.1\%) missing data regarding the conditions made it impossible to 
determine with certainty whether an impairment or disability was present. As absence of impairment or disability was a defining criterion for each of the three outcome groups of interest, the above 605 children were filtered out prior to analysis.

In the second step, 860 children were filtered out. Monthly headache was reported for $825(16.9 \%)$ of the children without an impairment or disability (see Appendix C). For 35 $(0.7 \%)$ children missing data made it impossible to determine headache frequency. As weekly headache was the defining criterion for the outcome weekly headache, and the absence of weekly or monthly headache was a defining criterion for both other outcome groups, the above 860 children were filtered out prior to analysis.

In the third and final step, 256 children were filtered out. Among the 4,009 children without monthly headache and without impairment or disability, 78 had both weekly headache and other chronic illness (see Appendix C). For 178 children (4.4\%) missing data regarding the individual chronic illnesses made it impossible to determine with certainty whether chronic illness was absent. As absence of chronic illness was a defining criterion for the outcome groups good health and weekly headache, these 256 children were filtered out prior to analysis.

Table 6. Absolute and relative frequency of the outcome groups weekly headache, chronic illness (with differentiation according to individual illnesses), and good health in 3,753 children and adolescents

\begin{tabular}{lccc}
\hline & $\begin{array}{c}\text { Female } \\
(\mathrm{n}=1881)\end{array}$ & $\begin{array}{c}\text { Male } \\
(\mathrm{n}=1872)\end{array}$ & $\begin{array}{c}\text { Total } \\
(\mathrm{n}=3753)\end{array}$ \\
\hline Weekly headache & $138(7.3 \%)$ & $68(3.6 \%)$ & $206(5.5 \%)$ \\
Chronic illness & $266(14.1 \%)$ & $291(15.5 \%)$ & $557(14.8 \%)$ \\
$\quad \begin{array}{l}\text { Asthma } \\
\text { Atopic dermatitis }\end{array}$ & $161(3.4 \%)$ & $121(6.5 \%)$ & $185(4.9 \%)$ \\
$\begin{array}{l}\text { Epilepsy } \\
\text { Congenital heart } \\
\text { disease }\end{array}$ & $1(0.1 \%)$ & $134(7.2 \%)$ & $295(7.9 \%)$ \\
$\begin{array}{l}\text { Chronic inflammatory } \\
\text { bowel disease }\end{array}$ & $23(1.2 \%)$ & $4(0.2 \%)$ & $5(0.1 \%)$ \\
Chronic kidney disease & $1(0.1 \%)$ & $21(1.1 \%)$ & $44(1.2 \%)$ \\
Muscle diseases & $4(0.2 \%)$ & $1(0.1 \%)$ & $2(0.1 \%)$ \\
$\begin{array}{l}\text { Juvenile rheumatoid } \\
\text { arthritis }\end{array}$ & $1(0.1 \%)$ & $2(0.1 \%)$ & $6(0.2 \%)$ \\
Diabetes & $4(0.2 \%)$ & $2(0.1 \%)$ & $3(0.1 \%)$ \\
Other & $1(0.1 \%)$ & $4(0.2 \%)$ & $8(0.2 \%)$ \\
Good health & $38(2.0 \%)$ & $3(0.2 \%)$ & $4(0.1 \%)$ \\
\hline
\end{tabular}

The remaining 3,753 children and adolescents fulfilled the criteria for the three outcome groups of interest: weekly headache, other chronic illness, and good health. Thus they compose the relevant sample for the present research. The vast majority of these children and adolescents were in good health, approximately one in six had chronic illness, and one in twenty chronic headache. The absolute and relative frequencies of the outcome groups and of the individual chronic illnesses are shown in Table 6. While most of the 
children in the chronic illness group were affected by only one chronic illness, multiple illnesses were reported for 81 of them (2.2\%).

The gender distribution was approximately equal in the outcome groups good health with 1,477 females (49.4\%) and 1,513 males (50.6\%), and chronic illness with 266 females (47.8\%) and 291 males (52.2\%). However, a substantial gender difference was evident in the chronic headache group with 138 females (67.0\%) versus 68 males (33.0\%). Mean age of the children and adolescents in the good health group was 10.1 years and in the chronic illness group 10.0; values approximating the mean age of the initial sample of 8,800 children (10.3 years). However, the mean age of 11.3 years in the chronic headache group was somewhat higher. These differences underscore the importance of controlling for age and gender in the statistical analyses. Descriptive data for all of the variables examined in the present study, differentiated according to outcome group, is shown in Table 7.

Table 7. Means and standard deviation for metric variables, absolute and relative frequency for non-metric variables, differentiated according to outcome group

\begin{tabular}{|c|c|c|c|c|}
\hline Domain & Variable & $\begin{array}{l}\text { Weekly headache } \\
\qquad M(S D) / f(\%)\end{array}$ & $\begin{array}{l}\text { Chronic illness } \\
M(S D) / f(\%)\end{array}$ & $\begin{array}{l}\text { Good health } \\
M(S D) / f(\%)\end{array}$ \\
\hline \multirow[b]{2}{*}{$\begin{array}{c}\text { Control } \\
\text { variables }\end{array}$} & Age & $11.3(2.05)$ & $10.0(2.18)$ & $10.1(2.27)$ \\
\hline & $\begin{array}{l}\text { Gender } \\
\text { Female } \\
\text { Male }\end{array}$ & $\begin{array}{l}138(67.0 \%) \\
68(33.0 \%)\end{array}$ & $\begin{array}{l}266(47.8 \%) \\
291(52.2 \%)\end{array}$ & $\begin{array}{l}1477(49.4 \%) \\
1513(50.6 \%)\end{array}$ \\
\hline \multirow[t]{2}{*}{$\begin{array}{c}\text { Sociodemo- } \\
\text { graphic } \\
\text { variables }\end{array}$} & $\begin{array}{l}\text { Social class } \\
\text { Lower } \\
\text { Middle } \\
\text { Upper }\end{array}$ & $\begin{array}{l}21(10.2 \%) \\
92(44.7 \%) \\
80(38.8 \%)\end{array}$ & $\begin{array}{c}31(5.6 \%) \\
239(42.9 \%) \\
270(48.5 \%)\end{array}$ & $\begin{array}{c}192(6.4 \%) \\
1289(43.1 \%) \\
1369(45.8 \%)\end{array}$ \\
\hline & Household crowding index ${ }^{a}$ & $.767(.243)$ & $.708(.203)$ & $.730(.216)$ \\
\hline \multirow{13}{*}{$\begin{array}{l}\text { Psychological } \\
\text { variables }\end{array}$} & Maladaptive coping & & & \\
\hline & Passive avoidance $^{a}$ & $.426(1.28)$ & $-.034(.984)$ & $-.117(.899)$ \\
\hline & Rumination $^{a}$ & $.309(.996)$ & $.000(1.00)$ & $-.109(.958)$ \\
\hline & Resignation $^{\mathrm{a}}$ & $.339(1.18)$ & $-.012(.978)$ & $-.116(.909)$ \\
\hline & Aggression $^{a}$ & $.266(1.03)$ & $-.029(.971)$ & $-.116(.973)$ \\
\hline & Anger expression & & & \\
\hline & Anger-in ${ }^{a}$ & $.160(.987)$ & $-.053(.989)$ & $-.074(.981)$ \\
\hline & Anger-out $^{\mathrm{a}}$ & $-.015(1.02)$ & $.090(.970)$ & $-.051(.993)$ \\
\hline & Anger control $^{a}$ & $-.075(.997)$ & $-.030(.962)$ & $.036(1.00)$ \\
\hline & Anxiety/depression ${ }^{a}$ & $.421(1.10)$ & $-.068(.953)$ & $-.166(.908)$ \\
\hline & Hyperactivity $^{a}$ & $.010(1.03)$ & $.009(.993)$ & $-.113(.938)$ \\
\hline & Aggressive behavior $^{a}$ & $.028(.978)$ & $-.033(.963)$ & $-.064(.912)$ \\
\hline & Sleep disturbance ${ }^{a}$ & $.291(1.13)$ & $.033(1.03)$ & $-.142(.890)$ \\
\hline \multirow{2}{*}{$\begin{array}{c}\text { Health } \\
\text { variables }\end{array}$} & Pain other than headache ${ }^{a}$ & $.858(1.29)$ & $-.137(.950)$ & $-.212(.845)$ \\
\hline & Other somatic complaints $^{a}$ & $.719(1.16)$ & $-.101(.879)$ & $-.208(.845)$ \\
\hline
\end{tabular}

${ }^{\mathrm{a}}$ Z-scores 
Table 7. continued

\begin{tabular}{|c|c|c|c|c|}
\hline & & $\begin{array}{l}\text { Weekly headache } \\
\qquad M(S D) / f(\%)\end{array}$ & $\begin{array}{l}\text { Chronic illness } \\
M(S D) / f(\%)\end{array}$ & $\begin{array}{l}\text { Good health } \\
M(S D) / f(\%)\end{array}$ \\
\hline \multirow{5}{*}{$\begin{array}{l}\text { Family } \\
\text { variables }\end{array}$} & $\begin{array}{l}\text { Number of parents in } \\
\text { household } \\
\text { One } \\
\text { Two }\end{array}$ & $\begin{array}{l}32(15.8 \%) \\
171(84.2 \%)\end{array}$ & $\begin{array}{l}71(12.9 \%) \\
481(87.1 \%)\end{array}$ & $\begin{array}{c}412(14.0 \%) \\
2522(85.6 \%)\end{array}$ \\
\hline & $\begin{array}{l}\text { Number of other children in } \\
\text { household }\end{array}$ & $1.15(.899)$ & $1.04(.774)$ & $1.13(.893)$ \\
\hline & $\begin{array}{l}\text { Negative family } \\
\text { environment }^{\mathrm{a}}\end{array}$ & $.128(1.07)$ & $.012(.975)$ & $-.084(.968)$ \\
\hline & $\begin{array}{l}\text { Negative conflict solving } \\
\text { strategies }^{\mathrm{a}}\end{array}$ & $.154(1.10)$ & $-.032(.941)$ & $-.040(.985)$ \\
\hline & $\begin{array}{l}\text { Weekly family conflict } \\
\text { No } \\
\text { Yes }\end{array}$ & $\begin{array}{l}134(65.0 \%) \\
69(33.5 \%)\end{array}$ & $\begin{array}{l}397(71.3 \%) \\
150(26.9 \%)\end{array}$ & $\begin{array}{c}2229(74.5 \%) \\
686(22.9 \%)\end{array}$ \\
\hline \multirow{4}{*}{$\begin{array}{c}\text { School } \\
\text { variables }\end{array}$} & Index of school difficulties & $.543(.758)$ & $.293(.615)$ & $.266(.581)$ \\
\hline & $\begin{array}{l}\text { Time spent of homework } \\
\quad<1 \text { hour } \\
1-2 \text { hours } \\
2-3 \text { hours } \\
>3 \text { hours }\end{array}$ & $\begin{array}{c}105(51.0 \%) \\
76(36.9 \%) \\
15(7.3 \%) \\
5(2.4 \%)\end{array}$ & $\begin{array}{c}348(62.5 \%) \\
161(28.9 \%) \\
20(3.6 \%) \\
2(0.4 \%)\end{array}$ & $\begin{array}{c}1924(64.3 \%) \\
840(28.1 \%) \\
97(3.2 \%) \\
7(0.2 \%)\end{array}$ \\
\hline & School stress ${ }^{a}$ & $.428(1.17)$ & $.004(.890)$ & $-.162(.905)$ \\
\hline & Reaction to failure ${ }^{a}$ & $.148(1.10)$ & $.023(1.01)$ & $-.100(.978)$ \\
\hline \multirow{6}{*}{$\begin{array}{l}\text { Leisure } \\
\text { variables }\end{array}$} & Physical activities $^{a}$ & $-.104(.963)$ & $.102(.990)$ & $.037(1.01)$ \\
\hline & Recreational activities $^{a}$ & $.080(1.01)$ & $.062(.991)$ & $.046(.992)$ \\
\hline & Amount of free time ${ }^{a}$ & $-.159(1.13)$ & $-.037(1.02)$ & $.047(.941)$ \\
\hline & Time spent on TV / video ${ }^{a}$ & $.309(1.07$ & $-.141(.933)$ & $-.048(.985)$ \\
\hline & $\begin{array}{l}\text { Time spent on computer / } \\
\text { game console }\end{array}$ & $-.038(.988)$ & $-.110(.916)$ & $-.028(.986)$ \\
\hline & $\begin{array}{l}\text { Amount of friends } \\
0-1 \text { friend } \\
2-5 \text { friends } \\
>5 \text { friends }\end{array}$ & $\begin{array}{l}99(48.1 \%) \\
22(10.7 \%) \\
74(35.9 \%)\end{array}$ & $\begin{array}{c}368(66.1 \%) \\
31(5.6 \%) \\
144(25.9 \%)\end{array}$ & $\begin{array}{c}1791(59.9 \%) \\
224(7.5 \%) \\
894(29.9 \%)\end{array}$ \\
\hline Life events & Index of life events & $1.29(1.24)$ & $1.05(1.10)$ & $.968(1.09)$ \\
\hline \multirow{3}{*}{$\begin{array}{l}\text { Parental } \\
\text { psychological } \\
\text { variables }\end{array}$} & $\begin{array}{l}\text { Anxiety/Depression } \\
\quad \text { (index) }\end{array}$ & $.269(1.06)$ & $-.022(1.01)$ & $-.120(.937)$ \\
\hline & Habitual worry ${ }^{a}$ & $.250(1.04)$ & $-.025(1.02)$ & $-.107(.965)$ \\
\hline & Sleep disturbance ${ }^{a}$ & $.205(1.14)$ & $-.095(.985)$ & $-.099(.942)$ \\
\hline \multirow{6}{*}{$\begin{array}{l}\text { Parental health } \\
\text { variables }\end{array}$} & General health $^{\mathrm{a}}$ & $-.140(1.04)$ & $-.055(1.05)$ & $.094(.953)$ \\
\hline & $\begin{array}{l}\text { Number of doctor } \\
\text { appointments }^{a}\end{array}$ & $.244(1.63)$ & $.063(1.06)$ & $-.074(.920)$ \\
\hline & $\begin{array}{l}\text { Regular medication } \\
\text { No } \\
\text { Yes }\end{array}$ & $\begin{array}{l}129(62.6 \%) \\
71(34.5 \%)\end{array}$ & $\begin{array}{l}397(71.3 \%) \\
149(26.8 \%)\end{array}$ & $\begin{array}{c}2227(74.5 \%) \\
678(22.7 \%)\end{array}$ \\
\hline & $\begin{array}{l}\text { Headache } \\
\text { No } \\
\text { Yes }\end{array}$ & $\begin{array}{l}43(20.9 \%) \\
153(74.3 \%)\end{array}$ & $\begin{array}{l}211(37.9 \%) \\
327(58.7 \%)\end{array}$ & $\begin{array}{l}1347(45.1 \%) \\
1534(51.3 \%)\end{array}$ \\
\hline & Pain other than headache $e^{a}$ & $.114(1.12)$ & $.054(1.00)$ & $-.100(.981)$ \\
\hline & Other somatic complaints ${ }^{a}$ & $.137(.976)$ & $.127(1.04)$ & $-.106(.957)$ \\
\hline
\end{tabular}




\subsection{Multicollinearity Analyses}

Prior to the logistic regression analyses, the degree of multicollinearity, or redundancy, between the independent variables was determined using the following two methods (cf. Glantz \& Slinker, 2001; Stevens, 2002). First, bivariate correlations were calculated for variables belonging to the same domain plus age and gender. In accordance with the literature, correlations exceeding $r=.80$ were seen as an indication of possible multicollinearity (Glantz \& Slinker, 2001; Tabachnik \& Fidell, 2001). Second, SPSS multicollinearity diagnostics were run for variables belonging to the same domain plus age and gender. This procedure yields a variance inflation factor (VIF) for each independent variable. The value of a variable's VIF indicates whether there is a linear association between it and the remaining variables. VIFs exceeding a value of 4 are viewed as worthy of investigation values of 10 or more as an indication of serious multicollinearity (Glantz \& Slinker, 2001). Correlation matrices and VIFs can be found in Appendix D.

\subsubsection{Age and Gender}

The intercorrelation between the control variables, age and gender, was close to null $(r=-.004)$, indicating together with the VIFs of 1.000 the absence of problematic multicollinearity.

\subsubsection{Sociodemographic Variables}

Moderate to high intercorrelations $(r=.494$ to $r=.628)$ between the constituent variables of socioeconomic position (education, occupational position, household net income) led to the decision to utilize the aggregate variable socioeconomic position in the analyses. Intercorrelations between control variables and sociodemographic variables (after aggregation of socioeconomic class) ranged from $r=-.169$ to $r=.022$ and VIFs from 1.001 to 1.029 , indicating the absence of problematic multicollinearity.

\subsubsection{Child Psychological Variables}

Moderate intercorrelations were found between a number of independent variables: Maladaptive coping strategies were moderately intercorrelated with one another $(r=.390$ to $r=.496)$ and with anxiety / depression $(r=.404$ to $r=.548)$. Furthermore, anger control was moderately intercorrelated with outward expression of anger $(r=-.552)$. However, as these subscales were designed to tap different constructs and the VIFs were satisfactory (1.073 to 1.974), the variables were maintained in their original form in the analyses.

\subsubsection{Child Health Variables}

Pain other than headache and other somatic complaints were moderately intercorrelated $(r=.529)$. However, as differentiation between pain and other somatic complaints was of particular relevance for the research focus on chronic headache and as the VIFs were satisfactory $(1.023$ to 1.428$)$, the separate indices were maintained in the analyses. 


\subsubsection{Family Variables}

Intercorrelations between control variables and family variables ranged from $r=-.126$ to $r=.488$ and VIFs from 1.000 to 1.526 , indicating the absence of problematic multicollinearity.

\subsubsection{School Variables}

Intercorrelations between control variables and school variables ranged from $r=-.112$ to $r=.359$ and VIFs from 1.021 to 1.273 , indicating the absence of problematic multicollinearity.

\subsubsection{Leisure Variables}

Intercorrelations between control variables and leisure variables ranged from $r=-.372$ to $r=.359$ and VIFs from 1.024 to 1.458 , indicating the absence of problematic multicollinearity.

\subsubsection{Life Events}

Intercorrelations between control variables and the index of life events ranged from $r=-.028$ to $r=-.004$ and the VIFs had values of 1.000 to 1.001 , indicating the absence of problematic multicollinearity.

\subsubsection{Parental Psychological Variables}

Moderate to high intercorrelations $(r=.522$ to $r=.668)$ between the individual items assessing anxieties and depressed mood and the mental health scale (CHQ-PF50) led to the decision to aggregate these to form an index of parental anxiety and depression. The aggregation was deemed appropriate as the contents of the five mental health items focused on anxiety and depression. Intercorrelations between control variables and parental psychological variables (after aggregation of anxiety and depression) ranged from $r=-.022$ to $r=.462$ with the exception of the pairwise correlation between anxiety / depression and habitual worry which reached $r=.624$. Despite the overlap, no further aggregation was performed because of the differing constructs tapped by the mental health scale and the PSWQ. The VIFs ranged from 1.001 to 1.862 , indicating the absence of problematic multicollinearity.

\subsubsection{Parental Health Variables}

Intercorrelations between control variables and parental health variables ranged from $r=-.334$ to $r=.420$ and VIFs from 1.001 to 1.351 , indicating the absence of problematic multicollinearity.

\subsection{Analyses Regarding Weekly Headache vs. Good Health}

\subsubsection{Age and Gender (Control Model)}

A direct logistic regression analysis was performed on health status as outcome (weekly headache vs. good health) and the control variables age and gender as predictors. Data from 
3,196 families were available for this analysis: 206 children with chronic headache and 2,990 healthy children.

A test of the control model against the constant-only model indicated that inclusion of the control variables, as a set, significantly improved model fit $\left(\chi_{2,3196}^{2}=77.94, p<.001\right)$. However, the amount of variance in health status accounted for by the control variables is small (Nagelkerke's $\mathrm{R}^{2}=.065$ ).

The odds ratios (OR), 99\% confidence intervals $(\mathrm{Cl})$, Wald statistics, and p-values for the control variables are presented in Table 8 . Weekly headache was significantly associated with both age $(\mathrm{OR}=1.27,99 \% \mathrm{Cl}=1.17-1.38)$ and gender $(\mathrm{OR}=2.12,99 \% \mathrm{Cl}=1.42-3.15)$.

Table 8. Association between weekly headache and age and gender

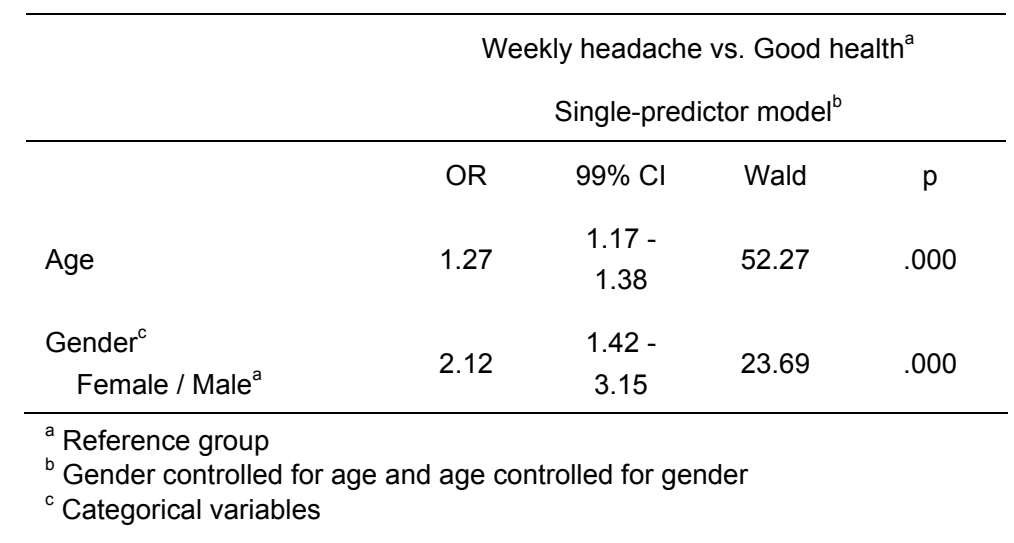

\subsubsection{Sociodemographic Variables}

Logistic regression analyses were performed on health status as outcome (weekly headache vs. good health), age and gender as control variables, and the following two sociodemographic variables as predictors: social class, household crowding index.

In the single-predictor model analyses, weekly headache was significantly associated with household crowding $\left(\mathrm{OR}=7.82^{8}, 99 \% \mathrm{Cl}=1.07-5.59\right)$. In addition, the association between weekly headache and the categorical variable social class approached significance, though the individual constituent contrasts did not (lower class vs. middle class; upper class vs. middle class; see Table 9, left-hand side).

In a second step, a sequential logistic regression analysis was performed on health status as outcome (weekly headache vs. good health), with age and gender as control variables in block one, and the sociodemographic variables in block two. Data from 2,967 families were available for analysis of the full model: 188 children with chronic headache and 2,779 healthy children.

A test of the full domain model (sociodemographic plus control variables) against the control model indicated that inclusion of the sociodemographic variables, as a set, significantly improved model fit $\left(\chi^{2}{ }_{5,2967}=12.32, p=.006\right)$. Nevertheless, the variance in health status accounted for by the full model is small (Nagelkerke's $R^{2}=.081$ ), and the

\footnotetext{
${ }^{8}$ Note that the large odds ratio is due to the unit of measurement.
} 
amount of variance accounted for by the sociodemographic variables (beyond that explained by age and gender) is minute (Nagelkerke's $\mathrm{R}^{2}=.011$ ).

Though inclusion of sociodemographic variables increased model fit, neither of the sociodemographic variables was significantly associated with weekly headache in the analysis of the full domain model. In other words, the multivariate analysis of the full domain model indicated that neither household crowding nor social class was independently associated with weekly headache (see Table 9, right-hand side).

Table 9. Association between weekly headache and sociodemographic variables

\begin{tabular}{|c|c|c|c|c|c|c|c|c|}
\hline & \multicolumn{8}{|c|}{ Weekly headache vs. Good health ${ }^{a}$} \\
\hline & \multicolumn{4}{|c|}{ Single-predictor model ${ }^{b}$} & \multicolumn{4}{|c|}{ Full domain model } \\
\hline & OR & $99 \% \mathrm{Cl}$ & Wald & $\mathrm{p}$ & OR & $99 \% \mathrm{Cl}$ & Wald & $\mathrm{p}$ \\
\hline Age & 1.27 & $\begin{array}{l}1.17- \\
1.38\end{array}$ & 52.27 & .000 & 1.29 & $\begin{array}{c}1.18- \\
1.41\end{array}$ & 53.06 & .000 \\
\hline $\begin{array}{l}\text { Gender }^{\mathrm{c}} \\
\quad \text { Female / Male }\end{array}$ & 2.12 & $\begin{array}{l}1.42- \\
3.15\end{array}$ & 23.69 & .000 & 2.26 & $\begin{array}{l}1.49- \\
3.45\end{array}$ & 25.12 & .000 \\
\hline Social class ${ }^{c}$ & & & 8.12 & .017 & & & 7.44 & .024 \\
\hline Lower / Middle class $\left.{ }^{\mathrm{a}}\right]$ & 1.62 & $\begin{array}{l}.83- \\
3.16\end{array}$ & 3.45 & .063 & 1.72 & $\begin{array}{l}.87- \\
3.41\end{array}$ & 4.17 & .041 \\
\hline Upper / Middle class ${ }^{a}$ & .78 & $\begin{array}{l}.52- \\
1.18\end{array}$ & 2.36 & .125 & .81 & $\begin{array}{l}.53- \\
1.25\end{array}$ & 1.54 & .215 \\
\hline $\begin{array}{l}\text { Household crowding } \\
\text { index }\end{array}$ & 2.45 & $\begin{array}{l}1.07- \\
5.59\end{array}$ & 7.82 & .005 & 1.74 & $\begin{array}{l}.71- \\
4.26\end{array}$ & 2.53 & .111 \\
\hline
\end{tabular}

${ }^{\text {a }}$ Reference group

${ }^{\mathrm{b}}$ All variables controlled for age and gender, except gender (controlled for age) and age (controlled for gender)

${ }^{\mathrm{C}}$ Categorical variables

\subsubsection{Child Psychological Variables}

Logistic regression analyses were performed on health status as outcome (weekly headache vs. good health), with age and gender as control variables, for each of the following eleven child psychological variables: passive avoidance, rumination, resignation, aggression, anger-in, anger-out, anger control, anxiety/depression, hyperactivity, aggressive behavior, sleep disturbance.

In the single-predictor model analyses, an increased risk of weekly headache was significantly associated with the four maladaptive coping strategies: passive avoidance $(\mathrm{OR}=1.51,99 \% \mathrm{Cl}=1.28-1.77)$, rumination $(\mathrm{OR}=1.49,99 \% \mathrm{Cl}=1.23-1.82)$, resignation $(\mathrm{OR}=1.47,99 \% \mathrm{Cl}=1.24-1.73)$, and aggression $(\mathrm{OR}=1.44,99 \% \mathrm{Cl}=1.19-1.74)$. Weekly headache was also associated with child's anxiety/depression $(\mathrm{OR}=1.70,99 \% \mathrm{Cl}=1.43$ 2.03), hyperactivity $(\mathrm{OR}=1.34,99 \% \mathrm{Cl}=1.10-1.63)$, aggressive behavior $(\mathrm{OR}=1.26,99 \%$ $\mathrm{Cl}=1.04-1.53)$, and sleep disturbance $(\mathrm{OR}=1.50,99 \% \mathrm{Cl}=1.27-1.77)$. Furthermore, the association between increased risk of weekly headache and anger-in (OR $=1.19,99 \%$ $\mathrm{Cl}=$.99-1.43) approached significance. However, anger out was not associated with weekly headache, and anger control was associated with a reduced risk of weekly headache 
$(\mathrm{OR}=.83,99 \% \mathrm{Cl}=.68-1.00)$. The results of the single-predictor model analyses are presented in Table 10 (left-hand side).

Then, a sequential logistic regression analysis was performed with age and gender as control variables in block one, and the eleven child psychological variables as predictors in block two. Data from 2,750 families were available for analysis: 182 children with weekly headache and 2,568 healthy children.

Table 10. Association between weekly headache and child psychological variables

\begin{tabular}{|c|c|c|c|c|c|c|c|c|}
\hline & \multicolumn{8}{|c|}{ Weekly headache vs. Good health ${ }^{\mathrm{a}}$} \\
\hline & \multicolumn{4}{|c|}{ Single-predictor model ${ }^{b}$} & \multicolumn{4}{|c|}{ Full domain model } \\
\hline & OR & $99 \% \mathrm{Cl}$ & Wald & $\mathrm{p}$ & OR & $99 \% \mathrm{Cl}$ & Wald & $\mathrm{p}$ \\
\hline Age & 1.27 & $\begin{array}{l}1.17- \\
1.38\end{array}$ & 52.27 & .000 & 1.25 & $\begin{array}{l}1.13- \\
1.37\end{array}$ & 34.47 & .000 \\
\hline $\begin{array}{l}\text { Gender }^{\mathrm{C}} \\
\quad \text { Female } / \text { Male }^{\mathrm{a}}\end{array}$ & 2.12 & $\begin{array}{l}1.42- \\
3.15\end{array}$ & 23.69 & .000 & 2.16 & $\begin{array}{l}1.35- \\
3.44\end{array}$ & 17.87 & .000 \\
\hline \multicolumn{9}{|l|}{ Maladaptive coping } \\
\hline Passive avoidance $^{d}$ & 1.51 & $\begin{array}{c}1.28- \\
1.77\end{array}$ & 43.43 & .000 & 1.15 & $\begin{array}{l}.92- \\
1.43\end{array}$ & 2.73 & .099 \\
\hline Rumination $^{d}$ & 1.49 & $\begin{array}{c}1.23- \\
1.82\end{array}$ & 27.42 & .000 & 1.16 & $\begin{array}{l}.89- \\
1.52\end{array}$ & 2.16 & .141 \\
\hline Resignation $^{d}$ & 1.47 & $\begin{array}{c}1.24- \\
1.73\end{array}$ & 35.54 & .000 & 1.04 & $\begin{array}{l}.81- \\
1.34\end{array}$ & .15 & .704 \\
\hline Aggression $^{d}$ & 1.44 & $\begin{array}{c}1.19- \\
1.74\end{array}$ & 23.90 & .000 & 1.03 & $\begin{array}{l}.77- \\
1.37\end{array}$ & .06 & .808 \\
\hline \multicolumn{9}{|l|}{ Anger expression } \\
\hline Anger-in $^{d}$ & 1.19 & $\begin{array}{l}.99- \\
1.43\end{array}$ & 5.73 & .017 & 1.01 & $\begin{array}{l}.79- \\
1.29\end{array}$ & .01 & .932 \\
\hline Anger-out $^{d}$ & 1.07 & $\begin{array}{l}.88- \\
1.29\end{array}$ & .80 & .372 & .71 & $.54-.94$ & 9.84 & .002 \\
\hline Anger control $^{d}$ & .83 & $\begin{array}{l}.68- \\
1.00\end{array}$ & 6.70 & .010 & .81 & $\begin{array}{l}.62- \\
1.05\end{array}$ & 4.33 & .038 \\
\hline Anxiety/depression ${ }^{d}$ & 1.70 & $\begin{array}{l}1.43- \\
2.03\end{array}$ & 61.82 & .000 & 1.41 & $\begin{array}{c}1.08- \\
1.84\end{array}$ & 11.25 & .001 \\
\hline Hyperactivity $^{d}$ & 1.34 & $\begin{array}{c}1.10- \\
1.63\end{array}$ & 14.23 & .000 & 1.00 & $\begin{array}{l}.76- \\
1.33\end{array}$ & .00 & .995 \\
\hline Aggressive behavior $^{d}$ & 1.26 & $\begin{array}{c}1.04- \\
1.53\end{array}$ & 9.28 & .002 & 1.11 & $\begin{array}{l}.87- \\
1.42\end{array}$ & 1.24 & .266 \\
\hline Sleep disturbance ${ }^{d}$ & 1.50 & $\begin{array}{c}1.27- \\
1.77\end{array}$ & 38.65 & .000 & 1.37 & $\begin{array}{c}1.13- \\
1.66\end{array}$ & 17.57 & .000 \\
\hline
\end{tabular}

${ }^{\text {a }}$ Reference group

${ }^{\mathrm{b}}$ All variables controlled for age and gender, except gender (controlled for age) and age (controlled for gender)

${ }^{\mathrm{c}}$ Categorical variables

' Z-scores

A test of the full domain model (child psychological plus control variables) against the control model indicated that inclusion of the psychological variables, as a set, significantly 
improved model fit $\left(\chi_{11,2568}^{2}=93.71, p<.001\right)$. The variance in health status accounted for by the full model is moderate (Nagelkerke's $R^{2}=.149$ ), and the amount of variance accounted for by the psychological variables alone is small (Nagelkerke's $R^{2}=.084$ ).

In the multivariate analysis of the full domain model, increased risk of weekly headache was associated with child's anxiety/depression ( $\mathrm{OR}=1.49,99 \% \mathrm{Cl}=1.08-1.84)$, and sleep disturbance $(\mathrm{OR}=1.49,99 \% \mathrm{Cl}=1.13-1.66)$. On the other hand, a reduced risk of weekly headache was significantly associated with the outward expression of anger $(\mathrm{OR}=1.49,99 \% \mathrm{Cl}=.54-.94)$. However, the pattern of results indicated that anger-out is a traditional suppressor variable (Bortz, 1989): Examined alone (in the single-predictor model) it is not significantly associated with health outcome, but in the full model anger-out became significantly negatively associated with weekly headache. As anger out is moderately correlated with the other domain variables ( $r=.169$ to $r=.459$, see also Appendix $D$ ), it can be presumed that anger-out suppresses some of what would otherwise be error variance in the other domain variables. None of the other child psychological variables were significantly associated with weekly headache. In other words, The variables passive avoidance, rumination, resignation, aggression, anger-in, anger control, hyperactivity, and aggressive behavior were not independently associated with weekly headache in the multivariate analysis of the full model (see Table 10, right-hand side).

\subsubsection{Child Health Variables}

The child health variables pain other than headache and other somatic complaints were examined in logistic regression analyses together with age and gender as control variables and health status (weekly headache vs. good health) as the outcome variable..

In the single-predictor model analyses, an increased risk of weekly headache was significantly associated with both health variables; pain other than headache $(O R=2.24$, $99 \% \mathrm{Cl}=1.88-2.67)$, other somatic complaints $(\mathrm{OR}=2.24,99 \% \mathrm{Cl}=1.87-2.70)$.

Table 11. Association between weekly headache and child health variables

\begin{tabular}{|c|c|c|c|c|c|c|c|c|}
\hline & \multicolumn{8}{|c|}{ Weekly headache vs. Good health ${ }^{\mathrm{a}}$} \\
\hline & \multicolumn{4}{|c|}{ Single-predictor model ${ }^{b}$} & \multicolumn{4}{|c|}{ Full domain model } \\
\hline & OR & $99 \% \mathrm{Cl}$ & Wald & $p$ & OR & $99 \% \mathrm{Cl}$ & Wald & $\mathrm{p}$ \\
\hline Age & 1.27 & $\begin{array}{c}1.17- \\
1.38\end{array}$ & 52.27 & .000 & 1.19 & $\begin{array}{c}1.08- \\
1.31\end{array}$ & 21.70 & .000 \\
\hline $\begin{array}{l}\text { Gender }^{\mathrm{c}} \\
\text { Female / Male }^{\mathrm{a}}\end{array}$ & 2.12 & $\begin{array}{l}1.42- \\
3.15\end{array}$ & 23.69 & .000 & 1.53 & $\begin{array}{l}.98- \\
2.39\end{array}$ & 6.02 & .014 \\
\hline $\begin{array}{l}\text { Pain other than } \\
\text { headache }^{d}\end{array}$ & 2.24 & $\begin{array}{c}1.88- \\
2.67\end{array}$ & 138.79 & .000 & 1.72 & $\begin{array}{l}1.39- \\
2.13\end{array}$ & 43.66 & .000 \\
\hline Other somatic complaints $^{d}$ & 2.24 & $\begin{array}{c}1.87- \\
2.70\end{array}$ & 127.89 & .000 & 1.70 & $\begin{array}{c}1.37- \\
2.12\end{array}$ & 39.98 & .000 \\
\hline
\end{tabular}

\footnotetext{
${ }^{a}$ Reference group

${ }^{\mathrm{b}}$ All variables controlled for age and gender, except gender (controlled for age) and age (controlled for gender)

${ }^{\mathrm{c}}$ Categorical variables

${ }^{d}$ Z-scores
} 
In a subsequent step, a sequential logistic regression analysis was performed on health status as outcome (weekly headache vs. good health), with age and gender as control variables in block one, and the two child health variables as predictors in block two. Data from 3,002 families were available for this analysis: 183 children with chronic headache and 2,819 healthy children.

A test of the full domain model (child health and control variables) against the control model (age, gender, and constant) indicated that inclusion of the child health variables, as a set, significantly improved model fit $\left(\chi_{2,3002}^{2}=167.71, p<.001\right)$. The variance in health status accounted for by the full model is moderate (Nagelkerke's $R^{2}=.206$ ), as is the amount of variance accounted for by the child health variables (Nagelkerke's $R^{2}=.145$ ).

In the multivariate analysis of the full domain model, increased risk of weekly headache was again significantly associated with both child health variables, pain other than headache $(\mathrm{OR}=1.72,99 \% \mathrm{Cl}=1.39-2.13)$, and other somatic complaints $(\mathrm{OR}=1.70,99 \%$ $\mathrm{Cl}=1.37-2.12$; see Table 11, right-hand side).

\subsubsection{Family Variables}

Using the same outcome variable (weekly headache vs. good health) and age and gender as control variables, each of the following five family variables was examined via logistic regression: number of parents in the household, number of other children in the household, negative family environment, negative family conflict solving strategies, and weekly family conflict.

In the single-predictor model analyses, increased risk of weekly headache was associated with a negative family environment $(\mathrm{OR}=1.21,99 \% \mathrm{Cl}=1.00-1.46)$ and the presence of weekly family conflict $(\mathrm{OR}=1.69,99 \% \mathrm{Cl}=1.12-2.53)$. In addition, the association between increased risk of weekly headache and negative family conflict solving strategies $(\mathrm{OR}=1.19,99 \% \mathrm{Cl}=.99-1.43)$ approached significance. On the other hand, weekly headache was not associated with the number of parents or children in the household (see Table 12, left-hand side).

In a second step, a sequential logistic regression analysis was performed with age and gender as control variables in block one, and all six family variables as predictors of health status (weekly headache vs. good health) in block two. Data from 3,048 families were available for the analysis of this domain: 195 children with weekly headache and 2,853 healthy children.

A test of the full domain model (family plus control variables) against the control model indicated that inclusion of family variables, as a set, significantly improved model fit $\left(\chi_{5,3048}^{2}=12.81, p=.011\right)$. However, the variance in health status accounted for by the full model is small (Nagelkerke's $R^{2}=.078$ ) and the variance accounted for by family variables alone is minute (Nagelkerke's $\mathrm{R}^{2}=.013$ ). 
Table 12. Association between weekly headache and family variables

\begin{tabular}{|c|c|c|c|c|c|c|c|c|}
\hline & \multicolumn{8}{|c|}{ Weekly headache vs. Good health ${ }^{a}$} \\
\hline & \multicolumn{4}{|c|}{ Single-predictor model ${ }^{b}$} & \multicolumn{4}{|c|}{ Full domain model } \\
\hline & OR & $99 \% \mathrm{Cl}$ & Wald & $\mathrm{p}$ & OR & $99 \% \mathrm{Cl}$ & Wald & $\mathrm{p}$ \\
\hline Age & 1.27 & $\begin{array}{c}1.17- \\
1.38\end{array}$ & 52.27 & .000 & 1.26 & $\begin{array}{c}1.16- \\
1.38\end{array}$ & 47.15 & .000 \\
\hline $\begin{array}{l}\text { Gender }^{\mathrm{c}} \\
\quad \text { Female / Male }\end{array}$ & 2.12 & $\begin{array}{l}1.42- \\
3.15\end{array}$ & 23.69 & .000 & 2.16 & $\begin{array}{l}1.43- \\
3.25\end{array}$ & 23.23 & .000 \\
\hline $\begin{array}{l}\text { Number of parents in } \\
\text { household } \\
\text { One } / \text { Two }^{\mathrm{a}}\end{array}$ & 1.17 & $\begin{array}{l}.70- \\
1.98\end{array}$ & .62 & .430 & 1.15 & $\begin{array}{l}.68- \\
1.97\end{array}$ & .47 & .491 \\
\hline $\begin{array}{l}\text { Number of children in } \\
\text { household }\end{array}$ & 1.02 & $\begin{array}{l}.82- \\
1.27\end{array}$ & .06 & .807 & 1.01 & $\begin{array}{l}.82- \\
1.26\end{array}$ & .02 & .884 \\
\hline $\begin{array}{l}\text { Negative family } \\
\text { environment }^{d}\end{array}$ & 1.21 & $\begin{array}{c}1.00- \\
1.46\end{array}$ & 6.85 & .009 & 1.17 & $\begin{array}{l}.94- \\
1.45\end{array}$ & 3.24 & .072 \\
\hline $\begin{array}{l}\text { Negative conflict solving } \\
\text { strategies }^{d}\end{array}$ & 1.19 & $\begin{array}{l}.99- \\
1.43\end{array}$ & 6.08 & .014 & 1.03 & $\begin{array}{l}.82- \\
1.30\end{array}$ & .10 & .752 \\
\hline $\begin{array}{l}\text { Weekly family conflict } \\
\text { Yes } / \mathrm{No}^{\mathrm{a}}\end{array}$ & 1.69 & $\begin{array}{l}1.12- \\
2.53\end{array}$ & 11.03 & .001 & 1.46 & $\begin{array}{l}.91- \\
2.35\end{array}$ & 4.17 & .041 \\
\hline
\end{tabular}

${ }^{a}$ Reference group

${ }^{\mathrm{b}}$ All variables controlled for age and gender, except gender (controlled for age) and age (controlled for gender)

${ }^{\mathrm{C}}$ Categorical variables

${ }^{\mathrm{d}}$ Z-scores

Though inclusion of family variables increased model fit, none of the individual family variables was significantly associated with weekly headache. In other words, the multivariate analysis indicated that the variables number of parents in household, number of other children in household, negative family environment, negative conflict solving strategies, and weekly family conflict were not independently associated with weekly headache (see Table 12, right-hand side).

\subsubsection{School Variables}

Logistic regression analyses were performed on health status (weekly headache vs. good health) as outcome, with age and gender as control variables, and each of the following four school variables: index of school difficulties, time spent on homework, school stress, and reaction to failure.

In the analyses of the single-predictor models, an increased risk of weekly headache was significantly associated with the index of school problems $(\mathrm{OR}=1.64,99 \% \mathrm{Cl}=1.27$ 2.12), school stress $(\mathrm{OR}=1.77,99 \% \mathrm{Cl}=1.48-2.12)$, and reaction to failure $(\mathrm{OR}=1.42$, $99 \% \mathrm{Cl}=1.17-1.72)$. In addition, an increased risk of weekly headache was significantly associated with the categorical variable time spent on homework, as a whole, and with the constituent contrast " $>3$ hours" as opposed to " $<1$ hour" spent on homework (OR $=9.94$, $99 \% \mathrm{Cl}=2.02-48.94)$. The other constituent contrasts were not significantly associated with weekly headache (see Table 13, left-hand side). 
A sequential logistic regression analysis was then performed on health status (weekly headache vs. good health) as outcome, with age and gender as control variables in block one, and the four school variables as predictors in block two. Data from 2,884 families were available for analysis: 185 children with chronic headache and 2,699 healthy children.

A test of the full domain model (school and control variables) against the control model indicated that the inclusion of school variables, as a set, significantly improved model fit $\left(\chi^{2} 6,2884=82.977, p<.001\right)$. The variance in health status accounted for by the full model is moderate (Nagelkerke's $R^{2}=.138$ ), and the amount of variance accounted for by the school variables alone is small (Nagelkerke's $R^{2}=.073$ ).

In the multivariate analysis of the full domain model, increased risk of weekly headache was significantly associated with school stress $(\mathrm{OR}=1.66,99 \% \mathrm{Cl}=1.34-2.05)$. In addition, the association between weekly headache and the categorical variable time spent on homework, as a whole, approached significance. Once again, weekly headache was significantly associated with " $>3$ hours" as opposed to " $<1$ hour" spent on homework $(\mathrm{OR}=9.94,99 \% \mathrm{Cl}=1.19-41.29)$. The other constituent contrasts did not yield significant associations with weekly headache. In addition, the multivariate analysis of the full model indicated that neither school difficulties nor reaction to failure were independently associated with weekly headache (see Table 13 , right-hand side).

Table 13. Association between weekly headache and school variables

\begin{tabular}{|c|c|c|c|c|c|c|c|c|}
\hline & \multicolumn{8}{|c|}{ Weekly headache vs. Good health ${ }^{a}$} \\
\hline & \multicolumn{4}{|c|}{ Single-predictor model ${ }^{\mathrm{b}}$} & \multicolumn{4}{|c|}{ Full domain model } \\
\hline & OR & $99 \% \mathrm{Cl}$ & Wald & $p$ & OR & $99 \% \mathrm{Cl}$ & Wald & $p$ \\
\hline Age & 1.27 & $\begin{array}{c}1.17- \\
1.38\end{array}$ & 52.27 & .000 & 1.24 & $\begin{array}{c}1.13- \\
1.37\end{array}$ & 35.09 & .000 \\
\hline $\begin{array}{l}\text { Gender }^{c} \\
\text { female / male }\end{array}$ & 2.12 & $\begin{array}{l}1.42- \\
3.15\end{array}$ & 23.69 & .000 & 2.43 & $\begin{array}{l}1.56- \\
3.77\end{array}$ & 27.02 & .000 \\
\hline Index of school difficulties & 1.64 & $\begin{array}{l}1.27- \\
2.12\end{array}$ & 24.47 & .000 & 1.17 & $\begin{array}{l}.88- \\
1.57\end{array}$ & 1.96 & .162 \\
\hline Time spent on homework $^{c}$ & & & 17.73 & .000 & & & 10.36 & .016 \\
\hline $1-2$ hours $/<1$ hour $^{a}$ & 1.21 & $\begin{array}{l}.80- \\
1.84\end{array}$ & 1.39 & .239 & 1.07 & $\begin{array}{l}.69- \\
1.66\end{array}$ & .14 & .709 \\
\hline 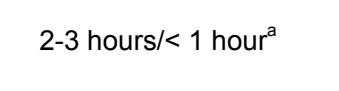 & 1.94 & $\begin{array}{l}.89- \\
4.22\end{array}$ & 4.77 & .029 & 1.72 & $\begin{array}{l}.74- \\
3.98\end{array}$ & 2.77 & .096 \\
\hline$>3$ hours $/<1$ hour $^{a}$ & 9.94 & $\begin{array}{l}2.02- \\
48.94\end{array}$ & 13.76 & .000 & 7.01 & $\begin{array}{l}1.19- \\
41.29\end{array}$ & 8.01 & .005 \\
\hline School stress $^{d}$ & 1.77 & $\begin{array}{l}1.48- \\
2.12\end{array}$ & 67.74 & .000 & 1.66 & $\begin{array}{l}1.34- \\
2.05\end{array}$ & 36.80 & .000 \\
\hline Reaction to failure $^{d}$ & 1.42 & $\begin{array}{c}1.17 \text { - } \\
1.72\end{array}$ & 22.14 & .000 & 1.20 & $\begin{array}{l}.95- \\
1.50\end{array}$ & 4.15 & .042 \\
\hline
\end{tabular}

\footnotetext{
${ }^{\text {a }}$ Reference group

${ }^{\mathrm{b}}$ All variables controlled for age and gender, except gender (controlled for age) and age (controlled for gender)

${ }^{\mathrm{c}}$ Categorical variables

d Z-scores
} 


\subsubsection{Leisure Variables}

Using the outcome variable health status (weekly headache vs. good health) and age and gender as control variables, each of the following six leisure variables was examined via logistic regression: physical activities, other recreational activities, amount of free time, time spent on TV/video, time spent on computer/game console, and amount of friends.

In the analyses of the single-predictor models, an increased risk of weekly headache was significantly associated with time spent on $T V /$ video $(O R=1.30,99 \% \mathrm{Cl}=1.07-1.58)$. None of the other leisure variables were significantly associated with weekly headache. In other words, the analyses of single-predictor models indicated that physical activities, recreational activities, amount of free time, time spent on computer/game console, and amount of friends were not significantly associated with weekly headache (see Table 14, lefthand side).

In a second step, sequential logistic regression analysis was performed on health status as outcome (weekly headache vs. good health), with age and gender as control variables in block one, and the six leisure variables as predictors in block two. Data from 2,967 families were available for analysis: 186 children with chronic headache and 2,781 healthy children.

Table 14. Association between weekly headache and leisure variables

\begin{tabular}{|c|c|c|c|c|c|c|c|c|}
\hline & \multicolumn{8}{|c|}{ Weekly headache vs. Good health ${ }^{a}$} \\
\hline & \multicolumn{4}{|c|}{ Single-predictor model ${ }^{\mathrm{b}}$} & \multicolumn{4}{|c|}{ Full domain model } \\
\hline & OR & $99 \% \mathrm{Cl}$ & Wald & $P$ & OR & $99 \% \mathrm{Cl}$ & Wald & $\mathrm{p}$ \\
\hline Age & 1.27 & $\begin{array}{l}1.17- \\
1.38\end{array}$ & 52.27 & .000 & 1.22 & $\begin{array}{c}1.10- \\
1.34\end{array}$ & 25.97 & .000 \\
\hline $\begin{array}{l}\text { Gender }^{\mathrm{c}} \\
\text { Female / Male }\end{array}$ & 2.12 & $\begin{array}{l}1.42- \\
3.15\end{array}$ & 23.69 & .000 & 1.86 & $\begin{array}{c}1.14- \\
3.05\end{array}$ & 10.65 & .001 \\
\hline Physical activities $^{d}$ & .98 & $\begin{array}{l}.81- \\
1.18\end{array}$ & .10 & .752 & 1.01 & $\begin{array}{l}.83- \\
1.24\end{array}$ & .03 & .873 \\
\hline Recreational activities $^{d}$ & .99 & $\begin{array}{l}.80- \\
1.23\end{array}$ & .01 & .939 & 1.05 & $\begin{array}{l}.83- \\
1.33\end{array}$ & .27 & .603 \\
\hline Amount of free time $^{d}$ & .87 & $\begin{array}{l}.72- \\
1.04\end{array}$ & 4.03 & .045 & .78 & $.64-.96$ & 9.57 & .002 \\
\hline Time spent on TV / video ${ }^{d}$ & 1.30 & $\begin{array}{c}1.07- \\
1.58\end{array}$ & 11.74 & .001 & 1.40 & $\begin{array}{c}1.12- \\
1.75\end{array}$ & 14.62 & .000 \\
\hline $\begin{array}{l}\text { Time spent on computer / } \\
\text { game console }{ }^{d}\end{array}$ & .96 & $\begin{array}{l}.77- \\
1.20\end{array}$ & .19 & .660 & .89 & $\begin{array}{l}.70- \\
1.13\end{array}$ & 1.58 & .209 \\
\hline Amount of friends ${ }^{c}$ & & & 5.75 & .057 & & & 5.34 & .069 \\
\hline $0-1$ friends $/ 2-5$ friends $^{a}$ & 1.70 & $\begin{array}{l}.89- \\
3.25\end{array}$ & 4.52 & .034 & 1.69 & $\begin{array}{l}.87- \\
3.29\end{array}$ & 4.14 & .042 \\
\hline$>5$ friends $/ 2-5$ friends $^{a}$ & 1.30 & $\begin{array}{l}.86- \\
1.98\end{array}$ & 2.70 & .101 & 1.30 & $\begin{array}{l}.85- \\
2.01\end{array}$ & 2.48 & .115 \\
\hline
\end{tabular}

\footnotetext{
${ }^{a}$ Reference group

${ }^{\mathrm{b}}$ All variables controlled for age and gender, except gender (controlled for age) and age (controlled for gender)

${ }^{\mathrm{C}}$ Categorical variables

${ }^{\mathrm{d}}$ Z-scores
} 
A test of the full domain model (leisure and control variables) against the control model indicated that inclusion of leisure variables, as a set, significantly improved model fit $\left(\chi^{2} 7,2967=26.15, p<.001\right)$. However, the variance in health status accounted for by the full model is small (Nagelkerke's $R^{2}=.084$ ), and the amount of variance accounted for by the leisure variables in addition to age and gender is minimal (Nagelkerke's $R^{2}=.023$ ).

In the multivariate analysis of the full domain model, increased risk of weekly headache was significantly associated with the amount of time spent on TV / video $(\mathrm{OR}=1.40,99 \% \mathrm{Cl}=1.12-1.75)$. On the other hand, a reduced risk of weekly headache was significantly associated with amount of free time $(\mathrm{OR}=.78,99 \% \mathrm{Cl}=.64-.96)$. Finally, the multivariate analysis of the full model indicated that physical activities, recreational activities, time spent on computer/game console, and amount of friends were not significantly associated with weekly headache (see Table 14, right-hand side).

\subsubsection{Life Events}

As an index was calculated to quantify the number of life events experienced by the child and this index is the only variable of the domain, the first step of analyzing singlepredictor models became unnecessary. Therefore, the statistical analysis began with a sequential logistic regression performed on health status (weekly headache vs. good health) as outcome, with age and gender as control variables, and the index of life events as a predictor. Data from 2,939 families were available for analysis: 206 children with chronic headache and 2,990 children in good health.

A test of the full domain model (index of life events and control variables) against the control model indicated that inclusion of the index significantly improved model fit $\left(\chi^{2}\right.$, $2990=18.012, p<.001)$. However, the variance in health status accounted for by the full model is small (Nagelkerke's $R^{2}=.079$ ), and the amount of variance accounted for by the index of life events alone is minimal (Nagelkerke's $R^{2}=.014$ ). Nevertheless, the multivariate analysis of the full domain model indicated that increased risk of weekly headache was significantly associated with the number of life events experienced by the child $(O R=1.29$, $99 \% \mathrm{Cl}=1.11-1.50 ;$ see Table 15, right-hand side).

Table 15. Association between weekly headache and life events

\begin{tabular}{|c|c|c|c|c|c|c|c|c|}
\hline & \multicolumn{8}{|c|}{ Weekly headache vs. Good health ${ }^{a}$} \\
\hline & \multicolumn{4}{|c|}{ Single-predictor model ${ }^{b}$} & \multicolumn{4}{|c|}{ Full domain model } \\
\hline & OR & $99 \% \mathrm{Cl}$ & Wald & $\mathrm{p}$ & OR & $99 \% \mathrm{Cl}$ & Wald & $\mathrm{p}$ \\
\hline Age & 1.27 & $\begin{array}{l}1.17- \\
1.38\end{array}$ & 52.27 & .000 & 1.28 & $\begin{array}{l}1.17- \\
1.39\end{array}$ & 54.76 & .000 \\
\hline $\begin{array}{l}\text { Gender }^{\mathrm{c}} \\
\quad \text { Female / Male }\end{array}$ & 2.12 & $\begin{array}{l}1.42- \\
3.15\end{array}$ & 23.69 & .000 & 2.13 & $\begin{array}{l}1.43- \\
3.18\end{array}$ & 24.03 & .000 \\
\hline Index of life events & & & & & 1.29 & $\begin{array}{c}1.11- \\
1.50\end{array}$ & 19.36 & .000 \\
\hline
\end{tabular}

\footnotetext{
${ }^{a}$ Reference group

${ }^{\mathrm{b}}$ All variables controlled for age and gender, except gender (controlled for age) and age (controlled for gender)

${ }^{\mathrm{c}}$ Categorical variables
} 


\subsubsection{Parental Psychological Variables}

Logistic regression analyses were performed on health status (weekly headache vs. good health) as outcome, with age and gender as control variables, and each of the following three parental psychological variables: parental anxiety/depression (index), parental habitual worry, and parental sleep disturbance.

In the single-predictor model analyses, increased risk of weekly headache was significantly associated with each of the investigated parental psychological variables: parental anxiety/depression (index) $(\mathrm{OR}=1.51,99 \% \mathrm{Cl}=1.25-1.82)$, parental habitual worry $(\mathrm{OR}=1.44,99 \% \mathrm{Cl}=1.20-1.73)$, and parental sleep disturbance $(\mathrm{OR}=1.35,99 \% \mathrm{Cl}=1.13$ 1.63; see Table 16, left-hand side).

Then a sequential logistic regression analysis was performed on health status as outcome, with age and gender as control variables in block one, and the parental psychological variables as predictors in block two. Data from 3,044 families were available for analysis: 195 children with chronic headache and 2,849 healthy children.

Table 16. Association between weekly headache and parental psychological variables

\begin{tabular}{|c|c|c|c|c|c|c|c|c|}
\hline & \multicolumn{8}{|c|}{ Weekly headache vs. Good health ${ }^{a}$} \\
\hline & \multicolumn{4}{|c|}{ Single-predictor model ${ }^{\mathrm{b}}$} & \multicolumn{4}{|c|}{ Full domain model } \\
\hline & OR & $99 \% \mathrm{Cl}$ & Wald & $p$ & OR & $99 \% \mathrm{Cl}$ & Wald & $\mathrm{p}$ \\
\hline Age & 1.27 & $\begin{array}{c}1.17- \\
1.38\end{array}$ & 52.27 & .000 & 1.27 & $\begin{array}{c}1.16- \\
1.38\end{array}$ & 48.34 & .000 \\
\hline $\begin{array}{l}\text { Gender }^{\mathrm{c}} \\
\quad \text { Female / Male }\end{array}$ & 2.12 & $\begin{array}{l}1.42- \\
3.15\end{array}$ & 23.69 & .000 & 2.16 & $\begin{array}{l}1.43- \\
3.26\end{array}$ & 23.31 & .000 \\
\hline $\begin{array}{l}\text { Anxiety / depression } \\
(\text { index) })^{d}\end{array}$ & 1.51 & $\begin{array}{c}1.25- \\
1.82\end{array}$ & 31.75 & .000 & 1.26 & $\begin{array}{l}.98- \\
1.62\end{array}$ & 5.42 & .020 \\
\hline Habitual worry ${ }^{d}$ & 1.44 & $\begin{array}{c}1.20- \\
1.73\end{array}$ & 25.38 & .000 & 1.20 & $\begin{array}{l}.95- \\
1.53\end{array}$ & 3.92 & .048 \\
\hline Sleep disturbance $^{d}$ & 1.35 & $\begin{array}{c}1.13- \\
1.63\end{array}$ & 17.85 & .000 & 1.17 & $\begin{array}{l}.95- \\
1.44\end{array}$ & 3.53 & .060 \\
\hline
\end{tabular}

${ }^{a}$ Reference group

${ }^{\mathrm{b}}$ All variables controlled for age and gender, except gender (controlled for age) and age (controlled for gender)

${ }^{\mathrm{C}}$ Categorical variables

${ }^{\mathrm{d}}$ Z-scores

A test of the full domain model (parental psychological and control variables) against the control model (age, gender, and constant) indicated that inclusion of parental psychological variables, as a set, significantly improved model fit $\left(\chi^{2} 3,3044=38.09, p<.001\right)$. However, the variance in health status accounted for by the full model is small (Nagelkerke's $\left.\mathrm{R}^{2}=.095\right)$, as is the amount of variance accounted for by the parental psychological variables (Nagelkerke's $R^{2}=.032$ ).

Though inclusion of parental psychological variables increased model fit, none of the individual variables was significantly associated with weekly headache. In other words, the multivariate analysis of the full domain model indicated that parental anxiety/depression, 
parental habitual worry, and parental sleep disturbance were not independently associated with weekly headache (see Table 16, right-hand side)

\subsubsection{Parental Health Variables}

Using health status (weekly headache vs. good health) as the outcome variable, and age and gender as control variables, each of the following six parental health variables was examined via logistic regression: general health, doctor appointments, regular medication, headache, pain other than headache, and other somatic complaints.

Table 17. Association between weekly headache and parental health variables

\begin{tabular}{|c|c|c|c|c|c|c|c|c|}
\hline & \multicolumn{8}{|c|}{ Weekly headache vs. Good health ${ }^{a}$} \\
\hline & \multicolumn{4}{|c|}{ Single-predictor model ${ }^{b}$} & \multicolumn{4}{|c|}{ Full domain model } \\
\hline & OR & $99 \% \mathrm{Cl}$ & Wald & $\mathrm{p}$ & OR & $99 \% \mathrm{Cl}$ & Wald & $\mathrm{p}$ \\
\hline Age & 1.27 & $\begin{array}{l}1.17- \\
1.38\end{array}$ & 52.27 & .000 & 1.24 & $\begin{array}{c}1.13- \\
1.35\end{array}$ & 36.80 & .000 \\
\hline $\begin{array}{l}\text { Gender }^{\mathrm{c}} \\
\quad \text { Female / Male }\end{array}$ & 2.12 & $\begin{array}{l}1.42- \\
3.15\end{array}$ & 23.69 & .000 & 2.16 & $\begin{array}{l}1.41- \\
3.30\end{array}$ & 21.72 & .000 \\
\hline General heath $^{d}$ & .79 & $.66-.95$ & 11.49 & .001 & .92 & $\begin{array}{l}.75- \\
1.15\end{array}$ & .88 & .348 \\
\hline $\begin{array}{l}\text { Number of doctor } \\
\text { appointments }^{d}\end{array}$ & 1.20 & $\begin{array}{c}1.05- \\
1.38\end{array}$ & 12.62 & .000 & 1.16 & $\begin{array}{l}.99- \\
1.36\end{array}$ & 5.68 & .017 \\
\hline $\begin{array}{l}\text { Regular medication }{ }^{\mathrm{c}} \\
\text { Yes } / \mathrm{No}^{\mathrm{a}}\end{array}$ & 1.71 & $\begin{array}{l}1.14- \\
2.56\end{array}$ & 11.62 & .001 & 1.40 & $\begin{array}{l}.86- \\
2.27\end{array}$ & 3.19 & .074 \\
\hline $\begin{array}{l}\text { Headache }^{\mathrm{c}} \\
\text { Yes } / \mathrm{No}^{\mathrm{a}}\end{array}$ & 3.17 & $\begin{array}{c}2.00- \\
5.02\end{array}$ & 41.84 & .000 & 2.86 & $\begin{array}{l}1.77- \\
4.63\end{array}$ & 31.60 & .000 \\
\hline $\begin{array}{l}\text { Pain other than } \\
\text { headache }^{d}\end{array}$ & 1.22 & $\begin{array}{c}1.01- \\
1.49\end{array}$ & 6.96 & .008 & 1.03 & $\begin{array}{l}.83- \\
1.28\end{array}$ & .13 & .718 \\
\hline Other somatic complaints ${ }^{d}$ & 1.24 & $\begin{array}{c}1.04- \\
1.49\end{array}$ & 9.47 & .002 & .99 & $\begin{array}{l}.79- \\
1.24\end{array}$ & .01 & .917 \\
\hline
\end{tabular}

${ }^{a}$ Reference group

${ }^{\mathrm{b}}$ All variables controlled for age and gender, except gender (controlled for age) and age (controlled for gender)

${ }^{\mathrm{c}}$ Categorical variables

d Z-scores

In the analyses of the single-predictor models, weekly headache was significantly associated with each of the investigated parental health variables. Increased risk of weekly headache was associated with number of doctor appointments $(\mathrm{OR}=1.20,99 \% \mathrm{Cl}=1.05$ 1.38), regular medication ( $O R=1.71,99 \% \mathrm{Cl}=1.14-2.56)$, headache $(\mathrm{OR}=3.17,99 \%$ $\mathrm{Cl}=2.00-5.02)$, pain other than headache $(\mathrm{OR}=1.22,99 \% \mathrm{Cl}=1.01-1.49)$, and other somatic complaints $(\mathrm{OR}=1.24,99 \% \mathrm{Cl}=1.04-1.49)$, while a reduced risk of weekly headache was associated with general health $(\mathrm{OR}=.79,99 \% \mathrm{Cl}=.66-.95$; see Table 17 , left-hand side).

In a second step, sequential logistic regression analysis was performed on health status as outcome (weekly headache vs. good health), with age and gender as control variables in block one, and the six parental health variables as predictors in block two. Data 
from 2,954 families were available for analysis: 184 children with chronic headache and 2,770 healthy children.

A test of the full domain model (parental health and control variables) against the control model indicated that inclusion of parental health variables, as a set, significantly improved model fit $\left(\chi^{2} 6,2954=60.40, p<.001\right)$. The variance in health status accounted for by the full model is small (Nagelkerke's $R^{2}=.110$ ), as is the amount of variance accounted for by the parental health variables alone (Nagelkerke's $R^{2}=.053$ ).

Though inclusion of parental health variables increased model fit, only one of the variables, namely parental headache, was significantly associated with weekly headache $(\mathrm{OR}=2.86,99 \% \mathrm{Cl}=1.77-4.63)$ in the multivariate analysis of the full domain model. In addition, the association between number of doctor appointments and weekly headache approached significance $(\mathrm{OR}=1.16,99 \% \mathrm{Cl}=.99-1.36)$. None of the other variables was associated with weekly headache. In other words, the multivariate analysis of the full domain model indicated that regular medication, pain other than headache, and other somatic complaints were not independently associated with weekly headache (see Table 17, righthand side).

\subsubsection{Summary of Full Domain Model Analyses}

The amount of variance explained by each set of domain variables is presented in Table 18. Variable domains are listed in descending order according to the amount of variance explained beyond that explained by age and gender. As Table 18 shows, only child health variables, child psychological variables, and school variables explain more variance than the two control variables, age and gender.

Table 18. Amount of variance explained per domain (beyond that explained by age and gender)

\begin{tabular}{lcc}
\hline & \multicolumn{2}{c}{ Weekly headache vs. Good health } \\
\cline { 2 - 3 } Domain & Nagelkerke's R & Rank \\
\hline Age \& Gender & $6.5 \%$ & 1 \\
\hline Child health variables & $14.5 \%$ & 2 \\
Child psychological variables & $8.4 \%$ & 3 \\
School variables & $7.3 \%$ & 4 \\
Parental health variables & $5.3 \%$ & 5 \\
Parental psychological variables & $3.2 \%$ & 6 \\
Leisure variables & $2.3 \%$ & 7 \\
Life events & $1.4 \%$ & 8 \\
Family variables & $1.3 \%$ & 9 \\
Sociodemographic variables & $1.1 \%$ & \\
\hline
\end{tabular}




\subsubsection{Aggregate Model}

In order to integrate the data from the nine domains an aggregate model was created comprising age and gender, as control variables, and the following eleven variables which reached significance $(p \leq .01)$ in the multivariate domain analyses:

- anger-out

- anxiety/depression

- sleep disturbance

- pain other than headache

- other somatic complaints

- time spent on homework

- school stress

- amount of free time

- time spent on TV/video

- index of life events

- parental headache.

The results of the single-predictor model analyses for these variables are presented in Table 19 (left-hand side). This information is a reiteration of the single-predictor model data reported the respective domain analyses tables.

Prior to the analysis of the aggregate model, the degree of multicollinearity between the independent variables was determined via pairwise correlations and VIFs. The intercorrelation of all but five of the variables was minimal ( $r=-.159$ to $r=.287)$. However, pain other than headache was moderately correlated with other somatic complaints $(r=.532)$, anxiety/depression ( $r=.308)$, and sleep disturbances $(r=.334)$. The variable other somatic complaints was also moderately correlated with anxiety/depression ( $r=.356)$, and sleep disturbance $(r=.383)$. Finally, anxiety/depression was also moderately correlated with sleep disturbance $(r=.308)$, and school stress $(r=.501)$. However, the VIFs were satisfactory (range: 1.05-1.54), indicating the absence of problematic multicollinearity. The variables were, therefore, maintained in their original form in the analyses. Detailed information on the intercorrelation of the variables and the corresponding VIFs can be found in Appendix E.

A sequential logistic regression analysis was performed on health status as outcome (weekly headache vs. good health), with age and gender as control variables, and the eleven variables, which reached significance $(p \leq .01)$ in the multivariate domain analyses. Data from 2,672 families were available for analysis: 168 children with chronic headache and 2,504 healthy children.

A test of the full aggregate model (significant predictors from the full domain models plus control variables) against the control model (age, gender, and constant) indicated that inclusion of the selected variables, as a set, significantly improved model fit $\left(\chi_{13,2672}^{2}=214.00, p<.000\right)$. The variance in health status accounted for by the full aggregate model is substantial (Nagelkerke's $R^{2}=.262$ ), as is the amount of variance accounted for by the selected (non-control) variables (Nagelkerke's $R^{2}=.201$ ). 
Table 19. Association between weekly headache and all significant variables from domain analyses

Weekly headache vs. Good health ${ }^{\mathrm{a}}$

\begin{tabular}{|c|c|c|c|c|c|c|c|c|}
\hline & \multicolumn{4}{|c|}{ Single-predictor model ${ }^{\mathrm{b}}$} & \multicolumn{4}{|c|}{ Full aggregate model } \\
\hline & OR & $99 \% \mathrm{Cl}$ & Wald & $\mathrm{p}$ & OR & $99 \% \mathrm{Cl}$ & Wald & $P$ \\
\hline Age & 1.27 & $\begin{array}{c}1.17- \\
1.38\end{array}$ & 52.27 & .000 & 1.16 & $\begin{array}{c}1.04- \\
1.29\end{array}$ & 12.12 & .000 \\
\hline $\begin{array}{l}\text { Gender }^{\mathrm{c}} \\
\quad \text { Female / Male }\end{array}$ & 2.12 & $\begin{array}{l}1.42- \\
3.15\end{array}$ & 23.69 & .000 & 1.55 & $\begin{array}{l}.96- \\
2.52\end{array}$ & 5.42 & .020 \\
\hline Anger-out ${ }^{d}$ & 1.07 & $\begin{array}{l}.88- \\
1.29\end{array}$ & .80 & .372 & .81 & $\begin{array}{l}.64- \\
1.03\end{array}$ & 4.90 & .027 \\
\hline Anxiety/depression $^{d}$ & 1.70 & $\begin{array}{l}1.43- \\
2.03\end{array}$ & 61.82 & .000 & 1.11 & $\begin{array}{l}.86- \\
1.44\end{array}$ & 1.12 & .290 \\
\hline Sleep disturbance ${ }^{d}$ & 1.50 & $\begin{array}{l}1.27- \\
1.77\end{array}$ & 38.65 & .000 & 1.08 & $\begin{array}{l}.85- \\
1.35\end{array}$ & .65 & .420 \\
\hline $\begin{array}{l}\text { Pain other than } \\
\text { headache }^{d}\end{array}$ & 2.24 & $\begin{array}{l}1.88- \\
2.67\end{array}$ & 138.79 & .000 & 1.55 & $\begin{array}{c}1.23- \\
1.97\end{array}$ & 23.23 & .000 \\
\hline Other somatic complaints ${ }^{d}$ & 2.24 & $\begin{array}{l}1.87- \\
2.70\end{array}$ & 127.89 & .000 & 1.57 & $\begin{array}{l}1.22- \\
2.02\end{array}$ & 21.56 & .000 \\
\hline Time spent on homework ${ }^{c}$ & & & 17.73 & .000 & & & 6.79 & .079 \\
\hline $1-2$ hours $/<1$ hour $^{a}$ & 1.21 & $\begin{array}{l}.80- \\
1.84\end{array}$ & 1.39 & .239 & .97 & $\begin{array}{l}.59- \\
1.60\end{array}$ & .03 & .875 \\
\hline $2-3$ hours $/<1$ hour $^{a}$ & 1.94 & $\begin{array}{l}.89- \\
4.22\end{array}$ & 4.77 & .029 & 1.69 & $\begin{array}{l}.65- \\
4.39\end{array}$ & 2.03 & .154 \\
\hline$>3$ hours $/<1$ hour $^{a}$ & 9.94 & $\begin{array}{l}2.02- \\
48.94\end{array}$ & 13.76 & .000 & 5.62 & $\begin{array}{l}.71- \\
44.64\end{array}$ & 4.60 & .032 \\
\hline School stress ${ }^{d}$ & 1.77 & $\begin{array}{l}1.48- \\
2.12\end{array}$ & 67.74 & .000 & 1.39 & $\begin{array}{c}1.07- \\
1.79\end{array}$ & 10.77 & .001 \\
\hline Amount of free time ${ }^{d}$ & .87 & $\begin{array}{l}.72- \\
1.04\end{array}$ & 4.03 & .045 & .90 & $\begin{array}{l}.71- \\
1.13\end{array}$ & 1.43 & .231 \\
\hline Time spent on TV/video ${ }^{d}$ & 1.30 & $\begin{array}{c}1.07- \\
1.58\end{array}$ & 11.74 & .001 & 1.21 & $\begin{array}{l}.95- \\
1.53\end{array}$ & 4.24 & .040 \\
\hline Index of life events & 1.29 & $\begin{array}{l}1.11- \\
1.50\end{array}$ & 19.36 & .000 & 1.05 & $\begin{array}{l}.86- \\
1.27\end{array}$ & .35 & .553 \\
\hline $\begin{array}{l}\text { Parental headache }{ }^{\mathrm{c}} \\
\text { Yes } / \mathrm{No}^{\mathrm{a}}\end{array}$ & 3.17 & $\begin{array}{l}2.00- \\
5.02\end{array}$ & 41.84 & .000 & 2.36 & $\begin{array}{c}1.39- \\
3.98\end{array}$ & 17.70 & .000 \\
\hline
\end{tabular}

${ }^{a}$ Reference group

${ }^{\mathrm{b}}$ All variables controlled for age and gender, except gender (controlled for age) and age (controlled for gender)

${ }^{\mathrm{C}}$ Categorical variables

${ }^{\mathrm{d}}$ Z-scores

In the multivariate analysis of the full aggregate model, increased risk of weekly headache was significantly associated with age $(\mathrm{OR}=1.16,99 \% \mathrm{Cl}=1.04-1.29)$, pain other than headache $(\mathrm{OR}=1.55,99 \% \mathrm{Cl}=1.23-1.97)$, other somatic complaints $(\mathrm{OR}=1.57,99 \%$ $\mathrm{Cl}=1.22-2.02)$, school stress $(\mathrm{OR}=1.39,99 \% \mathrm{Cl}=1.07-1.79)$, and parental headache $(\mathrm{OR}=2.36,99 \% \mathrm{Cl}=1.39-3.98)$. The association between weekly headache and gender 
$(\mathrm{OR}=1.55,99 \% \mathrm{Cl}=.96-2.52)$ approached significance. None of the other variables was significantly associated with weekly headache. In other words, in the multivariate analysis of the full aggregate model, anger-out, anxiety/depression, sleep disturbance, time spent on homework, amount of free time, time spent on TV/video, and index of life events were not independently associated with weekly headache (see Table 19, right-hand side).

\subsection{Analyses Regarding Chronic Illness vs. Good Health}

\subsubsection{Age and Gender (Control Model)}

A direct logistic regression analysis was performed on health status as outcome (chronic illness vs. good health) and the control variables age and gender as predictors. Data from 3,547 families were available for analysis: 557 children with chronic illness and 2,990 healthy children.

A test of the control model against the constant-only model indicated that the inclusion of the control variables, as a set, did not significantly improve model fit $\left(\chi_{2,3547}^{2}=\right.$ $1.829, p=.401)$. Accordingly, almost no variance in health status is accounted for by the control variables (Nagelkerke's $\mathrm{R}^{2}=.001$ ).

Table 20 shows odds ratios, $99 \%$ confidence intervals, Wald statistics, and p-values for the two control variables. Chronic illness was not significantly associated with age or gender.

Table 20. Association between chronic illness and control variables

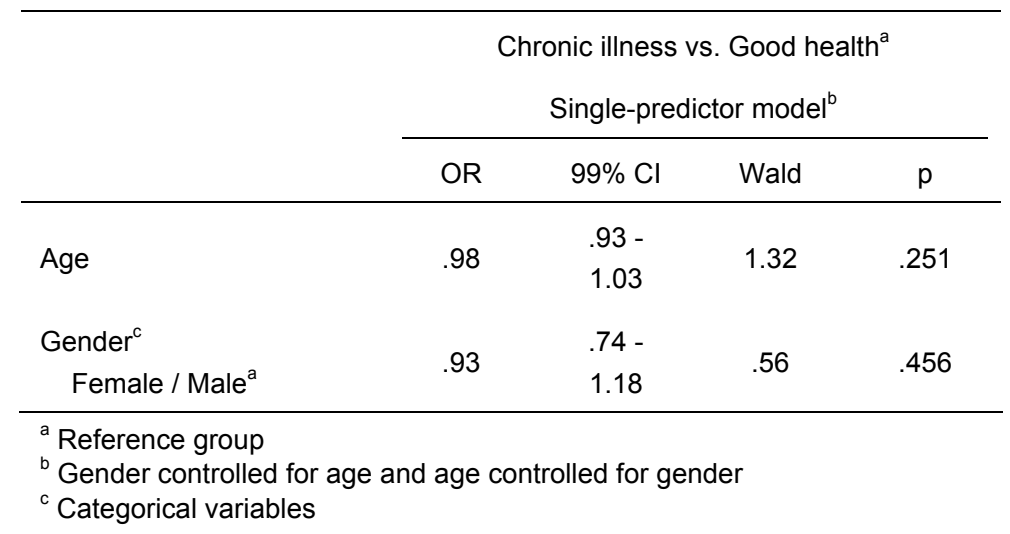

Though the control variables were not significantly associated with chronic illness, sequential logistic regression with control variables in the first block and domain variables in the second block were performed in order to maintain procedural continuity.

\subsubsection{Sociodemographic Variables}

Logistic regression analyses were performed on health status as outcome (chronic illness vs. good health), with age and gender as control variables, and the following two sociodemographic variables as predictors: social class, household crowding index.

In the single-predictor model analyses, chronic illness was not significantly associated with either of the sociodemographic variables (see Table 21). 
In a second step, a sequential logistic regression analysis was performed on health status as outcome (chronic illness vs. good health), with age and gender as control variables in block one, and the sociodemographic variables in block two. Data from 3,310 families were available for the multivariate analysis: 531 children with chronic headache and 2,779 healthy children.

A test of the full domain model (sociodemographic and control variables) against the control model indicated that inclusion of the sociodemographic variables did not significantly increase model fit $\left(\chi_{3,3310}^{2}=3.823, p=.281\right)$. The variance in health status accounted for by the full model is minute (Nagelkerke's $R^{2}=.003$ ), as is the amount of variance accounted for by the sociodemographic variables alone (Nagelkerke's $R^{2}=.002$ ). Accordingly, neither of the two sociodemographic variables, social class and household crowding, were significantly associated with chronic illness in the full domain model.

Table 21. Association between chronic illness and sociodemographic variables

\begin{tabular}{|c|c|c|c|c|c|c|c|c|}
\hline & \multicolumn{8}{|c|}{ Chronic conditions vs. Good health $^{a}$} \\
\hline & \multicolumn{4}{|c|}{ Single-predictor model ${ }^{\mathrm{b}}$} & \multicolumn{4}{|c|}{ Full domain model } \\
\hline & OR & $99 \% \mathrm{Cl}$ & Wald & $p$ & OR & $99 \% \mathrm{Cl}$ & Wald & $\mathrm{p}$ \\
\hline Age & .98 & $\begin{array}{l}.93- \\
1.03\end{array}$ & 1.32 & .251 & .98 & $\begin{array}{l}.93- \\
1.03\end{array}$ & 1.18 & .277 \\
\hline $\begin{array}{l}\text { Gender }^{\mathrm{c}} \\
\text { Female / Male }^{\mathrm{a}}\end{array}$ & .93 & $\begin{array}{l}.74- \\
1.18\end{array}$ & .56 & .456 & .91 & $\begin{array}{l}.71- \\
1.16\end{array}$ & .99 & .321 \\
\hline Social class & & & 1.24 & .539 & & & .02 & .989 \\
\hline Lower / Middle class ${ }^{a}$ & .87 & $\begin{array}{l}.51- \\
1.47\end{array}$ & .49 & .482 & .99 & $\begin{array}{l}.58- \\
1.70\end{array}$ & .00 & .996 \\
\hline Upper / Middle class ${ }^{a}$ & 1.07 & $\begin{array}{l}.83- \\
1.37\end{array}$ & .44 & .509 & 1.01 & $\begin{array}{l}.78- \\
1.31\end{array}$ & .02 & .898 \\
\hline $\begin{array}{l}\text { Household crowding } \\
\text { index }\end{array}$ & .60 & $\begin{array}{l}.33- \\
1.08\end{array}$ & 5.04 & .025 & .65 & $\begin{array}{l}.35- \\
1.19\end{array}$ & 3.35 & .067 \\
\hline
\end{tabular}

${ }^{a}$ Reference group

${ }^{\mathrm{b}}$ All variables controlled for age and gender, except gender (controlled for age) and age (controlled for gender)

${ }^{\mathrm{C}}$ Categorical variables

\subsubsection{Child Psychological Variables}

Using health status (chronic illness vs. good health) as outcome and age and gender as control variables, each of the following eleven psychological variables was examined via logistic regression: passive avoidance, rumination, resignation, aggression, anger-in, angerout, anger control, anxiety/depression, hyperactivity, aggressive behavior, sleep disturbance.

In the single-predictor model analyses, an increased risk of chronic illness was significantly associated with anger-out $(\mathrm{OR}=1.15,99 \% \mathrm{Cl}=1.02-1.30)$, and sleep disturbance $(\mathrm{OR}=1.21,99 \% \mathrm{Cl}=1.07-1.36)$. In addition, associations approaching significance were found between chronic illness and rumination $(\mathrm{OR}=1.13,99 \% \mathrm{Cl}=.99$ 1.28), resignation $(\mathrm{OR}=1.13,99 \% \mathrm{Cl}=1.00-1.28)$, anxiety/depression $(\mathrm{OR}=1.12,99 \%$ $\mathrm{Cl}=.99-1.27)$ and hyperactivity $(\mathrm{OR}=1.13,99 \% \mathrm{Cl}=1.00-1.28)$. On the other hand, chronic 
illness was not significantly associated with passive avoidance, aggression, anger-in, anger control, and aggressive behavior (see Table 22, left-hand side).

Table 22. Association between chronic illness and child psychological variables

\begin{tabular}{|c|c|c|c|c|c|c|c|c|}
\hline & \multicolumn{8}{|c|}{ Chronic illness vs. Good health $^{a}$} \\
\hline & \multicolumn{4}{|c|}{ Single-predictor model ${ }^{b}$} & \multicolumn{4}{|c|}{ Full domain model } \\
\hline & OR & $99 \% \mathrm{Cl}$ & Wald & $\mathrm{p}$ & OR & $99 \% \mathrm{Cl}$ & Wald & $\mathrm{p}$ \\
\hline Age & .98 & $\begin{array}{l}.93- \\
1.03\end{array}$ & 1.32 & .251 & .96 & $\begin{array}{l}.91- \\
1.02\end{array}$ & 2.81 & .094 \\
\hline $\begin{array}{l}\text { Gender }^{\mathrm{c}} \\
\quad \text { Female / Male }\end{array}$ & .93 & $\begin{array}{l}.74- \\
1.18\end{array}$ & .56 & .456 & .97 & $\begin{array}{l}.74- \\
1.27\end{array}$ & .07 & .790 \\
\hline \multicolumn{9}{|l|}{ Maladaptive coping } \\
\hline Passive avoidance $^{d}$ & 1.11 & $\begin{array}{l}.98- \\
1.26\end{array}$ & 4.53 & .033 & 1.00 & $\begin{array}{l}.85- \\
1.18\end{array}$ & .00 & .960 \\
\hline Rumination $^{d}$ & 1.13 & $\begin{array}{l}.99- \\
1.28\end{array}$ & 5.80 & .016 & 1.05 & $\begin{array}{l}.89- \\
1.23\end{array}$ & .53 & .466 \\
\hline Resignation $^{d}$ & 1.13 & $\begin{array}{c}1.00- \\
1.28\end{array}$ & 6.34 & .012 & 1.10 & $\begin{array}{l}.92- \\
1.31\end{array}$ & 1.81 & .179 \\
\hline Aggression $^{d}$ & 1.10 & $\begin{array}{l}.97- \\
1.24\end{array}$ & 3.97 & .046 & .97 & $\begin{array}{l}.82- \\
1.16\end{array}$ & .18 & .671 \\
\hline \multicolumn{9}{|l|}{ Anger expression } \\
\hline Anger- in ${ }^{d}$ & 1.03 & $\begin{array}{l}.91- \\
1.17\end{array}$ & .47 & .495 & 1.01 & $\begin{array}{l}.86- \\
1.17\end{array}$ & .01 & .916 \\
\hline Anger-out $^{d}$ & 1.15 & $\begin{array}{c}1.02- \\
1.30\end{array}$ & 8.82 & .003 & 1.11 & $\begin{array}{l}.93- \\
1.33\end{array}$ & 2.48 & .115 \\
\hline Anger control $^{d}$ & .95 & $\begin{array}{l}.84- \\
1.07\end{array}$ & 1.42 & .234 & 1.01 & $\begin{array}{l}.85- \\
1.19\end{array}$ & .01 & .905 \\
\hline Anxiety/depression $^{d}$ & 1.12 & $\begin{array}{l}.99- \\
1.27\end{array}$ & 5.41 & .020 & .98 & $\begin{array}{l}.82- \\
1.18\end{array}$ & .05 & .826 \\
\hline Hyperactivity $^{d}$ & 1.13 & $\begin{array}{c}1.00- \\
1.28\end{array}$ & 6.33 & .012 & 1.06 & $\begin{array}{l}.90- \\
1.26\end{array}$ & .92 & .337 \\
\hline Aggressive behavior $^{d}$ & 1.02 & $\begin{array}{l}.90- \\
1.17\end{array}$ & .21 & .650 & .94 & $\begin{array}{l}.80- \\
1.11\end{array}$ & .93 & .334 \\
\hline Sleep disturbance ${ }^{d}$ & 1.21 & $\begin{array}{c}1.07- \\
1.36\end{array}$ & 16.70 & .000 & 1.18 & $\begin{array}{c}1.03- \\
1.36\end{array}$ & 9.72 & .002 \\
\hline
\end{tabular}

${ }^{a}$ Reference group

${ }^{\mathrm{b}}$ All variables controlled for age and gender, except gender (controlled for age) and age (controlled for gender)

${ }^{c}$ Categorical variables

${ }^{\mathrm{d}}$ Z-scores

Subsequently a sequential logistic regression analysis was performed on health status as outcome, with age and gender as control variables in block one, and the eleven child psychological variables as predictors in block two. Data from 3,062 families were available for analysis: 494 children with chronic illness and 2,568 healthy children.

A test of the full domain model (child psychological and control variables) against the control model indicated that inclusion of the child psychological variables, as a set, 
significantly improved model fit $\left(\chi^{2} 11,3062=25.39, p=.008\right)$. The variance in health status accounted for by the full domain model is small (Nagelkerke's $R^{2}=.016$ ), as is the amount of variance accounted for by the child psychological variables alone (Nagelkerke's $R^{2}=.015$ ).

Though inclusion of the child psychological variables increased model fit, only one of the variables, sleep disturbance $(\mathrm{OR}=1.18,99 \% \mathrm{Cl}=1.03-1.36)$ was significantly associated with chronic illness in the multivariate analysis of the full model. None of the other child psychological variables were significantly associated with chronic illness (see Table 22). In other words, in the multivariate analysis of the full domain model, chronic illness was not independently associated with passive avoidance, rumination, resignation, aggression, anger-in, anger-out, anger control, anxiety/depression, hyperactivity, and aggressive behavior.

\subsubsection{Child Health Variables}

The child health variables, pain other than headache and other somatic complaints, were examined in logistic regression analyses together with age and gender as control variables and health status (chronic illness vs. good health) as outcome.

In the single-predictor model analyses, an increased risk of chronic illness was significantly associated with child's other somatic complaints $(\mathrm{OR}=1.18,99 \% \mathrm{Cl}=1.01$ 1.33). However, chronic illness was not significantly associated with pain other than headache (see Table 23, left-hand side).

A sequential logistic regression analysis was then performed with age and gender as control variables in block one, and the child health variables as predictors of health status in block two. Data from 3,336 families were available for analysis: 517 children with chronic illness and 2,819 healthy children.

Table 23. Association between chronic illness and child health variables

\begin{tabular}{|c|c|c|c|c|c|c|c|c|}
\hline & \multicolumn{8}{|c|}{ Chronic conditions vs. Good health ${ }^{a}$} \\
\hline & \multicolumn{4}{|c|}{ Single-predictor model ${ }^{\mathrm{b}}$} & \multicolumn{4}{|c|}{ Full domain model } \\
\hline & OR & $99 \% \mathrm{Cl}$ & Wald & $\mathrm{p}$ & OR & $99 \% \mathrm{Cl}$ & Wald & $\mathrm{p}$ \\
\hline Age & .98 & $\begin{array}{l}.93- \\
1.03\end{array}$ & 1.32 & .251 & .98 & $\begin{array}{l}.93- \\
1.04\end{array}$ & .64 & .423 \\
\hline $\begin{array}{l}\text { Gender }^{\mathrm{c}} \\
\quad \text { Female / Male }\end{array}$ & .93 & $\begin{array}{l}.74- \\
1.18\end{array}$ & .56 & .456 & .90 & $\begin{array}{l}.70- \\
1.16\end{array}$ & 1.11 & .291 \\
\hline $\begin{array}{l}\text { Pain other than } \\
\text { headache }^{d}\end{array}$ & 1.12 & $\begin{array}{l}.98- \\
1.28\end{array}$ & 4.41 & .036 & 1.05 & $\begin{array}{l}.89- \\
1.23\end{array}$ & .50 & .481 \\
\hline Other somatic complaints $^{d}$ & 1.16 & $\begin{array}{c}1.01- \\
1.33\end{array}$ & 7.39 & .007 & 1.13 & $\begin{array}{l}.97- \\
1.33\end{array}$ & 4.17 & .041 \\
\hline
\end{tabular}

\footnotetext{
${ }^{a}$ Reference group

${ }^{\mathrm{b}}$ All variables controlled for age and gender, except gender (controlled for age) and age (controlled for gender)

${ }^{\mathrm{c}}$ Categorical variables

${ }^{\mathrm{d}}$ Z-scores
} 
A test of the full domain model (health and control variables) against the control model (age, gender, and constant) indicated that inclusion of the child health variables, as a set, improved model fit to a degree that approached significance $\left(\chi_{2,3336}^{2}=7.72, p=.021\right)$. However, the variance in health status accounted for by the full model is minute (Nagelkerke's $R^{2}=.005$ ), as is the amount of variance accounted for by the health variables alone (Nagelkerke's $\mathrm{R}^{2}=.004$ ).

In line with the lack of significant model fit, the multivariate analysis of the full domain model indicated that neither of the child health variables (i.e., pain other than headache and other somatic complaints) was significantly associated with chronic illness (see Table 23, right-hand side).

\subsubsection{Family Variables}

Using the same outcome variable (chronic illness vs. good health) and age and gender as control variables, each of the following five family variables was examined via logistic regression: number of parents in the household, number of other children in the household, negative family environment, negative conflict solving strategies, and weekly family conflict.

In the single-predictor analyses, none of the individual family variables was significantly associated with chronic illness (see Table 24, left-hand side). In other words, the analyses indicated that the variables number of parents in household, number of other children in household, negative family environment, negative conflict solving strategies, and weekly family conflict were not significantly associated with chronic illness.

In a subsequent step, a sequential logistic regression analysis was performed on health status as outcome (chronic illness vs. good health), with age and gender as control variables in block one, and the five family variables as predictors in block two. Data from 3,395 families were available for the analysis of this domain: 542 children with chronic illness and 2,853 healthy children.

A test of the full domain model (family plus control variables) against the control model indicated that inclusion of family variables, as a set, significantly improved model fit $\left(\chi^{2}{ }_{5,3395}=16.10, p=.007\right)$. However, the variance in health status accounted for by the full model is minute (Nagelkerke's $R^{2}=.009$ ), as is the variance accounted for by family variables alone (Nagelkerke's $R^{2}=.008$ ).

Though inclusion of family variables increased model fit, only the association between negative family environment and chronic illness (OR $=1.14,99 \% \mathrm{Cl}=.99-1.32)$ approached significance. None of the other family variables was independently associated with chronic illness (see Table 24, right-hand side). 
Table 24. Association between chronic illness and family variables

\begin{tabular}{|c|c|c|c|c|c|c|c|c|}
\hline & \multicolumn{8}{|c|}{ Chronic conditions vs. Good health ${ }^{a}$} \\
\hline & \multicolumn{4}{|c|}{ Single-predictor model ${ }^{\mathrm{b}}$} & \multicolumn{4}{|c|}{ Full domain model } \\
\hline & OR & $99 \% \mathrm{Cl}$ & Wald & $P$ & OR & $99 \% \mathrm{Cl}$ & Wald & $\mathrm{p}$ \\
\hline Age & .98 & $\begin{array}{l}.93- \\
1.03\end{array}$ & 1.32 & .251 & .97 & $\begin{array}{l}.92- \\
1.03\end{array}$ & 1.54 & .214 \\
\hline $\begin{array}{l}\text { Gender }^{\mathrm{c}} \\
\text { Female / Male }^{\mathrm{a}}\end{array}$ & .93 & $\begin{array}{l}.74- \\
1.18\end{array}$ & .56 & .456 & .93 & $\begin{array}{l}.73- \\
1.18\end{array}$ & .66 & .418 \\
\hline $\begin{array}{l}\text { Number of parents in } \\
\text { household } \\
\text { One } / \text { Two }^{\mathrm{a}}\end{array}$ & .90 & $\begin{array}{l}.63- \\
1.29\end{array}$ & .54 & .461 & .84 & $\begin{array}{l}.58- \\
1.21\end{array}$ & 1.48 & .223 \\
\hline $\begin{array}{l}\text { Number of children in } \\
\text { household }\end{array}$ & .89 & $\begin{array}{l}.77- \\
1.03\end{array}$ & 4.21 & .040 & .88 & $\begin{array}{l}.76- \\
1.02\end{array}$ & 5.18 & .023 \\
\hline $\begin{array}{l}\text { Negative family } \\
\text { environment }^{d}\end{array}$ & 1.11 & $\begin{array}{l}.98- \\
1.25\end{array}$ & 4.76 & .029 & 1.14 & $\begin{array}{l}.99- \\
1.32\end{array}$ & 5.96 & .015 \\
\hline $\begin{array}{l}\text { Negative conflict solving } \\
\text { strategies }^{d}\end{array}$ & 1.01 & $\begin{array}{l}.89- \\
1.14\end{array}$ & .02 & .878 & .91 & $\begin{array}{l}.78- \\
1.06\end{array}$ & 2.65 & .103 \\
\hline $\begin{array}{l}\text { Weekly family conflict } \\
\text { Yes / } \mathrm{No}^{\mathrm{a}}\end{array}$ & 1.23 & $\begin{array}{l}.93- \\
1.61\end{array}$ & 3.72 & .054 & 1.29 & $\begin{array}{l}.94- \\
1.75\end{array}$ & 4.40 & .036 \\
\hline
\end{tabular}

\subsubsection{School Variables}

Logistic regression analyses were performed on health status as outcome (chronic illness vs. good health), with age and gender as control variables, and the following four school variables: index of school difficulties, time spent on homework, school stress, and reaction to failure.

In the single-predictor model analyses, an increased risk of chronic illness was significantly associated with school stress $(\mathrm{OR}=1.21,99 \% \mathrm{Cl}=1.07-1.38)$. In addition, the association between an increased risk for chronic illness and reaction to failure $(O R=1.13$, $99 \% \mathrm{Cl}=1.00-1.28$ ) approached significance. None of the other school variables were significantly associated with chronic illness in the single-predictor model analyses (see Table 25, left-hand side).

Then a sequential logistic regression analysis was performed on health status as outcome (chronic illness vs. good health), with age and gender as control variables in block one, and the four school variables as predictors in block two. Data from 3,195 families were available for analysis: 496 children with chronic headache and 2,699 healthy children.

A test of the full domain model (school and control variables) against the control model indicated that inclusion of the school variables, as a set, significantly improved model fit $\left(\chi_{6,3195}^{2}=17.05, p=.009\right)$. The variance in health status accounted for by the full model is small (Nagelkerke's $R^{2}=.010$ ), as is the amount of variance accounted for by the school variables alone (Nagelkerke's $R^{2}=.009$ ). 
Table 25. Association between chronic illness and school variables

\begin{tabular}{|c|c|c|c|c|c|c|c|c|}
\hline & \multicolumn{8}{|c|}{ Chronic conditions vs. Good health ${ }^{a}$} \\
\hline & \multicolumn{4}{|c|}{ Single-predictor model ${ }^{\mathrm{b}}$} & \multicolumn{4}{|c|}{ Full domain model } \\
\hline & OR & $99 \% \mathrm{Cl}$ & Wald & $\mathrm{p}$ & OR & $99 \% \mathrm{Cl}$ & Wald & $\mathrm{p}$ \\
\hline Age & .98 & $\begin{array}{l}.93- \\
1.30\end{array}$ & 1.32 & .251 & .98 & $\begin{array}{l}.92- \\
1.04\end{array}$ & 8.34 & .361 \\
\hline $\begin{array}{l}\text { Gender }^{\mathrm{c}} \\
\text { Female / Male }^{\mathrm{a}}\end{array}$ & .93 & $\begin{array}{l}.74- \\
1.18\end{array}$ & .56 & .456 & .95 & $\begin{array}{l}.73- \\
1.22\end{array}$ & .30 & .583 \\
\hline Index of school difficulties & 1.09 & $\begin{array}{l}.88- \\
1.34\end{array}$ & 1.10 & .295 & .99 & $\begin{array}{l}.79- \\
1.24\end{array}$ & .02 & .885 \\
\hline Time spent on homework ${ }^{\mathrm{c}}$ & & & 1.54 & .673 & & & 1.10 & .776 \\
\hline $1-2$ hours $/<1$ hour $^{a}$ & 1.11 & $\begin{array}{l}.84- \\
1.46\end{array}$ & .86 & .354 & 1.06 & $\begin{array}{l}.80- \\
1.42\end{array}$ & .31 & .577 \\
\hline $2-3$ hours $/<1$ hour $^{a}$ & 1.20 & $\begin{array}{l}.62- \\
2.32\end{array}$ & .53 & .468 & 1.28 & $\begin{array}{l}.66- \\
2.50\end{array}$ & .92 & .338 \\
\hline$>3$ hours $/<1$ hour $^{a}$ & 1.67 & $\begin{array}{l}.21- \\
13.28\end{array}$ & .41 & .524 & .87 & $\begin{array}{l}.05- \\
14.30\end{array}$ & .02 & .900 \\
\hline School stress ${ }^{d}$ & 1.21 & $\begin{array}{l}1.07- \\
1.38\end{array}$ & 15.26 & .000 & 1.20 & $\begin{array}{c}1.03- \\
1.39\end{array}$ & 9.49 & .002 \\
\hline Reaction to failure $^{d}$ & 1.13 & $\begin{array}{c}1.00- \\
1.28\end{array}$ & 6.13 & .013 & 1.07 & $\begin{array}{l}.93- \\
1.23\end{array}$ & 1.44 & .231 \\
\hline
\end{tabular}

${ }^{a}$ Reference group

${ }^{\mathrm{b}}$ All variables controlled for age and gender, except gender (controlled for age) and age (controlled for gender)

${ }^{\mathrm{C}}$ Categorical variables

${ }^{\mathrm{d}}$ Z-scores

In the multivariate analysis of the full domain model, increased risk of chronic illness was significantly associated with school stress $(\mathrm{OR}=1.20,99 \% \mathrm{Cl}=1.03-1.39)$. None of the other school variables were significantly associated with chronic illness. In other words, the multivariate analysis of the full model indicated that school difficulties, time spent on homework, and reaction to failure were not significantly associated with chronic illness (see Table 25, right-hand side)

\subsubsection{Leisure Variables}

Using the same outcome variable (chronic illness vs. good health) and age and gender as control variables, each of the following six leisure variables was examined via logistic regession: physical activities, other recreational activities, amount of free time, time spent on TV / video, time spent on computer/internet/game console, amount of friends.

In the single-predictor model analyses, not one of the leisure variables was significantly associated with chronic illness. In other words, chronic illness was not significantly associated with physical activities, recreational activities, amount of free time, time spent on TV / video, time spent on computer/game console, or amount of friends (see Table 26, left-hand side).

Nevertheless, a sequential logistic regression analysis was performed on health status as outcome, with age and gender as control variables in block one, and the six leisure 
variables as predictors in block two. Data from 3,298 families were available for analysis: 517 children with chronic headache and 2,781 healthy children.

Table 26. Association between chronic illness and leisure variables

\begin{tabular}{|c|c|c|c|c|c|c|c|c|}
\hline & \multicolumn{8}{|c|}{ Chronic conditions vs. Good health ${ }^{a}$} \\
\hline & \multicolumn{4}{|c|}{ Single-predictor model ${ }^{b}$} & \multicolumn{4}{|c|}{ Full domain model } \\
\hline & OR & $99 \% \mathrm{Cl}$ & Wald & $P$ & OR & $99 \% \mathrm{Cl}$ & Wald & $\mathrm{p}$ \\
\hline Age & .98 & $\begin{array}{l}.93- \\
1.03\end{array}$ & 1.32 & .251 & 1.00 & $\begin{array}{l}.94- \\
1.06\end{array}$ & .02 & .891 \\
\hline $\begin{array}{l}\text { Gender }^{\mathrm{c}} \\
\quad \text { Female / Male }^{\mathrm{a}}\end{array}$ & .93 & $\begin{array}{l}.74- \\
1.18\end{array}$ & .56 & .456 & .86 & $\begin{array}{l}.65- \\
1.14\end{array}$ & 1.89 & .169 \\
\hline Physical activities $^{d}$ & 1.06 & $\begin{array}{l}.94- \\
1.20\end{array}$ & 1.53 & .216 & 1.06 & $\begin{array}{l}.93- \\
1.21\end{array}$ & 1.24 & .266 \\
\hline Recreational activities $^{d}$ & 1.03 & $\begin{array}{l}.90- \\
1.17\end{array}$ & .27 & .605 & 1.01 & $\begin{array}{l}.87- \\
1.16\end{array}$ & .01 & .924 \\
\hline Amount of free time ${ }^{d}$ & .90 & $\begin{array}{l}.80- \\
1.02\end{array}$ & 4.38 & .036 & .92 & $\begin{array}{l}.80- \\
1.05\end{array}$ & 2.93 & .087 \\
\hline Time spent on TV / video ${ }^{d}$ & .92 & $\begin{array}{l}.81- \\
1.04\end{array}$ & 3.34 & .068 & .94 & $\begin{array}{l}.81- \\
1.08\end{array}$ & 1.31 & .253 \\
\hline $\begin{array}{l}\text { Time spent on computer / } \\
\text { game console }^{d}\end{array}$ & .90 & $\begin{array}{l}.78- \\
1.04\end{array}$ & 3.34 & .067 & .91 & $\begin{array}{l}.78- \\
1.07\end{array}$ & 2.11 & .146 \\
\hline Amount of friends ${ }^{c}$ & & & 7.38 & .025 & & & 6.20 & .045 \\
\hline $0-1$ friends $/ 2-5$ friends $^{a}$ & .67 & $\begin{array}{l}.40- \\
1.13\end{array}$ & 3.88 & .049 & .67 & $\begin{array}{l}.39- \\
1.15\end{array}$ & 3.64 & .057 \\
\hline$>5$ friends $/ 2-5$ friends $^{a}$ & .79 & $\begin{array}{l}.60- \\
1.05\end{array}$ & 4.63 & .031 & .82 & $\begin{array}{l}.61- \\
1.08\end{array}$ & 3.45 & .063 \\
\hline
\end{tabular}

${ }^{a}$ Reference group

${ }^{\mathrm{b}}$ All variables controlled for age and gender, except gender (controlled for age) and age (controlled for gender)

${ }^{\mathrm{C}}$ Categorical variables

${ }^{\mathrm{d}}$ Z-scores

A test of the full domain model (leisure and control variables) against the control model indicated that inclusion of the leisure variables, as a set, improved model fit to a degree that approached significance $\left(\chi^{2}{ }_{7}, 3298=17.53, p=.014\right)$. The variance in health status accounted for by the full model is minimal (Nagelkerke's $R^{2}=.010$ ), as is and the amount of variance accounted for by the leisure variables alone (Nagelkerke's $R^{2}=.009$ ).

In line with the lack of significant model fit and the results from the single-predictor model analyses, the multivariate analysis of the full domain model indicated that none of the leisure variables was significantly associated with chronic illness (see Table 26, right-hand side).

\subsubsection{Life Events}

Again, as an index was calculated to quantify the number of life events experienced by the child and this index is the only variable of the domain, the first step of analyzing single-predictor models became unnecessary. Therefore, the statistical analysis began with a sequential logistic regression analysis that was performed on health status as outcome 
(chronic illness vs. good health), with age and gender as control variables in block one, and the index of life events as predictor in block two. Data from 3,547 families were available for analysis: 557 children with chronic illness and 2,990 healthy children.

Table 27. Association between chronic illness and life events

\begin{tabular}{|c|c|c|c|c|c|c|c|c|}
\hline & \multicolumn{8}{|c|}{ Chronic illness vs. Good health ${ }^{a}$} \\
\hline & \multicolumn{4}{|c|}{ Single-predictor model ${ }^{\mathrm{b}}$} & \multicolumn{4}{|c|}{ Full domain model } \\
\hline & OR & $99 \% \mathrm{Cl}$ & Wald & $p$ & OR & $99 \% \mathrm{Cl}$ & Wald & $\mathrm{p}$ \\
\hline Age & .98 & $\begin{array}{l}.93- \\
1.03\end{array}$ & 1.32 & .251 & .98 & $\begin{array}{l}.93- \\
1.03\end{array}$ & 1.09 & .296 \\
\hline $\begin{array}{l}\text { Gender }^{\mathrm{c}} \\
\quad \text { Female / Male }\end{array}$ & .93 & $\begin{array}{l}.74- \\
1.18\end{array}$ & .56 & .456 & .93 & $\begin{array}{l}.74- \\
1.19\end{array}$ & .55 & .460 \\
\hline Index of life events & & & & & 1.07 & $\begin{array}{l}.96- \\
1.19\end{array}$ & 2.35 & .125 \\
\hline
\end{tabular}

${ }^{\text {a }}$ Reference group

${ }^{\mathrm{b}}$ All variables controlled for age and gender, except gender (controlled for age) and age (controlled for gender)

${ }^{\mathrm{c}}$ Categorical variables

A test of the full domain model (life event index and control variables) against the control model indicated that the inclusion of the index of life events did not significantly improve model fit $\left(\chi^{2}{ }_{1,3547}=2.312, p=.128\right)$. The variance in health status accounted for by the full model is minute (Nagelkerke's $R^{2}=.002$ ), as is the amount of variance accounted for by the index of life events alone (Nagelkerke's $R^{2}=.001$ ). Accordingly, the multivariate analysis of the full domain model indicated that number of experienced life events was not significantly associated with chronic illness (see Table 27 , right-hand side).

\subsubsection{Parental Psychological Variables}

Logistic regression analyses were performed on health status as outcome (chronic illness vs. good health), with age and gender as control variables, and the following three parental psychological variables: parental anxiety/depression (index), parental habitual worry, and parental sleep disturbances.

In single-predictor model analyses, none of the parental psychological variables was significantly associated with chronic illness (see Table 28 , left-hand side).

Nevertheless, in a second step, a sequential logistic regression analysis was performed on health status as outcome (chronic illness vs. good health), with age and gender as control variables in block one, and the three parental psychological variables as predictors in block two. Data from 3,380 families were available for analysis: 531 children with chronic illness and 2,849 healthy children.

A test of the full domain model (parental psychological and control variables) against the control model (age, gender, and constant) indicated that inclusion of the parental psychological variables, as a set, did not significantly improve model fit, $\left(\chi^{2}{ }_{3,3380}=5.371\right.$, $p=.147$ ). Accordingly, almost no variance in health status accounted for by the full model (Nagelkerke's $R^{2}=.003$ ), and the amount of variance accounted for by the parental psychological variables, alone, is minute (Nagelkerke's $R^{2}=.002$ ). 
Table 28. Association between chronic illness and parental psychological variables

\begin{tabular}{|c|c|c|c|c|c|c|c|c|}
\hline & \multicolumn{8}{|c|}{ Chronic illness vs. Good health ${ }^{a}$} \\
\hline & \multicolumn{4}{|c|}{ Single-predictor model ${ }^{b}$} & \multicolumn{4}{|c|}{ Full domain model } \\
\hline & OR & $99 \% \mathrm{Cl}$ & Wald & $\mathrm{p}$ & OR & $99 \% \mathrm{Cl}$ & Wald & $\mathrm{p}$ \\
\hline Age & .98 & $\begin{array}{l}.93- \\
1.03\end{array}$ & 1.32 & .251 & .98 & $\begin{array}{l}.93- \\
1.04\end{array}$ & .73 & .394 \\
\hline 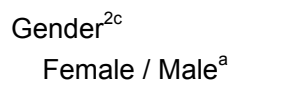 & .93 & $\begin{array}{l}.74- \\
1.18\end{array}$ & .56 & .456 & .93 & $\begin{array}{l}.73- \\
1.18\end{array}$ & .63 & .426 \\
\hline $\begin{array}{l}\text { Parental anxiety / } \\
\text { depression }^{d}\end{array}$ & 1.11 & $\begin{array}{l}.98- \\
1.26\end{array}$ & 4.73 & .030 & 1.12 & $\begin{array}{l}.95- \\
1.33\end{array}$ & 3.09 & .079 \\
\hline Parental worry as trait ${ }^{\mathrm{d}}$ & 1.09 & $\begin{array}{l}.96- \\
1.23\end{array}$ & 3.19 & .074 & 1.02 & $\begin{array}{l}.87- \\
1.19\end{array}$ & .10 & .750 \\
\hline $\begin{array}{l}\text { Parental sleep } \\
\text { disturbance }^{d}\end{array}$ & 1.00 & $\begin{array}{l}.88- \\
1.14\end{array}$ & .01 & .937 & .95 & $\begin{array}{l}.82- \\
1.10\end{array}$ & .90 & .342 \\
\hline
\end{tabular}

${ }^{\text {a }}$ Reference group

${ }^{\mathrm{b}}$ All variables controlled for age and gender, except gender (controlled for age) and age (controlled for gender)

${ }^{\mathrm{C}}$ Categorical variables

${ }^{\mathrm{d}}$ Z-scores

In line with the lack of significant model fit and the results from the single-predictor model analyses, the multivariate analysis of the full domain model indicated that none of the parental psychological variables was significantly associated with chronic illness. In other words, chronic illness was not significantly associated with parental anxiety/depression, parental habitual worry, or parental sleep disturbances (see Table 28, right-hand side).

\subsubsection{Parental Health Variables}

Using health status (chronic illness vs. good health) as the outcome variable, with age and gender as controls, each of the following six parental health variables was examined via logistic regression: general health, number of doctor appointments, regular medication, headache, pain other than headache, and somatic complaints.

In the analyses of single-predictor models, an increased risk of chronic illness was associated with number of doctor appointments $(\mathrm{OR}=1.20,99 \% \mathrm{Cl}=1.02-1.27)$, parental headache $(O R=1.20,99 \% \mathrm{Cl}=1.06-1.74)$, parental pain other than headache $(O R=1.20$, $99 \% \mathrm{Cl}=1.04-1.33)$, and parental other somatic complaints $(\mathrm{OR}=1.20,99 \% \mathrm{Cl}=1.12$ 1.41). A reduced risk of chronic illness was associated with general health $(O R=1.20,99 \%$ $\mathrm{Cl}=.77-.97$ ). Chronic illness was not associated with regular medication (see Table 29, lefthand side).

In a subsequent step, a sequential logistic regression analysis was performed on health status as outcome (chronic illness vs. good health), with age and gender as control variables in block one, and the six parental health variables as predictors in block two. Data from 3,281 families were available for analysis: 511 children with chronic illness and 2,770 healthy children. 
Table 29. Association between chronic illness and parental health variables

\begin{tabular}{|c|c|c|c|c|c|c|c|c|}
\hline & \multicolumn{8}{|c|}{ Chronic illness vs. Good health ${ }^{a}$} \\
\hline & \multicolumn{4}{|c|}{ Single-predictor model ${ }^{b}$} & \multicolumn{4}{|c|}{ Full domain model } \\
\hline & OR & $99 \% \mathrm{Cl}$ & Wald & $\mathrm{p}$ & OR & $99 \% \mathrm{Cl}$ & Wald & $\mathrm{p}$ \\
\hline Age & .98 & $\begin{array}{l}.93- \\
1.03\end{array}$ & 1.32 & .251 & .98 & $\begin{array}{l}.93- \\
1.04\end{array}$ & .83 & .363 \\
\hline $\begin{array}{l}\text { Gender }^{\mathrm{c}} \\
\quad \text { Female / Male }\end{array}$ & .93 & $\begin{array}{l}.74- \\
1.18\end{array}$ & .56 & .456 & .94 & $\begin{array}{l}.73- \\
1.20\end{array}$ & .45 & .504 \\
\hline General health $^{d}$ & .86 & $.77-.97$ & 10.50 & .001 & .97 & $\begin{array}{l}.84- \\
1.11\end{array}$ & .43 & .513 \\
\hline $\begin{array}{l}\text { Number of doctor } \\
\text { appointments }^{d}\end{array}$ & 1.14 & $\begin{array}{c}1.02- \\
1.27\end{array}$ & 9.08 & .003 & 1.07 & $\begin{array}{l}.93- \\
1.23\end{array}$ & 1.50 & .221 \\
\hline $\begin{array}{l}\text { Regular medication }{ }^{\mathrm{c}} \\
\text { Yes } / \mathrm{No}^{\mathrm{a}}\end{array}$ & 1.24 & $\begin{array}{l}.95- \\
1.63\end{array}$ & 4.16 & .041 & .94 & $\begin{array}{l}.68- \\
1.29\end{array}$ & .28 & .595 \\
\hline $\begin{array}{l}\text { Headache }^{\mathrm{c}} \\
\text { Yes } / \mathrm{No}^{\mathrm{a}}\end{array}$ & 1.36 & $\begin{array}{c}1.06- \\
1.74\end{array}$ & 10.14 & .001 & 1.26 & $\begin{array}{l}.97- \\
1.63\end{array}$ & 5.01 & .025 \\
\hline $\begin{array}{l}\text { Pain other than } \\
\text { headache }^{d}\end{array}$ & 1.17 & $\begin{array}{c}1.04- \\
1.33\end{array}$ & 11.27 & .001 & 1.07 & $\begin{array}{l}.94- \\
1.23\end{array}$ & 1.81 & .179 \\
\hline Other somatic complaints ${ }^{d}$ & 1.26 & $\begin{array}{c}1.12- \\
1.41\end{array}$ & 25.59 & .000 & 1.20 & $\begin{array}{c}1.04- \\
1.38\end{array}$ & 10.89 & .001 \\
\hline
\end{tabular}

\footnotetext{
${ }^{\mathrm{a}}$ Reference group

${ }^{\mathrm{b}}$ All variables controlled for age and gender, except gender (controlled for age) and age (controlled for gender)

${ }^{\mathrm{C}}$ Categorical variables

${ }^{\mathrm{d}}$ Z-scores
}

A test of the full domain model (parental health and control variables) against the control model indicated that inclusion of the parental health variables, as a set, significantly improved model fit $\left(\chi^{2} 6,3281=35.021, p<.001\right)$. The variance in health status accounted for by the full model is small (Nagelkerke's $R^{2}=.019$ ), as is the amount of variance accounted for by the parental health variables alone (Nagelkerke's $R^{2}=.018$ ).

In the multivariate analysis of the full domain model, an increased risk of chronic illness was significantly associated with parental other somatic complaints (OR $=1.20,99 \%$ $\mathrm{Cl}=1.04-1.38)$. None of the other parental health variables was significantly associated with chronic illness. In other words, in the multivariate analysis of the full model chronic illness was not independently associated with general health, number of doctor appointments, regular medication, headache and pain other than headache (see Table 29, right-hand side).

\subsubsection{Summary of Full Domain Model Analyses}

The amount of variance explained by each set of domain variables is presented in Table 30. Variable domains are listed in descending order according to the amount of variance explained beyond that explained by age and gender. However, as Table 30 shows, the amount of variance explained by the individual domains is quite small. 
Table 30. Amount of variance explained per domain (beyond that explained by age and gender)

\begin{tabular}{lcc}
\hline & \multicolumn{2}{c}{ Chronic illness vs. Good health ${ }^{\mathrm{a}}$} \\
\cline { 2 - 3 } Domain & Nagelkerke's R & Rank \\
\hline Age \& Gender & $0.1 \%$ & 1 \\
\hline Parental health variables & $1.8 \%$ & 2 \\
Child psychological variables & $1.5 \%$ & 3 \\
School variables & $0.9 \%$ & 3 \\
Leisure variables & $0.9 \%$ & 5 \\
Family variables & $0.8 \%$ & 6 \\
Child health variables & $0.4 \%$ & 7 \\
Sociodemographic variables & $0.2 \%$ & 7 \\
Parental psychological variables & $0.2 \%$ & 9 \\
Life events & $0.1 \%$ & \\
\hline
\end{tabular}

\subsubsection{Aggregate Model}

In order to integrate the data regarding chronic illness from all nine domains, an aggregate model was created comprising age and gender, and the following three variables which reached significance $(p \leq .01)$ in the multivariate full domain model analyses:

- sleep disturbance,

- school stress,

- other parental somatic complaints.

The results of the single-predictor model analyses for these variables are presented in Table 31 (left-hand side). This information is a reiteration of the single-predictor model data reported in the respective domain analyses tables.

Prior to the analysis of the aggregate model, the degree of multicollinearity between the independent variables was determined via pairwise correlations and VIFs. The intercorrelation of the variables was minimal $(r=-.038$ to $r=.231)$. Accordingly, the VIFs were satisfactory (range: 1.01-1.07), indicating the absence of problematic multicollinearity. The variables were, therefore, maintained in their original form in the analyses. Detailed information on the intercorrelation of the variables and the corresponding VIFs can be found in Appendix E.

A sequential logistic regression analysis was performed on health status as outcome (chronic illness vs. good health), with age and gender as control variables in block one, and the three variables which reached significance $(p \leq .01)$ in the multivariate domain analyses in block two. Data from 3,249 families were available for analysis: 504 children with chronic illness and 2,745 healthy children.

A test of the full aggregate model (above three variables plus control variables) against the control model indicated that inclusion of the three variables, as a set, significantly increased model fit $\left(\chi^{2}{ }_{10,3249}=43.70, p<.000\right)$. However, the variance in health status 
accounted for by the full model is small (Nagelkerke's $R^{2}=.024$ ). The bulk of the explained variance is accounted for by the three variables alone (Nagelkerke's $R^{2}=.023$ ).

Table 31. Association between chronic illness and all significant variables from domain analyses

\begin{tabular}{|c|c|c|c|c|c|c|c|c|}
\hline & \multicolumn{8}{|c|}{ Chronic illness vs. Good health ${ }^{a}$} \\
\hline & \multicolumn{4}{|c|}{ Single predictor model ${ }^{b}$} & \multicolumn{4}{|c|}{ Full aggregate model } \\
\hline & OR & $99 \% \mathrm{Cl}$ & Wald & $\mathrm{p}$ & OR & $99 \% \mathrm{Cl}$ & Wald & $\mathrm{p}$ \\
\hline Age & .98 & $\begin{array}{l}.93- \\
1.03\end{array}$ & 1.32 & .251 & .97 & $\begin{array}{l}.92- \\
1.03\end{array}$ & 1.82 & .178 \\
\hline $\begin{array}{l}\text { Gender }^{\mathrm{c}} \\
\quad \text { Female / Male }\end{array}$ & .93 & $\begin{array}{l}.74- \\
1.18\end{array}$ & .56 & .456 & .93 & $\begin{array}{l}.72- \\
1.19\end{array}$ & .62 & .433 \\
\hline Sleep disturbance ${ }^{d}$ & 1.21 & $\begin{array}{l}1.07- \\
1.36\end{array}$ & 16.70 & .000 & 1.16 & $\begin{array}{l}1.02- \\
1.32\end{array}$ & 8.73 & .003 \\
\hline School stress $^{d}$ & 1.21 & $\begin{array}{c}1.07- \\
1.38\end{array}$ & 15.26 & .000 & 1.16 & $\begin{array}{c}1.02- \\
1.33\end{array}$ & 8.29 & .004 \\
\hline $\begin{array}{l}\text { Parental other somatic } \\
\text { complaints }^{d}\end{array}$ & 1.26 & $\begin{array}{c}1.12- \\
1.41\end{array}$ & 25.59 & .000 & 1.21 & $\begin{array}{c}1.07- \\
1.37\end{array}$ & 16.69 & .000 \\
\hline
\end{tabular}

${ }^{\text {a }}$ Reference group

${ }^{\mathrm{b}}$ All variables controlled for age and gender, except gender (controlled for age) and age (controlled for gender)

${ }^{\mathrm{c}}$ Categorical variables

' Z-scores

In the multivariate analysis of the full aggregate model, increased risk of chronic illness was significantly associated with sleep disturbance $(\mathrm{OR}=1.16,99 \% \mathrm{Cl}=1.02-1.32)$, school stress $(\mathrm{OR}=1.16,99 \% \mathrm{Cl}=1.02-1.33)$, and parental other somatic complaints $(\mathrm{OR}=1.21,99 \% \mathrm{Cl}=1.07-1.37)$ Chronic illness was not significantly associated with age or gender (see Table 31, right-hand side).

\section{5 Specificity Model (Analyses Regarding Weekly Headache vs. Chronic IIIness)}

Finally, in order to determine the specificity of the variables significantly related with weekly headache logistic regression analyses were performed on health status as outcome (weekly headache vs. chronic illness), with age and gender as control variables, and each of the following six variables which achieved significance $(p \leq .01)$ in the aggregate model for either weekly headache or chronic illness:

- pain other than headache,

- other somatic complaints,

- sleep disturbance,

- school stress,

- parental headache, and

- parental other somatic complaints.

Prior to the analyses, the degree of multicollinearity between the independent variables was determined via pairwise correlations and VIFs. The intercorrelation of all but three of the variables was minimal ( $r=-.047$ to $r=.281$ ). However, the variable sleep disturbance was moderately correlated with pain other than headache $(r=.319)$, and other 
somatic complaints $(r=.379)$. There was also a moderate intercorrelation of pain other than headache and other somatic complaints $(r=.529)$. However, the VIFs were satisfactory (range: 1.02-1.49), indicating the absence of problematic multicollinearity. The variables were, therefore, maintained in their original form in the analyses. Detailed information on the intercorrelation of the variables and the corresponding VIFs can be found in Appendix E.

In the single-predictor model analyses, weekly headache was significantly associated with pain other than headache $(\mathrm{OR}=1.92,99 \% \mathrm{Cl}=1.55-2.39)$, other somatic complaints $(\mathrm{OR}=2.04,99 \% \mathrm{Cl}=1.60-2.60)$, sleep disturbance $(\mathrm{OR}=1.24,99 \% \mathrm{Cl}=1.02-1.52)$, school stress $(\mathrm{OR}=1.51,99 \% \mathrm{Cl}=1.21-1.90)$, and parental headache $(\mathrm{OR}=2.47,99 \% \mathrm{Cl}=1.46$ 4.19). Other parental somatic complaints were not significantly associated with either of the health outcomes in the specificity model (see Table 32, left-hand side).

In a second step, a sequential logistic regression analysis was performed on health status (weekly headache vs. chronic illness) as outcome, with age and gender as control variables in block one, and the above six variables as predictors in block two. Data from 633 families were available for analysis: 168 children with weekly headache and 465 children with chronic illness.

Table 32. Association between weekly headache and chronic illness

\begin{tabular}{|c|c|c|c|c|c|c|c|c|}
\hline & \multicolumn{8}{|c|}{ Weekly headache vs. Chronic illness ${ }^{a}$} \\
\hline & \multicolumn{4}{|c|}{ Single-predictor model ${ }^{b}$} & \multicolumn{4}{|c|}{ Full specificity model } \\
\hline & OR & $99 \% \mathrm{Cl}$ & Wald & $p$ & OR & $99 \% \mathrm{Cl}$ & Wald & $p$ \\
\hline Age & 1.34 & $\begin{array}{l}1.21- \\
1.48\end{array}$ & 52.14 & .000 & 1.25 & $\begin{array}{l}1.10- \\
1.41\end{array}$ & 19.92 & .000 \\
\hline $\begin{array}{l}\text { Gender }^{\mathrm{C}} \\
\quad{\text { Female } / \text { Male }^{\mathrm{a}}}\end{array}$ & 2.36 & $\begin{array}{l}1.50- \\
3.74\end{array}$ & 23.46 & .000 & 1.79 & $\begin{array}{l}1.03- \\
3.11\end{array}$ & 7.29 & .007 \\
\hline $\begin{array}{l}\text { Pain other than } \\
\text { headache }^{d}\end{array}$ & 1.92 & $\begin{array}{l}1.55- \\
2.39\end{array}$ & 60.59 & .000 & 1.45 & $\begin{array}{l}1.10- \\
1.91\end{array}$ & 12.27 & .000 \\
\hline Other somatic complaints ${ }^{d}$ & 2.04 & $\begin{array}{l}1.60- \\
2.60\end{array}$ & 56.64 & .000 & 1.69 & $\begin{array}{l}1.22- \\
2.34\end{array}$ & 17.02 & .000 \\
\hline Sleep disturbance $^{d}$ & 1.24 & $\begin{array}{c}1.02- \\
1.52\end{array}$ & 7.78 & .005 & .951 & $\begin{array}{l}.73- \\
1.24\end{array}$ & .23 & .631 \\
\hline School stress $^{d}$ & 1.51 & $\begin{array}{l}1.21- \\
1.90\end{array}$ & 22.04 & .000 & 1.26 & $\begin{array}{l}.96- \\
1.67\end{array}$ & 4.64 & .031 \\
\hline $\begin{array}{l}\text { Parental headache } \\
\text { Yes } / \mathrm{No}^{\mathrm{a}}\end{array}$ & 2.47 & $\begin{array}{l}1.46- \\
4.19\end{array}$ & 19.58 & .000 & 1.91 & $\begin{array}{l}1.05- \\
3.48\end{array}$ & 7.79 & .005 \\
\hline $\begin{array}{l}\text { Other parental somatic } \\
\text { complaints }^{d}\end{array}$ & 1.04 & $\begin{array}{l}.83- \\
1.30\end{array}$ & .22 & .642 & .83 & $\begin{array}{l}.63- \\
1.09\end{array}$ & 3.01 & .083 \\
\hline
\end{tabular}

${ }^{\text {a }}$ Reference group for contrast

${ }^{\mathrm{b}}$ All variables controlled for age and gender, except gender (controlled for age) and age (controlled for gender)

${ }^{\mathrm{c}}$ Categorical variables

d Z-scores

A test of the full specificity model with all six predictors against the control model (age, gender, and constant) indicated that inclusion of the variables, as a set, significantly increased model fit $\left(\chi^{2}{ }_{13,633}=94.73, p<.000\right)$. The variance in health status (weekly 
headache vs. chronic illness) accounted for by the full model is moderate (Nagelkerke's $\mathrm{R}^{2}=.311$ ), as is the variance accounted for by the six variables alone (Nagelkerke's $\left.\mathrm{R}^{2}=.185\right)$.

In the multivariate analysis of the full specificity model, increased risk of weekly headache was significantly associated with pain other than headache (OR $=1.45,99 \%$ $\mathrm{Cl}=1.10-1.91)$, other somatic complaints $(\mathrm{OR}=1.69,99 \% \mathrm{Cl}=1.22-2.34)$, and parental headache $(\mathrm{OR}=1.91,99 \% \mathrm{Cl}=1.05-3.48)$. In addition, weekly headache was significantly associated with the control variables age $(\mathrm{OR}=1.25,99 \% \mathrm{Cl}=1.10-1.41)$ and gender $(\mathrm{OR}=1.79,99 \% \mathrm{Cl}=1.03-3.11)$. None of the other variables were significantly associated with weekly headache or chronic illness (see Table 32, right-hand side). In other words, in the multivariate analysis of the specificity model sleep disturbance, school stress, and parental other somatic complaints were not significantly associated with the health outcome of interest. 


\section{DISCUSSION}

Three topics will be covered in the following discussion. First, the prevalence of weekly headache will be discussed within the context of national and international epidemiological studies. Second, the results concerning correlates of weekly headache will be discussed. The single-predictor analyses will be summarized and integrated with previous research, thus yielding an updated appraisal of the empirical status of the examined variables. Results from the domain models and the final aggregate model will then be covered. As a third topic, the results regarding the specificity of the correlates for weekly headache will be discussed. Finally, directions for future research will be outlined.

\subsection{Prevalence of Weekly Headache}

The prevalence of weekly headache in the present sample of German children and adolescents (aged 7 to 14 ) was $6.5 \%$. This prevalence rate is relatively low in comparison to international studies which have reported rates of headache occurring at least once a week in the past 12 months to range from $10.8 \%$ for 7 - to 15 -year-olds (Laurell et al., 2004) to $29.7 \%$ for 11 - to 21 -year-olds (Rhee, 2000 ; see also Table 1 ).

Nevertheless, similar rates have been reported in several studies. For example, Carlsson (1996) found a $6 \%$ prevalence rate for headache occurring at least "several times a week" in Swedish school children of a similar age range (7 to 16 years). In addition, Kristjánsdóttir (1997) reported weekly headache to be experienced by $6.2 \%$ of Icelandic adolescents (aged 11 to 12 and 15 to 16), and a prevalence rate of $7 \%$ was reported for 12 to 17-year-olds in USA (Linet et al., 1989). However, these three studies were conducted about a decade ago, and as there is evidence that the prevalence of both headache and weekly headache has increased in the past decades (Rhee, 2000; Scheidt et al., 2000; Sillanpää \& Anttila, 1996), a higher rate of weekly headache was to be expected in the present research. On the other hand, a recent study from Norway reported weekly headache to occur in $8 \%$ of adolescents aged 13 to 18 (Zwart et al., 2004). Thus, it could be argued that the present prevalence of $6.5 \%$ was acceptably within the range of rates reported in the literature.

Noteworthy is, however, that the prevalence rate found in the present study differs drastically from those reported in other German studies. The three large-scale studies that have assessed weekly headache among German children and adolescents have found prevalence rates ranging from $21.2 \%$ to $25 \%$ (Frankenberg \& Pothmann, 1995; RavensSieberer et al., 2003; Scheidt et al., 2000). A possible explanation for this divergence is the use of different sources of information. While child report data was analyzed in the other three studies (Frankenberg \& Pothmann, 1995; Ravens-Sieberer et al., 2003; Scheidt et al., 2000), the present research employed parental questionnaires. It is possible that parents underreport child's headache, as their ability to estimate headache frequency depends on the extent to which the child verbalizes experiencing headache and on parents' ability to perceive non-verbal indicators of child's headache.

Evidence of parental underreporting of child headache has been documented by Grøholt et al. (2003). The rate of headache prevalence reported by parents with co- 
responding children was 1.2 times higher than that reported by parents with non-coresponding children. A preliminary analysis of data from the child questionnaires of the Children, Adolescents \& Headache Study revealed the presence of a similar situation. While a prevalence rate of $8.0 \%{ }^{9}$ for the 9 - to 14 -year-olds was calculated on the basis of parent report, a substantially higher rate was reported by children and adolescents, namely $16.7 \%$.

In sum, the prevalence rate found in the present study is lower than the rates previously reported for German children and adolescents. Though it is within the range of prevalence rates for weekly headache that have been reported in the extant literature, it appears to underreport headache occurrence in comparison to child report.

\subsection{Correlates of Weekly Headache}

Pediatric headache has received unprecedented scientific attention in the past two decades (McGrath \& Hillier, 2001) and numerous potentially related variables have been examined in this time. An overview of the research on these variables was given in the Theoretical and Empirical Background and the empirical status of the variables was evaluated. The results presented in the overview were primarily based on contingency tables and $\chi^{2}$ tests or regression analyses looking at single independent variables. As a consequence, the empirical status of the variables presented in Table 2 and Table 3 was determined on the basis of single-predictor models or their equivalents. Accordingly, integration of the present research was performed on the basis of single-predictor models comparing weekly headache to good health. The revised status of the variables, subsequent to this integration, is presented in Table 33.

As a reiteration, the classification of the variables as being inconclusively, tentatively, or conclusively associated with weekly headache depended on the number of studies investigating the variable and the reported results: Variables examined in a single study were classified as inconclusive pending further research, as it was thought unsuitable to draw conclusions on the basis of a single study. Variables with conflicting results that were relatively balanced between affirmation and refutation were also classified as being inconclusive (due to contradiction). Variables were classified as tentatively conclusive if they had been corroborated in several studies and the number of studies affirming or refuting the association exceeded the number of opposing studies by at least two. Finally, variables were classified as conclusive if they had been corroborated in several studies and the number of studies affirming or refuting the association exceeded the number of opposing studies by at least four.

\footnotetext{
${ }^{9}$ This prevalence rate differs from the previously reported $6.5 \%$, as it was calculated for the children and adolescents aged 9 to 14. The younger children (7- and 8-year-olds) were excluded in order to make the prevalence rates from parent- and child-report comparable. This was necessary as child questionnaires were only sent to those 9 or older.
} 
Table 33. Empirical status of variables potentially relevant to pediatric weekly headache after integration of the present research

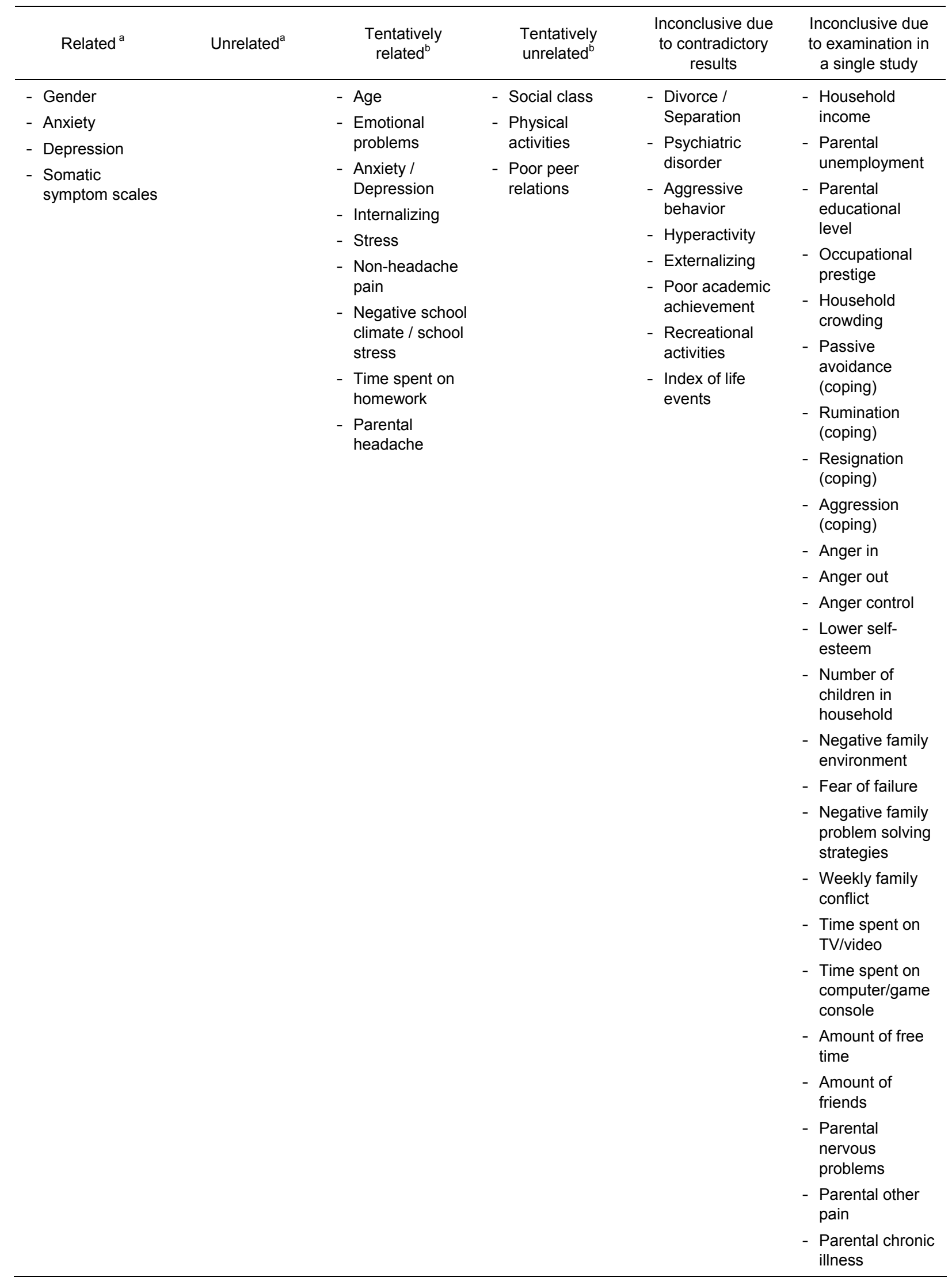

a The number of studies including the present one affirming the variable's status exceeds the number of opposing studies by at least four ${ }^{b}$ The number of studies including the present one affirming the variable's status exceeds the number of opposing studies by at least two 


\subsubsection{Age and Gender}

Weekly headache was associated with age and gender in the analysis of the singlepredictor model of the control variables. Together, age and gender explained $6.5 \%$ of the variance differentiating between weekly headache and good health. The odds ratio indicated that a one-year increase in age was associated with a $27 \%$ higher likelihood of weekly headache. However, gender was the stronger of the two control variables, with female gender being associated with an over twofold higher likelihood of weekly headache.

The empirical status of the variable age as being inconclusive due to contradictory findings is not changed by the present research. Age has not been a major focus of research on weekly headache: Only a few prior studies investigated its association with weekly headache, and the results were conflicting: While an inverse relation between age and prevalence of weekly headache was reported in one study (Kristjánsdóttir \& Wahlberg, 1993), two other studies indicated that the prevalence of weekly headache increased with age (Egermark-Eriksson, 1982; Scheidt et al., 2000). In contrast, three further studies found age and weekly headache to be unrelated (Carlsson, 1996; King \& Sharpley, 1990; Passchier \& Orlebeke, 1985). Including the present research, three studies report a significant positive association between age and weekly headache, one study reports a significant negative relation, and three studies indicate age and weekly headache to be unrelated. Further research is necessary in order to clarify to status of the variable age.

The results regarding gender confirm its empirical status of being related to weekly headache. As yet, no contradictory findings have been reported. All known studies investigating gender and weekly headache have concluded that gender is a highly relevant factor (Bandell-Hoekstra et al., 2001; Brattberg \& Wickman, 1992; Carlsson, 1996; Fichtel \& Larsson, 2002; King \& Sharpley, 1990; Larsson, 1988; Passchier \& Orlebeke, 1985; Rhee, 2000; Scheidt et al., 2000; Sillanpää, 1983; Zwart et al., 2004).

\subsubsection{Sociodemographic Variables}

Weekly headache was significantly associated with household crowding in the singlepredictor analysis. The odds ratio indicated that with a one unit increase in household crowding, the likelihood of weekly headache more than doubled. However, as no other studies on weekly headache have examined this variable, no conclusions regarding its status can be drawn. In addition, research on headache (without regard to frequency) has yielded conflicting results (Karwautz et al., 1999; Sillanpää et al., 1991; Zuckerman et al., 1987), rendering household crowding inconclusive in this area as well. Further research is necessary before it can be determined whether household crowding plays a role in weekly headache.

The other sociodemographic variable, social class, was not significantly associated with weekly headache in the single-predictor model. This is in line with the results from Larsson (1988) in the only other study that has investigated social class (as an aggregate variable) to date. Taken together, these results indicate that social class is tentatively unrelated to weekly headache. 
Though the sociodemographic variables significantly increased model fit in the full model analysis of the domain, the amount variance explained by the two variables (beyond that explained by age and gender) was minimal. In addition, neither of the variables reached significance in the full model.

\subsubsection{Child Psychological Variables}

Weekly headache was associated with anxiety/depression in the single-predictor analysis. The odds ratio indicated that children and adolescents with one standard deviation more anxiety/depression were $70 \%$ more likely to have weekly headache. This corroborates data from Larsson (1988) and thus changes the status of anxiety/depression to that of a variable tentatively related to weekly headache. The relevance of anxiety and depression for weekly headache is further underscored by research that has examined these as separate variables and found both anxiety (Andrasik et al., 1988; Engström, 1992; Fichtel \& Larsson, 2002; Larsson, 1988; Martin-Herz et al., 1999) and depression (Andrasik et al., 1988; Engström, 1992; Fichtel \& Larsson, 2002; Gordon et al., 2004; Martin-Herz et al., 1999) to be significantly associated with weekly headache.

Aggressive behavior and hyperactivity were also significantly associated with weekly headache. The odds ratios indicated that children and adolescents with one standard deviation more hyperactivity were $34 \%$ more likely to have weekly headache. Those with more aggressive behavior were $26 \%$ more likely to have weekly headache. In the only other study to date that has investigated these variables with regard to weekly headache, Gordon et al. (2004) found associations approaching significance were for both variables. However, as only the present research has found significant associations, the status of aggressive behavior and hyperactivity remains inconclusive.

Weekly headache was significantly associated with sleep disturbance in the singlepredictor analysis. The odds ratio indicated that children and adolescents with one standard deviation more frequent sleep disturbances were $50 \%$ more likely to have weekly headache. However, no real conclusions can be drawn regarding the status of the variable, as no other studies on weekly headache have examined it thus far. On the other hand, sleep disturbance was classified as being tentatively related to headache without regard to frequency (see Table 2), as four studies reported a significant association (Aromaa et al., 1998; Grøholt et al., 2003; Laurell et al., 2005; Rhee, 2000) and only one did not (Kowal \& Pritchard, 1990). Further research is necessary before in can be determined, whether sleep disturbances are relevant to weekly headache and the results regarding headache in general suggest it worthwhile to pursue this this issue.

All four of the maladaptive coping strategies (passive avoidance, rumination, resignation, aggression) reached significance in the single-predictor analyses. The odds ratios indicated that children and adolescents with one standard deviation more of the maladaptive coping strategies were $44 \%$ to $51 \%$ more likely to have weekly headache. As this is the only study that has examined stress coping strategies with regard to weekly headache, no conclusions can be drawn regarding the four coping strategies. However, a single study has investigated stress coping with regard to headache (Luka-Krausgrill \& Reinhold, 1996). The authors found adolescents with monthly headache to employ 
avoidance coping significantly more often than those with less frequent or no headache. No differences were found with regard to active or internal coping strategies. On the other hand, Hampel, Rudolph, Stachow, Laß-Lentzsch, and Petermann (2005) found that children and adolescents with chronic illness employed passive avoidance significantly less often than healthy controls. The authors concluded on the basis of this and other findings that "coping with a chronic illness may lead to more effective coping with everyday stressors" (p. 145). With respect to our results, this does not seem to be true for weekly headache.

Of the three types of anger expression, only anger control reached significance in the single-predictor analyses. The odds ratio indicated that one standard deviation less anger control increased the likelihood of weekly headache by $20 \%$. On the other hand, the association between outward expression of anger and weekly headache approached significance. Nevertheless, no real conclusions can be drawn regarding anger control, or inward and outward expression of anger, as these variables have not yet been examined in any other studies on weekly headache. However, the tentative evidence of an association between anger and headache in general (Carlsson et al., 1996; Sillanpää et al., 1991), may be grounds for including anger expression in future research.

As a set, the child psychological variables significantly increased model fit in the full model analysis of the domain and explained a moderate amount $(8.4 \%)$ of the variance differentiating children and adolescents with weekly headache from those without headache (beyond that explained by age and gender). Indeed, child psychological variables ranked second after child health variables among the nine domains with regard to amount of explained variance (see Table 18).

Though nine of the eleven child psychological variables reached significance in the single-predictor analyses, only anxiety/depression and sleep disturbance maintained significance in the multivariate analysis of the full domain model. A one standard deviation increase in anxiety/depression was associated with $41 \%$ higher likelihood of weekly headache. For sleep disturbances the risk of weekly headache increased by $37 \%$. In addition, anger out reached significance in the multivariate analysis of the full model, though it was unrelated to weekly headache in the single-predictor analysis. However, this significance is ascribable to a suppressor effect, rather than indicating that outward expression of anger is a variable relevant to weekly headache in its own right.

\subsubsection{Child Health Variables}

Pain other than headache was significantly associated with weekly headache in the single-predictor analysis and the odds ratio indicated that children and adolescents with nonheadache pain had an over twofold increased risk of weekly headache. This is in line with research by Fichtel and Larsson (2002), in which two-thirds of the adolescents with weekly headache reported experiencing at least one further weekly pain. Half of these had a single additional pain, while the others experienced two or more additional weekly pains. This combined with the present research makes pain other than headache a variable tentatively related to weekly headache.

The second child health variable, other somatic complaints was also significantly associated with weekly headache in the single-predictor analysis. The odds ratio indicated 
that children and adolescents with one standard deviation more somatic complaints were also at an over twofold higher risk of experiencing weekly headache. Nevertheless, no conclusions regarding the status of this variable can be drawn, as no other studies on weekly headache have examined somatic complaints (excluding pain) as an individual variable.

Noteworthy is, however, that a number of prior studies on weekly headache have employed somatic symptoms scales, i.e., composite measures encompassing both nonheadache pains and other physical symptoms. Scores on these scales have been consistently found to be associated with weekly headache (Andrasik et al., 1988; Engström, 1992; Larsson, 1988; Martin-Herz et al., 1999). Somatic symptoms (including pain) were accordingly classified as a variable related to weekly headache in Table 3. Unfortunately, these studies did not differentiate between non-headache pain and other somatic symptoms. Thus it is not possible to determine whether the elevated scores were due to one or the other of the variables, or both together. The results of the present study seem to indicate that both are relevant. This issue warrants clarification in future research.

Taken together, the child health variables significantly increased model fit in the multivariate analysis of the full domain model and explained a moderate amount $(14.5 \%)$ of the variance in health outcome (weekly headache vs. good health). Indeed, child health variables ranked first in amount of explained variance among the nine domains (see Table 18). In addition, both variables maintained significance in the multivariate analysis of the full domain model. The odds ratios indicated that the likelihood of experiencing weekly headache increased by $70 \%$ with a one standard deviation increase in non-headache pains and by or $72 \%$ with a one standard deviation increase in other somatic symptoms.

\subsubsection{Family Variables}

Weekly headache was not significantly related to whether the child lived in a one- or two-parent household in the single-predictor analysis. This is in contrast to Larsson's (1988) report that parents of children with headache were significantly more often divorced than those of healthy controls. However, the majority of these parents had been divorced for at least three years and no information was given on potential new relationships. Though often correlated, the number of parents in a household is not exclusively dependent on marital status. Taken together, the status of the variable one- vs. two-parent household is inconclusive. Differentiating between marital status and number of (biological or other) parents in a household seems appropriate in modern times and would help to clarify the role this family variable may play with regard to weekly headache.

Single-predictor analysis also indicated the number of children in the household was not significantly associated with weekly headache. This is in line with research on headache in general, which has consistently found headache to be unrelated to number of siblings (Aromaa et al., 1998; Carlsson et al., 1996; Metsähonkala et al., 1998). However, as the variable has not been investigated with regard to weekly headache in any further studies, no real conclusions regarding its status can be drawn.

On the other hand, weekly headache was significantly associated with both negative family environment and weekly family conflict in the single-predictor model analyses. Negative family environment was the weaker of the two variables, with a one standard 
deviation increase thereof being associated with a $21 \%$ higher risk of weekly headache. In contrast, children and adolescents in families with weekly conflict had a $69 \%$ increased risk of weekly headache. Surprisingly, the variable negative conflict solving strategies was not significantly associated with weekly headache, despite its similarity to negative family environment and weekly conflict. As no other studies on weekly headache have investigated these variables, their status is inconclusive pending further research. Similar findings regarding headache in general (Aromaa et al., 2000; Brattberg, 1994; Kowal \& Pritchard, 1990 ) may be seen as indicating it worthwhile to pursue these variables.

Though family variables, as a set, significantly increased model fit in the multivariate analysis of the full domain model, the amount of the variance that they explained was minute $(1.3 \%)$. Family variables ranked eighth in amount of explained variance among the nine domains (see Table 18). In addition, neither of the two family variables that reached significance in the single-predictor analyses was able to maintain significance in the full domain model analysis.

\subsubsection{School Variables}

The index of school difficulties, which encompassed a number of indications of poor academic achievement, was significantly associated with weekly headache in the singlepredictor analyses. The odds ratio indicated that the presence of an additional academic difficulty increased the risk of weekly headache by $64 \%$. However, prior research on weekly headache has yielded contradictory results: Gordon et al. (2004) reported poor academic achievement to be related to weekly headache, but no such relation was found by Engström (1992). Taken together, the status of the variable poor academic achievement remains inconclusive due to contradictory results.

Single-predictor analysis also indicated that time spent on homework was significantly associated with weekly headache. According to the odds ratio, children and adolescents who spent more than 3 hours per day on homework were almost tenfold more likely to have weekly headache than those who spent less than an hour a day on homework. It could be postulated this association is an artifact, attributable to age-related increases in prevalence of weekly headache and amount of homework. However, the single-predictor model controlled for age, making this argument dismissible. Furthermore, the result is in line with data from the study by Larsson (1988). Therefore time spent on homework can be classified as a variable tentatively related to weekly headache.

Negative school climate (what was called school stress in the present research) was also associated with weekly headache. The odds ratio indicated that an increase in school stress of one standard deviation was associated with a $77 \%$ increase in risk of weekly headache. Thus the present research corresponds with the results reported by Gordon et al. (2004). As a consequence, the status of the variable negative school climate can be classified as tentatively related to weekly headache. This is in line with research on headache in general, which has also documented an association between negative school climate and headache (Brattberg, 1994; Metsähonkala et al., 1998; Williams et al., 1996).

Finally, weekly headache was also associated with fear of failure. The odds ratio indicated that a one standard deviation increase in neurotic reaction to failure was associated 
with a $42 \%$ increase in risk of weekly headache. However, as the variable has not been investigated with regard to weekly headache in any further studies, no real conclusions regarding its status can be drawn. Research on headache in general has yielded conflicting results with two studies reporting a significant association between fear of failure and headache (Metsähonkala et al., 1998; Passchier \& Orlebeke, 1985) and one finding the two to be unrelated (Karwautz et al., 1999).

Taken together, school variables significantly increased model fit in the multivariate analysis of the full domain model. They explained a moderate amount of the variance $(7.3 \%)$ differentiating children and adolescents with weekly headache from those in good health. Indeed, school variables ranked third among the nine domains in amount of explained variance (see Table 18). Nevertheless, though all four variables reached significance in the single-predictor models, only two maintained significance in the full domain model, namely time spent on homework and negative school climate. According to the odds ratio from the full domain model, children and adolescents who spent more than 3 hours per day on homework were almost sevenfold more likely to have weekly headache than those who spent less than an hour a day on homework. Furthermore, those with one standard deviation more negative school climate were at a $66 \%$ higher risk of weekly headache.

\subsubsection{Leisure Variables}

Neither physical activities nor other recreational activities were significantly associated with weekly headache in the single-predictor analyses of the present research. A previous study also documented the lack of significant associations between weekly headache and these variables (Gordon et al., 2004). In contrast, Engström (1992) found children and adolescents with weekly tension-type headache to score significantly lower on an aggregate measure of physical and recreational activities and household tasks than healthy controls. The latter data, however, does not lend itself to integration as it allows no differentiation between the three types of activities. Therefore, on the basis of the present research and the study by Gordon et al. (2004) physical and other recreational activities are classified as variables tentatively unrelated to weekly headache.

Amount of free time was not associated with weekly headache in the single-predictor analysis. However, it is not possible to draw conclusions regarding the status of this variable, as no other studies on weekly headache have examined it to date. Nor has it been examined in research on headache in general. Thus the variable is classified as being inconclusive.

Time spent watching TV / video was significantly associated with weekly headache in the single-predictor analysis. The odds ratio indicated one standard deviation of more time spent watching TV or videos was associated with a $30 \%$ higher risk of weekly headache. Unfortunately, no other studies on weekly headache have examined this variable to date. Thus it is classified as being inconclusive due to lack of further research. Noteworthy is, however, that research on headache has identified watching TV as a headache trigger (Luka-Krausgrill \& Reinhold, 1996) and that, compared to their headache-free counterparts, children with headache have been reported to watch significantly more television (Aromaa et al., 2000). 
The leisure variable time spent on computer / game console was not significantly associated with weekly headache in the single-predictor analysis. Unfortunately, the present research is, once again, the only study on weekly headache that has examined this variable to date. Time spent using a computer or game console is, therefore, classified as inconclusive pending further research. It may, however, be worthwhile to include this variable in future studies, as it was reported to be significantly associated with headache (without regard to frequency) in the only other study that has examined the variable to date (Oksanen et al., 2005).

Weekly headache was not significantly associated with amount of friends in the single-predictor analysis. This seems to correspond with Engström's (1992) finding that children with weekly tension-type headache did not differ from healthy controls on an aggregate measure tapping amount of friends, quality of peer relationships, and hobbies. However, as Engström did not differentiate between the constituent variables of the aggregate measure, it is not possible to integrate the results. Accordingly, the status of the variable amount of friends remains classified as being inconclusive.

Though leisure variables, as a set, significantly increased model fit in the multivariate analysis of the full domain model, the amount of the variance that they explained was minimal $(2.3 \%)$. Leisure variables ranked sixth in amount of explained variance among the nine variable domains (see Table 18). Nevertheless, time spent on TV / video, the only variable that reached significance in the single-predictor analysis, was able to maintain its significance in the full model. According to the odds ratio, a one standard deviation increase in time spent watching TV or videos was associated with a $40 \%$ higher risk of weekly headache. Amount of free time also reached significance in the multivariate analysis of the full domain model, though it was unrelated to weekly headache in the single-predictor analysis. However, this significance is attributable to a suppressor effect, rather than indicating that lack of free time is a variable relevant to weekly headache.

\subsubsection{Life Events}

Number of life events was significantly associated with weekly headache in the present research. The odds ratio indicated that experiencing an additional life event increased the risk of having weekly headache by $29 \%$. However, previous research stands in contrast: Andrasik et al. (1988) found life events to be unrelated to weekly headache. No other studies on weekly headache have investigated life events to date. Therefore the variable is classified as inconclusive due to contradictory results. Interestingly, research on headache in general yields a similar lack of clarity, with one study that documented a significant association (Liakopoulou-Kairis et al., 2002) and two that did not (Cooper et al., 1987; Kowal \& Pritchard, 1990).

Inclusion of the index of life events significantly increased model fit in the multivariate analysis of the domain. However, the amount of variance explained by the index was minimal $(1.4 \%)$. Life events ranked seventh in amount of explained variance among the nine domains (see Table 18). 


\subsubsection{Parental Psychological Variables}

Parental anxiety/depression was significantly associated with weekly headache in the single-predictor analysis. The odds ratio indicated that one standard deviation increase in parental anxiety/depression was associated with a $51 \%$ increase in risk of weekly headache. This is in line with Larsson's (1988) finding that weekly headache was associated with parental "nervous problems". Thus the variable parental anxiety/depression is classified as being tentatively related to weekly headache.

Weekly headache was also significantly associated with parental habitual worry in the single-predictor analysis. The odds ratio indicated that with an increase of one standard deviation in parental worry the risk of weekly headache increased by $44 \%$. However, no other study on weekly headache has investigated parental worry to date, thus no real conclusions can be drawn regarding this variable. Nevertheless, the results of the present study suggest that inclusion of this variable in future research would be worthwhile.

The final of the three parental psychological variables, parental sleep disturbance, was also significantly associated with weekly headache. The odds ratio indicated that with one standard deviation increase in frequency of sleep disturbances, the risk of weekly headache increased by $35 \%$. Unfortunately, this is the only study to date that has investigated parental insomnia with regard to weekly headache. Therefore no conclusions regarding the variable can be drawn, due to lack of sufficient studies. However, one study that looked at parent insomnia and child's headache (without regarding frequency) found a significant association between the two (Grøholt et al., 2003). This may be seen as grounds for inclusion of this variable in future research.

Taken together, parental psychological variables significantly improved model fit in the multivariate analysis of the full domain model. However, they only explained a small amount of variance $(3.2 \%)$ beyond that explained by the control variables age and gender. Parental psychological variables ranked fifth among the nine domains with regard to the amount of explained variance (see Table 18). Furthermore, though all three variables reached significance in the single-predictor model, none of them was able to maintain significance in the full domain model.

\subsubsection{Parental Health Variables}

In the final of the nine domains, parental health, all six of the examined variables reached significance in the single-predictor analyses. General health was significantly associated with weekly headache. However, in contrast to the other parental health variables this association was negative: The odds ratio indicated that an increase in parental general health of one standard deviation was associated with a $52 \%$ reduction in risk for child's weekly headache. As this is the first study that has looked at general health and weekly headache, no conclusions can be drawn with regard to this variable. Interestingly, two studies looking at headache (without regard to frequency) reported it to be unrelated to parental general health (Karwautz et al., 1999; Zuckerman et al., 1987).

The related variables number of doctor appointments and regular medication were also significantly associated with weekly headache. The odds ratio indicated that an increase 
of one standard deviation in the frequency of parental doctor appointments was associated with a $20 \%$ increase in child's risk of weekly headache. Children of parents taking regular medication had a $71 \%$ higher risk of weekly headache than those whose parents did not. However, as this is the first study to look at these variables with regard to weekly headache, it is not possible to draw conclusions regarding their status.

Weekly headache was also significantly associated with parental headache in the single-predictor analysis. The odds ratio indicated that child's risk of weekly headache was over threefold higher when there was a parental history of headache. This is in line with data from Larsson (1988). Thus, parental headache can be classified as a variable tentatively related to weekly headache. Furthermore, taking data on headache (without regard to frequency) into account, it seems highly probable that future research will confirm this association. As yet, negative results have not been reported, and the number of studies indicating an association between parental and child headache is substantial (Aromaa et al., 1998; Aromaa et al., 1998; Grøholt et al., 2003; Larsson, 1988; Mortimer et al., 1992; Virtanen et al., 2002; Waldie \& Poulton, 2002).

Parental pain other than headache was also associated with weekly headache, though not as strongly as parental headache was. The odds ratio indicated that an increase of one standard deviation in parental other pain was associated with a $22 \%$ increase in the risk of weekly headache. The only other study that has looked at weekly headache and parental other pain found an association that approached significance (Larsson, 1988). However, as only the present research has found a significant association, the status of parental pain other than headache is still inconclusive. On the other hand, research on headache in general has indicated that child's headache is related to certain non-headache pains in the parent, e.g., back and abdominal pain (Grøholt et al., 2003), and maternal (but not paternal) weekly pain (Brattberg, 1994). These results seem to indicate that the variable warrants inclusion in future research.

The last of the parental health variables, other somatic complaints, was also significantly associated with weekly headache in the single-predictor analysis. The odds ratio indicated that children of parents with one standard deviation more other somatic complaints were at a $24 \%$ increased risk of weekly headache. To date, this is the only study that has investigated parental other somatic complaints. Therefore no conclusions can be drawn regarding this variable. However, research on headache in general has indicated that child's headache is related to some individual somatic complaints in the parent, e.g., dizziness and loss of appetite (Grøholt et al., 2003). This suggests that inclusion of the variable in future studies would be worthwhile.

As a set, the parental health variables significantly improved model fit in the multivariate analysis of the full domain model. However, they only explained a small amount of variance beyond that explained by the control variables age and gender $(5.3 \%)$. This domain ranked fourth with regard to the amount of explained variance. Though all six variables reached significance in the single-predictor model, only parental headache was able to maintain significance in the full domain model. The odds ratio indicated that children had an almost threefold higher risk of weekly headache when there was a parental history of headache. 


\subsubsection{Summary}

In sum, in the present study the sets of variables explaining a fair amount of variance beyond the control variables (age and gender) were child health variables, child psychological variables, and to a lesser degree school variables and parental health variables. The contribution of all other domains was minimal or negligible. Concerning individual variables, the present study corroborated previous findings in establishing gender as a confirmed correlate of weekly headache, and anxiety/depression, pain other than headache, negative school climate, parental headache and parental pain other than headache as tentative correlates thereof.

In addition, a number of variables, whose relevance to weekly headache was examined in the present research for the first time, reached significance in the singlepredictor analyses. These variables warrant inclusion in future research in order to elucidate their status: Household crowding, sleeping disorders, maladaptive coping strategies (passive avoidance, rumination, resignation, aggression), anger control, other somatic complaints, negative family environment, weekly family conflict, time spent on TV / video, parental habitual worry, parental sleep disturbances, number of parental doctor appointments, parental regular medication, and parental other somatic complaints.

Finally, a number of the variables that attained significance in the single-predictor models were also able to maintain it in their respective full domain model. These variables formed the basis for the aggregate model for weekly headache, the topic of the next section.

\subsection{Aggregate Model for Weekly Headache vs. Good Health}

A total of eleven variables were identified in the full model analyses of the individual variable domains as being significantly $(p \leq .01)$ associated with weekly headache and were thus included in the aggregate model. In addition to the control variables age and gender, the aggregate model comprised the following variables: Anger out, anxiety/depression, sleep disturbance, pain other than headache, other somatic complaints, time spent on homework, school stress, amount of free time, time spent on TV / video, index of life events, and parental headache. Inclusion of these variables, as a set, significantly improved model fit in the multivariate analysis of the aggregate model. Altogether, the aggregate model explained $26.2 \%$ of the variance differentiating children and adolescents with weekly headache from those in good health.

Most prior research on headache has employed single-predictor models or their equivalents. Only a few studies have conducted multivariate analyses of full models and only one of them examined weekly headache (Larsson, 1988). Three others looked at headache frequency (Kowal \& Pritchard, 1990; Luka-Krausgrill \& Reinhold, 1996; Passchier \& Orlebeke, 1985), and one study each focused on headache (Laurell et al., 2005) and recurrent headache (Grøholt et al., 2003). Therefore, in order to have a broader perspective, the results from all six of these prior studies employing multivariate analyses will be presented as context.

The amount of headache-related variance explained in these studies has varied widely. Two of the studies reported substantial explained variance: Larsson (1988) 
investigated a full model consisting of ten variables that had demonstrated significance in univariate analyses. Six of these maintained their significance in the multivariate model and were able to explain $48 \%$ of the variance differentiating adolescents with weekly headache from those without. Luka-Krausgrill and Reinhold (1996) entered all of the twelve variables investigated in their study into a full model analysis. Five of the variables reached significance therein and explained $45 \%$ of the variance in headache frequency. In contrast, much lower amounts of explained variance in headache frequency were reported by Passchier and Orlebeke (1985): For children attending elementary school 12.1\%, and 9.2\% for those in secondary school. In the study by Kowal and Pritchard (1990), none of the four variables entered into the multivariate model contributed significantly to the prediction of headache frequency and no information regarding the explained variance was reported, though it was presumably minimal given the non-significance of the individual variables. In the final two studies, the multivariate analysis results were only reported regarding the individual variables and their significance, the total amount explained variance was not documented (Grøholt et al., 2003; Laurell et al., 2005).

Noteworthy is that the higher amount of variance explained in the study by Larsson (1988) may be due, in part, to the inclusion of the variable "school absence due to somatic complaints" in the multivariate analysis. According to the t-values, this variable was the second most important in the model. Therefore, a sizeable amount of the explained variance was attributable to this variable. As the headache group was composed of adolescents with weekly headache, recruited with the offer of subsequent psychological treatment, it is possible that these adolescents frequently experienced disabling headaches that interfered with their ability to attend school. As the author did not differentiate between school absence due to headache and school absence due to other somatic symptoms, the association between headache frequency and school absence could be ascribable to this overlap.

Perhaps the source of information may have influenced the amount of variance that was explained in the present research. In the study by Larsson (1988), three different sources of information were employed: adolescent, parent, teacher. In the multivariate model both child- and parent-report variables contributed significantly to the explained variance. Only one source of data was utilized in the studies by Passchier and Orlebeke (1985) and Luka-Krausgrill and Reinhold (1996), namely the children. In contrast, the present aggregate model employed parent report only. It is possible that this may have lessened the amount of explained variance. Other the other hand, the child-report variables in the study from Passchier and Orlebeke (1985) explained less variance than the parent-report variables of the present study.

In sum, the amount of explained variance in the present research was lower than that reported by Larsson (1988) and Luka-Krausgrill and Reinhold (1996), yet greater than that reported by Passchier and Orlebeke (1985). Presumably, it also exceeded the amount of variance explained by the multivariate model from Kowal and Pritchard (1990). 
Turning to the individual variables included in the aggregate model, only four of the eleven variables were able to maintain significance in the multivariate analysis, namely

- pain other than headache,

- other somatic complaints,

- school stress, and

- parental headache.

Interestingly, though age remained significant in the aggregate model, the control variable gender only approached significance.

Again, in order to place these results in context, it is important to have an overview of the results regarding individual variables from the multivariate models in prior studies. Results from the six studies are presented in Table 34. In the top half of the table those variables are listed that maintained significance in the multivariate analysis, in the bottom half those variables that did not. As the outcome variables examined in the studies differed somewhat, these are also noted in the table.

In the present research, the control variable age was significantly associated with weekly headache. The odds ratio indicated that with an increase in age of one year, the likelihood of having weekly headache increased $16 \%$. This is in line with the results reported by Luka-Krausgrill and Reinhold (1996), who found age to be significantly associated with headache frequency in their multivariate analysis. However, a further study investigating age and headache frequency in a multivariate model reported contradictory results (Passchier \& Orlebeke, 1985). In this study two multivariate models were tested, one for children in elementary school and one for those in secondary school. It is possible that age could not achieve significance in the elementary school model as only two grades from the elementary school were assessed and the total variance in age was therefore limited. Within the model for children attending secondary school (four grades were assessed), the authors found a significant age-gender interaction. However, age itself remained non-significant. Finally, age was not significantly associated with headache in the multivariate model tested by Laurell et al. (2005). However, this is not meaningful as the headache and non-headache groups were matched for age.

The association between gender, the second control variable, and weekly headache approached significance in the present aggregate model. The odds ratio indicated that girls were at a $55 \%$ higher risk for weekly headache. However, contradictory results have been reported in the literature. While Passchier and Orlebeke (1985) found gender to be significantly related to headache frequency in their multivariate model, Luka-Krausgrill and Reinhold (1996) did not. In the study by Laurell et al. (2005) the headache and nonheadache groups in the study were matched for gender, therefore their results are not interpretable.

Both pain other than headache and other somatic complaints were significantly associated with weekly headache in the multivariate analysis of the aggregate model. The odds ratios indicated that with a one standard deviation increase in pain other than headache, children were at a $55 \%$ higher risk of weekly headache and with one standard deviation increase in other somatic complaints at a $57 \%$ higher risk. This is in line with data 
from Grøholt et al. (2003) who showed recurrent headache to be significantly associated with abdominal and back pain as well as loss of appetite and dizziness in a multivariate model. No other pain locations or physical symptoms were assessed in the study, therefore, it can be concluded that recurrent headache (at least once every other week) was significantly associated with other recurrent pains and other recurrent somatic symptoms. In addition, studies using scales encompassing both non-headache pain and other somatic symptoms found these symptoms to be significantly related to headache (Laurell et al., 2005) and weekly headache (Larsson, 1988) in multivariate models. On the other hand, somatic symptoms as assessed via parent-report were not significantly related with headache in Laurell et al.'s (2005) multivariate analysis. Two other studies have documented opposing results as well: Neither Kowal and Pritchard (1990) nor Luka-Krausgrill and Reinhold (1996) found somatic symptoms to be related to headache frequency.

Table 34. Variables examined in multivariate analyses in pediatric headache research and their significance or non-significance

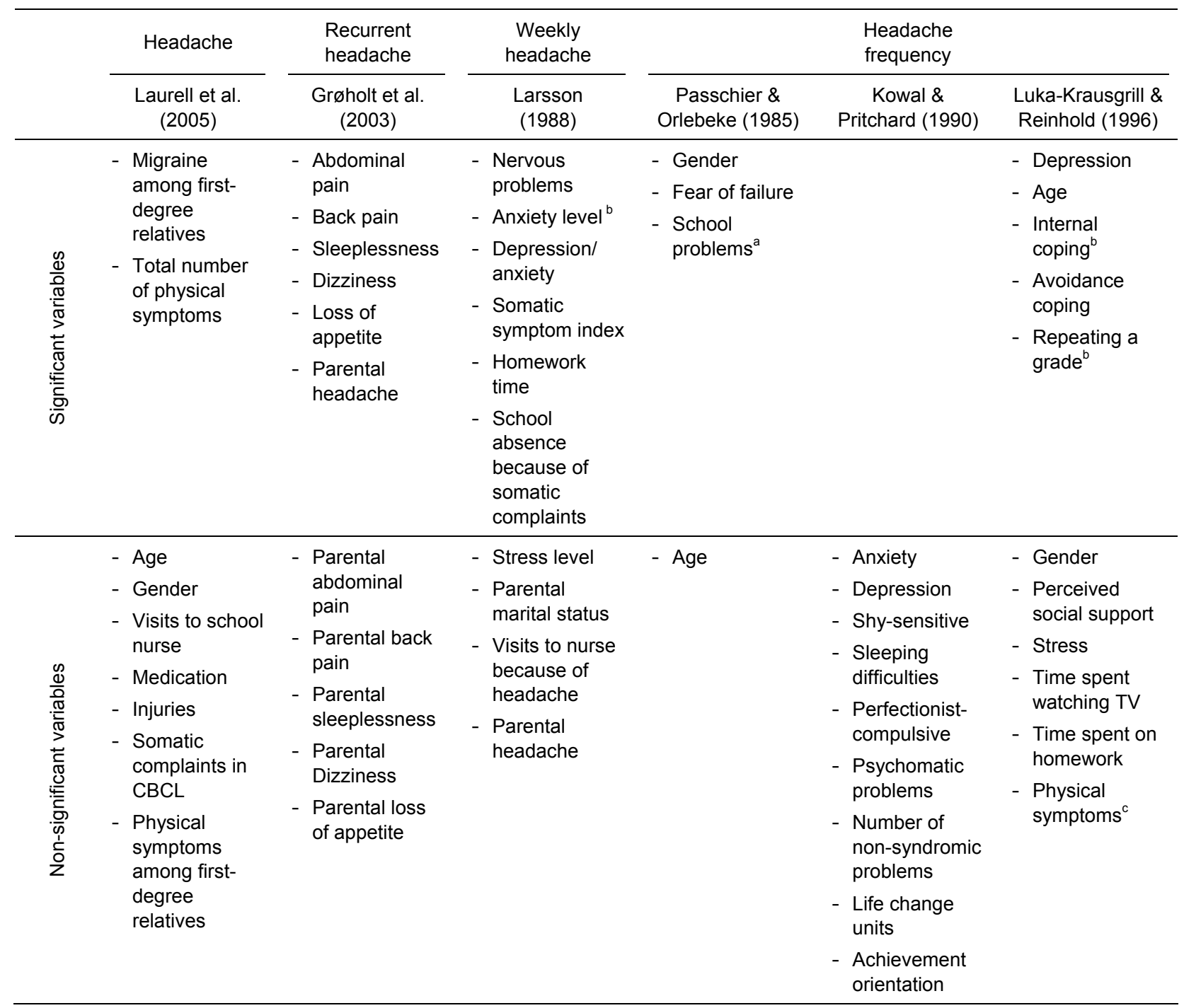

\footnotetext{
a School problems was only significant in the model for children in elementary schools, not for those in secondary schools

b The association with this variable was negative

${ }^{c}$ This variable was not explicitly listed among the non-significant variables, but appears to have been non-significant
} 
Parental headache also maintained significance in the full aggregate model of the present study. The odds ratio indicated that children had an over twofold higher risk of weekly headache when there was a parental history of headache. This is in line with data from Grøholt et al. (2003), who found parental recurrent headache to be significantly associated with child's recurrent headache in a multivariate model. Similarly, migraine among first-degree relatives was significantly associated with child's headache in the multivariate model reported by Laurell et al. (2005). In contrast, the only previous study on weekly headache that conducted a multivariate analysis reported parental headache to be unrelated to child's headache (Larsson, 1988).

The final of the four variables that maintained significance in the multivariate analysis of the present study was negative school environment. The odds ratio indicated that a one standard deviation increase in school stress was associated with a $39 \%$ higher risk of weekly headache. None of the prior multivariate studies investigated negative school environment. Instead, their models included school variables tapping poor academic achievement (LukaKrausgrill \& Reinhold, 1996; Passchier \& Orlebeke, 1985) or fear of failure (Passchier \& Orlebeke, 1985).

It is not only of interest, which variables maintained significance in the aggregate model, but also which did not. A total of seven variables were not significantly associated with weekly headache in the multivariate analysis, namely

- outward expression of anger,

- anxiety/depression,

- sleep disturbance,

- time spent on homework,

- amount of free time,

- time spent on TV/video, and

- life events.

The present study is the first to examine outward expression of anger with regard to weekly headache. Therefore, it is not possible to compare the present results with any further research. It should be noted, however, that anger-out was included in the aggregate model due to its significance in the full domain model of child psychological variables, though it was not significantly associated with weekly headache in the single-predictor analysis. Thus, the significance of the variable in the full model analysis was due to a suppressor effect. Apparently the combination of variables in the aggregate model for weekly headache did not lend themselves to the creation of a suppressor effect the way the child psychological variables did. Inspection of the correlation matrices supports this assumption (see Appendixes $D$ and $E$ ): While moderate intercorrelations ( $r \geq 350)$ occurred between anger-out and four of other child psychological variables, no such intercorrelations were present in the aggregate model.

Though the variable anxiety/depression has been classified as being tentatively related to weekly headache, it was not able to maintain its significance in the present aggregate model. This result was unexpected and stands in contrast to data reported by Larsson (1988), who found anxiety/depression to be significantly related to weekly headache in his multivariate analysis. In addition, it also conflicts with results from studies on weekly 
headache that examined anxiety and depression as separate variables and led to the classification of each as being conclusively related to weekly headache. However, the correlation matrix for the aggregate model supplies a possible explanation for the present results (see Appendix E): Anxiety/depression was moderately intercorrelated with two of the other variables: School stress ( $r=.501)$, and other somatic complaints $(r=.356)$. It was also correlated with both sleep disturbances and pain other than headache, though to a somewhat lesser degree (both $r=.308$ ). As both school stress and pain other than headache attained significance in the aggregate model, it is possible that the overlap between these variables and anxiety/depression rendered the latter insignificant in the full aggregate model.

Studies that examined anxiety and depression as separate variables in multivariate analyses reported mixed results: While Luka-Krausgrill and Reinhold (1996) documented the presence of a significant association between depression and headache frequency, Kowal and Pritchard (1990) found neither anxiety nor depression to be significantly associated with headache frequency in their multivariate analysis. However, the small size of the sample employed in the latter study $(n=46)$ may have contributed to the non-significance. Finally, Larsson (1988) found a measure of anxiety to be significantly, albeit inversely, related to weekly headache in his multivariate analysis. This was surprising, as anxiety had been positively associated with weekly headache in the univariate analysis. Unfortunately, Larsson (1988) did not comment on this peculiarity. The statistical pattern, however, points to a negative suppressor effect (Bortz, 1989).

Sleep disturbance was a further variable that was unable to maintain significance in the multivariate analysis. The present study was the first to examine this variable with regard to weekly headache. Therefore, the variable was classified as inconclusive though warranting further research because of its tentative relation to headache in general. The present multivariate result of non-significance stands in conflict with data from Grøholt et al. (2003), in which sleep disturbance was related to recurrent headache. Again, the nonsignificant result of the present research could, perhaps, be due to overlap between sleep disturbance and three of the other variables in the aggregate model: Sleep disturbance was correlated with anxiety/depression ( $r=.308)$, pain other than headache $(r=.334)$, and other somatic complaints ( $r=.383$; see Appendix E). On the other hand, non-significance has also been reported by Kowal and Pritchard (1990), who found sleep disturbance to be unrelated to headache frequency.

Though the variable time spent on homework has been classified as being tentatively related to weekly headache, it was not able to maintain its significance in the present aggregate model. This result stands in contrast to data reported by Larsson (1988), who found time spent on homework to be significantly related to weekly headache in his multivariate analysis. It is, however, in line with data from one of the other multivariate studies which found time spent on homework to be unrelated to headache frequency (LukaKrausgrill \& Reinhold, 1996).

Amount of free time was a further of the seven variables that did not reach significance in the analysis of the aggregate model for weekly headache. Unfortunately it is not possible to compare this result with previous research, as the present study was the first to examine amount of free time. As was the case with anger-out, amount of free time was 
included in the aggregate model due to its significance in the full model of its domain, though it was not significantly associated with weekly headache in the single-predictor analysis. Thus, the significance of the variable in the full model analysis was due to a suppressor effect. Apparently the combination of variables in the aggregate model for weekly headache did not lend themselves to the creation of a suppressor effect the way the leisure variables did.

The present study was also the first to examine time spent watching TV / video with regard to weekly headache. Therefore, it is not possible to compare the present nonsignificant results with any further research. However, the present non-significance is in line with data from Luka-Krausgrill and Reinhold (1996), who found time spent watching TV to be unrelated to headache frequency in their multivariate analysis.

Finally, number of life events did not reach significance in the present aggregate model for weekly headache. This is in line with data from the only other multivariate study that examined the variable and found units of life change to be unrelated to headache frequency (Kowal \& Pritchard, 1990).

Up until now, multivariate models like the present aggregate model for weekly headache have only been examined in a limited number of headache studies: Only one prior study on weekly headache and six prior studies in total have conducted such analyses. Results from all six of these studies were taken into account in the discussion of the aggregate model of weekly headache. In sum, no set of variables consistently reached significance in multivariate analyses. However, pain other than headache, other somatic complaints, and parental headache were able to assert themselves in more multivariate analyses than not. It is conspicuous that these "assertive" variables were somatic or biological in nature, while the results regarding the examined psychosocial variables were more evenly balanced between significance and non-significance.

Research on headache would profit from a more widespread usage of multivariate analyses, as these promote a better understanding of the interrelations between examined variables (Glantz \& Slinker, 2001), rather than disregarding other variables and their interrelations in order to focus on a single variable of interest, as is the case in singlepredictor models. At the same time, the taking into account of other variables and their interrelations can complicate the interpretation of results. It would, therefore, be advantageous if both types of analyses were included in future studies.

\subsection{Specificity Model (Weekly Headache vs. Chronic Illness)}

As an intermediate step prior to calculation of the specificity model, it was necessary to determine which variables were significantly associated with chronic illness. These analyses were not only conducted to determine the correlates of chronic illness but also to ensure that all variables were included in the specificity analyses that were either significantly correlated with weekly headache or with chronic illness. As the analyses regarding chronic illness primarily serve the purpose of identifying correlates of chronic illness for inclusion in the specificity model, the results are summarized in Table 35 along with the results from the analyses comparing weekly headache to good health. The table indicates which variables 
were significantly associated with weekly headache (left-hand side) and chronic illness (righthand side) on the basis of both the single-predictor models and the full domain analyses. The variable domains explained between $1.1 \%$ and $14.5 \%$ of the variance differentiating children with weekly headache from those in good health. With regard to chronic illness the same domains only explained $0.1 \%$ to $1.8 \%$ of the variance.

Table 35 makes the discrepancy in the amount of variables significantly related to weekly headache as opposed to the amount related to chronic illness quite apparent. Including age and gender, 29 variables were significantly associated with weekly headache in single-predictor analyses and 13 of these maintained significance in the multivariate analyses of the respective variable domains. In comparison, 9 variables were significantly associated with chronic illness in the single-predictor analyses and a mere 3 variables maintained significance in the full model analyses of the respective domains. With regard to the variables reaching significance in the multivariate analyses there was an overlap. Two of the three variables significantly associated with chronic illness were also significantly associated with weekly headache in domain analyses: Sleep disturbance and school stress.

Table 35. Variables that reached significance in the single-predictor model and full domain model analyses

\begin{tabular}{|c|c|c|c|c|c|}
\hline \multirow[t]{2}{*}{ Domain } & \multirow[t]{2}{*}{ Variable } & \multicolumn{2}{|c|}{ Weekly headache } & \multicolumn{2}{|c|}{ Chronic illness } \\
\hline & & $\begin{array}{c}\text { Single-predictor } \\
\text { model }\end{array}$ & $\begin{array}{l}\text { Full domain } \\
\text { model }\end{array}$ & $\begin{array}{c}\text { Single-predictor } \\
\text { model }\end{array}$ & $\begin{array}{c}\text { Full domain } \\
\text { model }\end{array}$ \\
\hline \multirow{2}{*}{$\begin{array}{l}\text { Control } \\
\text { variables }\end{array}$} & Age & $x$ & $x$ & & \\
\hline & Gender & $x$ & $x$ & & \\
\hline \multirow{8}{*}{$\begin{array}{l}\text { Sociodemo- } \\
\text { graphic } \\
\text { variables }\end{array}$} & Social class & & & & \\
\hline & Household crowding index ${ }^{a}$ & & & & \\
\hline & Maladaptive coping & & & & \\
\hline & Passive avoidance $^{a}$ & $x$ & & & \\
\hline & Rumination $^{a}$ & $x$ & & & \\
\hline & Resignation $^{a}$ & $x$ & & & \\
\hline & Aggression $^{a}$ & $x$ & & & \\
\hline & Anger expression & & & & \\
\hline \multirow{7}{*}{$\begin{array}{l}\text { Psychological } \\
\text { variables }\end{array}$} & Anger-in ${ }^{a}$ & & & & \\
\hline & Anger-out ${ }^{\mathrm{a}}$ & & $x$ & $x$ & \\
\hline & Anger control $^{\mathrm{a}}$ & $x$ & & & \\
\hline & Anxiety/depression ${ }^{a}$ & $x$ & $x$ & & \\
\hline & Hyperactivity $^{a}$ & $x$ & & & \\
\hline & Aggressive behavior $^{a}$ & $x$ & & & \\
\hline & Sleep disturbance ${ }^{a}$ & $x$ & $x$ & $x$ & $x$ \\
\hline
\end{tabular}

\footnotetext{
${ }^{\mathrm{a}}$ Z-scores
} 
Table 35. continued

\begin{tabular}{|c|c|c|c|c|c|}
\hline & & \multicolumn{2}{|c|}{ Weekly headache } & \multicolumn{2}{|c|}{ Chronic illness } \\
\hline & & $\begin{array}{l}\text { Single-predictor } \\
\text { model }\end{array}$ & $\begin{array}{l}\text { Full domain } \\
\text { model }\end{array}$ & $\begin{array}{l}\text { Single-predictor } \\
\text { model }\end{array}$ & $\begin{array}{l}\text { Full domain } \\
\text { model }\end{array}$ \\
\hline \multirow{2}{*}{$\begin{array}{c}\text { Health } \\
\text { variables }\end{array}$} & Pain other than headache ${ }^{a}$ & $x$ & $x$ & & \\
\hline & Other somatic complaints ${ }^{a}$ & $x$ & $x$ & $x$ & \\
\hline \multirow[t]{5}{*}{$\begin{array}{c}\text { Family } \\
\text { variables }\end{array}$} & $\begin{array}{l}\text { Number of parents in } \\
\text { household }\end{array}$ & & & & \\
\hline & $\begin{array}{l}\text { Number of other children in } \\
\text { household }\end{array}$ & & & & \\
\hline & $\begin{array}{l}\text { Negative family } \\
\text { environment }^{\mathrm{a}}\end{array}$ & $x$ & & & \\
\hline & $\begin{array}{l}\text { Negative conflict solving } \\
\text { strategies }^{a}\end{array}$ & & & & \\
\hline & Weekly conflict & $x$ & & & \\
\hline \multirow{4}{*}{$\begin{array}{c}\text { School } \\
\text { variables }\end{array}$} & Index of school difficulties & $x$ & $x$ & & \\
\hline & Time spent of homework & & & & \\
\hline & School stress ${ }^{a}$ & $x$ & $x$ & $x$ & $x$ \\
\hline & Reaction to failure $^{a}$ & $x$ & & & \\
\hline \multirow{6}{*}{$\begin{array}{l}\text { Leisure } \\
\text { variables }\end{array}$} & Physical activities $^{a}$ & & & & \\
\hline & Recreational activities $^{a}$ & & & & \\
\hline & Amount of free time ${ }^{a}$ & & $x$ & & \\
\hline & Time spent on TV / video ${ }^{a}$ & $x$ & $x$ & & \\
\hline & $\begin{array}{l}\text { Time spent on computer / } \\
\text { game console }\end{array}$ & & & & \\
\hline & Amount of friends & & & & \\
\hline Life events & Index of life events & & $x$ & & \\
\hline \multirow{3}{*}{$\begin{array}{c}\text { Parental } \\
\text { psychological } \\
\text { variables }\end{array}$} & $\begin{array}{l}\text { Anxiety/Depressivity } \\
\quad(\text { index) })^{\mathrm{a}}\end{array}$ & $x$ & & & \\
\hline & Habitual worry ${ }^{a}$ & $x$ & & & \\
\hline & Sleep disturbance ${ }^{a}$ & $x$ & & & \\
\hline \multirow{6}{*}{$\begin{array}{l}\text { Parental health } \\
\text { variables }\end{array}$} & General health $^{a}$ & $x$ & & $x$ & \\
\hline & $\begin{array}{l}\text { Number of doctor } \\
\text { appointments }^{a}\end{array}$ & $x$ & & $x$ & \\
\hline & Regular medication & $x$ & & & \\
\hline & Parental headache & $x$ & $x$ & $x$ & \\
\hline & Pain other than headache ${ }^{a}$ & $x$ & & $x$ & \\
\hline & Other somatic complaints ${ }^{a}$ & $x$ & & $x$ & $x$ \\
\hline
\end{tabular}

${ }^{a}$ Z-scores

The question arises, why so few of the variables were significantly associated with chronic illness. There are a number of possible explanations. First, the variables examined in the present research were selected on the basis of the extant research on pediatric headache and the empirical status of variables that have been investigated thus far. The discrepancy in the amount of related variables could be due to this selection process. It is 
possible that the variables are less relevant to chronic illness, as a whole, than to weekly headache.

Second, in line with the concept of broad specificity (Garber \& Hollon, 1991), a heterogeneous control group was employed in the present research. The heterogeneity of the children and adolescents in the chronic illness group may have contributed to the discrepancy in amount of relevant variables. It is possible that the degree to which the variables were present varied depending on the chronic illness and that the aggregation across all chronic illnesses leveled out significant differences present for individual chronic illnesses in comparison to healthy controls. For example, it is possible that anxiety/depression is significantly associated with asthma, but that children and adolescents with diabetes exhibit significantly less anxiety/depression. Averaged across both groups the extremes would be evened out. Note that research examining narrow specificity would lend itself to identifying such possible differences between the individual chronic illnesses.

However, if the group of children and adolescents with chronic illness were particularly heterogeneous with regard to the examined variables, it would be expected that the standard deviations in the chronic illness group would be elevated compared to the group of children with weekly headache. This was not the case. The standard deviations were comparable and in the few cases of discrepancy the children and adolescents with weekly headache exhibited the larger standard deviation. The only exception is parental general health (weekly headache $S D=1.04$ vs. chronic illness $S D=1.05$; see Table 7 ). Altogether, this seems to speak against the leveling out explanation.

Third, the proportional composition of the heterogeneous chronic illness group, which was determined by the prevalence of the individual chronic illnesses in the population-based sample, may have contributed to the disparity. Over half of the children and adolescents in the chronic illness group had atopic dermatitis (53\%), and one third asthma (33\%). Thus, the chronic illness group consisted mainly of children and adolescents with one of these two illnesses. It is possible that a different pattern of correlates would be identified had the heterogeneous group been recruited in a manner that balanced the presence of various chronic illnesses. However, a recruiting procedure of this kind could not be realized within the framework of the present population-based study.

The variables that reached significance in the domain models formed the basis from which the aggregate models for weekly headache and for chronic illness were generated. The results concerning the comparisons between weekly headache vs. good health and chronic illness vs. good health are depicted in Table 36. Note that the aggregate models differ with regard to the included variables because different variables were identified as correlates in the respective domain analyses. The specificity model comprised those variables that maintained significance in the aggregate model for weekly headache or chronic illness. The results of the specificity analysis are also shown in Table 36 (far right column).

In the specificity model, a number of variables were significantly associated with weekly headache and can therefore be seen as being specific to weekly headache in 
comparison to chronic illness: Age, gender, pain other than headache, other somatic complaints, and parental headache.

Table 36. Variables examined in the aggregate and specificity models and their significance or non-signficance

\begin{tabular}{|c|c|c|c|}
\hline & $\begin{array}{c}\text { Aggregate model } \\
\text { for weekly headache }\end{array}$ & $\begin{array}{l}\text { Aggregate model } \\
\text { for chronic illness }\end{array}$ & Specificity model \\
\hline 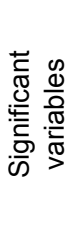 & $\begin{array}{l}\text { - Age } \\
\text { - Pain other than headache } \\
\text { - Other somatic complaints } \\
\text { - School stress } \\
\text { - Parental headache }\end{array}$ & $\begin{array}{l}\text { - Sleep disturbance } \\
\text { - School stress } \\
\text { - Parental other somatic complaints }\end{array}$ & $\begin{array}{l}\text { - Age } \\
\text { - Gender } \\
\text { - Pain other than headache } \\
\text { - Other somatic complaints } \\
\text { - Parental headache }\end{array}$ \\
\hline 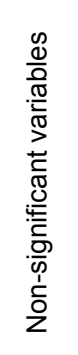 & $\begin{array}{l}\text { - Gender } \\
\text { - Anger out } \\
\text { - Anxiety/depression } \\
\text { - Sleep disturbance } \\
\text { - Time spent on homework } \\
\text { - Amount of free time } \\
\text { - Time spent on TV / video } \\
\text { - Life events }\end{array}$ & $\begin{array}{l}\text { - Age } \\
\text { - Gender }\end{array}$ & $\begin{array}{l}\text { - Sleep disturbance } \\
\text { - School stress } \\
\text { - Parental other somatic complaints }\end{array}$ \\
\hline
\end{tabular}

The control variables, age and gender, were significantly associated with weekly headache in the specificity model. The odds ratios indicated that an increase in age of one year was associated with a $25 \%$ higher likelihood of having weekly headache rather than other chronic illness and that the likelihood of having weekly headache (as opposed to other chronic illness) was $79 \%$ higher among girls than among boys. It should be noted, however, that gender gained entry into the specificity model by virtue of being a control variable, not because it fulfilled the significance criterion: Gender only approached significance in the aggregate model for weekly headache. Despite this limitation, age and gender are understood as being specific to weekly headache. The data from the three other specificity studies is not comparable regarding age and gender, as none of the samples were population-based, two employed samples of consecutive patients (Powers et al., 2003; Smith et al., 2003) and in the other subjects were matched for age and gender (Engström, 1992).

Pain other than headache and other somatic complaints were significantly associated with weekly headache in the specificity model. The odds ratios indicated that an increase in non-headache pain was associated with a $45 \%$ higher likelihood of having weekly headache, and a similar increase in other somatic symptoms was associated with a $69 \%$ higher likelihood of having weekly headache as opposed to chronic illness. Thus pain other than headache and other somatic complaints can be considered specific correlates of weekly headache. Unfortunately, these variables have not been examined separately in other specificity studies. Instead, somatic symptoms scales that encompassed both pains and other somatic symptoms have been employed.

For example, Engström (1992) found male children and adolescents with weekly tension-type headache to score significantly higher on a somatic symptoms scale than those with chronic illness (IBD or diabetes), and healthy controls. Females, on the other hand, scored significantly higher on the scale than children and adolescents with diabetes and 
healthy controls, but did not differ significantly from those with IBD. As the analyses were conducted separately for girls and boys, it remains unclear, whether analyses over all subjects would identify somatic symptoms as a correlate specific to weekly headache or as an unspecific correlate of weekly headache and IBD.

Smith et al. (2003) also investigated somatic symptoms in their specificity study. They found somatization to be more pronounced among children with chronic fatigue syndrome fulfilling the criteria of the Center for Disease Control and Prevention (CDC-CFS) than among those with migraine and idiopathic chronic fatigue syndrome (I-CFS). However, these results do not lend themselves to integration for a number of reasons. First, it cannot be ruled out that the instrument used to measure somatization was biased toward CFS, as it included a number of symptoms which are defining for chronic fatigue (e.g., low in energy, weakness in body parts, dizziness, muscle weakness). Thus the correlation may merely be attributable to the illness fulfilling its own criteria. In order to avoid this problem all items related to the investigated illnesses would have to be eliminated prior to analysis. Second, migraine frequency was not taken into account in the study. Therefore, it cannot be ruled out that the result is ascribable to the juxtapositioning of children and adolescents with (seldom) attacks of migraine and those with persistent chronic fatigue.

Parental headache is the last of the variables found to be significantly associated with weekly headache in the specificity model. The odds ratio indicated that children of parents with a history of headache were $91 \%$ more likely to have weekly headache as opposed to other chronic illness. Thus parental headache is a specific correlate of weekly headache. Unfortunately, none of the other specificity studies has investigated this variable to date. Nevertheless, results from a study comparing children with recurrent headache to those with recurrent abdominal and back pain can be seen as corroborating the specificity: Grøholt et al. (2003) found that when parental pains and other complaints were looked at in combination with pains and complaints of their children only the concordant pains remained significantly associated with one another, i.e., parental headache with child headache, parental abdominal pain with child abdominal pain, and parental back pain with child back pain. These and the findings of the present study suggest that genetic factors may play a role in child's headache experience. Parental role modeling may also contribute to the relation between parental and child pain.

The focus of attention will now be turned to those variables that did not reach significance in the specificity model, namely sleep disturbance, school stress, and other parental somatic complaints. In order to determine what this means, it is necessary to reiterate the results of the aggregate models for weekly headache and chronic illness:

Sleep disturbance gained entry into the specificity model due to its significance in the aggregate model for chronic illness. However, in the single-predictor specificity analysis it was paradoxically associated with weekly headache, rather than chronic illness $(O R=1.24)$., only to become non-significant in the full specificity model. The question arises, why sleep disturbance lost its significance in the full specificity model. One possible explanation is its intercorrelation with other variables in the model (anxiety/depression: $r=.308$, pain other than headache: $r=.334$, other somatic complaints: $r=.383$; see Appendix E). As none of the other specificity studies examined sleeping disturbances as a separate variable, they cannot help 
to clarify this issue. Altogether, sleep disturbance can be regarded as an unspecific correlate of chronic illness (including weekly headache) on the basis of the relevance of the variable to chronic illness in the full aggregate model and the lack of significant association with one of the health outcome in the full specificity model. Further research appears necessary, however, in order to disentangle the interrelated variables.

School stress gained entry into the specificity model due to its significance in the aggregate model for both weekly headache and chronic illness. In other words, children and adolescents with weekly headache or other chronic illness experienced significantly more school stress than their healthy counterparts. In the first step of the specificity analysis, the single-predictor model, school stress was significantly associated with weekly headache $(\mathrm{OR}=1.51)$. However, in the full specificity model, school stress did not attain significance. Therefore, on the basis of the full specificity and the preceding aggregate models, school stress can be regarded as an unspecific correlate of chronic illness (including weekly headache).

School stress, as it was measured in the present research, was a composite measure that included being academically over- or under-challenged, getting teased or bullied, being alone or isolated, being afraid of school, and negative school climate. Thus the variable can best be understood as a measure of negative school climate. It the study by Powers et al (2003) children with migraine reported significantly lower school functioning (paying attention in class, forgetting things, keeping up with schoolwork, school absence because ill, school absence due to doctor appointments or hospitalization) than those with cancer or rheumatic conditions. A further specificity study (Engström, 1992) indicated that children with weekly headache did not differ from those with IBD or diabetes, or healthy children on a school scale tapping academic achievement (school performance in comparison to others, repeating a grade, having learning or other difficulties in school). Though these specificity studies have also looked at school variables, they focused on other school-related aspects (not negative school climate). It is, therefore, not possible to integrate the results.

The variable parental other somatic complaints gained entry into in the specificity model due to its significance in the aggregate model for chronic illness. However, parental other somatic complaints remained non-significant in both specificity analyses (singlepredictor model, full model). This could be interpreted as indicating that the variable is an unspecific correlate of chronic illness (including headache). However, parental other somatic complaints were only significantly associated with weekly headache in the single-predictor model. The variable did not reach significance in the full domain model analysis (weekly headache vs. good health) and was therefore excluded from the aggregate model for weekly headache. Therefore, no clear-cut interpretation emerges. Unfortunately, none of the other specificity studies looked at parental variables, so they offer no further insights.

In sum, a number of variables were identified as being specific to weekly headache: Age, pain other than headache, other somatic complaints, and parental headache not only differentiated children with weekly headache from those with other chronic illness but also from their healthy counterparts. In addition, female gender turned out to be more common among children with weekly headache than children with other chronic illnesses. 


\subsection{Summary and Future Directions}

The present research followed two main objectives, namely to identify the correlates of weekly headache and to determine their specificity. To achieve the first aim a wide range of variables was determined relevant for the present research on the basis of a comprehensive review of the literature on pediatric headache. In total, nine different variable domains and 42 individual variables were selected for inclusion in the parental questionnaire. Survey materials were sent out to 8,800 households with a child between 7 and 14 years of age in Lower Saxony. Valid questionnaires were returned from 5,474 of these households. On the basis of this data children and adolescents with weekly headache were compared to those in good health. Several steps of comparison were made, including analyses of singlepredictor models, full domain models, and the aggregate model for weekly headache.

The variables examined in the present research explained $26 \%$ of the variance differentiating children with weekly headache from those in good health. This is an acceptable amount, as it lies within the range of explained variance that has been reported in the literature. Nevertheless, over two-thirds of variance remains unaccounted for. This is a clear sign that some contributing variables have not yet found inclusion in multivariate models of weekly headache. As not all variables that have demonstrated a significant association with weekly headache (in single-predictor models or their equivalents) have been investigated in multivariate models, it is possible that the systematic inclusion of these variables could increase the total explained variance. This calls for more widespread use of multivariate analyses. Of course, it is also additionally possible that other variables exist whose association with weekly headache has not yet been postulated, let alone investigated.

Of the investigated variables, age and gender accounted for $6.5 \%$ of the variance differentiating between children with weekly headache and their healthy counterparts. This was to be expected as these variables have demonstrated their relevance to headache in prior research. Substantial further variance was explained by child health variables (pain other than headache, other somatic symptoms), child psychological variables (in particular anxiety/depression, and sleep disturbance), and to a lesser degree by school variables (in particular negative school climate) and parental health variables (in particular parental headache, and parental non-headache pain). Thus, the present study corroborated previous findings in establishing gender as a confirmed correlate of weekly headache, and anxiety/depression, non-headache pain, negative school climate, parental headache, and parental non-headache pain as tentative correlates thereof.

A number of further variables were examined with regard to weekly headache in the present research for the first time. Some of these variables reached significance in the single-predictor analyses and are therefore potential candidate variables for future research. Of these, five particularly warrant inclusion, as evidence of their relevance has been reported in studies on headache in general: Other somatic complaints, negative family environment, weekly family conflict, time spent on TV / video, and parental other somatic complaints.

Noteworthy is also that three of the four variables, which maintained their significance in the multivariate analysis of the full aggregate model for weekly headache (pain other than headache, other somatic complaints, and parental headache), are somatic or biological in 
nature. In addition, the control variable gender (a further biological variable) approached significance in the present study. These findings point to the importance of research addressing the biological underpinnings of (weekly) headache. Several projects within the German Headache Consortium are active in this line of research.

It is, however, possible that non-headache pain, other somatic symptoms, and parental headache are not exclusively biological in nature. For example, non-headache pain and other somatic symptoms could be due to an increased susceptibility for physical symptoms or to the psychological process of somatic amplification. Similarly, the association between parental headache and child's headache may indicate a genetic contribution, or alternatively observational learning from a parental role model. It is also possible that a combination of biological and psychological mechanisms is relevant to these variables. It is essential that these issues be addressed in future research, as knowledge of their nature is the prerequisite for development of tailored prevention and intervention strategies.

With respect to the second objective, broad specificity was selected as the type of specificity to be addressed. Indeed, this has been suggested to be the appropriate starting point when beginning with specificity research in a given area. As a consequence, the comparison group for weekly headache had to be the higher-order category to which it belonged, namely chronic illness. In order to achieve this second objective an intermediary step was necessary, in which children with chronic illness (excluding weekly headache) were compared to their healthy counterparts, thus determining the correlates of chronic illness. Finally, the specificity of the identified correlates (of either weekly headache or chronic illness) was established by comparing children and adolescents with weekly headache to those with chronic illness.

In the specificity analysis a number of variables were identified as being specific to weekly headache, namely, age, pain other than headache, other somatic complaints, and parental headache. In addition, female gender was also found to be more common among children with weekly headache than among those with other chronic illness. Since the analysis addressed broad specificity children with weekly headache were compared to a heterogeneous group of children and adolescents with diverse chronic illnesses. Some limitations regarding the heterogeneous comparison group in the present study have been pointed out (e.g., unequal representation of the different illnesses, potential leveling out of effects through aggregation). Therefore, confirmation of the results through further studies addressing broad specificity would be worthwhile, perhaps with a more balanced illness representation in the comparison group. At the same time, conduction of narrow specificity studies could yield useful complementary knowledge regarding patterns of correlates and their specificity among the individual chronic illnesses.

All of the analyses presented here were based on cross-sectional data. Therefore, they only allow for the identification of correlates. It was not possible to determine whether the variables were risk factors for weekly headache as the temporal sequence of the variables relative to occurrence of weekly headache was not assessed. For example, it is possible that school stress and depression are consequences of having weekly headache rather than being causally related to the development of the pain disorder. Longitudinal studies and prospective analyses are needed in order to identify causal relations, as these 
take temporal sequence into account. Fortunately, the Children, Adolescents \& Headache Study was conceptualized as a longitudinal study with the capability and explicit purpose of determining risk factors for headache and weekly headache in the future. 


\section{REFERENCES}

Achenbach, T. M. (1991). Manual for the Child Behavior Checklist/4-18 and 1991 profile. Burlington, VT: University of Vermont, Department of Psychiatry.

Andrasik, F., Kabela, E., Quinn, S., Attanasio, V., Blanchard, E. B., \& Rosenblum, E. L. (1988). Psychological functioning of children who have recurrent migraine. Pain, 34, 43-52.

Anttila, P., Metsähonkala, L., Helenius, H., \& Sillanpää, M. (2000). Predisposing and provoking factors in childhood headache. Headache, 40, 351-356.

Anttila, P., Sourander, A., Metsähonkala, L., Aromaa, M., Helenius, H., \& Sillanpää, M. (2004). Psychiatric symptoms in children with primary headache. Journal of the American Academy of Child and Adolescent Psychiatry, 43, 412-419.

Arbeitsgruppe Deutsche Child Behavior Checklist. (1998). Elternfragebogen über das Verhalten von Kindern und Jugendlichen; deutsche Bearbeitung der child Behavior Checklist (CBCL 4-18). Einführung und Anleitung zur Handauswertung (Vol. 2. Auflage mit deutschen Normen). Köln, Germany: Arbeitsgruppe Kinder-, Jugend- und Familiendiagnostik.

Aromaa, M., Rautava, P., Helenius, H., \& Sillanpää, M. (1998). Factors of early life as predictors of headache in children at school entry. Headache, 38, 23-30.

Aromaa, M., Sillanpää, M., Rautava, P., \& Helenius, H. (2000). Pain experience of children with headache and their families: A controlled study. Pediatrics, 106, 270-275.

Aromaa, M., Sillanpää, M. L., Rautava, P., \& Helenius, H. (1998). Childhood headache at school entry: A controlled study. Neurology, 50, 1729-1736.

Bandell-Hoekstra, I., Abu-Saad, H. H., Passchier, J., \& Knipschild, P. (2000). Recurrent headache, coping and quality of life in children: A review. Headache, 40, 357-370.

Bandell-Hoekstra, I. E., Abu-Saad, H. H., Passchier, J., Frederiks, C. M., Feron, F. J., \& Knipschild, P. (2001). Prevalence and characteristics of headache in Dutch schoolchildren. European Journal of Pain, 5, 145-153.

Barea, L. M., Tannhauser, M., \& Rotta, N. T. (1996). An epidemiologic study of headache among children and adolescents of southern Brazil. Cephalalgia, 16, 545-549.

Bille, B. (1962). Migraine in school children. Acta Paediatrica Scandinavica, 51(Suppl.), 1151.

Bille, B. (1981). Migraine in childhood and its prognosis. Cephalalgia, 1, 71-75.

Bille, B. (1989). Migraine in childhood: A 30 years follow-up. In G. Lanzi, U. Balottin \& A. Cernibori (Eds.), Headache in children and adolescents: Proceedings of the first international symposium on headache in children and adolescents (pp. 19-26). Amsterdam, Netherlands: Excerpta Medica.

Bille, B. (1997). A 40-year follow-up of school children with migraine. Cephalalgia, 17, 487491. 
Bortz, J. (1989). Statistik für Sozialwissenschaftler (3 ed.). Berlin, Germany: Springer.

Brattberg, G. (1994). The incidence of back pain and headache among Swedish school children. Quality of Life Research, 3(Suppl. 1), S27-S31.

Brattberg, G., \& Wickman, V. (1992). Prevalence of back pain and headache in Swedish school children: A questionnaire survey. The Pain Clinic, 5, 211-220.

Camarda, R., Monastero, R., Santangelo, G., Raimondo, D., Puma, D., Pipia, C., et al. (2002). Migraine headaches in adolescents: A five-year follow-up study. Headache, 42, 1000-1005.

Carlsson, J. (1996). Prevalence of headache in schoolchildren: Relation to family and school factors. Acta Paediatrica, 85, 692-696.

Carlsson, J., Larsson, B., \& Mark, A. (1996). Psychosocial functioning in schoolchildren with recurrent headaches. Headache, 36, 77-82.

Connelly, M. (2003). Recurrent pediatric headache: A comprehensive review. Children's Health Care, 32, 153-189.

Cooper, P. J., Bawden, H. N., Camfield, P. R., \& Camfield, C. S. (1987). Anxiety and life events in childhood migraine. Pediatrics, 79, 999-1004.

Cunningham, S. J., McGrath, P. J., Ferguson, H. B., Humphreys, P., D'Astous, J., Latter, J., et al. (1987). Personality and behavioural characteristics in pediatric migraine. Headache, 27, 16-20.

deGrauw, T. J., Hershey, A. D., Powers, S. W., \& Bentti, A. L. (1999). Diagnosis of migraine in children attending a pediatric headache clinic. Headache, 39, 481-485.

Denecke, H., \& Kröner-Herwig, B. (2000). Kopfschmerztherapie mit Kindern und Jugendlichen. Göttingen, Germany: Hogrefe.

Dillman, D. A. (2000). Mail and internet surveys. The tailored design method (2 ed.). New York, NY: John Wiley \& Sons, Inc.

Dooley, J., \& Bagnell, A. (1995). The prognosis and the treatment of headaches in children a ten year follow-up. Canadian Journal of Neurological Sciences, 22(1), 47-49.

Döpfner, M., Schmeck, K., Berner, W., Lehmkuhl, G., \& Poustka, F. (1994). Zur Reliabilität und faktoriellen Validität der Child Behavior Checklist: Eine Analyse in einer klinischen und einer Feldstichprobe. Zeitschrift für Kinder- und Jugendpsychiatrie, 22, 189-205.

Egermark-Eriksson, I. (1982). Prevalence of headache in Swedish schoolchildren. A questionnaire survey. Acta paediatrica Scandinavica, 71, 135-140.

Egger, H. L., Angold, A., \& Costello, E. J. (1998). Headaches and psychopathology in children and adolescents. Journal of the American Academy of Child \& Adolescent Psychiatry, 37, 951-958. 
Egger, H. L., Costello, E. J., Erkanli, A., \& Angold, A. (1999). Somatic complaints and psychopathology in children and adolescents: Stomachaches, musculoskeletal pains, and headaches. Journal of the American Academy of Child \& Adolescent Psychiatry, 38, 852-860.

Engström, I. (1992). Mental health and psychological functioning in children and adolescents with inflammatory bowel disease: A comparison with children having other chronic illnesses and with healthy children. Journal of Child Psychology \& Psychiatry \& Allied Disciplines, 33, 563-582.

Essau, C. A., Conradt, J., \& Petermann, F. (1999). Prevalence, comorbidity and psychosocial impairment of somatoform disorders in adolescents. Psychology, Health \& Medicine, 4, 169-180.

Esser, G., Blanz, B., Geisel, B., \& Laucht, M. (1989). Mannheimer Elterninterview (MEI): Strukturiertes Interview zur Erfassung von kinderpsychiatrischen Auffälligkeiten. Weinheim: Beltz.

Fearon, P., \& Hotopf, M. (2001). Relation between headache in childhood and physical and psychiatric symptoms in adulthood: National birth cohort study. British Medical Journal, 322, 1-6.

Fernandez, E., \& Turk, D. C. (1995). The scope and significance of anger in the experience of chronic pain. Pain, 61, 165-175.

Fichtel, A., \& Larsson, B. (2002). Psychosocial impact of headache and comorbidity with other pains among Swedish school adolescents. Headache, 42, 766-775.

Frankenberg, S. v., \& Pothmann, R. (1995). Epidemiologie von Kopfschmerzen bei Schulkindern. psychomed, 7, 157-163.

Garber, J., \& Hollon, S. D. (1991). What can specificity designs say about causality in psychopathology research? Psychological Bulletin, 110, 129-136.

Glantz, S. A., \& Slinker, B. K. (2001). Primer of applied regression \& analysis of variance (2nd ed.). New York: McGraw-Hill, Inc.

Göbel, H. (1997). Die Kopfschmerzen. Berlin, Germany: Springer.

Gordon, K. E., Dooley, J. M., \& Wood, E. P. (2004). Self-reported headache frequency and features associated with frequent headaches in Canadian young adolescents. Headache, 44, 555-561.

Gortmaker, S. L., Walker, D. K., Weitzman, M., \& Sobol, A. M. (1990). Chronic conditions, socioeconomic risks, and behavioral problems in children and adolescents. Pediatrics, 85, 267-276

Grøholt, E.-K., Stigum, H., Nordhagen, R., \& Kohler, L. (2003). Recurrent pain in children, socio-economic factors and accumulation in families. European Journal of Epidemiology, 18, 965-975.

Guidetti, V., \& Galli, F. (1998). Evolution of headache in childhood and adolescence: An 8year follow-up. Cephalalgia, 18, 449-454. 
Haggerty, R. J. (1983). Breaking the link between stress and illness in children. What role can physicians play? Postgraduate Medicine, 74, 287-295.

Hampel, P., Petermann, F., \& Dickow, B. (2001). Stressverarbeitungsfragebogen von Janke und Erdmann angepasst für Kinder und Jugendliche (SVF-KJ). Göttingen, Germany: Hogrefe.

Hampel, P., Rudolph, H., Stachow, R., Laß-Lentzsch, A., \& Petermann, F. (2005). Coping among children and adolescents with chronic illness. Anxiety, Stress \& Coping, 18, 145-155.

Headache Classification Committee of the International Headache Society. (1988). Classification and diagnostic criteria for headache disorders, cranial neuralgias, and facial pain. Cephalalgia, 8(Suppl.7), 1-96.

Headache Classification Committee of the International Headache Society. (2004). The International Classification of Headache Disorders, 2nd edition. Cephalalgia, 24(Suppl.1), 9-160.

Hershey, A. D. (2005). What is the impact, prevalence, disability, and quality of life of pediatric headache? Current Pain and Headache Reports, 9, 341-344.

Hoepner-Stamos, F. (1995). Prävalenz und Ätiologie chronischer Erkrankungen im Kindesund Jugendalter. In P. Kolip, K. Hurrelmann \& P.-E. Schnabel (Eds.), Jugend und Gesundheit (pp. 49-67). Weinheim, Germany: Juventa.

Holden, E. W., Deichmann, M. M., \& Levy, J. D. (1999). Empirically supported treatments in pediatric psychology: Recurrent pediatric headache. Journal of Pediatric Psychology, 24, 91-109.

Hurrelmann, K., Klocke, A., Melzer, W., \& Ravens-Sieberer, U. (2003). WHOJugendgesundheitssurvey. Konzept und ausgewählte Ergebnisse für die Bundesrepublik Deutschland. Erziehungswissenschaft, 27, 79-108.

Just, U., Oelkers, R., Bender, S., Parzer, P., Ebinger, F., Weisbrod, M., et al. (2003). Emotional and behavioural problems in children and adolescents with primary headache. Cephalalgia, 23, 206-213.

Karwautz, A., Wöber, C., Lang, T., Böck, A., Wagner-Ennsgraber, C., Vesely, C., et al. (1999). Psychosocial factors in children and adolescents with migraine and tensiontype headache: A controlled study and review of the literature. Cephalalgia, 19, 3243.

Kerbeck, K., \& Luka-Krausgrill, U. (1999). "Help Yourself". Ein Selbsthilfetraining für Jugendliche mit chronischen Kopfschmerz. In H. W. Hoefert \& B. Kröner-Herwig (Eds.), Schmerzbehandlung. Psychologische und medikamentöse Interventionen. München, Germany: Reinhardt.

King, N. J., \& Sharpley, C. F. (1990). Headache activity in children and adolescents. Journal of Paediatric Child Health, 26, 50-54. 
Kolip, P., Nordlohne, E., \& Hurrelmann, K. (1995). Der Jugendgesundheitssurvey 1993. In P. Kolip, K. Hurrelmann \& P.-E. Schnabel (Eds.), Jugend und Gesundheit (pp. 25-48). Weinheim, Germany: Juventa.

Kowal, A., \& Pritchard, D. W. (1990). Psychological characteristics of children who suffer from headache: A research note. Journal of Child Psychology and Psychiatry and Allied Disciplines, 31, 637-649.

Krieger, N., Williams, D. R., \& Moss, N. E. (1997). Measuring social class in US public health research: Concepts, methodologies, and guidelines. Annual Review of Public Health, 18, 341-378.

Kristjánsdóttir, G. (1997). Prevalence of pain combinations and overall pain: a study of headache, stomach pain and back pain among school-children. Scandinavian Journal of Social Medicine, 25, 58-63.

Kristjánsdóttir, G., \& Wahlberg, V. (1993). Sociodemographic differences in the prevalence of self-reported headache in Icelandic school-children. Headache, 33, 381-385.

Labbé, E. E. (1998). Pediatric headaches. In T. H. Ollendick \& M. Hersen (Eds.), Handbook of child psychopathology (pp. 381-394). New York, NY: Plenum Press.

Landgraf, J. M., Maunsell, E., Speechley, K. N., Bullinger, M., Campbell, S., Abetz, L., et al. (1998). Canadian-French, German and UK versions of the Child Health Questionnaire: methodology and preliminary item scaling results. Quality of Life Research, 7, 433-445.

Larsson, B. (1988). The role of psychological, health-behaviour and medical factors in adolescent headache. Developmental Medicine \& Child Neurology, 30, 616-625.

Larsson, B., \& Melin, L. (1988). The psychological treatment of recurrent headache in adolescents: Short-term outcome and its prediction. Headache, 28, 187-195.

Laurell, K., Larsson, B., \& Eeg-Olofsson, O. (2004). Prevalence of headache in Swedish schoolchildren, with a focus on tension-type headache. Cephalalgia, 24, 380-388.

Laurell, K., Larsson, B., \& Eeg Olofsson, O. (2005). Headache in schoolchildren: Association with other pain, family history and psychosocial factors. Pain, 119, 150-158.

Liakopoulou-Kairis, M., Alifieraki, T., Protagora, D., Korpa, T., Kondyli, K., Dimosthenous, E., et al. (2002). Recurrent abdominal pain and headache: psychopathology, life events and family functioning. European Child and Adolescent Psychiatry, 11(3), 115-122.

Linet, M. S., Stewart, W. F., Celentano, D. D., Ziegler, D., \& Sprecher, M. (1989). An epidemiologic study of headache among adolescents and young adults. Journal of the American Medical Association, 261, 2211-2216.

Linna, S.-L., Moilanen, I., \& Keistinen, H. (1991). Prevalence of psychosomatic symptoms in children. Psychotherapy \& Psychosomatics, Vol 56(1-2), 85-87.

Luka-Krausgrill, U., \& Reinhold, B. (1996). Kopfschmerzen bei Kindern: Auftretensrate und Zusammenhang mit Streß, Streßbewältigung, Depressivität und sozialer Unterstützung. Zeitschrift für Gesundheitspsychologie, 4, 137-151. 
Maratos, J., \& Wilkinson, M. (1982). Migraine in children: A medical and psychiatric study. Cephalalgia, 2, 179-187.

Martin-Herz, S. P., Smith, M. S., \& McMahon, R. J. (1999). Psychosocial factors associated with headache in junior high school students. Journal of Pediatric Psychology, 24, 1323.

Martin, S. E., \& Smith, M. S. (1995). Psychosocial factors in recurrent pediatric headache. Pediatric Annals, 24, 464-474.

Mattsson, A. (1972). Long-term physical illness in childhood: A challenge to psychosocial adjustment. Pediatrics, 50, 801-811.

Mazzone, L., Vitiello, B., Incorpora, G., \& Mazzone, D. (2006). Behavioural and temperamental characteristics of children and adolescents suffering from primary headache. Cephalalgia, 26, 194-201.

McGrath, P. A. (2001). Headache in children: The nature of the problem. In P. A. McGrath \& L. M. Hillier (Eds.), The child with headache: Diagnosis and treatment (pp. 1-27). Seattle, WA: IASP Press.

McGrath, P. A., \& Hillier, L. M. (2001). Preface. In P. A. McGrath \& L. M. Hillier (Eds.), The child with headache: Diagnosis and treatment (pp. ix-x). Seattle, WA: IASP Press, 2001.

McGrath, P. A., \& Koster, A. L. (2001). Headache measures for children: A practical approach. In P. A. McGrath \& L. M. Hillier (Eds.), The child with headache: Diagnosis and treatment (pp. 29-55). Seattle, WA: IASP Press, 2001.

McGrath, P. A., Speechley, K. N., Seifert, C. E., Biehn, J. T., Cairney, A. E. L., Gorodzinsky, F. P., et al. (2000). A survey of children's acute, recurrent, and chronic pain: Validation of the pain experience interview. Pain, 87, 59-73.

McMahon, S. D., Grant, K. E., Compas, B. E., Thurm, A. E., \& Ey, S. (2003). Stress and psychopathology in children and adolescents: Is there evidence of specificity? Journal of Child Psychology and Psychiatry, 44, 107-133.

Metsähonkala, L., Sillanpää, M., \& Tuominen, J. (1997). Outcome of early school-age migraine. Cephalalgia, 17, 662-665.

Metsähonkala, L., Sillanpää, M., \& Tuominen, J. (1998). Social environment and headache in 8- to 9-year-old children: A follow-up study. Headache, 38, 222-228.

Meyer, T. J., Miller, M. L., Metzger, R. L., \& Borkovec, T. D. (1990). Development and validation of the Penn State Worry Questionnaire. Behavior Research and Therapy, $28,487-495$.

Mortimer, M. J., Kay, J., \& Jaron, A. (1992). Epidemiology of headache and childhood migraine in an urban general practice using Ad Hoc, Vahlquist and IHS criteria. Developmental Medicine and Child Neurology, 34, 1095-1101. 
Mortimer, M. J., Kay, J., Jaron, A., \& Good, P. A. (1992). Does a history of maternal migraine or depression predispose children to headache and stomach-ache? Headache, 32, 353-355.

Neuhauser, H., Dippelhofer, A., \& Holling, H. (2002). Befragung zur korperlichen Gesundheit im Rahmen des Kinder- und Jugendgesundheitssurveys. Gesundheitswesen, 64(1), 17-22.

Newacheck, P. W., Budetti, P. P., \& McManus, P. (1984). Trends in childhood disability. American Journal of Public Health, 74, 232-236.

Newacheck, P. W., \& Stoddard, J. J. (1994). Prevalence and impact of multiple childhood chronic illnesses. The Journal of Pediatrics, 124, 40-48.

Newacheck, P. W., \& Taylor, W. R. (1992). Childhood chronic illness: Prevalence, severity, and impact. American Journal of Public Health, 82, 364-371.

Oksanen, A., Metsähonkala, L., Anttila, P., Aromaa, M., Jappila, E., Viander, S., et al. (2005). Leisure activities in adolescents with headache. Acta Paediatrica, 94, 609-615.

Passchier, J., \& Orlebeke, F. (1985). Headaches and stress in schoolchildren: An epidemiological study. Cephalagia, 5, 167-176.

Perrin, E. C., Newacheck, P., Pless, I. B., Drotar, D., Gortmaker, S. L., Leventhal, J., et al. (1993). Issues involved in the definition and classification of chronic health conditions. Pediatrics, 91, 787-793.

Petersen, S., Bergström, E., \& Brulin, C. (2003). High prevalence of tiredness and pain in young schoolchildren. Scandinavian Journal of Public Health, 31, 367-374.

Pine, D. S., Cohen, P., \& Brook, J. (1996). The association between major depression and headache: Results of a longitudinal epidemiologic study in youth. Journal of Child and Adolescent Psychopharmacology, 6, 153-164.

Pless, I. B., \& Douglas, J. (1971). Chronic illness in childhood: I. Epidemiological and clinical characteristics. Pediatrics, 47, 405-414.

Poikolainen, K., Aalto-Setala, T., Marttunen, M., Tuulio-Henriksson, A., \& Lonnqvist, J. (2000). Predictors of somatic symptoms: A five year follow up of adolescents. Archives of Disease in Childhood, 83, 388-392.

Pothmann, R., Frankenberg, v. S., Müller, B., Sartory, G., \& Hellmeier, W. (1994). Epidemiology of headache in children and adolescents: Evidence of high prevalence of migraine among girls under 10. International Journal of Behavioral Medicine, 1, 7689.

Powers, S. W., Patton, S. R., Hommel, K. A., \& Hershey, A. D. (2003). Quality of life in childhood migraines: Clinical impact and comparison to other chronic illnesses. Pediatrics, 112, e1-e5. 
Ravens-Sieberer, U., Thomas, C., \& Erhart, M. (2003). Körperliche, psychische und soziale Gesundheit von Jugendlichen. In K. Hurrelmann, A. Klocke, W. Melzer \& U. RavensSieberer (Eds.), Jugendgesundheitssurvey - Internationale Vergleichsstudie im Auftrag der Weltgesundheitsorganisation WHO (pp. 19-98). Weinheim, Germany: Juventa.

Rhee, H. (2000). Prevalence and predictors of headaches in US adolescents. Headache, 40, 528-538.

Riemann, D., Backhaus, J., Schramm, E., \& Hohagen, F. (1996). Ein Modell zur Genese primärer/psychophysiologischer Insomnien. In D. Riemann \& J. Backhaus (Eds.), Behandlung von Schlafstörungen. Ein psychologisches Gruppenprogramm (pp. 2128). Weinheim: Psychologie Verlags Union.

Rossi, L. N., Cortinovis, I., Menegazzo, L., Brunelli, G., Bossi, A., \& Macchi, M. (2001). Classification criteria and distinction between migraine and tension-type headache in children. Developmental Medicine and Child Neurology, 43, 45-51.

Roth-Isigkeit, A., Thyen, U., Raspe, H. H., Stoven, H., \& Schmucker, P. (2004). Reports of pain among German children and adolescents: An epidemiological study. Acta Paediatrica, 93, 258-263.

Rothner, A. D. (2001). Differential diagnosis of headaches in children and adolescents. In P. A. McGrath \& L. M. Hillier (Eds.), The child with headache: Diagnosis and treatment (pp. 57-76). Seattle, WA: IASP Press, 2001.

Scalas, C., \& Calistri, L. (2005). Chronic daily headache in a paediatric headache centre. The Journal of Headache and Pain, 6, 274-276.

Scheidt, P., Overpeck, M. D., Wyatt, W., \& Aszmann, A. (2000). Adolescents' general health and wellbeing. In C. Currie, K. Hurrelmann, W. Settertobulte, R. Smith \& J. Todd (Eds.), Health and health behavior amoung young people (pp. 24-38). Copenhagen, Denmark: World Health Organization.

Schmidt, M. H., Blanz, B., \& Esser, G. (1992). Häufigkeit und Bedeutung des Kopfschmerzes im Kindes- und Jugendalter. Kindheit und Entwicklung, 1, 31-35.

Schwarzer, R. (2004). Psychologie des Gesundheitsverhaltens: Einführung in die Gesundheitspsychologie (3rd ed.). Göttingen, Germany: Hogrefe.

Schwenkmezger, P., Hodapp, V., \& Spielberger, C. D. (1992). Das State-TraitÄrgerausdrucks-Inventar (STAXI). Handbuch. Bern: Huber.

Seshia, S. S. (1996). Specificity of IHS criteria in childhood headache. Headache, 36, 295299.

Sillanpää, M. (1976). Prevalence of migraine and other headache in Finnish children starting school. Headache, 15, 288-290.

Sillanpää, M. (1983a). Changes in the prevalence of migraine and other headaches during the first seven school years. Headache, 23, 15-19.

Sillanpää, M. (1983b). Prevalence of headache in prepuberty. Headache, 23, 10-14. 
Sillanpää, M., \& Anttila, P. (1996). Increasing prevalence of headache in 7-year-old schoolchildren. Headache, 36, 466-470.

Sillanpää, M., Piekkala, P., \& Kero, P. (1991). Prevalence of headache at preschool age in an unselected child population. Cephalalgia, 11, 239-242.

Smith, M. S., Martin-Herz, S. P., Marsigan, J. L., \& Womack, W. M. (2003). Comparative study of anxiety, depression, somatization, functional disability, and illness attribution in adolescents With chronic fatigue or migraine. Pediatrics, 111, e376-e381.

Spielberger, C. D. (1988). State-Trait Anger Expression Inventory (STAXI). Odessa: Psychological Assessment Resources.

Stein, R. E., Bauman, L. J., Westbrook, L. E., Coupey, S. M., \& Ireys, H. T. (1993). Framework for identifying children who have chronic conditions: the case for a new definition. The Journal of Pediatrics, 122, 342-347.

Stein, R. E., \& Silver, E. J. (1999). Operationalizing a conceptually based noncategorical definition: A first look at US children with chronic conditions. Archives of Pediatrics and Adolescent Medicine, 153, 68-74.

Stevens, J. (2002). Applied multivariate statistics for the social sciences (4th ed.). London: Lawrence Erlbaum Associates.

Stöber, J. (1995). Besorgnis: Ein Vergleich dreier Inventare zur Erfassung allgemeiner Sorgen. Zeitschrift für Differentielle und Diagnostische Psychologie, 16, 50-63.

Tabachnik, B. G., \& Fidell, L. S. (2001). Using multivariate statistics (4th ed.). Needham Heights, MA: Allyn \& Bacon.

Virtanen, R., Aromaa, M., Rautava, P., Metsähonkala, L., Anttila, P., Helenius, H., et al. (2002). Changes in headache prevalence between pre-school and pre-pubertal ages. Cephalalgia, 22, 179-185.

Wagner, H., \& Baumgärtel, F. (1978). Hamburger Persönlichkeitsfragebogen für Kinder (HAPEF-K). Göttingen: Hogrefe.

Waldie, K. E. (2001). Childhood headache, stress in adolescence, and primary headache in young adulthood: A longitudinal cohort study. Headache, 41, 1-10.

Waldie, K. E., \& Poulton, R. (2002). Physical and psychological correlates of primary headache in young adulthood: A 26 year longitudinal study. Journal of Neurology, Neurosurgery \& Psychiatry, 72, 86-92.

Warschburger, P. (2000). Chronisch kranke Kinder und Jugendliche. Psychosoziale Belastungen und Bewältigungsanforderungen. Göttingen, Germany: Hogrefe.

Wiendels, N. J., van der Geest, M. C., Neven, A. K., Ferrari, M. D., \& Laan, L. A. (2005). Chronic daily headache in children and adolescents. Headache, 45, 678-683.

Williams, K., Chambers, M., Logan, S., \& Robinson, D. (1996). Association of common health symptoms with bullying in primary school children. British Medical Journal, 313, 17-19. 
Winkler, J. (1998). Die Messung des sozialen Status mit Hilfe eines Index in den Gesundheitssurveys der DHP. In W. Ahrens, B.-M. Bellach \& K.-H. Jöckel (Eds.), Messung soziodemographischer Merkmale in der Epidemiologie (pp. 69-74). München: MMV Medizin Verlag.

World Health Organization. (2000). Headache disorders and public health. Education and management implications (WHO/MSD/MBD/00.9). Geneva, Switzerland: World Health Organization.

Zebenholzer, K., Wober, C., Kienbacher, C., \& Wober Bingol, C. (2000). Migrainous disorder and headache of the tension-type not fulfilling the criteria: A follow-up study in children and adolescents. Cephalalgia, 20, 611-616.

Zuckerman, B., Stevenson, J., \& Bailey, V. (1987). Stomaches and headaches in a community sample of preschool children. Pediatrics, 79, 677-682.

Zwart, J. A., Dyb, G., Holmen, T. L., Stovner, L. J., \& Sand, T. (2004). The prevalence of migraine and tension-type headaches among adolescents in Norway. The NordTrøndelag Health Study (Head-HUNT-Youth), a large population-based epidemiological study. Cephalalgia, 24(5), 373-379. 


\section{APPENDIX}

A ICHD-II Criteria for Migraine Without Aura, Migraine With Aura, and Tension-Type Headache

B Material from the Children, Adolescents \& Headache Study (i.e., Prenotice letter, Cover Letter, Parent Questionnaire, Postcard)

C Descriptive Data Regarding the Children and Adolescents Not Fulfilling the Criteria for the Three Outcome Groups of Interest

D Correlation Matrix and VIFs for the Full Domain Models (Weekly Headache vs. Good Health, Chronic Illness vs. Good Health)

E Correlation Matrix and VIFs for the Aggregate Models (Weekly Headache vs. Good Health, Chronic Illness vs. Good Health) and the Specificity Model (Weekly Headache vs. Chronic Illness) 


\section{Appendix A}

ICHD-II Criteria

(Headache Classification Committee of the International Headache Society, 2004)

\subsection{Migraine without aura}

A. At least 5 attacks fulfilling criteria B-D

B. Headache attacks lasting 4-72 hours (untreated or unsuccessfully treated) ${ }^{1}$

C. Headache has at least two of the following characteristics

1. unilateral location ${ }^{2,3}$

2. pulsating quality

3. moderate or severe pain intensity

4. aggravation by or causing avoidance of routine physical activity (eg, walking or climbing stairs)

D. During headache at least one of the following

1. nausea and/or vomiting

2. photophobia and phonophobia ${ }^{4}$

E. Not attributed to another disorder

\subsection{Migraine with aura}

A. At least 2 attacks fulfilling criterion $B$

B. Migraine aura fulfilling criteria $B$ and $C$ for one of the subforms 1.2.1-1.2.6

[Typical aura with migraine headache most common, subform 1.2.1, shown below]

B. Aura consisting of at least one of the following but no motor weakness:

1. fully reversible visual symptoms including positive features (eg, flickering lights, spots or lines) and/or negative features (ie, loss of vision)

2. fully reversible sensory symptoms including positive features (ie, pins and needles) and/or negative features (ie, numbness)

3. fully reversible dysphasic speech disturbance

C. At least two of the following:

1. homonymous visual symptoms and/or unilateral sensory symptoms

2. at least one aura symptom develops gradually over $\geq 5$ minutes and/or different aura symptoms occur in succession over $\geq 5$ minutes

3. each symptom lasts $\geq 5$ and $<60$ minutes

D. Headache fulfilling criteria B-D for 1.1 Migraine without aura begins during the aura or

follow aura within 60 minutes

C. Not attributed to another disorder 


\section{Tension-type headache}

A. At least 10 episodes fulfilling criteria $B-D$

B. Headache lasting from 30 minutes to 7 days

C. Headache has at least two of the following characteristics

1. bilateral location

2. pressing/tightening (non-pulsating) quality

3. mild or moderate intensity

4. not aggravated by routine physical activity such as walking or climbing stairs

D. Both of the following

1. no nausea or vomiting (anorexia may occur)

2. no more than one of photophobia or phonophobia

E. Not attributed to another disorder 


\section{Appendix B}

B1 Prenotice letter

B2 Cover Letter

B3 Parent Questionnaire

B4 Postcard (Thank You / Reminder) 
An

Familie \{Nachnamen\}

$\{$ Straße $\{$ Hausnummer $\}$

$\{P L Z\}\{$ Ort $\}$

Sehr geehrte Familie \{Nachnamen\},

in einigen Tagen werden Sie Post erhalten, in der Sie gebeten werden, an einer Befragung teilzunehmen. Diese Befragung ist Teil des Forschungsprojektes "Kinder, Jugendliche \& Kopfschmerz", kurz KIJUKO. Sie wird von der Universität Göttingen durchgeführt und vom Bundesministerium für Bildung und Forschung gefördert.

Ziel des Projektes ist es, Informationen über die Gesundheit von Kindern und Jugendlichen in Deutschland zu gewinnen. Ihre Angaben helfen uns, Bedingungen zu erkennen, die einen Einfluss auf die Gesundheit nehmen.

Wir schreiben Ihnen schon heute, weil wir bei früheren Untersuchungen die Erfahrung gemacht haben, dass viele Leute lieber im Vorfeld einer solchen Befragung informiert werden möchten.

Wir wären Ihnen sehr dankbar, wenn Sie durch Ihre freundliche Teilnahme diese Forschung möglich machen würden.

Mit freundlichen Grüßen

Ihre

$$
\text { Ysoner-Heoniy }
$$

Prof. Dr. Birgit Kröner-Herwig

P.S. Unter allen Teilnehmern dieser Befragung werden wir interessante Sachpreise verlosen. Weitere Informationen erhalten Sie zusammen mit den Fragebögen.

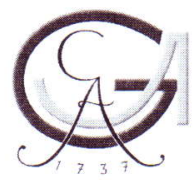


Sehr geehrte Familie \{Nachnamen\},

wir möchten Sie um die Teilnahme an unserer Fragebogenuntersuchung bitten. Sie sind zusammen mit 8800 anderen Familien aus Niedersachsen zufällig ausgewählt worden. Da unsere Befragung im öffentlichen Interesse liegt - es geht um die Gesundheit unserer Kinder - sind die Einwohnermeldeämter berechtigt, Adressen von Familien mit Kindern zur Verfügung zu stellen. Die Befragung wird von der Universität Göttingen durchgeführt und vom Bundesministerium für Bildung und Forschung gefördert.

Wir untersuchen den gesundheitlichen Zustand und die spezifischen Lebensbedingungen von Kindern und Jugendlichen. Diese Untersuchung ist notwendig, um die Bedingungen herauszufinden, die zu gesundheitlichen Problemen - insbesondere zu Kopfschmerzen - führen können. Die Studie bildet die Grundlage für die Entwicklung gezielter Programme zur Vorbeugung von gesundheitlichen Problemen. Es ist wichtig, dass Sie den beiliegenden Fragebogen zu Ihrer/lhrem \{Alter des Kindes\}-jährigen Tochter/Sohn \{Vornamen des Kindes\} ausfüllen, auch wenn sie/er keine gesundheitlichen Probleme hat. Nur durch einen Vergleich von beschwerdefreien Kindern und Kindern mit gesundheitlichen Problemen ist es möglich, Ansätze zur Vorbeugung abzuleiten.

Damit die Studie aussagekräftig ist und wirkungsvolle Präventionsprogramme konzipiert werden können, ist es unbedingt notwendig, Daten über einen längeren Zeitraum hinweg zu erheben. Wir werden Sie daher in einem Jahr wieder kontaktieren und um Ihre erneute Teilnahme bitten.

Für die gesamte Untersuchung garantieren wir Ihre Anonymität: Ihre Adressdaten werden nur für die Kontaktaufnahme verwendet. Die Ergebnisse der Befragung werden ausschließlich in anonymisierter Form, d.h. ohne Namen und Anschrift berichtet. Das bedeutet, niemand kann aus den Ergebnissen erkennen, von welcher Familie die Angaben gemacht worden sind.

Die Teilnahme an dieser Untersuchung ist natürlich freiwillig. Sie helfen uns aber sehr, wenn Sie sich 30 - 45 Minuten Zeit nehmen, um den Fragebogen auszufüllen.

Als Dankeschön für die Rücksendung Ihres Fragebogens nehmen Sie automatisch an einer Verlosung teil. Es gibt eine Mini-HiFi-Anlage und diverse Gutscheine für Bücher, CDs, DVDs und Kinokarten zu gewinnen.

Für Ihre Bereitschaft an dieser Befragung teilzunehmen, möchten wir uns im Voraus bei Ihnen bedanken. Wenn Sie Fragen oder Anmerkungen haben, können Sie sich jederzeit an uns wenden.

Mit freundlichen Grüßen

Ihre

$$
\text { Yrover-Heonij }
$$

GEFÖRDERT VOM

Prof. Dr. Birgit Kröner-Herwig

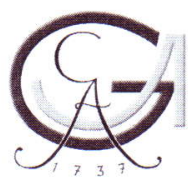




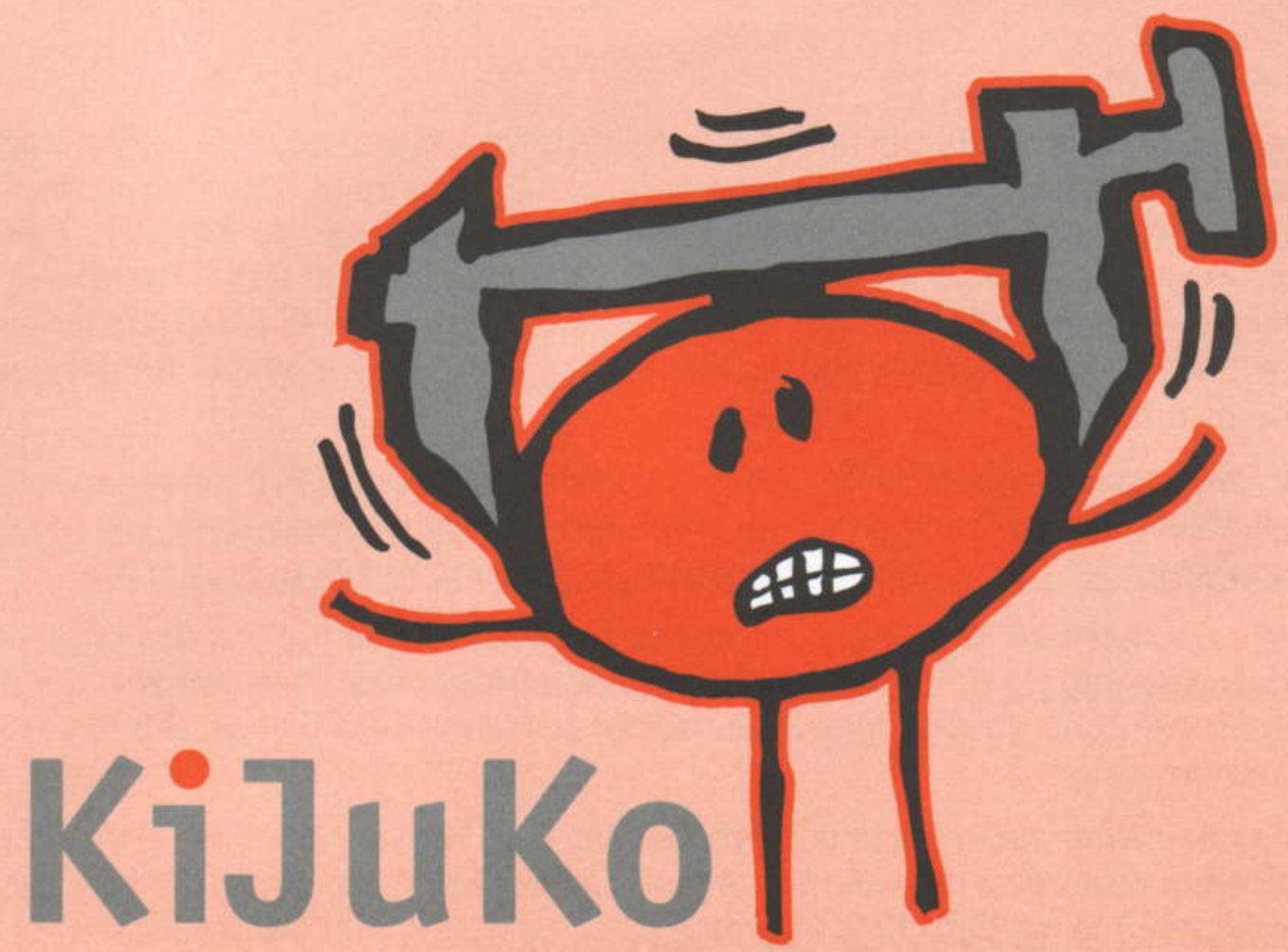

Kinder, Jugendliche \& Kopfschmerz

Studie zur Gesundheit und zum Kopfschmerz von Kindern und Jugendlichen 
Liebe Eltern,

Ihre Mitarbeit ist uns wichtig, um mehr über den gesundheitlichen Zustand von Kindern und Jugendlichen zu erfahren. Deshalb haben wir eine Menge Fragen an Sie über Ihr Kind und Ihre Familie.

Falls Sie mehrere Kinder haben, beziehen Sie sich bitte nur auf das im beiliegenden Brief genannte Kind. Wir möchten Sie daran erinnern, dass Sie und Ihr Kind die Fragebögen unabhängig voneinander beantworten, ohne sich miteinander abzustimmen.

Manche Kinder leben nicht mit ihren beiden leiblichen Eltern zusammen. Viele Fragen betreffen den Vater oder die Mutter oder beide Eltern, damit meinen wir die Personen, die mit dem Kind in einem Haushalt leben. Mit der Bezeichnung "Mutter" oder "Vater" sind auch diejenigen gemeint, die diese Rolle einnehmen, z. B. die Lebenspartnerin des Vaters, der Stiefvater o. a..

- Bitte beantworten Sie alle Fragen vollständig!

- Kreuzen Sie bitte bei jeder Frage eine Antwort an. Bei Fragen, die auf Ihr Kind oder Sie nicht zutreffen, kreuzen Sie bitte "Nein" an. Nur so können wir sicher sein, dass es auf Ihr Kind oder Sie nicht zutrifft!

- Wenn Ihnen eine Antwort schwer fällt, so versuchen Sie bitte dennoch, sich zu entscheiden!

- Überspringen Sie eine Frage nur, wenn für Sie der Hinweis gilt:

$\supset$ Gehen Sie zu Frage ... !

Die Ergebnisse der Befragung werden ausschließlich in anonymisierter Form, d.h. ohne Namen und Anschrift ausgewertet und dargestellt. Niemand kann feststellen, wer welche Angaben gemacht hat.

Wenn Sie Fragen haben, können Sie sich jederzeit an uns wenden.

KIJUKO-Team

Georg-August Universität Göttingen

Institut für Psychologie (Abteilung 7)

Gosslerstraße 14

37073 Göttingen

Telefon: 0551 / 39-3566

e-mail: kijuko@uni-goettingen.de 


\section{Persönliche Angaben zu Ihnen und Ihrem Kind}

1. Bei wem lebt Ihr Kind hauptsächlich? (Hier bitte nur ein Kreuz machen!)

$\square$ Leiblichen Eltern

$\square$ Leiblicher Mutter und ihrem Partner

$\square$ Leiblichem Vater und seiner Partnerin

$\square$ Leiblicher Mutter

$\square$ Leiblichem Vater

$\square$ Adoptiveltern / Pflegeeltern

$\square$ Großeltern oder anderen Verwandten

$\square$ In einem Heim

2. Geburtsdatum Ihres Kindes

|_I_l Tag |_I_ Monat |_I_I__| Jahr

3. Wer beantwortet diesen Fragebogen?

$\square$ Mutter

$\square$ Vater

$\square$ Mutter und Vater

$\square$ Adoptiveltern / Pflegeeltern

$\square$ Großeltern oder andere Verwandte

$\square$ Betreuer/in

4. Wie viele leibliche Geschwister hat Ihr Kind? (Gemeint sind auch Halbgeschwister.)

$\square$ Es ist ein Einzelkind.

Es hat |_I_| leibliche ältere Geschwister.

Es hat |_I_ leibliche jüngere Geschwister.

Es hat |_I_| leibliche gleichaltrige Geschwister (Zwilling, Mehrlinge).

5. Mit wie vielen älteren und jüngeren Geschwistern lebt Ihr Kind zusammen? (Gemeint sind in diesem Fall auch Halbgeschwister, Adoptivgeschwister und angeheiratete Geschwister.)

$\square$ Mein Kind lebt mit keinen Geschwistern zusammen.

Mein Kind lebt mit |_l_| älteren Geschwistern zusammen.

Mein Kind lebt mit |_l_l jüngeren Geschwistern zusammen.

Mein Kind lebt mit |_I_| gleichaltrigen Geschwistern zusammen. 


\section{Gesundheit Ihres Kindes}

6. Wie groß ist Ihr Kind?

Mein Kind ist L_L_l_l cm groß.

7. Wie viel wiegt Ihr Kind?

Mein Kind wiegt |_l_l_l kg.

8. Wie würden Sie die Gesundheit Ihres Kindes im Allgemeinen beschreiben?

$\begin{array}{ccccc}\begin{array}{c}\text { Sehr } \\ \text { gut }\end{array} & \text { Gut } & \begin{array}{l}\text { Mittel- } \\ \text { mäßig }\end{array} & \text { Schlecht } & \begin{array}{c}\text { Sehr } \\ \text { schlecht }\end{array} \\ \square & \square & \square & \square & \square\end{array}$

9. Bitte geben Sie das Geschlecht Ihres Kindes an!

$\square$ Männlich

$\square$ Weiblich

(1)

Wenn Ihr Kind ein Mädchen ist, in welchem Alter hat die Regelblutung begonnen?

Mit |_|_| Jahren

$\square$ Sie hat noch keine Regelblutung.

10. Leidet Ihr Kind an folgenden chronischen körperlichen Erkrankungen? Wenn Ihr Kind nicht an einer der aufgeführten Erkrankungen leidet, kreuzen Sie bitte "Nein" an!

Asthma

Neurodermitis / atopische Erkrankung

Allergien

Epilepsie

Angeborener Herzfehler

Chronisch entzündliche Darmerkrankungen

Chronische Nierenerkrankung

Muskelerkrankungen

Rheuma

Diabetes

Andere

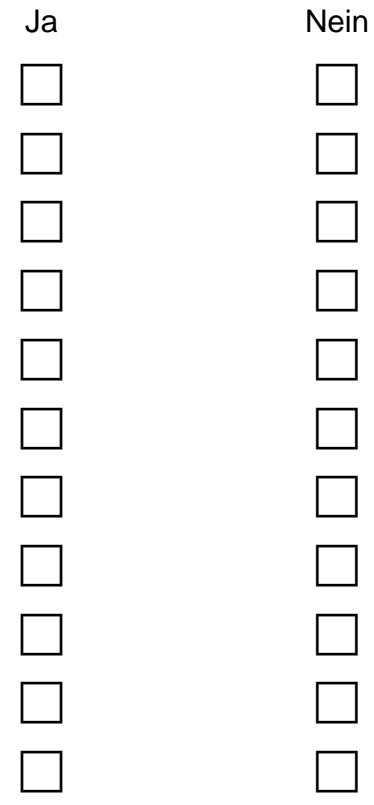


11. Wie stark ist Ihr Kind durch die schwerste dieser Erkrankungen beeinträchtigt?

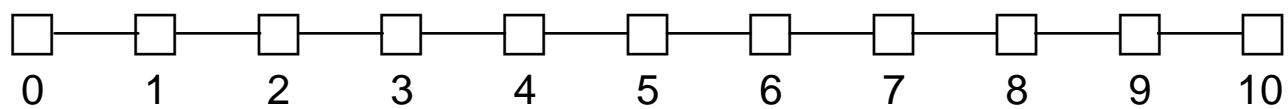

Gar nicht

beeinträchtigt

Völlig beeinträchtigt, d.h. kann an keinen üblichen Aktivitäten teilnehmen

12. Befindet sich Ihr Kind aufgrund der Erkrankung/en in regelmäßiger ärztlicher Behandlung?

$\square$ Nein

$\square \mathrm{Ja}$

13. Leidet Ihr Kind an folgenden Störungen bzw. Beeinträchtigungen? Wenn Ihr Kind nicht an einer der aufgeführten Beeinträchtigungen leidet, kreuzen Sie bitte "Nein" an!

$\begin{array}{lll}\text { Entwicklungsverzögerungen oder geistige } & \text { Ja } \\ \text { Behinderung } & \square \\ \text { Hörprobleme oder Taubheit } & \square \\ \text { Sprachstörungen } & \square \\ \text { Schwere Sehstörung oder Blindheit } & \square\end{array}$

Wenn Ihr Kind

an keiner dieser

Störungen

leidet, $\rightarrow$ weiter

mit Frage 15!

14. Wie stark ist Ihr Kind durch die schwerste dieser Störungen beeinträchtigt?

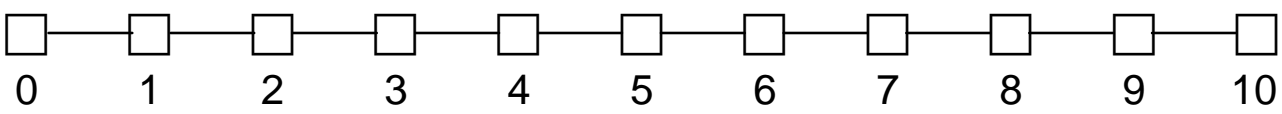

Gar nicht beeinträchtigt

Völlig beeinträchtigt, d.h. kann an keinen üblichen Aktivitäten teilnehmen 
15. Wie häufig kam es in den letzten 3 Monaten vor, dass Ihr Kind unter den folgenden Beschwerden litt? (Wenn Ihr Kind die genannte Beschwerde nicht hat, kreuzen Sie bitte "Nie" an!)

$\begin{array}{lllllll} & \text { Nie } & \text { Selten } & \begin{array}{c}\text { Manch- } \\ \text { mal }\end{array} & \begin{array}{c}\text { Sehr oft } \\ \text { (mindestens } \\ \text { 1mal pro } \\ \text { Woche) }\end{array} & \begin{array}{c}\text { Weiß } \\ \text { nicht }\end{array} \\ \text { Bauchschmerzen } & \square & \square & \square & \square & \square & \square \\ \text { Appetitlosigkeit } & \square & \square & \square & \square & \square & \square \\ \text { Schwindel } & \square & \square & \square & \square & \square & \square \\ \begin{array}{l}\text { Schlafstörungen } \\ \text { (beim Ein- oder Durchschlafen) }\end{array} & \square & \square & \square & \square & \square & \square \\ \text { Verstopfung } & \square & \square & \square & \square & \square & \square \\ \text { Übelkeit oder Erbrechen } & \square & \square & \square & \square & \square \\ \text { (ohne dass Kopfschmerzen } & \square & \square & \square & \square & \square & \square \\ \text { vorlagen) } & \square & \square & \square & \square \\ \text { Reiseübelkeit } & \square & \square & \square & \square \\ \text { Müdigkeit / Schlappheit } & \square & \square & \square & \square & \square \\ \text { Rückenschmerzen } & \square & \square & \square & \square & \square\end{array}$

16. Befindet sich Ihr Kind wegen dieser Beschwerden in Behandlung?

$\square$ Nein

$\square \mathrm{Ja}$

17. Nimmt Ihr Kind zurzeit regelmäßig Medikamente ein? (Medikamente zur Behandlung von Kopfschmerzen hier bitte nicht nennen, da sie gesondert erfragt werden!)

$\square$ Nein

$\square \mathrm{Ja}$

18. Wie viele Nächte war Ihr Kind in den letzten 12 Monaten zur stationären Behandlung in einem Krankenhaus?

Ungefähr |_l_| Nächte

Keine Nacht 
19. In den folgenden Aussagen geht es um die allgemeine Gesundheit Ihres Kindes. Bitte schätzen Sie ein, inwieweit jede dieser Aussagen auf Ihr Kind zutrifft!

\begin{tabular}{|c|c|c|c|}
\hline $\begin{array}{c}\text { Trifft } \\
\text { überhaupt } \\
\text { nicht zu }\end{array}$ & $\begin{array}{c}\text { Trifft } \\
\text { eher nicht } \\
\text { zu }\end{array}$ & $\begin{array}{c}\text { Trifft } \\
\text { teilweise } \\
\text { zu }\end{array}$ & $\begin{array}{c}\text { Trifft eher } \\
\text { zu }\end{array}$ \\
\hline
\end{tabular}

Mein Kind scheint etwas leichter als andere Kinder krank zu werden.

Mein Kind ist im Allgemeinen gesund.

20. Hat Ihr Kind in den letzten 6 Monaten über Kopfschmerzen berichtet?

$\square$ Nein $\Rightarrow$ weiter mit Frage 51 !

$\square \mathrm{Ja}$

$\square$ Weiß nicht $\bigcirc$ weiter mit Frage 51!

\section{Kopfschmerzen Ihres Kindes}

21. In welchem Alter hatte Ihr Kind zum ersten Mal Kopfschmerzen?

Mit I_l_l Jahren

$\square$ Weiß nicht

22. Was trifft auf Ihr Kind zu? Mein Kind hatte in den letzten 6 Monaten Kopfschmerzen...

$\square$ Mindestens $1 \mathrm{mal}$ in der Woche

$\stackrel{\leftrightarrow}{\rightarrow}$ Mein Kind hatte ungefähr I_Imal in der Woche Kopfschmerzen.

$\square$ Mindestens $1 \mathrm{mal}$ im Monat, aber weniger als $1 \mathrm{mal}$ in der Woche

$\leftrightarrow$ Mein Kind hatte ungefähr I_Imal im Monat Kopfschmerzen.

$\square$ Weniger als 1mal im Monat

$\stackrel{\leftrightarrow}{\hookrightarrow}$ Mein Kind hatte ungefähr I_Imal in den letzten 6 Monaten Kopfschmerzen.

23. Wie lange hielten die Kopfschmerzen durchschnittlich an?

$\square$ Bis zu 1 Stunde

1-2 Stunden

$\square$ 2-4 Stunden

$\square 4$ Stunden bis zu einem Tag

$\square$ Länger als einen Tag

$\square 2$ Tage und länger

$\square$ Weiß nicht 
24. Wie stark waren die Kopfschmerzen Ihres Kindes im Durchschnitt? Bitte versuchen Sie, es nach Ihrem Eindruck einzuschätzen!

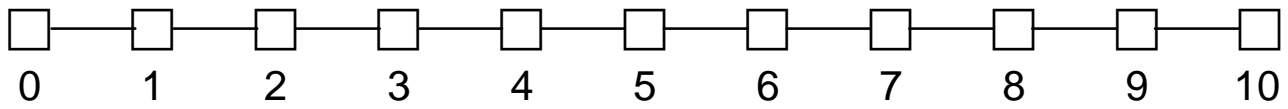

Kein

Schmerz

Schlimmster vorstellbarer

Schmerz

$\square$ Schmerzintensität lässt sich nicht angeben

25. Wo treten die Schmerzen auf? (Hier sind mehrere Antworten möglich.)

$\square$ Im Schläfenbereich

$\square$ Im Stirnbereich

$\square$ Am Hinterkopf

$\square$ Am ganzen Kopf

$\square$ Auf einer Seite des Kopfes

$\square$ Weiß nicht

26. Treten folgende Symptome im Vorfeld der Kopfschmerzen Ihres Kindes auf? Ja Nein $\begin{aligned} & \text { Weiß } \\ & \text { nicht }\end{aligned}$

Sehstörungen (z.B. Linien, Blitze, Einschränkung des Blickfeldes)

Sprachstörungen

Lähmungen

Empfindungsstörungen (z.B. Kribbeln, Taubheit)

27. Treten folgende Symptome zusammen mit den Kopfschmerzen Ihres Kindes auf?

Übelkeit oder Erbrechen

Lichtempfindlichkeit

Geräuschempfindlichkeit

Verstärkung der Schmerzen bei Bewegung

Ja Nein Weiß

nicht 
28. Wie beschreibt Ihr Kind im Allgemeinen die Schmerzempfindung?

$\square$ Dumpf oder drückend

$\square$ Pulsierend oder pochend

$\square$ Weiß nicht

29. Welche Faktoren lösen Ihrer Meinung nach bei Ihrem Kind Kopfschmerzen aus? (Wenn Sie den Eindruck haben, dass ein Faktor keinen Kopfschmerz auslöst, kreuzen Sie bitte "Nie" an!)

\begin{tabular}{|c|c|c|c|c|c|}
\hline & $\mathrm{Nie}$ & Selten & $\begin{array}{c}\text { Manch- } \\
\text { mal }\end{array}$ & Oft & Immer \\
\hline Geistige Anstrengung & $\square$ & $\square$ & $\square$ & $\square$ & $\square$ \\
\hline Schulische Belastung & $\square$ & $\square$ & $\square$ & $\square$ & $\square$ \\
\hline $\begin{array}{l}\text { Ärger in der Schule / in der } \\
\text { Familie }\end{array}$ & $\square$ & $\square$ & $\square$ & $\square$ & $\square$ \\
\hline Müdigkeit / Schlafmangel & $\square$ & $\square$ & $\square$ & $\square$ & $\square$ \\
\hline Unregelmäßige Mahlzeiten & $\square$ & $\square$ & $\square$ & $\square$ & $\square$ \\
\hline Erkältungskrankheiten & $\square$ & $\square$ & $\square$ & $\square$ & $\square$ \\
\hline Wetterveränderung & $\square$ & $\square$ & $\square$ & $\square$ & $\square$ \\
\hline $\begin{array}{l}\text { Besondere } \\
\text { Lichtverhältnisse } \\
\text { (z.B. starkes Sonnenlicht) }\end{array}$ & $\square$ & $\square$ & $\square$ & $\square$ & $\square$ \\
\hline Lärm & $\square$ & $\square$ & $\square$ & $\square$ & $\square$ \\
\hline $\begin{array}{l}\text { Genuss bestimmter } \\
\text { Nahrungsmittel (z.B. Käse, } \\
\text { Schokolade, Zitrusfrüchte) }\end{array}$ & $\square$ & $\square$ & $\square$ & $\square$ & $\square$ \\
\hline Lange Fahrten im Auto & $\square$ & $\square$ & $\square$ & $\square$ & $\square$ \\
\hline Langes Fernsehen & $\square$ & $\square$ & $\square$ & $\square$ & $\square$ \\
\hline $\begin{array}{l}\text { Spielen / Arbeiten am } \\
\text { Computer }\end{array}$ & $\square$ & $\square$ & $\square$ & $\square$ & $\square$ \\
\hline Für Mädchen: Regelblutung & $\square$ & $\square$ & $\square$ & $\square$ & $\square$ \\
\hline
\end{tabular}

30. Kreuzen Sie bitte an, welcher Satz mehr für Sie zutrifft!

$\square$ Ich kann mir meistens erklären, weshalb mein Kind Kopfschmerzen bekommt.

$\square$ Ich kann mir meistens nicht erklären, weshalb mein Kind Kopfschmerzen bekommt. 
Die folgenden Fragen (31-36) beziehen sich auf die letzten 3 Monate. Bitte versuchen Sie, sich an diesen Zeitraum zu erinnern! Falls Sie sich im Einzelfall nicht genau erinnern können, geben Sie Ihre bestmögliche Schätzung an!

31. An wie vielen Tagen hatte Ihr Kind Kopfschmerzen?

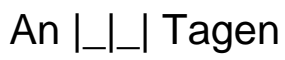

32. An wie vielen Tagen hat Ihr Kind in den letzten drei Monaten ganze Schultage wegen Kopfschmerzen versäumt?

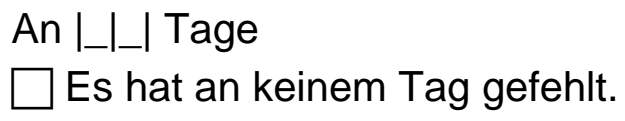

33. An wie vielen Tagen hat Ihr Kind in den letzten drei Monaten einzelne Schulstunden wegen Kopfschmerzen versäumt? (Bitte nicht die ganzen Tage, die in der vorherigen Frage gezählt wurden, hinzuzählen!)

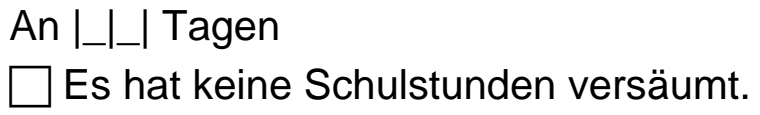

34. An wie vielen Tagen war Ihr Kind in den letzten drei Monaten nur halb so leistungsfähig wie sonst in der Schule wegen Kopfschmerzen? (Bitte nicht die Tage, die in den beiden vorherigen Fragen gezählt wurden, hinzuzählen!)
An |_l_| Tagen
$\square$ Weiß nicht

35. An wie vielen Tagen war Ihr Kind nicht in der Lage, Aufgaben zu Hause (z.B. Hausaufgaben, Zimmer aufräumen, zu Hause helfen) wegen Kopfschmerzen zu erledigen?

\section{An |_l_| Tagen}

$\square$ Es hat an allen Tagen trotz Kopfschmerzen die Aufgaben zu Hause erledigt.

36. An wie vielen Tagen war Ihr Kind nicht in der Lage, an anderen Aktivitäten (z.B. Spielen, Sport, ins Kino gehen) wegen Kopfschmerzen teilzunehmen?

An I_l_l Tagen

$\square$ Es hat an allen Tagen trotz Kopfschmerzen an Aktivitäten teilgenommen.

37. An wie vielen Tagen hat Ihr Kind an diesen Aktivitäten teilgenommen, war aber nur halb so leistungsfähig wie sonst? (Bitte nicht die Tage, die in der vorherigen Frage gezählt wurden, hinzuzählen!)
An |_l_| Tagen
$\square$ Weiß nicht 
38. Wenn Ihr Kind Kopfschmerzen hat, kann es dann das Folgende noch machen? Nie Selten $\begin{gathered}\text { Manch- } \\ \text { mal }\end{gathered}$ Oft Immer

Es kann lebhafte Spiele spielen

(z. B. Fangen und Fußball).

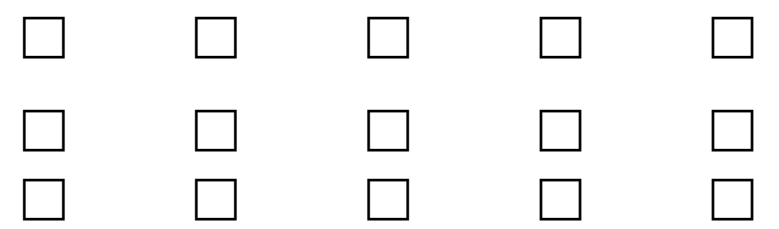

Es kann fernsehen.

Es kann Bücher oder Comics lesen.

Es ist gezwungen, sich hinzulegen.

39. Was hilft Ihrem Kind, wenn es Kopfschmerzen hat?

Nie Selten $\begin{gathered}\text { Manch- } \\ \text { mal }\end{gathered}$ Oft Immer $\begin{gathered}\text { Macht } \\ \text { Kind } \\ \text { nicht }\end{gathered}$

Sich hinzulegen / Schlafen

Stirn zu kühlen

Abdunkeln des Zimmers

Ablenkung

Entspannung

Einnahme von Medikamenten

Spaziergang an der frischen Luft
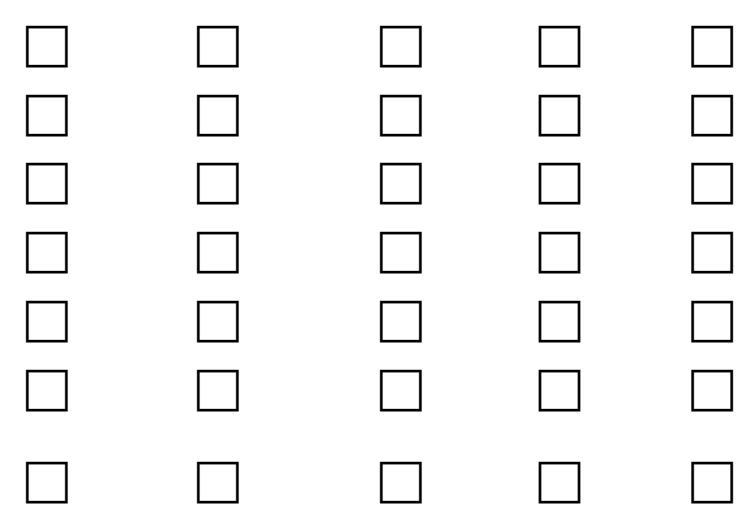

$\square$

40. Machen Sie sich Sorgen über die Kopfschmerzen Ihres Kindes?

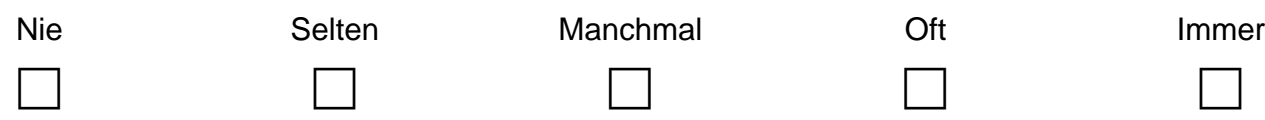

41. Waren Sie schon einmal mit Ihrem Kind wegen seiner Kopfschmerzen beim Arzt?

$\square$ Nein $\supset$ weiter mit Frage 46 !

$\square \mathrm{Ja}$

42. Haben Sie verschiedene Ärzte aufgesucht?

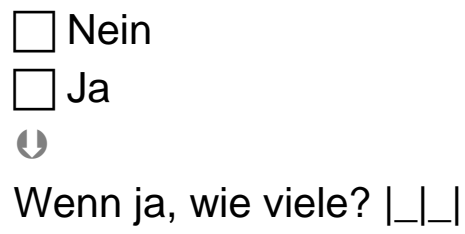


43. Welche Ärzte haben Sie aufgesucht? (Hier sind mehrere Antworten möglich.)

$\square$ Hausarzt

$\square$ Kinderarzt

$\square$ Neurologe

$\square$ Augenarzt

$\square$ Homöopath

$\square$ Andere

44. Welcher Befund bzw. welche Diagnose wurde Ihnen mitgeteilt? (Hier sind mehrere Antworten möglich.)

$\square$ Keine Diagnose

$\square$ Spannungskopfschmerz

$\square$ Migräne

$\square$ Weiß nicht

45. Ist der Kopfschmerz - nach Ansicht des Arztes - rückführbar auf eine der folgenden Ursachen?

$\begin{array}{llcc} & \text { Ja } & \text { Nein } & \begin{array}{l}\text { Weiß } \\ \text { nicht }\end{array} \\ \text { Unfall } & \square & \square & \square \\ \text { Erkrankung } & \square & \square & \square \\ \text { Operation } & \square & \square & \square \\ \text { Wachstum } & \square & \square & \square\end{array}$

46. Nimmt Ihr Kind Medikamente ein, um Kopfschmerz vorzubeugen?

$\square$ Nein 2 weiter mit Frage 48 !

$\square$ Betablocker (z.B. Beloc ${ }^{\circledR}$, Dociton ${ }^{\circledR}$ )

$\square$ Kalziumantagonisten (z.B. Sibelium ${ }^{\circledR}$ )

$\square$ Nicht-steriodale Serotoninagonisten (z.B. DET-MS ${ }^{\circledR}$ )

$\square$ Andere

47. Wie häufig nimmt Ihr Kind die Medikamente, um Kopfschmerzen vorzubeugen?

Nie

Selten

Manchmal

Oft

Immer
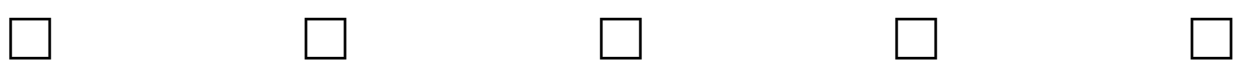
48. Nimmt Ihr Kind Medikamente ein, um bestehende Kopfschmerzen zu lindern bzw. zu beseitigen?

$\square$ Nein $\supset$ weiter mit Frage 50 !

$\square$ Acetylsalicylsäure (z.B. Aspirin ${ }^{\circledR}$, ASS $^{\circledR}$ )

$\square$ Paracetamol (z.B. Ben-u-ron ${ }^{\circledR}$ )

$\square$ Triptane (z.B. Imigran ${ }^{\circledR}$, Asco-Top $^{\circledR}$, Maxalt ${ }^{\circledR}$ )

$\square$ Ergotamine (z.B. Ergo-Kranit ${ }^{\circledR}$, ergo sanol ${ }^{\circledR}$ )

$\square$ Kombinationspräparate (z.B. Thomapyrin ${ }^{\circledR}$ )

$\square$ Anti-Übelkeitspräparate (z.B. Motilium ${ }^{\circledR}$, Paspertin ${ }^{\circledR}$ )

$\square$ Andere

49. Wie häufig nimmt Ihr Kind Medikamente, um beginnende oder bestehende Kopfschmerzen zu lindern bzw. zu beseitigen?

\begin{tabular}{|c|c|c|c|c|}
\hline $\mathrm{Nie}$ & Selten & $\begin{array}{c}\text { Manch- } \\
\text { mal }\end{array}$ & Oft & \\
\hline & $\square$ & $\square$ & $\square$ & \begin{tabular}{|l} 
\\
\end{tabular} \\
\hline
\end{tabular}

50. Die folgenden Fragen beziehen sich darauf, was Sie in den letzten 6 Monaten getan haben, wenn Ihr Kind Kopfschmerzen hatte!

Nie Selten $\begin{gathered}\text { Manch- } \\ \text { mal }\end{gathered}$ Oft Immer

Wie oft haben Sie Ihr Kind zu Hause gelassen, anstatt es zur Schule zu schicken, wenn es Kopfschmerzen hatte?

Wie oft haben Sie Ihrem Kind regelmäßige häusliche Pflichten (wie Müll 'rausbringen oder das Zimmer aufzuräumen) erlassen, wenn es Kopfschmerzen hatte?

Wie oft haben Sie mehr Zeit mit Ihrem Kind verbracht, wenn es Kopfschmerzen hatte?

Wie oft haben Sie Ihr Kind umsorgt oder verwöhnt, wenn es Kopfschmerzen hatte?

Wie oft haben Sie Ihrem Kind spezielle Privilegien eingeräumt oder es Dinge tun lassen, die es sonst nicht tun darf, wenn es Kopfschmerzen hatte?

Wie oft sind Sie selbst zu Hause geblieben oder früher von der Arbeit zurückgekommen (bzw. wenn Sie nicht berufstätig sind, wie oft sind Sie zu Hause geblieben statt Erledigungen zu machen), wenn Ihr Kind Kopfschmerzen hatte? 


\section{Kopfschmerzen in der Familie}

51. Bitte geben Sie an, inwieweit Sie den folgenden Aussagen zustimmen!

$\begin{array}{ccccc}\text { Stimme } & \text { Stimme } & \text { Stimme } & \text { Stimme } & \text { Stimme } \\ \text { überhaupt } & \text { eher nicht } & \text { teilweise } & \text { eher zu } & \text { ganz zu } \\ \text { nicht zu } & z u & z u & & \end{array}$

Kopfschmerzen haben vorwiegend eine psychische Ursache.

Kopfschmerzen haben vorwiegend eine körperliche Ursache.

Bei Kopfschmerzen sollte man Medikamente einnehmen.

Bei Kopfschmerzen sollte man immer den Arzt aufsuchen.

\section{Leiden Sie an Kopfschmerzen?}

$\square$ Nein $\curvearrowright$ weiter zu Frage 55!

$\square \mathrm{Ja}$

53. Welcher Art sind Ihre Kopfschmerzen?

Migräne-Kopfschmerz

(anfallartige Kopfschmerzen mit Übelkeit, Erbrechen, heftigem Schmerz, Licht-/Geräuschempfindlichkeit)

Spannungskopfschmerz (drückender/ziehender

Schmerz, beidseitig auftretend)

Anderer Kopfschmerz

54. Was trifft auf Sie zu? Ich hatte in den letzten 6 Monaten Kopfschmerzen...

$\square$ Mindestens $1 \mathrm{mal}$ in der Woche

$\stackrel{\leftrightarrow}{4}$ nämlich ungefähr |_|mal in der Woche.

$\square$ Mindestens $1 \mathrm{mal}$ im Monat, aber weniger als $1 \mathrm{mal}$ in der Woche $\Leftrightarrow$ nämlich ungefähr I_Imal im Monat.

$\square$ Weniger als $1 \mathrm{mal}$ im Monat $\Leftrightarrow$ nämlich ungefähr I_Imal in den letzten 6 Monaten.

55. Leidet Ihr Partner / Ihre Partnerin an Kopfschmerzen?

$\square$ Ich habe keinen Partner / keine Partnerin $\curvearrowright$ weiter zu Frage 58!

$\square$ Nein $\curvearrowright$ weiter zu Frage 58 !

$\square \mathrm{Ja}$ 
56. Welcher Art sind seine / ihre Kopfschmerzen?

Migräne-Kopfschmerz

(anfallartige Kopfschmerzen mit Übelkeit, Erbrechen, heftigem Schmerz, Licht-/Geräuschempfindlichkeit)

Spannungskopfschmerz (drückender/ziehender

Schmerz, beidseitig auftretend)

Anderer Kopfschmerz

57. Was trifft auf Ihren Partner bzw. Ihre Partnerin zu? Er bzw. sie hatte in den letzten 6 Monaten Kopfschmerzen...

Mindestens $1 \mathrm{mal}$ in der Woche

$\stackrel{\leftrightarrow}{\rightarrow}$ nämlich ungefähr |_Imal in der Woche

$\square$ Mindestens $1 \mathrm{mal}$ im Monat, aber weniger als $1 \mathrm{mal}$ in der Woche

$\stackrel{\leftrightarrow}{\Rightarrow}$ nämlich ungefähr I_Imal im Monat

$\square$ Weniger als $1 \mathrm{mal}$ im Monat

$\stackrel{\leftrightarrow}{\hookrightarrow}$ nämlich ungefähr I_Imal in den letzten 6 Monaten

$\square$ Weiß nicht

58. Wie viele Geschwister Ihres Kindes leiden öfter an Kopfschmerzen?

I_L_| Geschwister

$\square$ Mein Kind hat keine Geschwister.

\section{Ihre Gesundheit und die Ihrer Familie}

59. Wie oft waren Sie persönlich in den letzten 3 Monaten...

...sehr nervös und angespannt?

...niedergeschlagen, so dass Sie

nichts aufmuntern konnte?

...ruhig und gelassen?

...entmutigt und traurig?

...glücklich und zufrieden?

Nie Selten Manch-

Oft Immer

$\square \square$

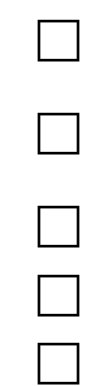


60. Wie oft haben Sie sich in den letzten 3 Monaten Sorgen gemacht...

...über Ihren Arbeitsplatz?

...über die Gesundheit Ihrer

Familie?

Nie Selten Manch-

Oft

Immer

...über Probleme in der Familie?

61. Inwieweit treffen die folgenden Aussagen auf Sie zu?

\begin{tabular}{|c|c|c|c|c|}
\hline $\begin{array}{c}\text { Trifft } \\
\text { überhaupt } \\
\text { nicht zu }\end{array}$ & $\begin{array}{c}\text { Trifft eher } \\
\text { nicht zu }\end{array}$ & $\begin{array}{c}\text { Trifft } \\
\text { teilweise } \\
\text { zu }\end{array}$ & $\begin{array}{c}\text { Trifft eher } \\
\text { zu }\end{array}$ & $\begin{array}{c}\text { Trifft ga } \\
\text { zu }\end{array}$ \\
\hline
\end{tabular}

Ich war schon immer jemand, der sich viele Sorgen macht.

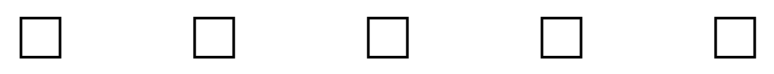

Über irgendetwas mache ich mir immer Sorgen.

Meine Sorgen wachsen mir über den Kopf.

Ich scheine etwas leichter als

andere krank zu werden.

Ich bin im Allgemeinen gesund.

62. Waren Sie in den letzten 6 Monaten beim Arzt?

$\square$ Nein

$\square$ Ja $\Rightarrow$ Wie oft? |_l_|mal

63. Wie häufig leiden Sie unter folgenden Beschwerden?

Nie Selten $\begin{gathered}\text { Manch- } \\ \text { mal }\end{gathered}$ Oft Immer

Schmerzen (z.B. Rücken, Gelenke)

Bauchschmerzen / Magen-Darm-

Beschwerden

Asthma / Allergien

Schilddrüsenfehlfunktion

Schlafstörungen

Herz- / Kreislaufbeschwerden /

Bluthochdruck

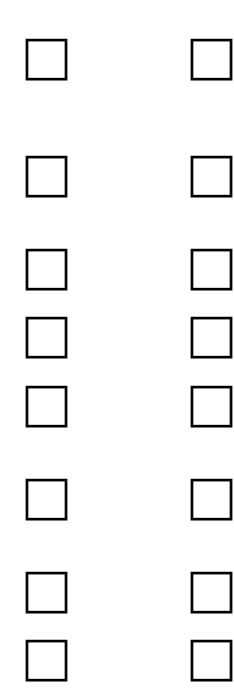

Depressive Verstimmung 
64. Wenn Sie an diesen oder anderen Beschwerden oder Schmerzen leiden...

Nie Selten $\begin{gathered}\text { Manch- } \\ \text { mal }\end{gathered}$ Oft Immer

... sagen Sie gemeinsame

Unternehmungen mit

FreundInnen oder der Familie $a b$ ?

...gehen Sie nicht zur Arbeit oder lassen Sie die Hausarbeit liegen?

...nimmt die Familie Rücksicht auf Sie?

....erhalten Sie Hilfe von anderen

Familienmitgliedern bei Pflichten im Haushalt?

65. Nehmen Sie regelmäßig Medikamente ein?

$\square$ Nein

$\square \mathrm{Ja}$

66. Bitte schätzen Sie ein, inwieweit jede dieser Aussagen auf Sie zutrifft!

$\begin{array}{ccccc}\text { Trifft } & \text { Trifft } & \text { Trifft } & \text { Trifft eher } & \text { Trifft } \\ \text { überhaupt } & \text { eher nicht } & \text { teilweise } & \mathrm{zu} & \text { ganz } z u \\ \text { nicht } z u & \mathrm{zu} & \mathrm{zu} & & \end{array}$

Wenn ich Beschwerden habe, suche ich für gewöhnlich einen Arzt auf.

Wenn ich Beschwerden habe, weiß ich, dass ich mir selbst helfen kann.

Ich verdanke es meinem Schicksal, wenn meine Beschwerden wieder verschwinden.

Wenn ich Beschwerden habe, frage ich andere um Rat.

Wenn es das Schicksal so will, dann bekomme ich körperliche Beschwerden.

Es liegt an mir, wenn meine Beschwerden nachlassen.

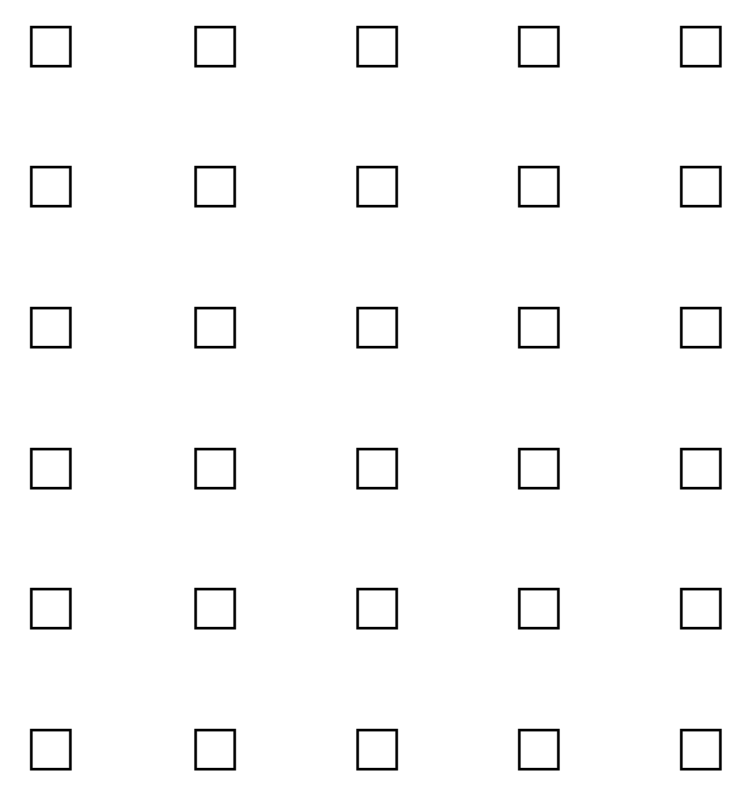

67. War Ihr Partner I Ihre Partnerin in den letzten 6 Monaten beim Arzt?

$\square$ Ich habe keinen Partner / keine Partnerin 2 weiter zu Frage 70 !

$\square$ Nein 2 weiter zu Frage 70 !

$\square$ Ja $\odot$ Wie oft? |_l_| mal

$\square$ Weiß nicht 
68. Wie häufig leidet Ihr Partner / Ihre Partnerin unter folgenden Beschwerden?

Nie Selten $\begin{gathered}\text { Manch- } \\ \text { mal }\end{gathered}$ Oft Immer $\begin{aligned} & \text { Weiß } \\ & \text { nicht }\end{aligned}$

Schmerzen (z.B. Rücken, Gelenke)

Bauchschmerzen / Magen-DarmBeschwerden

Asthma / Allergien

Schilddrüsenfehlfunktion

Schlafstörungen

Herz- / Kreislaufbeschwerden /

Bluthochdruck

Ängste

Depressive Verstimmung

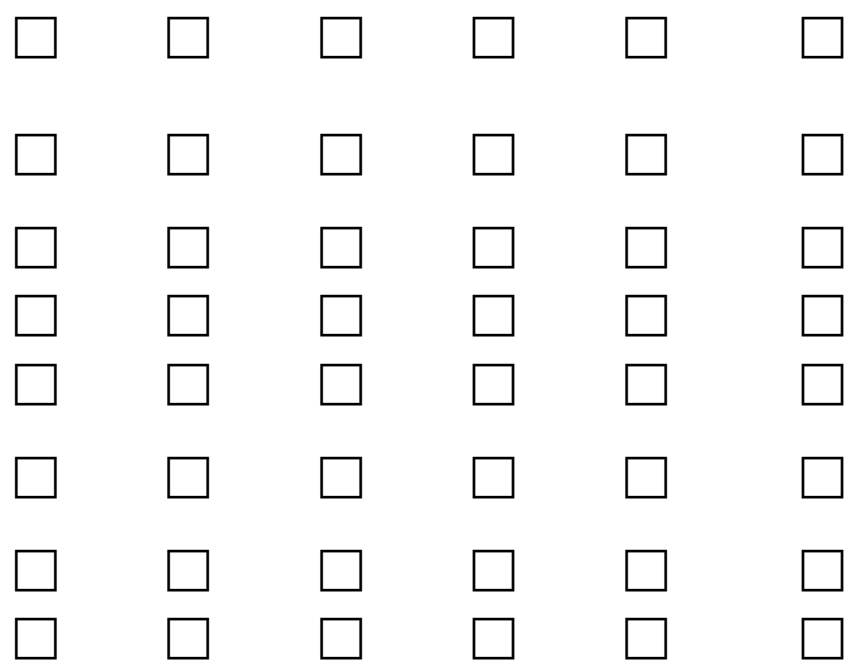

69. Nimmt Ihr Partnerl Ihre Partnerin regelmäßig Medikamente ein?

$\square$ Nein

$\square \mathrm{Ja}$

$\square$ Weiß nicht

\section{Familiäre Situation}

70. Bitte geben Sie an, wie häufig Folgendes für Ihre Familie zutrifft!

Haben Sie in Ihrer Familie Zeit füreinander?
Sind Sie zufrieden mit Ihren gemeinsamen
Aktivitäten?
$\begin{aligned} & \text { Reden Sie in Ihrer Familie über Ihre Sorgen } \\ & \text { und Probleme? }\end{aligned}$

71. Wenn es in Ihrer Familie zu Konflikten kommt, wie läuft das bei Ihnen ab?

$\begin{array}{lllll}\text { Wir versuchen das Problem zu lösen, } & \text { Nie } & \text { Selten } & \begin{array}{c}\text { Manch- } \\ \text { mal }\end{array} & \text { Oft } \\ \text { indem wir darüber reden. } & \square & \square & \square\end{array}$


72. Wie häufig kam es in den letzten 3 Monaten durchschnittlich zum Streit?

$\square$ Täglich

$\square$ Mehrmals pro Woche

$\square$ Ungefähr 1x pro Woche

$\square$ Seltener

$\square$ Nie

\section{Schule}

73. Auf was für eine Schule geht Ihr Kind?

$\square$ Grundschule

$\square$ Orientierungsstufe

$\square$ Hauptschule

$\square$ Realschule

$\square$ Gymnasium

$\square$ Gesamtschule

$\square$ Sonderschule

$\square$ Waldorfschule

74. Welche Schulklasse besucht Ihr Kind?

Es besucht zurzeit die |_|_|. Klasse

75. Hat Ihr Kind schon einmal eine Klasse wiederholt?

$\square$ Nein

$\square$ Ja, einmal

$\square$ Ja, zwei-/ mehrmals

76. Wird die Schulleistung Ihres Kindes benotet?

$\square$ Nein

$\square \mathrm{Ja}$

(1)

Wenn ja, wie ist die Schulleistung Ihres Kindes im letzten Halbjahr gewesen? Bitte geben Sie die Durchschnittsnoten Ihres Kindes in den folgenden Fächern an:

Lesen, Deutsch

Sachkunde, Geschichte, Sozialkunde, Erdkunde

Rechnen, Mathematik

Biologie, Chemie, Physik

Fremdsprachen 
77. Wie viel Zeit ungefähr braucht Ihr Kind täglich für seine Hausaufgaben?

$\square$ Bis zu 1 Stunde

$\square 1$ - 2 Stunden

$\square 2$ - 3 Stunden

$\square$ Mehr als 3 Stunden

78. Hat Ihr Kind zurzeit Lernschwierigkeiten oder andere Probleme in der Schule?

$\square$ Nein

$\square \mathrm{Ja}$

$\square$ Weiß nicht

79. Haben sich die Leistungen im Vergleich zum letzten Zeugnis deutlich verschlechtert (um mehr als eine Note)?

$\square$ Nein

$\square \mathrm{Ja}$

80. Ist die Versetzung gefährdet?

$\square$ Nein

$\square \mathrm{Ja}$

81. Wie häufig trifft Folgendes auf Ihr Kind zu?

$$
\text { Nie Selten } \begin{gathered}
\text { Manch- } \\
\text { mal }
\end{gathered} \text { Oft Immer Weiß }
$$

Wie häufig hat sich Ihr Kind im letzten Jahr über die Schule beklagt, insbesondere über das Klima in der Schule?

Wie häufig haben Sie den Eindruck, dass Ihr Kind unter dem Leistungsstress leidet (derart, dass die Anforderungen in der Schule für Ihr Kind schwierig zu erfüllen sind)?

Wie häufig wird Ihr Kind in der Schule von Mitschülern geärgert oder gequält?

Wie häufig ist Ihr Kind in der Schule isoliert oder alleine?

Wie häufig hat Ihr Kind Angst vor der Schule oder vor bestimmten Lehrern?

Wie häufig haben Sie den Eindruck, dass Ihr Kind sich in der Schule langweilt, weil es sich unterfordert fühlt? 
82. Wie häufig treffen folgende Aussagen auf Ihr Kind zu?

Nie Selten $\begin{gathered}\text { Manch- } \\ \text { mal }\end{gathered}$ Oft Immer $\begin{aligned} & \text { Weiß } \\ & \text { nicht }\end{aligned}$

Wenn meinem Kind etwas nicht glückt, ist es sehr enttäuscht.

Wenn eine Sache nicht klappt, wird es schnell ungeduldig.

Wenn es keinen Erfolg hat, ist es sehr schnell entmutigt.

\section{Freizeit}

83. Wie häufig führte Ihr Kind in den letzten 6 Monaten folgende Aktivitäten für mindestens 20 Minuten außerhalb der Schule aus?

\begin{tabular}{|c|c|c|c|}
\hline $\begin{array}{l}\text { Weniger } \\
\text { als 1mal } \\
\text { pro Woche }\end{array}$ & $\begin{array}{l}\text { 1-2mal pro } \\
\text { Woche }\end{array}$ & $\begin{array}{l}\text { 3-5mal pro } \\
\text { Woche }\end{array}$ & $\begin{array}{c}\text { Mehr als } \\
5 \text { mal pro } \\
\text { Woche }\end{array}$ \\
\hline
\end{tabular}

Radfahren

Ballspiele (Volleyball, Fußball

o.ä.)

Schwimmen

Tennis, Tischtennis, Federball

Gymnastik

Leichtathletik

Im Freien laufen, klettern, spielen o. ä.

Tanzen

Reiten

Inliner oder Skateboard fahren

Lesen

Malen, zeichnen, basteln
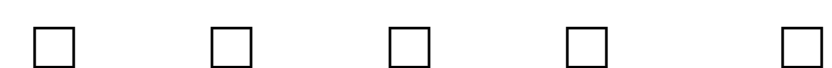
84. Wie häufig hat Ihr Kind Zeit zum Spielen bzw. Zeit für sich?

\begin{tabular}{|c|c|c|c|c|c|}
\hline $\mathrm{Nie}$ & Selten & $\begin{array}{l}\text { Manch- } \\
\text { mal }\end{array}$ & Oft & Immer & $\begin{array}{l}\text { Weiß } \\
\text { nicht }\end{array}$ \\
\hline$\square$ & 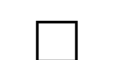 & $\square$ & $\square$ & $\square$ & $\square$ \\
\hline
\end{tabular}

85. Wie viele gute Freunde und Freundinnen hat Ihr Kind? (Geschwister bitte nicht mitzählen!)

$\square$ Keinen Freund bzw. keine Freundin

$\square$ Einen Freund bzw. eine Freundin

$\square$ Mehrere, nämlich ungefähr |_l_| Freunde und Freundinnen insgesamt

$\square$ Weiß nicht

86. An wie vielen Tagen in den letzten 2 Wochen hat Ihr Kind etwas mit seinen Freunden außerhalb der Schulstunden unternommen? (Auch wenn es bei Ihrem Kind sehr unterschiedlich ist, versuchen Sie bitte, eine Durchschnittszahl anzugeben!)

I_l_ Tage in der Woche

$\square$ Weiß nicht

87. Wie lange beschäftigt Ihr Kind sich mit folgenden Dingen durchschnittlich pro Taq? (Bitte kreuzen Sie an, was am ehesten zutrifft!)

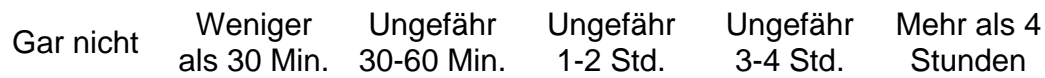

Fernsehen und

Videofilme
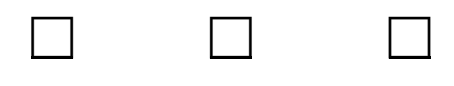

Computer, Internet,

Game Boy und

PlayStation 
88. Was passiert, wenn Ihr Kind in der Schule unter Druck gerät oder von anderen Kindern unter Druck gesetzt wird?

$$
\text { Nie Selten } \begin{gathered}
\text { Manch- } \\
\text { mal }
\end{gathered} \text { Oft Immer } \begin{array}{r}
\text { Weiß } \\
\text { nicht }
\end{array}
$$

Es möchte sich am liebsten krank stellen.

Seine Gedanken kreisen nur noch um diese Sache.

Es denkt, es hat sowieso keinen Zweck mehr.

Es nörgelt an allem herum.

Es möchte am liebsten im Bett bleiben.

Meinem Kind geht diese Situation immer wieder durch den Kopf.

Meinem Kind kommt alles sinnlos vor, was es tut.

Mein Kind bekommt schlechte Laune.

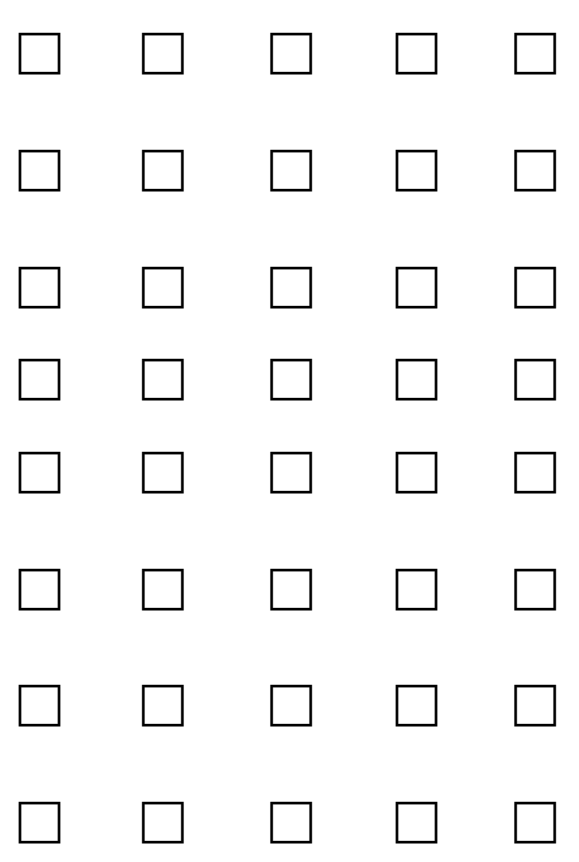

(1) 


\section{Stimmung und Verhalten}

\section{Bitte geben Sie an, inwieweit diese Aussagen auf Sie zutreffen!}

$\begin{array}{ccccc}\text { Trifft } & \text { Trifft } & \text { Trifft } & \text { Trifft eher } & \text { Trifft } \\ \text { überhaupt } & \text { eher } & \text { teilweise } & \text { zu } & \text { genau zu } \\ \text { nicht zu } & \text { nicht zu } & z u & & \end{array}$

Ich mache mir mehr Sorgen um mein Kind als andere Eltern.

Ich bin sehr besorgt um mein Kind und verbiete inm vieles aus Angst, dass ihm etwas passieren könnte.

$\square$

$\square$

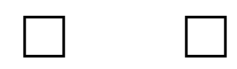

Ich ermahne mein Kind häufig, vorsichtig zu sein.

\section{Bitte geben Sie an, wie häufig folgende Gefühle bei Ihrem Kind in den letzten $\mathbf{3}$} Monaten vorgekommen sind!

$$
\text { Nie Selten } \begin{gathered}
\text { Manch- } \\
\text { mal }
\end{gathered} \text { Oft Immer } \begin{aligned}
& \text { Weiß } \\
& \text { nicht }
\end{aligned}
$$

Es hatte das Gefühl oder beklagte sich, dass niemand es liebt.

Es hatte zu starke Schuldgefühle.

Es war nervös oder angespannt.

Es wachte manchmal nachts auf und hatte Angst.

Es war misstrauisch.

Es machte sich zu viele Sorgen.

Es hatte Alpträume.

Es fühlte sich wertlos oder unterlegen.

Es war zu furchtsam oder zu ängstlich.

Es hatte Angst, Dinge falsch zu machen.

Es war unglücklich, traurig oder niedergeschlagen. 
92. Bitte geben Sie an, wie häufig folgende Verhaltensweisen bei Ihrem Kind in den letzten 3 Monaten vorgekommen sind!

Nie Selten $\begin{gathered}\text { Manch- } \\ \text { mal }\end{gathered}$ Oft Immer $\begin{aligned} & \text { Weiß } \\ & \text { nicht }\end{aligned}$

Es bedrohte andere.

Es konnte nicht still sitzen, war unruhig oder überaktiv.

$\square$

Es war gemein zu anderen oder schüchterte sie ein.

Es konnte sich nicht konzentrieren, konnte nicht lange aufpassen.

Es griff andere körperlich an.

Es war impulsiv oder handelte, ohne zu überlegen.
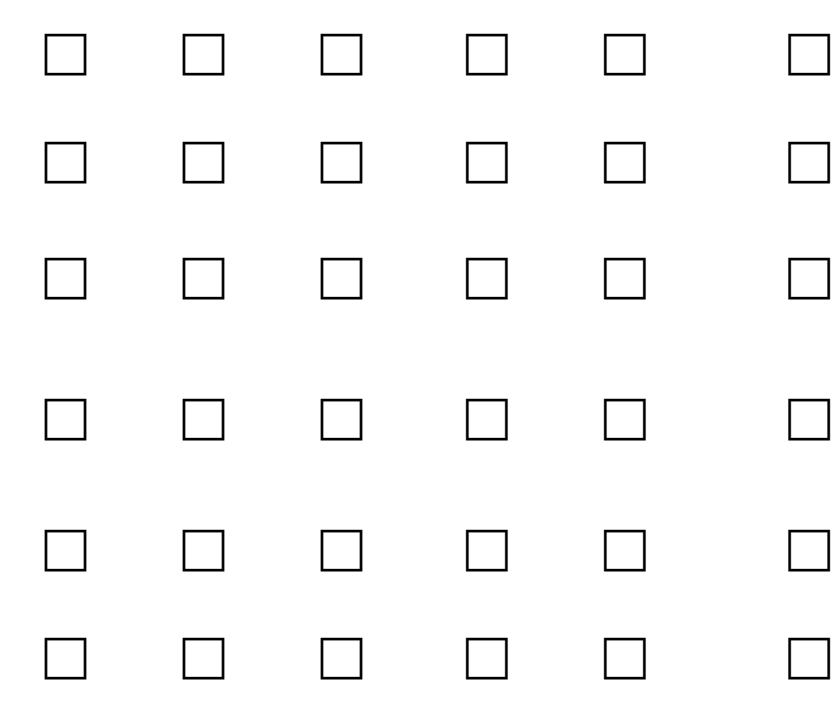

\section{Wichtige Ereignisse für Ihr Kind und die Familie}

93. War Ihr Kind in den letzten 5 Jahren in einem Heim oder in einem Internat? $\square$ Nein

$\square \mathrm{Ja}$

94. Hat Ihr Kind in den letzten 5 Jahren einen außergewöhnlichen Schulwechsel (nicht Regelwechsel von der Grundschule zur Orientierungsstufe oder zur weiterführenden Schule) gehabt?

$\square$ Nein

$\square \mathrm{Ja}$

95. Hat sich Ihr Kind in den letzten 5 Jahren von einer wichtigen Bezugsperson trennen müssen (z.B. durch Tod, Umzug, Scheidung)?

$\square$ Nein

$\square \mathrm{Ja}$

96. Sind in den letzten 5 Jahren neue Personen in die Familie aufgenommen worden (z.B. Geburt eines Geschwisters, neuer Lebenspartner)?
$\square$ Nein
$\square \mathrm{Ja}$ 
97. Leidet jemand aus Ihrer Familie an einer chronischen körperlichen Erkrankung, die ihn erheblich beeinträchtigt? (Bitte hier nicht das Kind nennen, auf das sich der Fragebogen im Wesentlichen bezieht!)

$\square$ Nein

$\square \mathrm{Ja}$

98. Gab es in den letzten 5 Jahren schwere Unfälle innerhalb Ihrer Familie?
$\square$ Nein
$\square \mathrm{Ja}$

99. Gibt es in Ihrer Familie eine hohe finanzielle Belastung?

$\square$ Nein

$\square \mathrm{Ja}$

100. Gibt es einen Pflegefall, der in der Familie versorgt wird?

$\square$ Nein

$\square \mathrm{Ja}$

\section{Soziodemographie}

Zur Erinnerung: Mit der Rubrik "Mutter" oder "Vater" sind hier auch diejenigen Personen gemeint, die für Ihr Kind diese Funktion übernehmen.

101. Welchen Schulabschluss haben Sie? (Nennen Sie nur den höchsten Abschluss. Bitte für beide Elternteile angeben!)

Mutter Vater

Hauptschulabschluss / Volksschulabschluss

Realschulabschluss (Mittlere Reife)

Abschluss Polytechnische Oberschule 10. Klasse (vor 1965: 8.Klasse)

Fachhochschulreife (Abschluss einer Fachoberschule)

Abitur, allgemeine oder fachgebundene

Hochschulreife (Gymnasium bzw. EOS)

Anderer Schulabschluss

Schule beendet ohne Abschluss

(Noch) keinen Schulabschluss 
102. Haben Sie eine abgeschlossene Berufsausbildung? Wenn ja, welche? (Nennen Sie bitte nur den höchsten Abschluss. Bitte für beide Elternteile angeben!)

Mutter Vater

Lehre (beruflich-betriebliche Ausbildung)

Berufsschule, Handelsschule (beruflich-schulische Ausbildung)

Fachschule (z. B. Meister-Technikerschule, Berufsoder Fachakademie)

Fachhochschule, Ingenieurschule

Universität, Hochschule

Anderer Ausbildungsabschluss

Kein beruflicher Abschluss (und auch nicht in der Ausbildung)

Noch in beruflicher Ausbildung (Auszubildender, Student)

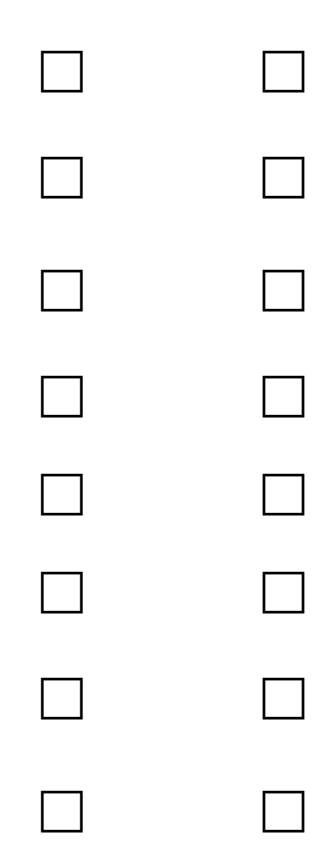

103. Welche der folgenden Angaben zur Berufstätigkeit trifft auf Sie zu? (Bitte für beide Elternteile jeweils nur eine Berufstätigkeit angeben!)

Mutter Vater

Zurzeit ...

...nicht berufstätig (Rentner, Student, usw.)

...arbeitslos

...vorübergehende Freistellung

(z. B. Erziehungsurlaub)

...Teilzeit oder stundenweise berufstätig

...voll berufstätig

...Auszubildender (z. B. Lehrling) 
104. In welcher beruflichen Stellung sind Sie hauptsächlich derzeit beschäftigt? Wenn Sie nicht mehr berufstätig sind, nennen Sie bitte die berufliche Stellung, die Sie zuletzt innehatten! (Bitte für beide Elternteile angeben!)

\section{Arbeiter}

Ungelernter Arbeiter

Angelernter Arbeiter (Teilqualifizierung)

Gelernter Arbeiter und Facharbeiter

Vorarbeiter, Kolonnenführer, Meister, Polier,

Brigadier

Selbstständiger (einschließlich mithelfender Familienangehöriger)

Selbstständiger Landwirt / Genossenschaftsbauer

Selbstständiger Akademiker, freier Beruf

Sonstiger Selbstständiger mit bis zu 9

Mitarbeitern

Sonstiger Selbstständiger mit 10 und mehr Mitarbeitern

Mithelfender Familienangehöriger

\section{Angestellter}

Industrie- und Werkmeister im

Angestelltenverhältnis

Angestellter mit einfacher Tätigkeit (z. B.

Verkäufer, Kontorist, Stenotypist)

Angestellter mit qualifizierter Tätigkeit (z. B.

Sachbearbeiter, Buchhalter, technischer

Zeichner)

Angestellter mit hochqualifizierter Tätigkeit oder

Leitungsfunktion (z. B. wissenschaftlicher

Mitarbeiter, Prokurist, Abteilungsleiter)

Angestellter mit umfassenden Führungsaufgaben

(z. B. Direktor, Geschäftsführer, Vorstand) 
Beamter (einschließlich Richter, Berufssoldat)

Einfacher Dienst

Mittlerer Dienst

Gehobener Dienst

Höherer Dienst

\section{Sonstige}

(z. B. Auszubildender, Schüler, Student,

Wehrpflichtiger, Zivildienstleistender, Praktikant)

Hausfrau / Hausmann

105. Wie hoch ist das durchschnittliche monatliche Haushaltseinkommen, d.h. das Nettoeinkommen, das alle Haushaltsmitglieder zusammen nach Abzug von Steuern und Sozialabgaben haben? (Einschließlich Erziehungsgeld und Kindergeld)

$\square$ Unter $500 €$

$\square 500 \quad$ bis unter $\quad 750 €$

$\square 750 \quad$ bis unter $1000 €$

$\square 1000$ bis unter $1250 €$

$\square 1250$ bis unter $1500 €$

$\square 1500$ bis unter $1750 €$

$\square 1750$ bis unter $2000 €$

$\square 2000$ bis unter $2250 €$

$\square 2250$ bis unter $2500 €$

$\square 2500$ bis unter $3000 €$

$\square \quad 3000$ bis unter $4000 €$

$\square 4000$ bis unter $5000 €$

$\square 5000 €$ und mehr 


\section{Lebensbedingungen}

106. Wie groß ist Ihre Wohnung?

Ungefähr |_I_I_|m²

107. Wie viele Räume einschließlich Küche (ohne Bad) bewohnen Sie?

I_I_| Räume

108. Wie viele Personen leben insgesamt in Ihrem Haushalt?

I_I_| Personen

109. Hat Ihr Kind ein eigenes Zimmer?

$\square \mathrm{Ja}$

$\square$ Nein

110. Wie viele Stunden am Tag ist Ihr Kind allein zu Hause?

Ungefähr |_| Stunden

111. Von wem wird Ihr Kind nach der Schule hauptsächlich betreut? (Hier bitte nur ein Kreuz machen!)

$\square$ Von Mutter oder Vater (bzw. Partnerin oder Partner)

$\square$ Von anderen Familienangehörigen (z.B. Großeltern, Geschwistern)

$\square$ Besucht Hort, Kindertagesstätte, Schülerladen

$\square$ Von anderen Personen außerhalb der Familie

Bitte prüfen Sie Ihre Angaben noch einmal auf Vollständigkeit!

Vielen Dank für die Beantwortung der Fragen! 
Die Fragen 1, 3-5, 8, 18, 101-105, 111 sind mit freundlicher Genehmigung des Robert-Koch-Institutes Berlin dem Fragebogen Kinder-Jugend-Gesundheit21.de entnommen.

\section{Impressum}

Herausgeber: Abteilung Klinische Psychologie und Psychotherapie, Georg-Elias-Müller-Institut für Psychologie, Georg-August-Universität Göttingen, Goßlerstr. 14, 37073 Göttingen

Umschlaggestaltung: Judy Flemming (Grafikdesignerin)

Druck: Pachnicke Druck, Güterbahnhofstr. 9, 37073 Göttingen

(c) Göttingen, 2003 


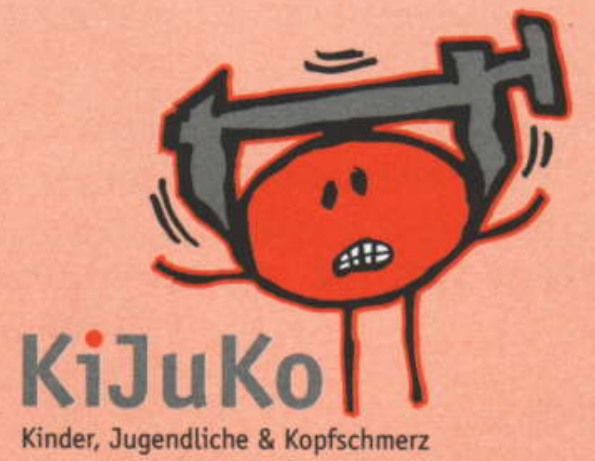

Georg-August-Universität Göttingen

Georg-Elias-Müller-Institut für Psychologie Abteilung Klinische Psychologie

Prof. Dr. Birgit Kröner-Herwig

Goßlerstr. 14 - 37073 Göttingen

kijuko@uni-goettingen.de 


\section{Appendix C}

Absolute and relative frequency of impairment or disability in $\mathbf{5 , 4 7 4}$ children and adolescents (all valid data sets)

\begin{tabular}{lccc}
\hline & $\begin{array}{c}\text { Female } \\
(\mathrm{n}=2706)\end{array}$ & $\begin{array}{c}\text { Male } \\
(\mathrm{n}=2768)\end{array}$ & $\begin{array}{c}\text { Total } \\
(\mathrm{n}=5474)\end{array}$ \\
\hline $\begin{array}{l}\text { Impairment or disability } \\
\begin{array}{l}\text { Delayed development or } \\
\text { mental retardation }\end{array}\end{array}$ & $140(5.2 \%)$ & $243(8.8 \%)$ & $383(7.0 \%)$ \\
$\begin{array}{l}\text { Hearing impairment or } \\
\text { deafness }\end{array}$ & $57(2.1 \%)$ & $99(3.6 \%)$ & $156(2.8 \%)$ \\
$\begin{array}{l}\text { Communication disorder } \\
\text { Vision impairment or } \\
\text { blindness }\end{array}$ & $59(2.2 \%)$ & $65(2.3 \%)$ & $104(1.9 \%)$ \\
\hline
\end{tabular}

Absolute and relative frequency of child's headache in 4,869 children and adolescents without impairment or disability

\begin{tabular}{lccc}
\hline & $\begin{array}{c}\text { Female } \\
(\mathrm{n}=2471)\end{array}$ & $\begin{array}{c}\text { Male } \\
(\mathrm{n}=2398)\end{array}$ & $\begin{array}{c}\text { Total } \\
(\mathrm{n}=4869)\end{array}$ \\
\hline No headache & $1109(44.9 \%)$ & $1160(48.4 \%)$ & $2269(46.6 \%)$ \\
Seldom headache & $702(28.4 \%)$ & $731(30.5 \%)$ & $1433(29.4 \%)$ \\
Monthly headache & $444(18.0 \%)$ & $381(15.9 \%)$ & $825(16.9 \%)$ \\
Weekly headache & $195(7.9 \%)$ & $112(4.7 \%)$ & $307(6.3 \%)$ \\
\hline
\end{tabular}

Absolute and relative frequency of chronic illness in $\mathbf{7 8}$ children and adolescents with comorbid chronic headache and chronic illness

\begin{tabular}{lccc}
\hline & $\begin{array}{c}\text { Female } \\
(\mathrm{n}=44)\end{array}$ & $\begin{array}{c}\text { Male } \\
(\mathrm{n}=34)\end{array}$ & $\begin{array}{c}\text { Total } \\
(\mathrm{n}=78)\end{array}$ \\
\hline Asthma & $13(29.5 \%)$ & $12(35.3 \%)$ & $25(32.1 \%)$ \\
Atopic dermatitis & $22(50.0 \%)$ & $12(35.3 \%)$ & $34(43.6 \%)$ \\
Epilepsy & $2(4.5 \%)$ & - & $2(2.6 \%)$ \\
Congenital heart disease & $2(4.5 \%)$ & $3(8.8 \%)$ & $5(6.4 \%)$ \\
$\begin{array}{l}\text { Chronic inflammatory } \\
\text { bowel disease }\end{array}$ & - & - & - \\
$\begin{array}{l}\text { Chronic kidney disease } \\
\text { Muscle diseases }\end{array}$ & $2(4.5 \%)$ & - & $3(3.8 \%)$ \\
$\begin{array}{l}\text { Juvenile rheumatoid } \\
\text { arthritis }\end{array}$ & $1(2.3 \%)$ & $2(5.9 \%)$ & $2(2.6 \%)$ \\
Diabetes & $1(2.3 \%)$ & $1(2.9 \%)$ & - \\
Other & - & - & $23(29.5 \%)$ \\
\hline
\end{tabular}




\section{Appendix D}

\section{Pearson correlations for control variables}

\begin{tabular}{lc}
\hline & Gender \\
\hline Age & -.004 \\
\hline
\end{tabular}

\section{VIFs for control variables}

\begin{tabular}{lc}
\hline & VIF \\
\hline Age & 1.000 \\
Gender & 1.000 \\
\hline
\end{tabular}

Spearman-Rho correlations for sociodemographic variables

\begin{tabular}{lcccccc}
\hline & Gender & $\begin{array}{c}\text { Education } \\
\text { level }\end{array}$ & $\begin{array}{c}\text { Occupa- } \\
\text { tional } \\
\text { prestige }\end{array}$ & $\begin{array}{c}\text { Household } \\
\text { net income }\end{array}$ & $\begin{array}{c}\text { Social } \\
\text { class }\end{array}$ & $\begin{array}{c}\text { Household } \\
\text { crowding } \\
\text { index }\end{array}$ \\
\hline Age & -.004 & -.037 & -.006 & .049 & -.013 & -.037 \\
Gender & & .024 & .026 & .025 & .022 & -.017 \\
Education level & & .628 & .494 & .599 & -.182 \\
Occupational prestige & & & .602 & .682 & -.265 \\
Household net income & & & & .621 & -.225 \\
Social class & & & & & -.169 \\
\hline
\end{tabular}

VIFs for sociodemographic variables

\begin{tabular}{lcc}
\hline & VIF & VIF \\
\hline Age & 1.010 & 1.002 \\
Gender & 1.001 & 1.001 \\
Education level & 1.699 & \\
Occupational prestige & 2.023 & \\
Household net income & 1.624 & \\
$\begin{array}{l}\text { Social class } \\
\text { Household crowding } \\
\text { index }\end{array}$ & 1.082 & 1.027 \\
\hline
\end{tabular}


Pearson correlations for psychological variables

\begin{tabular}{|c|c|c|c|c|c|c|c|c|c|c|c|c|}
\hline & Gender & $\begin{array}{l}\text { Passive } \\
\text { avoid- } \\
\text { ance }\end{array}$ & $\begin{array}{l}\text { Rumina- } \\
\text { tion }\end{array}$ & $\begin{array}{l}\text { Resigna- } \\
\text { tion }\end{array}$ & $\begin{array}{l}\text { Aggres- } \\
\text { sion }\end{array}$ & Anger-in & $\begin{array}{l}\text { Anger- } \\
\text { out }\end{array}$ & $\begin{array}{l}\text { Anger } \\
\text { control }\end{array}$ & $\begin{array}{l}\text { Anxiety/ } \\
\text { depress- } \\
\text { sion }\end{array}$ & $\begin{array}{l}\text { Hyper- } \\
\text { activity }\end{array}$ & $\begin{array}{l}\text { Aggres- } \\
\text { sive } \\
\text { behavior }\end{array}$ & $\begin{array}{l}\text { Sleep } \\
\text { disturb- } \\
\text { ance }\end{array}$ \\
\hline Age & -.004 & .088 & .032 & .086 & .059 & -.077 & .156 & .161 & .026 & -.119 & -.084 & .004 \\
\hline Gender & & .014 & .072 & -.050 & -.007 & -.034 & -.050 & -.002 & .040 & -.201 & -.179 & .020 \\
\hline Passive avoidance & & & .406 & .496 & .390 & .177 & .216 & -.099 & .404 & .198 & .166 & .207 \\
\hline Rumination & & & & .471 & .486 & .206 & .196 & -.069 & .449 & .182 & .095 & .203 \\
\hline Resignation & & & & & .490 & .229 & .243 & -.142 & .548 & .321 & .222 & .188 \\
\hline Aggression & & & & & & .421 & .168 & -.284 & .459 & .351 & .291 & .198 \\
\hline Anger-in & & & & & & & -.196 & -.552 & .260 & .397 & .357 & .112 \\
\hline Anger-out & & & & & & & & .326 & .248 & .027 & .011 & .095 \\
\hline Anger control & & & & & & & & & -.152 & -.335 & -.262 & -.067 \\
\hline Anxiety/depression & & & & & & & & & & .437 & .331 & .310 \\
\hline Hyperactivity & & & & & & & & & & & .444 & .206 \\
\hline Aggressive behavior & & & & & & & & & & & & .128 \\
\hline
\end{tabular}




\section{Variance inflation factors for psychological variables}

\begin{tabular}{lc}
\hline & VIF \\
\hline Age & 1.073 \\
Gender & 1.117 \\
Passive avoidance & 1.471 \\
Rumination & 1.556 \\
Resignation & 1.853 \\
Aggression & 1.815 \\
Anger-in & 1.805 \\
Anger-out & 1.345 \\
Anger control & 1.688 \\
Anxiety/depression & 1.974 \\
Hyperactivity & 1.675 \\
Aggressive behavior & 1.408 \\
Sleep disturbance & 1.133 \\
\hline
\end{tabular}


Pearson correlations for health variables

\begin{tabular}{lccc}
\hline & Gender & $\begin{array}{c}\text { Pain other } \\
\text { than } \\
\text { headache }\end{array}$ & $\begin{array}{c}\text { Other } \\
\text { somatic } \\
\text { complaints }\end{array}$ \\
\hline Age & -.004 & .150 & .103 \\
Gender & .160 & .067 \\
Pain other than headache & & .529 \\
\hline
\end{tabular}

Variance inflation factors for health variables

\begin{tabular}{ll}
\hline & VIF \\
\hline Age & 1.023 \\
Gender & 1.027 \\
Pain other than headache & 1.428 \\
Other somatic complaints & 1.382 \\
\hline
\end{tabular}

Pearson correlations for family variables

\begin{tabular}{|c|c|c|c|c|c|c|}
\hline & Gender & $\begin{array}{l}\text { Number of } \\
\text { parents }\end{array}$ & $\begin{array}{l}\text { Number of } \\
\text { children }\end{array}$ & $\begin{array}{l}\text { Negative } \\
\text { family } \\
\text { environ- } \\
\text { ment }\end{array}$ & $\begin{array}{l}\text { Negative } \\
\text { conflict } \\
\text { solving } \\
\text { strategies }\end{array}$ & $\begin{array}{c}\text { Weekly } \\
\text { family } \\
\text { conflict }\end{array}$ \\
\hline Age & -.004 & -.030 & -.003 & .051 & .002 & -.020 \\
\hline Gender & & -.005 & .003 & .001 & .011 & -.001 \\
\hline $\begin{array}{l}\text { Number of parents in } \\
\text { household }\end{array}$ & & & .104 & -.081 & -.054 & -.126 \\
\hline $\begin{array}{l}\text { Number of children in } \\
\text { household }\end{array}$ & & & & .044 & .015 & .039 \\
\hline $\begin{array}{l}\text { Negative family } \\
\text { environment }\end{array}$ & & & & & .488 & .285 \\
\hline $\begin{array}{l}\text { Negative conflict solving } \\
\text { strategies }\end{array}$ & & & & & & .447 \\
\hline
\end{tabular}

Variance inflation factors for family variables

\begin{tabular}{lc}
\hline & VIF \\
\hline Age & 1.004 \\
Gender & 1.000 \\
$\begin{array}{l}\text { Number of parents in } \\
\text { household }\end{array}$ & 1.032 \\
$\begin{array}{l}\text { Number of children in } \\
\text { household }\end{array}$ & 1.016 \\
$\begin{array}{l}\text { Negative family } \\
\text { environment }\end{array}$ & 1.328 \\
$\begin{array}{l}\text { Negative conflict solving } \\
\text { strategies }\end{array}$ & 1.526 \\
\begin{tabular}{l} 
Weekly family conflict \\
\hline
\end{tabular} & 1.280 \\
\hline
\end{tabular}


Spearman-Rho correlations for school variables

\begin{tabular}{lccccc}
\hline & Gender & $\begin{array}{c}\text { Index of } \\
\text { school } \\
\text { difficulties }\end{array}$ & $\begin{array}{c}\text { Time } \\
\text { spent on } \\
\text { homework }\end{array}$ & $\begin{array}{c}\text { School } \\
\text { stress }\end{array}$ & $\begin{array}{c}\text { Reaction } \\
\text { to failure }\end{array}$ \\
\hline Age & -.004 & .150 & .229 & .072 & -.094 \\
Gender & & -.053 & .081 & -.038 & -.112 \\
Index of school difficulties & & & .147 & .331 & .255 \\
Time spent on homework & & & & .123 & .036 \\
School stress & & & & & .359 \\
\hline
\end{tabular}

Variance inflation factors for school variables

\begin{tabular}{ll}
\hline & VIF \\
\hline Age & 1.087 \\
Gender & 1.021 \\
Index of school difficulties & 1.206 \\
Time spent on homework & 1.084 \\
School stress & 1.273 \\
Reaction to failure & 1.216 \\
\hline
\end{tabular}


Pearson correlations for leisure variables

\begin{tabular}{|c|c|c|c|c|c|c|c|}
\hline & Gender & $\begin{array}{l}\text { Physical } \\
\text { activities }\end{array}$ & $\begin{array}{l}\text { Recrea- } \\
\text { tional } \\
\text { activities }\end{array}$ & $\begin{array}{l}\text { Amount of } \\
\text { free time }\end{array}$ & $\begin{array}{c}\text { Time spent } \\
\text { on TV I } \\
\text { video }\end{array}$ & $\begin{array}{c}\text { Time spent } \\
\text { on game } \\
\text { console / } \\
\text { PC }\end{array}$ & $\begin{array}{l}\text { Amount of } \\
\text { friends }\end{array}$ \\
\hline Age & -.004 & -.197 & -.172 & -.095 & .252 & .316 & .106 \\
\hline Gender & & -.005 & .359 & -.051 & -.048 & -.372 & .053 \\
\hline Physical activities & & & .227 & .062 & -.099 & -.084 & .058 \\
\hline Recreational activities & & & & -.024 & -.236 & -.237 & .017 \\
\hline Amount of free time & & & & & .137 & .066 & .039 \\
\hline Time spent on TV / video & & & & & & .333 & .049 \\
\hline $\begin{array}{l}\text { Time spent on game } \\
\text { console / PC }\end{array}$ & & & & & & & .027 \\
\hline
\end{tabular}

\section{Variance inflation factors for leisure variables}

\begin{tabular}{lc}
\hline & VIF \\
\hline Age & 1.246 \\
Gender & 1.348 \\
Physical activities & 1.109 \\
Recreational activities & 1.295 \\
Amount of free time & 1.046 \\
Time spent on TV / video & 1.232 \\
Time spent on game & 1.458 \\
console / PC & 1.024 \\
Amount of friends & \\
\hline
\end{tabular}

Pearson correlations for life events

\begin{tabular}{lcc}
\hline & Gender & $\begin{array}{c}\text { Index of } \\
\text { life } \\
\text { events }\end{array}$ \\
\hline Age & -.004 & -.028 \\
Gender & & -.021 \\
\hline
\end{tabular}

Variance inflation factors for life events

\begin{tabular}{lc}
\hline & VIF \\
\hline Age & 1.001 \\
Gender & 1.000 \\
Index of life events & 1.001 \\
\hline
\end{tabular}


Pearson correlations for parental psychological variables

\begin{tabular}{lcccccc}
\hline & Gender & $\begin{array}{c}\text { Anxiety / } \\
\text { depression }\end{array}$ & Anxieties & $\begin{array}{c}\text { Depressed } \\
\text { mood }\end{array}$ & $\begin{array}{c}\text { Habitual } \\
\text { worry }\end{array}$ & $\begin{array}{c}\text { Sleep dis- } \\
\text { turbances }\end{array}$ \\
\hline Age & -.004 & .000 & .016 & -.008 & .014 & .041 \\
Gender & & -.010 & -.025 & -.027 & -.022 & -.020 \\
Anxiety / depression & & & .522 & .615 & .576 & .406 \\
Anxieties & & & .668 & .522 & .418 \\
Depressed mood & & & & .494 & .408 \\
Habitual worry & & & & & .350 \\
\hline
\end{tabular}

Pearson correlations for parental psychological variables

\begin{tabular}{|c|c|c|c|c|}
\hline & Gender & $\begin{array}{c}\text { Anxiety / } \\
\text { depression } \\
\text { (index) }\end{array}$ & $\begin{array}{l}\text { Habitual } \\
\text { worry }\end{array}$ & $\begin{array}{l}\text { Sleep dis- } \\
\text { turbances }\end{array}$ \\
\hline Age & -.004 & .003 & .015 & .042 \\
\hline Gender & & -.016 & -.022 & -.020 \\
\hline $\begin{array}{l}\text { Anxiety / depression } \\
\text { (index) }\end{array}$ & & & .624 & .462 \\
\hline Habitual worry & & & & .350 \\
\hline
\end{tabular}

Variance inflation factors for parental psychological variables

\begin{tabular}{lcc}
\hline & VIF & VIF \\
\hline Age & 1.003 & 1.002 \\
Gender & 1.001 & 1.001 \\
Anxiety / depression & 1.961 & \\
Anxieties & 2.045 & \\
Depressed mood & 2.232 & \\
Anxiety / depression & & \\
(index) & & 1.862 \\
Habitual worry & 1.697 & 1.672 \\
Sleep disturbances & \\
\hline
\end{tabular}


Pearson correlations for parental health variables

\begin{tabular}{lccccccc}
\hline & Gender & $\begin{array}{c}\text { General } \\
\text { health }\end{array}$ & $\begin{array}{c}\text { Doctor } \\
\text { appoint- } \\
\text { ments }\end{array}$ & Headache & $\begin{array}{c}\text { Pain other } \\
\text { than } \\
\text { headache }\end{array}$ & $\begin{array}{c}\text { Other } \\
\text { somatic } \\
\text { complaints }\end{array}$ & $\begin{array}{c}\text { Regular } \\
\text { medication }\end{array}$ \\
\hline Age & -.004 & .006 & .034 & .035 & .024 & .069 & .010 \\
Gender & & .019 & -.022 & .011 & -.011 & -.014 & -.011 \\
General health & & -.334 & -.273 & -.330 & -.230 & -.147 \\
Doctor appointments & & & .243 & .227 & .268 & .109 \\
Headache & & & & .239 & .127 & .199 \\
Pain other than headache & & & & & & .420 & .171 \\
Other somatic complaints & & & & & & & \\
\hline
\end{tabular}

\section{Variance inflation factors for parental health variables}

\begin{tabular}{lc}
\hline & VIF \\
\hline Age & 1.007 \\
Gender & 1.001 \\
General health & 1.251 \\
Doctor appointments & 1.202 \\
Headache & 1.156 \\
Pain other than headache & 1.351 \\
Other somatic complaints & 1.267 \\
Regular medication & 1.062 \\
\hline
\end{tabular}


Appendix E

Spearman-Rho correlations for aggregate model for weekly headache vs. good health

\begin{tabular}{|c|c|c|c|c|c|c|c|c|c|c|c|c|}
\hline & Gender & $\begin{array}{l}\text { Parental } \\
\text { headache }\end{array}$ & Anger-out & $\begin{array}{c}\text { Anxiety / } \\
\text { depression }\end{array}$ & $\begin{array}{l}\text { Sleep } \\
\text { disturb- } \\
\text { ance }\end{array}$ & $\begin{array}{l}\text { Pain other } \\
\text { than } \\
\text { headache }\end{array}$ & $\begin{array}{c}\text { Other } \\
\text { somatic } \\
\text { complaints }\end{array}$ & $\begin{array}{l}\text { Time spent } \\
\text { on } \\
\text { homework }\end{array}$ & $\begin{array}{l}\text { School } \\
\text { stress }\end{array}$ & $\begin{array}{c}\text { Index of } \\
\text { life events }\end{array}$ & $\begin{array}{l}\text { Amount of } \\
\text { free time }\end{array}$ & $\begin{array}{c}\text { Time spent } \\
\text { on TV I } \\
\text { Video }\end{array}$ \\
\hline Age & -.004 & .011 & -.081 & .023 & .017 & .123 & .093 & .229 & .072 & -.049 & -.095 & .252 \\
\hline Gender & & -.011 & -.035 & .052 & .029 & .166 & .078 & .081 & -.038 & -.017 & -.051 & -.048 \\
\hline Parental headache & & & .065 & .134 & .127 & .153 & .171 & .016 & .070 & .106 & .024 & .048 \\
\hline Anger-out & & & & .273 & .108 & .096 & .118 & -.021 & .226 & .074 & -.038 & -.039 \\
\hline Anxiety / depression & & & & & .308 & .308 & .356 & .114 & .501 & .212 & -.168 & -.004 \\
\hline Sleep disturbance & & & & & & .334 & .383 & .048 & .231 & .118 & -.050 & -.001 \\
\hline Pain other than headache & & & & & & & .532 & .113 & .250 & .135 & -.059 & .081 \\
\hline Other somatic complaints & & & & & & & & .093 & .287 & .142 & -.069 & .027 \\
\hline Time spent on homework & & & & & & & & & .123 & .003 & -.159 & .080 \\
\hline School stress & & & & & & & & & & .163 & -.102 & .027 \\
\hline Index of life events & & & & & & & & & & & .017 & .060 \\
\hline Amount of free time & & & & & & & & & & & & .137 \\
\hline
\end{tabular}


Variance inflation factors for aggregate model for weekly headache vs. good health

\begin{tabular}{ll}
\hline & VIF \\
\hline Age & 1.164 \\
Gender & 1.060 \\
Parental headache & 1.046 \\
Anger-out & 1.113 \\
Anxiety / depression & 1.537 \\
Sleep disturbance & 1.200 \\
Pain other than headache & 1.481 \\
Other somatic complaints & 1.501 \\
Time spent on homework & 1.111 \\
School stress & 1.404 \\
Index of life events & 1.089 \\
Amount of free time & 1.081 \\
Time spent on TV / Video & 1.098 \\
\hline
\end{tabular}


Spearman-Rho correlations for aggregate model for chronic illness vs. good health

\begin{tabular}{lcccc}
\hline Gender & $\begin{array}{c}\text { Sleep } \\
\text { disturbance }\end{array}$ & $\begin{array}{c}\text { School } \\
\text { stress }\end{array}$ & $\begin{array}{c}\text { Parental } \\
\text { other } \\
\text { somatic } \\
\text { complaints }\end{array}$ \\
\hline Age & -.004 & .017 & .072 & .016 \\
Gender & & .029 & -.038 & -.005 \\
Sleep disturbance & & .231 & .160 \\
School stress & & & .149 \\
\hline
\end{tabular}

Variance inflation factors for aggregate model for chronic illness vs. good health

\begin{tabular}{lc}
\hline & VIF \\
\hline Age & 1.005 \\
Gender & 1.005 \\
Sleep disturbance & 1.061 \\
School stress & 1.070 \\
$\begin{array}{l}\text { Parental other somatic } \\
\text { complaints }\end{array}$ & 1.038 \\
\hline
\end{tabular}


Pearson correlations for specificity model

\begin{tabular}{|c|c|c|c|c|c|c|c|}
\hline & Gender & $\begin{array}{l}\text { Sleep } \\
\text { disturb- } \\
\text { ance }\end{array}$ & $\begin{array}{c}\text { Pain other } \\
\text { than } \\
\text { headache }\end{array}$ & $\begin{array}{c}\text { Other } \\
\text { somatic } \\
\text { complaints }\end{array}$ & $\begin{array}{l}\text { School } \\
\text { stress }\end{array}$ & $\begin{array}{c}\text { Parental } \\
\text { headache }\end{array}$ & $\begin{array}{c}\text { Parental } \\
\text { other } \\
\text { somatic } \\
\text { complaints }\end{array}$ \\
\hline Age & -.004 & .004 & .150 & .102 & .057 & .011 & .024 \\
\hline Gender & & .020 & .160 & .067 & -.047 & -.011 & -.011 \\
\hline Sleep disturbance & & & .319 & .379 & .231 & .125 & .152 \\
\hline Pain other than headache & & & & .529 & .246 & .150 & .161 \\
\hline Other somatic complaints & & & & & .281 & .161 & .203 \\
\hline School stress & & & & & & .066 & .150 \\
\hline Parental headache & & & & & & & .171 \\
\hline
\end{tabular}

\section{Variance inflation factors for specificity model}

\begin{tabular}{ll}
\hline & VIF \\
\hline Age & 1.020 \\
Gender & 1.044 \\
Sleep disturbance & 1.165 \\
Pain other than headache & 1.457 \\
Other somatic complaints & 1.491 \\
School stress & 1.128 \\
Parental headache & 1.049 \\
Parental other somatic & 1.072 \\
complaints &
\end{tabular}




\section{ACKNOWLEDGEMENT}

The Children, Adolescents \& Headache Study was made possible through funding from the German Ministry of Research and Education (01EM0521). 


\section{CURRICULUM VITAE}

\section{Personal information}

Name: $\quad$ Lisette Morris

Date of birth: July 7, 1970

Place of birth: Oklahoma City, Oklahoma

Citizenship: USA

\section{Employment}

since 2001 Researcher and instructor in the Department of Clinical Psychology and Psychotherapy of the Georg-August-University in Göttingen

1999 - 2001 Researcher in the Center for the Research of Psychology of Eating at the Georg-August-University in Göttingen

1996 - 1998 Student assistant in the Department of Clinical Psychology and Psychotherapy of the Georg-August-University in Göttingen

1994 - 1998 Student assistant in the Department of Methodology and Psychology of Action of the Georg-August-University in Göttingen

1995 - 1996 Student assistant in the Department of Social Psychology and Communication of the Georg-August-University in Göttingen

\section{Education}

since 1999 Training as cognitive behavioral psychotherapist (Psychologische Psychotherapeut) at the Georg-August-University in Göttingen and the Technical University of Braunschweig

1999

"Diplom" (equivalent to M.A.) in Psychology

1992 - 1999 Psychology, Georg-August-University in Göttingen

1990 - 1992 German \& Economics, Macalester College, St. Paul, Minnesota 